\title{
Microstructure, Deformation, and Property of Wrought Magnesium Alloys
}

\begin{abstract}
J.F. NIE, K.S. SHIN, and Z.R. ZENG
Pure magnesium $(\mathrm{Mg})$ develops a strong basal texture after conventional processing of hot rolling or extrusion. Consequently, it exhibits anisotropic mechanical properties and is difficult to form at room temperature. Adding appropriate alloying elements can weaken the basal texture or even change it, but the improvement in formability and mechanical properties is still far from expectations. Over the past 20 years, considerable efforts have been made and significant progress has been made on wrought $\mathrm{Mg}$ alloys at the fundamental and technological levels. At the fundamental level, textures formed in sheets and extrusions of different alloy compositions and produced under different strain paths or thermomechanical processing conditions are relatively well established, with the assistance of the advanced characterization technique of electron backscatter diffraction. At the technological level, room temperature formability of sheet has been significantly improved, and tension-compression yield asymmetry of extrusion is also remarkably reduced or eliminated. This paper starts with an overview of dislocations, stacking faults and twins, and deformation of single crystals of pure $\mathrm{Mg}$ along different orientations and under different loading conditions, followed by a review of microstructure (texture and grain size) and deformation of polycrystalline pure $\mathrm{Mg}$ with different textures, grain sizes, and loading conditions. With this information as a base, texture, grain size, and deformation of polycrystalline $\mathrm{Mg}$ alloy sheets and extrusions produced under different processing conditions are systematically examined and compared. Remaining and emerging scientific and technology issues are then highlighted and discussed in the context of texture and grain size. The need for better-resolution diffraction and spectroscopy techniques is also discussed in the relationship between texture change and grain boundary solute segregation.
\end{abstract}

https://doi.org/10.1007/s11661-020-05974-z

(c) The Minerals, Metals \& Materials Society and ASM International 2020

\section{INTRODUCTION}

COMPRISING 2.7 pct of the earth's crust and being the third most plentiful element dissolved in seawater, magnesium $(\mathrm{Mg})$ is an abundant element. It is readily commercially produced, with a purity exceeding 99.8 pct, from seawater, lake brines, dolomite, magnesite, and other minerals. Its density is 66 pet of aluminum and 25 pct of steel. These unique features make $\mathrm{Mg}$ a promising material to substitute steel and aluminum

J.F. NIE is with the Department of Materials Science and Engineering, Monash University, Melbourne, VIC 3800, Australia. Contact e-mail: jianfeng.nie $@$ monash.edu K.S. SHIN is with the Department of Materials Science and Engineering, Seoul National University, 1 Gwannak-ro, Gwannak-gu, Seoul 08826, Republic of Korea. Z.R. ZENG is with the College of Engineering and Computer Science, The Australian National University, Canberra, ACT 2601, Australia.

Manuscript submitted April 21, 2020.

Article published online October 10, 2020 alloys for more energy-efficient and environmentally friendly applications. Statistical data indicate that each 100 kilogram reduction in vehicle weight reduces fuel consumption by $0.38 \mathrm{~L}$ per $100 \mathrm{~km}$ and $\mathrm{CO}_{2}$ emission by 8.7 gram per kilometer. ${ }^{[1]}$

Commercial production of magnesium metal was 277,000 tonnes per annum in 1999 , but rose rapidly to approximately 608,000 tonnes in 2009, and reached about 1,100,000 tonnes in 2019, Figure 1. In 2017, a new magnesium production plant was constructed in Qinghai Province China, with an annual production rate of 100,000 tonnes from lake brines. One year later, Magontec's new magnesium alloy cast house facility started its operation, with an initial annual production rate of 60,000 tonnes of alloy ingots. For the primary magnesium metal produced each year, about 35 pct is used for making magnesium alloys in the form of castings and wrought products. Wrought magnesium products account for only about 1 pet of magnesium consumption, even though they reached 6 pct in 2017 in the USA. The low figure of the wrought magnesium 




Fig. 1-Primary magnesium metal consumption each year in the period 1999-2019.

products is mainly due to low demands from the transportation and construction industries. However, a few significant developments have been made in recent years on the developments of wrought products. In 2014, Korean steel company POSCO and Renault Samsung Motors jointly developed a magnesium sheet to be used for the walls of VIP back seats and the trunks of upgraded SM7 vehicles. In 2015, Porsche selected Mg sheet for the roof of its new model of the 911 GT3 after its tests on $\mathrm{Mg}, \mathrm{Al}$, and carbon-fiber-reinforced polymers. In 2018, Nanjing Yunhai Special Metals Co. Ltd and Taiwan Jian Sin Industrial Co. Ltd announced a joint venture to invest one billion Yuan to build a new plant to produce one million forged magnesium wheels each year. With advances of processing and manufacturing technologies and alloy design, it is foreseeable that the global market for wrought magnesium products will expand significantly in the near future.

One of the major barriers to the larger usage and wider application of wrought magnesium alloys is their limited formability at room temperature, bulk magnesium is intrinsically difficult to form at this temperature. Therefore, processes such as extrusion, rolling, and press forging must be carried out in the temperature range 300 to $500{ }^{\circ} \mathrm{C}$. The productivity of magnesium alloy extrusions is much lower than that of aluminum alloys, and sheet production usually involves more stages of hot rolling. The processing cost is hence higher. Additionally, the extruded magnesium products often have tension-compression yield asymmetry: the compressive yield strength may be only half of the tensile yield strength, and rolled sheet usually has anisotropic formability and mechanical properties along different directions. Such problems have to be solved for any larger usage of wrought magnesium alloys.

Deformation modes that are commonly activated in $\mathrm{Mg}$ and its alloys include intra-granular slip and twinning and inter-granular grain boundary sliding, Figures 2(a) through (c). Dynamic recrystallization may also occur to assist the plastic deformation, depending on the strain level and the applied temperature, Figure 2(d). The available slip deformation modes are progressively more difficult to activate and this is compounded by a strong basal texture developed during thermomechanical processing. Twinning is highly dependent on orientation and exhausts after all suitably oriented grains have twinned, usually at around a strain of up to 0.08 . As a result, in contrast to the substantial formability of aluminum, fracture usually occurs when coarse-grained pure magnesium is cold-rolled by only 20 to 30 pet thickness reduction. The traditional approach to improve the room temperature formability of magnesium is to add appropriate alloying elements. Alloying additions can reduce the stress required to activate more deformation modes and/or weaken the texture to allow easier plastic deformation. While such approach has achieved some success in terms of formability improvement, it has not developed any magnesium products that are highly formable at room temperature, except those made of Mg-Li-based alloys.

The purpose of this article is to provide a comprehensive review of recent advances on wrought $\mathrm{Mg}$ alloys, covering (i) lattice defects and deformation modes, (ii) microstructures, (iii) mechanical properties and formability, and (iv) processing-microstructure-property relationships. The emphasis of the present review is focused on examination of two key microstructural factors: grain orientation (texture) and grain size in $\mathrm{Mg}$ sheets and extrusions that are produced under different processing conditions, and how they influence the deformation and the formability of the wrought products. The effects of alloying elements on texture and grain size and thus deformation and formability are also examined. This review ends with a discussion of microstructural design for better formability, and some scientific/technological challenges that require further research, and concluding remarks.

\section{LATTICE DEFECTS, DEFORMATION MODES, AND RECRYSTALLIZATION}

\section{A. Dislocations and Stacking Faults}

Magnesium has a hexagonal close-packed structure, with a $c / a$ ratio of approximately 1.623 at $27^{\circ} \mathrm{C}$. Its close-packed plane is (0001), and its close-packed directions are $\langle 11 \overline{2} 0\rangle$. The perfect dislocations are those with Burgers vectors in the basal plane $(1 / 3\langle 11 \overline{2} 0\rangle$, or $\langle a\rangle$ type), Burgers vectors perpendicular to the basal plane ([0001], or $\langle c\rangle$ type) and Burgers vectors that are the sum of these two types $(1 / 3\langle 11 \overline{2} 3\rangle$, or $\langle c+a\rangle$ type). The imperfect dislocations are those on the basal plane with a Shockley partial-type Burgers vector $(1 / 3\langle 10 \overline{1} 0\rangle)$, or with a Burgers vector perpendicular to the basal plane $(1 / 2[0001])$, or the combination of these two types $(1 / 6\langle 20 \overline{2} 3\rangle)$.

There are four types of stacking faults in magnesium and its alloys, namely intrinsic faults $I_{1}$ and $I_{2}$, the extrinsic fault $E$ and a twin-like fault $T_{2} \cdot{ }^{[2,3]}$ All of these faults have relatively low energy and do not affect the nearest-neighbor stacking sequence. The $I_{1}$ fault is produced by removing the basal $\mathrm{B}$ (or A) plane above an A (or B) plane and shearing the remaining planes 




(a)



(c)



(b)

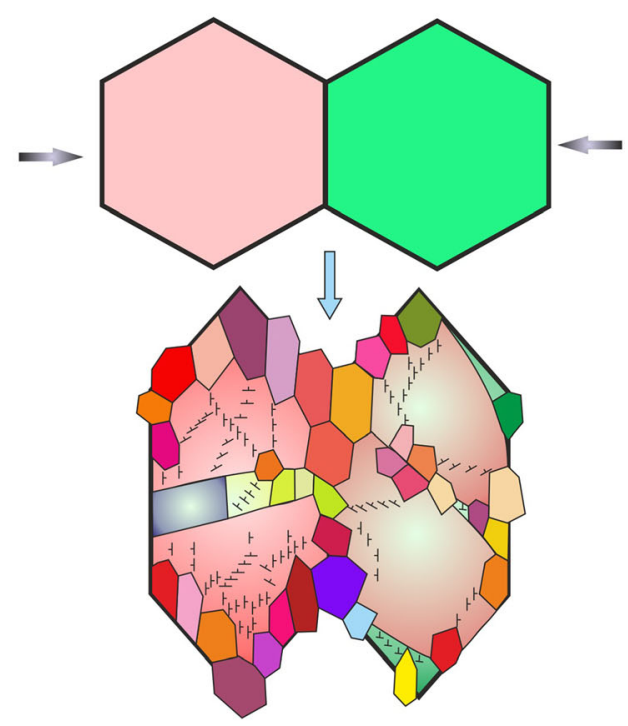

(d)

Fig. 2-Schematic diagrams showing (a) basal, prismatic, and pyramidal slip systems, (b) extension and contraction deformation twinning systems, $(c)$ grain boundary sliding, and $(d)$ dynamic recrystallization that may occur during plastic deformation of $\mathrm{Mg}$ and its alloys.

above the A (or B) plane by $1 / 3\langle 10 \overline{1} 0\rangle$. The $I_{1}$ fault changes the stacking order of the close-packed planes from $\mathrm{ABABABAB}$ to $\mathrm{ABABACAC}$, or $\mathrm{ABABABAB}$ to ABABCBCB. Traditionally, two different mechanisms have been proposed and accepted for the formation of the $I_{1}$ fault. $^{[4]}$ One involves dissociation of a $\langle c+a\rangle$ perfect dislocation, Figure 3(a1), while the other is vacancy condensation, Figure 3(a2). In each case, there are two sessile Frank partial dislocations $(\boldsymbol{b}=1 /$ $6\langle 02 \overline{2} 3\rangle$ ) each bounding an end of the $I_{1}$ fault.

Recent studies suggested that there are other mechanisms in generating an $I_{1}$ fault. One mechanism involves nucleation or formation of twinning disconnections of a single- or three-layer height on a fully coherent $\{10 \overline{1} 1\}^{[5]}$ or $\{10 \overline{1} 2\}^{[6]}$ twin boundary, as illustrated in Figure 4. For this mechanism, one end of the $I_{1}$ fault is an interfacial defect in the twin boundary, while the other end can be a Frank partial, if it terminates inside the twin, or bounded by another interfacial defect in the other side of the twin boundary, if it terminates at the twin boundary. Interaction between a basal $\langle a\rangle$ dislocation and a $\{10 \overline{1} 2\}$ twin boundary ${ }^{[7]}$ can also generate an $I_{1}$ fault inside the twin, but the essence of the interaction is identical to the geometry requirement such as that outlined in Figure 4. The interfacial defect located in the twin boundary is sessile, rather than glissile, and can migrate only with the twin boundary during twin thickening, which will increase the length of the $I_{1}$ fault. Such an $I_{1}$ fault is frequently observed inside $\{10 \overline{1} 2\}$ deformation twins, and may form in large quantities even inside a single twin. In the cases where a large quantity of the $I_{1}$ faults 


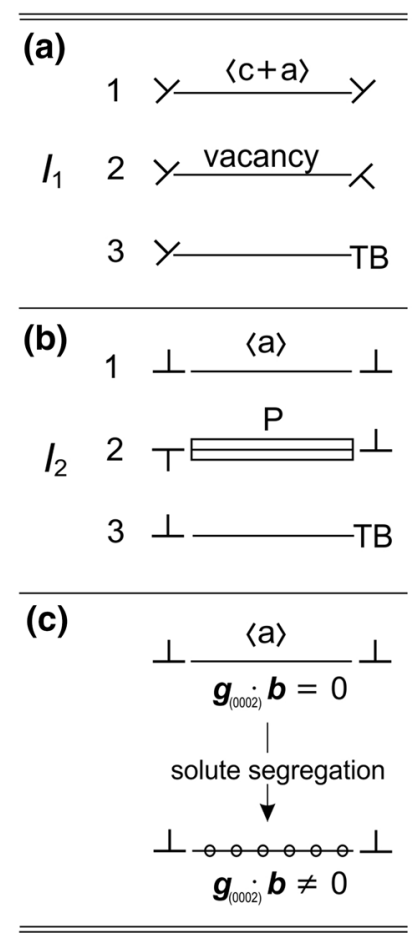

Fig. 3- Schematic diagrams showing stacking faults of $(a) I_{1}$ and $(b)$ $I_{2}$ that are generated by three different mechanisms. TB and $\mathrm{P}$ represent twin boundary and precipitate having an ABCA stacking, respectively. (c) An $I_{2}$ fault with segregated solute may appear like $I_{1}$ in conventional $\boldsymbol{g}_{(0002)} \cdot \boldsymbol{b}$ analysis.

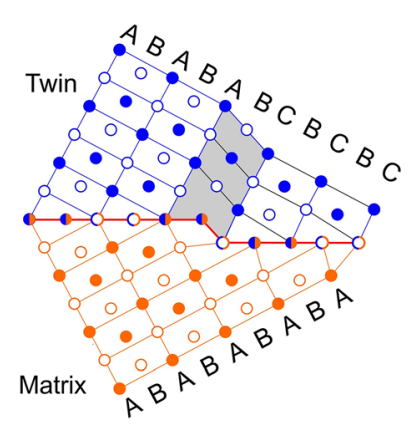

(a)

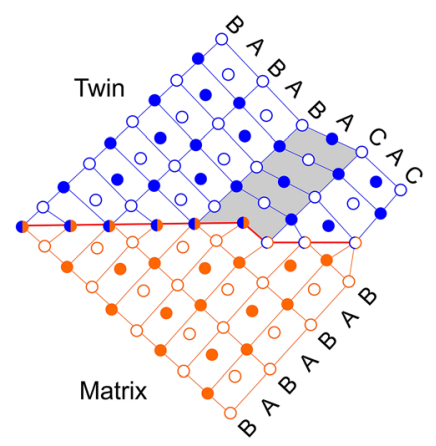

(b)
Fig. 4 - Schematic diagrams showing $I_{1}$ fault associated with a sessile disconnection of a single-layer height on a $(a)\{10 \overline{1} 1\}$ (reprinted from Ref. [5]), and (b) $\{10 \overline{1} 2\}$ twin boundary.

have terminated at a $\{10 \overline{1} 2\}$ twin boundary, the profuse presence of the sessile interfacial defects at the boundary leads to a substantial deviation of the macroscopic twin plane from the atomic $\{10 \overline{1} 2\}$ plane, resulting in twins with irregular shapes. It is to be noted that such $I_{1}$ fault is different from that resulting from dissociation from $\langle c+a\rangle$ dislocation, and it cannot be used to experimentally measure the energy of the $I_{1}$ fault. Precaution has to be taken when imaging and analyzing $I_{1}$ faults in scanning transmission electron microscopy (STEM), as a Frank partial may react with a basal $\langle a\rangle$ dislocation to form a complex configuration where an $I_{1}$ fault is bounded by a Frank partial at one end and a Shockley partial at the other end. ${ }^{[8]}$

It has been recognized that solute atoms may segregate to $I_{1}$ faults, but there are few experimental studies made by Z-contrast STEM. Most reports were based on first-principles density functional theory (DFT) calculations and considered only one solute atom in the fault plane. ${ }^{[9-18]}$ Figure 5(a) shows the energy of an $I_{1}$ fault in pure $\mathrm{Mg}\left(\sim 18 \mathrm{~mJ} \mathrm{~m}^{-2}{ }^{[10]}\right)$ and the calculated quantitative effect of solute segregation on the fault energy. Comparison of the stacking fault energy and the atomic size of the segregated solute ${ }^{[19]}$ does not suggest any correlation between them. It is to be noted that many of the elements listed in the plot are not in commercial or laboratory alloys, as they are either practically difficult to add to molten magnesium or cause corrosion and other issues. It is to be further noted that all the data are from binary solid solution alloys, the effect of solute segregation in ternary or quaternary alloy systems has not been studied at the computational level. The validity of these data has not been quantitatively examined or verified by experiments. For most commonly used alloying elements, $\mathrm{Al}, \mathrm{Mn}, \mathrm{Zr}, \mathrm{Y}, \mathrm{Nd}, \mathrm{Ce}, \mathrm{La}$, and $\mathrm{Ca}$, in wrought $\mathrm{Mg}$ alloys, their segregation in the $I_{1}$ stacking fault decreases the fault energy, implying that their presence in magnesium may cause more $I_{1}$ stacking faults to form. This aspect has, however, not been systematically and quantitatively evaluated at the experimental level. The segregation of $\mathrm{Li}$ or $\mathrm{Zn}$ does not seem to cause much variation of the $I_{1}$ fault energy. The solute-segregation-induced stacking fault energy reduction, especially in the case of $\mathrm{Y}$ additions, has been hypothesized to be the cause of more activities of $\langle c+a\rangle$ dislocation slip. ${ }^{[20]}$

The $I_{2}$ fault can be generated by shearing the hexagonal lattice by $1 / 3\langle 10 \overline{1} 0\rangle$, or the passage of a Shockley partial dislocation on the basal plane, i.e., dissociating a perfect $\langle a\rangle$ dislocation, Figure 3(b1). The passage of the Shockley partial, or shearing, changes the stacking sequence of close-packed planes from $\mathrm{ABA}$ $\mathrm{BABAB}$ to $\mathrm{ABABCACA}$, or $\mathrm{BABABABA}$ to BABACBCB. In contrast to the $I_{1}$ fault that is bounded by a pair of Frank partials, Figure 3(a1), a single $I_{2}$ fault is bounded by a pair of Shockley partial dislocations. The $I_{2}$ fault can also be generated by two other mechanisms. One mechanism involves precipitation of a plate-shaped particle having an ABCA stacking of close-packed planes, Figure 3(b2). The other involves formation of steps of single-layer height on twin boundaries, Figure 3(b3). The energy of the $I_{2}$ fault is $\sim 36 \mathrm{~mJ} \mathrm{~m}^{-2}$ for pure $\mathrm{Mg},{ }^{[10]}$ but can be much smaller in solid solutions of some binary $\mathrm{Mg}$ alloys. While there are computed data of energies of the $I_{2}$ faults for many binary magnesium solid solutions, Figure 5(b), there is again a lack of such data for ternary and quaternary magnesium solid solutions, and there is also a lack of experimental measurements that can be used to examine the validity of the computed data. It needs to be emphasized that an $I_{2}$ fault with segregated solute atoms, or a precipitate having ABCA stacking sequence, can be characterized to be an $I_{1}$ fault when analysis is 


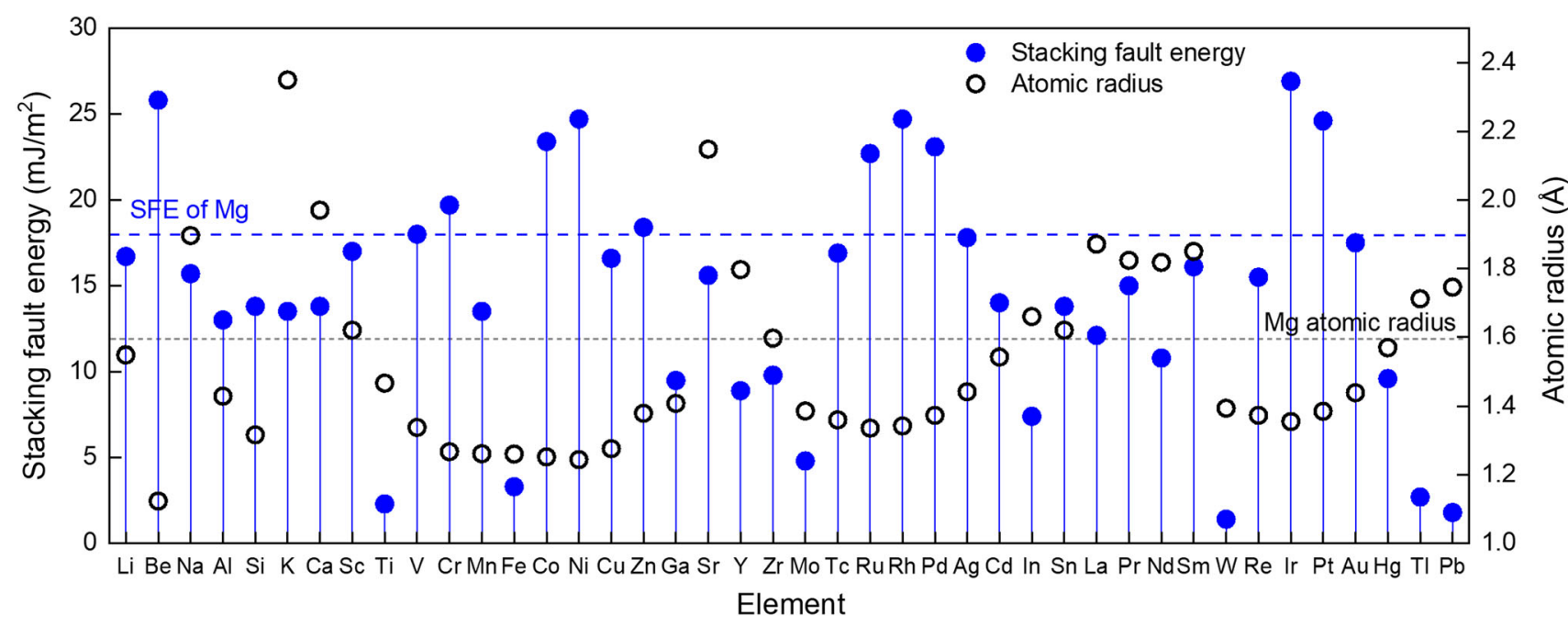

(a)

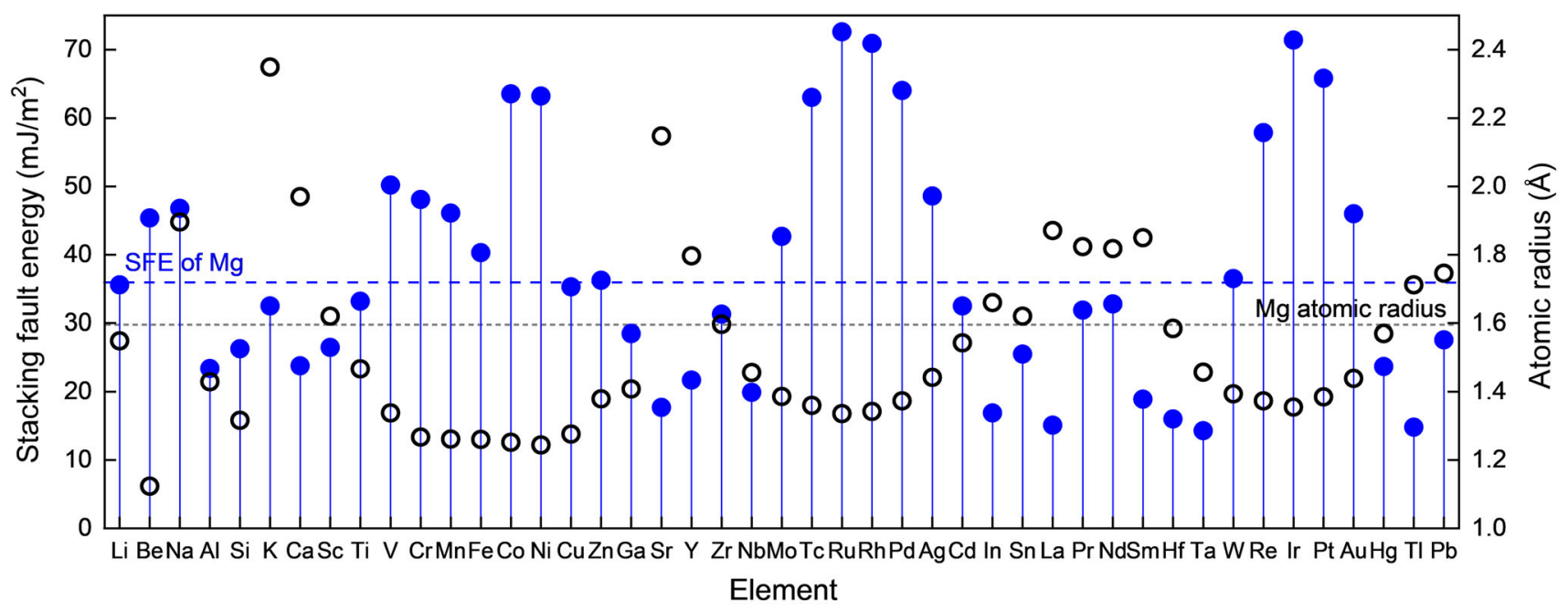

(b)

Fig. 5-Computed energies of (a) $I_{1}$ and (b) $I_{2}$ faults with segregated solutes (Data from Refs. [9-14]). Atomic sizes ${ }^{[19]}$ of Mg and solute atoms are also included.

made solely using the conventional invisibility criterion $\boldsymbol{g}_{(0002)} \boldsymbol{b} \neq 0$, Figure 3(c). In this situation, the contrast in the transmission electron microscopy (TEM) image, i.e., $\boldsymbol{g}_{(0002)} \boldsymbol{b} \neq 0$, is caused by the segregated solute atoms or the precipitate, rather than the elastic strain associated with the fault. Precaution is needed in the characterization of stacking faults using conventional TEM.

Stacking faults $I_{2}$ and $I_{1}$ have been frequently reported to form in magnesium alloys, even in alloys without any plastic deformation. Many of the so-called stacking faults are in fact thin precipitates lying on the basal plane of the $\mathrm{Mg}$ matrix, as illustrated in Figure 3(b2). Long and thin precipitates often form on the basal plane of the $\mathrm{Mg}$ matrix phase, especially in $\mathrm{Mg}-\mathrm{Gd}-\mathrm{Zn}$ and $\mathrm{Mg}-\mathrm{Y}-\mathrm{Zn}$-based alloys. ${ }^{[21,22]}$ The addition of even a trace amount of $\mathrm{Zn}$ to a binary $\mathrm{Mg}-\mathrm{Y}$ alloy can cause the formation of such precipitates. The thin planar defects observed in $\mathrm{Mg}-\mathrm{Y}-\mathrm{Zn}$ alloys have long been accepted as $I_{1}$ faults, based on the $\boldsymbol{g}_{(0002)} \cdot \boldsymbol{b} \neq$
0 analysis. It is to be noted that the contrast $\boldsymbol{g}_{(0002)} \cdot \boldsymbol{b} \neq$ 0 is due to the presence of the precipitate, rather than the elastic strain of the $\mathrm{Mg}$ lattice surrounding the fault. Studies using Z-contrast atomic-resolution STEM indicated that the so-called $I_{1}$ fault in the $\mathrm{Mg}$-Y- $\mathrm{Zn}$ alloys is in fact $\gamma^{\prime}$ precipitate that has an ABCA stacking of the close-packed planes. ${ }^{[23,24]}$ The $\gamma^{\prime}$ precipitate enriches in $\mathrm{Y}$ and/or $\mathrm{Zn}$ atoms in its $\mathrm{B}$ and $\mathrm{C}$ layers and is associated with a Shockley partial dislocation at each of its ends. Similar precipitates also form in aged $\mathrm{Mg}-\mathrm{Sn}$ alloys. ${ }^{[25]}$

The extrinsic fault $E$ is formed by inserting a $\mathrm{C}$ plane into the hexagonal stacking sequence, or the dissociation of a $c$ perfect dislocation. The $\mathrm{E}$ fault is bounded by Frank partial dislocations $(\boldsymbol{b}=1 / 2[0001])$. The $E$ fault changes $\mathrm{ABABABAB}$ to $\mathrm{ABABCABAB}$, or $\mathrm{ABABA}$ $\mathrm{BAB}$ to ABABACBAB. While the formation of an $E$ fault can also generate an ABCA segment, the stacking order of the close-packed planes outside this segment is different from that associated with an $I_{2}$ fault. The 
energy of the extrinsic fault is $\sim 54 \mathrm{~mJ} \mathrm{~m}^{-2}$ in pure Mg.

The twin-like $T_{2}$ fault can form from an $I_{2}$ fault or in association with ordered segregation of solute atoms. ${ }^{[27]}$ It is generated by displacing some atomic columns by $1 /$ $3\langle 0110\rangle$ in an $\mathrm{A}$ or $\mathrm{B}$ plane. The $T_{2}$ fault changes the stacking sequence from ABABABAB to ABABC$\mathrm{BABA}$, or to BABACABAB, and hence it leads to a twin-like arrangement of close-packed planes with respect to the fault plane $\mathrm{C}$. The energy of the $T_{2}$ fault in pure $\mathrm{Mg}$ is in the range 41 to $43 \mathrm{~mJ} \mathrm{~m}^{-2},{ }^{[12,27]}$ which is higher than those of $I_{1}$ and $I_{2}$ faults but lower than that of $E$ fault.

Stacking faults on non-basal planes such as prismatic I $\{10 \overline{1} 0\}$, prismatic II $\{11 \overline{2} 0\}$, pyramidal I $\{10 \overline{1} 1\}$, and pyramidal II $\{11 \overline{2} \overline{2}\}$ have also been reported, ${ }^{[10,28-31]}$ even though most of them have not been observed experimentally in pure $\mathrm{Mg}$ or its alloys. For the stacking faults on the pyramidal I and II planes, designated $\mathrm{SF}_{\text {pyI }}$ and $\mathrm{SF}_{\text {pyII }}$, respectively, they are found to occur in molecular dynamics (MD) simulations. The $\mathrm{SF}_{\text {pyI }}$ and $\mathrm{SF}_{\text {pyII }}$ values are 164 and $168 \mathrm{~mJ} \mathrm{~m}^{-2}$, respectively, for pure $\mathrm{Mg}$, and decrease linearly with increasing concentration of solutes such as $Y^{[10]}$ The separation distance between the two partials bounding each type of the faults is approximately $1.4 \mathrm{~nm}$ for pure $\mathrm{Mg}^{[28]}$ and is expected to be larger than $1.4 \mathrm{~nm}$ in the case of $\mathrm{Y}$ additions. These separation distances are all within the spatial resolution of most modern transmission electron microscopes, and therefore the presence of such pyramidal stacking faults in the microstructure should be detected readily in TEM or STEM. This aspect needs more careful TEM or STEM characterization in the future. It is to be noted that a notion of cross-slip energy barrier reduction was invoked in recent years to account for the effects of alloying elements on ductility. ${ }^{[30-32]}$ In this approach, the energy barrier to the cross-slip from a lower-energy pyramidal II plane to a higher-energy pyramidal I plane of an infinitely long $\langle c+a\rangle$ screw dislocation was considered to be large for pure $\mathrm{Mg}$, and the quantitative effects of solutes on the reduction of this barrier were computed and examined. The essence of the computations is how the added solute quantitatively influences the $\mathrm{SF}_{\text {pyI }}$ and $\mathrm{SF}_{\text {pyII }}$ values, under the condition of a single solute atom that is randomly distributed with respect to the stacking fault. While some binary systems with different concentrations of the solute, and even ternary and quaternary systems, have also been analyzed, the condition used in all these computations is just a linear addition of the effects of isolated individual solute atoms or elements. It remains to be fully assessed, at both computational and experimentally levels, whether the reduction of the energy barrier to the pyramidal cross-slip is the main cause for the improved ductility in some $\mathrm{Mg}$ alloys.

\section{B. Slip, Twinning, and Grain Boundary Sliding}

Basal slip is one of the major deformation modes in $\mathrm{Mg}$. It can be activated at a very low stress at room temperature. Non-basal slip, such as pyramidal I
$\{10 \overline{1} 1\}\langle 11 \overline{2} 3\rangle$ and pyramidal II $\{11 \overline{2} \overline{2}\}\langle 11 \overline{2} 3\rangle$ slip and prismatic slip, can also occur at room temperature, but at much higher stresses. For a given applied stress $\sigma$, the resolved shear stress along the slip or twinning direction on the slip or twin plane, $\tau$, is given by

$$
\tau=\sigma \cos \alpha \cos \beta,
$$

where $\alpha$ is the angle between the applied stress axis and the slip or twinning direction, and $\beta$ is the angle between the applied stress axis and the slip or twinning plane normal. The orientation factor, $\cos \alpha \cos \beta$, also called Schmid factor, is an important parameter in highly textured polycrystalline $\mathrm{Mg}$ and its alloys. $\tau$ value has to be larger than a critical value, the critical resolved shear stress (CRSS), in order to activate slip or twinning. The CRSS values for basal and non-basal slip and twinning modes are provided in Figure 6(a). Also included in this figure is the influence of temperature upon CRSS value. Basal slip and extension twinning are less temperature dependent, but CRSS values for others deformation modes decrease significantly with increasing temperature. Addition of solutes, via alloying additions, can

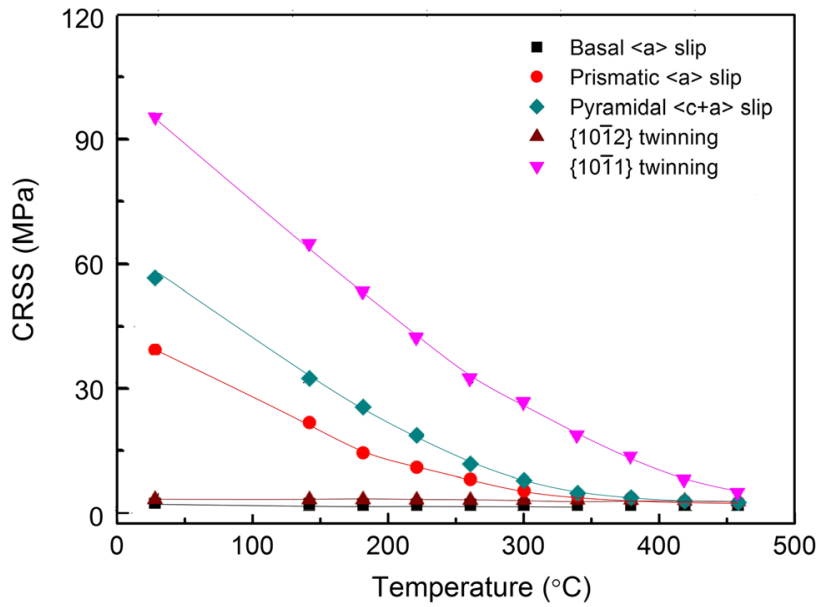

(a)

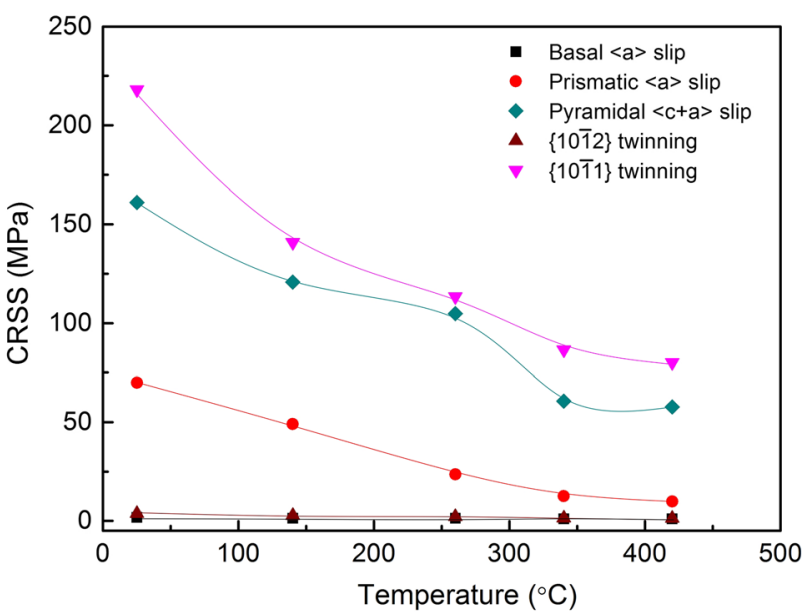

(b)

Fig. 6-Critical resolved shear stress values for different slip and twinning modes and their variation with temperature. (a) Pure $\mathrm{Mg}$ single crystals, and (b) Mg-1wt pct Al single crystals. 
decrease or increase the CRSS values, even at room temperature. As illustrated in Figure 6(b), the addition of 1 wt pct $\mathrm{Al}$ to $\mathrm{Mg}$ can significantly increase the room temperature CRSS values for pyramidal and prismatic slip and $\{10 \overline{1} 1\}\langle\overline{1012}\rangle$ twinning.

Despite the fact that basal slip can be activated readily, it provides only two independent slip systems, which are insufficient to allow individual magnesium grains to plastically deform to meet the shape changes imposed by their neighbors. Therefore, non-basal slip on pyramidal and/or prismatic planes also occurs at room temperature in orientations that favor their occurrence, even though at much higher stresses. The Burgers vector of gliding dislocations for both pyramidal I slip and pyramidal II slip is $\langle c+a\rangle$, and the easiness of activation of the $\langle c+a\rangle$ slip has been frequently used to explain deformation behavior and effects of alloying elements on the ductility of $\mathrm{Mg}$ alloys. It was recently reported $^{[33]}$ that the poor formability or ductility of pure magnesium is due to pyramidal $\langle c+a\rangle$ dislocation transformations to an immobile structure. ${ }^{[34-37]}$ Molecular dynamics simulations suggested that the easy-glide pyramidal $\langle c+a\rangle$ edge dislocations are unstable - they undergo a rapid transition to an "immobile" structure, comprising two Frank partial dislocations and a basal stacking fault between them, that limits the plastic strain along the $c$-axis. A subsequent computational study ${ }^{[32]}$ reported that adding appropriate alloying elements can lead to solute-enhanced cross-slip of $\langle c+a\rangle$ screw dislocations and thus improve ductility and formability. A large number of alloying elements, individually or in combination, were also proposed for achieving high ductility and high formability. It is to be noted that the proposed effects of the alloying elements are based exclusively on first-principles DFT calculations, as discussed in section A on pyramidal stacking faults, and they have not been examined by any MD simulations due to the lack of inter-atomic potentials for magnesium alloys. A very recent work based on in-situ transmission electron microscope mechanical testing, $3 \mathrm{D}$ image reconstruction, and atomistic simulations ${ }^{[38]}$ demonstrated that the $\langle c+a\rangle$ edge dislocation in pure $\mathrm{Mg}$ can glide on both pyramidal I and pyramidal II planes. A separate study of dislocations using weakbeam dark-field transmission electron microscopy reported that $\langle c+a\rangle$ dislocations do not dissociate in hot-rolled AZ31 (Mg-3Al-1Zn-0.3Mn; wt pct) alloy. ${ }^{[39]}$ Other experimental observations made by atomic-resolution STEM indicated that $\langle c+a\rangle$ dislocations dissociate in cold deformed samples of $\mathrm{Mg}-\mathrm{Bi}$ and $\mathrm{Mg}-\mathrm{Sn}$ alloys. ${ }^{[8,40]}$ Detailed and systematic characterization of more alloy systems and alloys subjected to different deformation conditions is needed in the future to resolve the controversial reports. Equally, more computation-based studies are needed in the future on solute-dislocation interactions and quantitative effects of solutes on dislocation slip activities in different slip systems. ${ }^{[41-45]}$

Apart from the basal and non-basal slip, twinning is also an important deformation mode. A variety of twinning modes have been reported to occur in $\mathrm{Mg}$ alloys, with twin planes on $\{10 \overline{1} 1\},\{10 \overline{1} 2\},\{10 \overline{1} 3\}$, $\{10 \overline{1} 4\},\{10 \overline{1} 5\},\{30 \overline{3} 4\},\{11 \overline{2} 1\}$, and $\{11 \overline{2} 4\} .{ }^{[46-49]}$ The $\{1012\}$ extension twins are most commonly observed, and their formation and growth lead to an extension along the $c$-axis. The $\{10 \overline{1} 1\}$ contraction twin forms under the stress condition that favors contraction along the $c$-axis. The CRSS value for the contraction twinning is much higher than that for the extension twinning, Figure 6. Homogeneous initiation of either deformation twinning inside a magnesium grain is extremely difficult. Instead, the initiation starts at a grain boundary or pre-existing twin boundary where stress concentrations are primarily located, ${ }^{[50,51]}$ Figure 7(a). Once nucleated, these twins can propagate readily and rapidly in the grain, often extending from one side of the grain to the other side, Figures 7(b) and (c). Under continued straining, new twins may nucleate

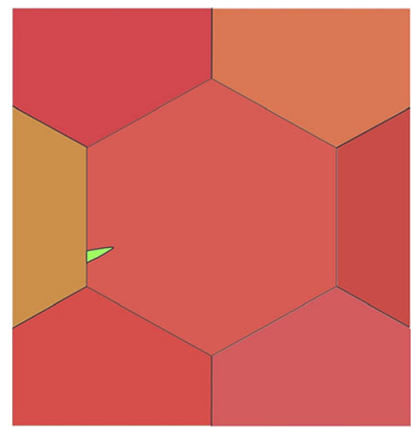

(a)



(c)



(b)

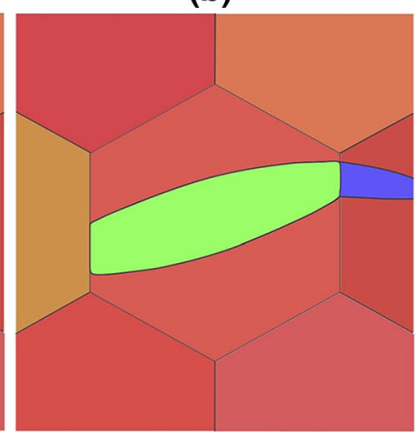

(d)



(e)

Fig. 7-Schematic diagrams showing (a) nucleation at a grain boundary, $(b)$ propagation or lengthening, and $(c)$ thickening of a deformation twin in a highly textured polycrystalline $\mathrm{Mg}$ or its alloy. (d) Twin transmission into a neighboring grain that is of a similar orientation, and (e) further twinning, i.e., secondary or double twinning, inside the primary twin. 
in a neighboring grain at grain boundary locations where primary twins have terminated, a phenomenon known as twin transmission, Figure 7(d), or inside the primary twins, which is known as secondary or double twinning, Figure 7(e). The twin transmission often occurs in such a manner that the adjacent grain pair has a small misorientation angle and the incoming and outgoing twin pair that have formed across the grain boundary provide the most effective accommodation of the stress concentrated at the boundary. ${ }^{[52-55]}$ A geometric compatibility factor, $m^{\prime}$, is often used to explain the twin transmission across, or stress accommodation at, the grain boundary. This factor is defined by $m^{\prime}=\cos \phi \cos \lambda$, where $\phi$ and $\lambda$ represent, respectively, the angles between the two twin planes and the two twin shear directions on the two twin planes. While this factor can be used to explain some cases of twin transmission, it has been reported ${ }^{[53]}$ in recent years that plastic anisotropy is also a major contributor to the twin transmission.

The secondary twinning illustrated in Figure 7(e) leads to the formation of a double-twin structure. The double twins reported so far include mainly $\{10 \overline{1} 1\}-\{10 \overline{1} 2\}$ and $\{10 \overline{1} 3\}-\{10 \overline{1} 2\},{ }^{[56]}$ even though a less common case of $\{10 \overline{1} 2\}-\{10 \overline{1} 2\}$ has also been reported. ${ }^{[57,58]}$ In the former, the $\{10 \overline{1} 1\}$ or $\{10 \overline{1} 3\}$ contraction twins form first under applied stress conditions that favor their formation, followed by the formation of $\{10 \overline{1} 2\}$ extension twins inside the primary contraction twins. This phenomenon can be understood by the fact that the applied stress condition that favors the formation of the primary $\{10 \overline{1} 1\}$ or $\{10 \overline{1} 3\}$ contraction twins in the parent grain also favors the formation of secondary $\{10 \overline{1} 2\}$ extension twins in regions of the primary contraction twins. In the latter, a $\{10 \overline{1} 2\}$ extension twin forms first under applied stress conditions that favor its formation in the parent grain, followed by the formation of a $\{10 \overline{1} 2\}$ secondary twin inside the primary extension twin, which is triggered by the impingement of the primary extension twin by another primary twin variant. ${ }^{[58]}$

While considerable efforts have been made on the nucleation, growth, and propagation of deformation twins, ${ }^{[50-63]}$ there were fewer studies on the effects of solutes ${ }^{[64,65]}$ and precipitates ${ }^{[66-70]}$ on twinning in $\mathrm{Mg}$ alloys.

It is now well known that solute segregation occurs in fully coherent twin boundaries. ${ }^{[71-75]}$ In general, solutes with an atomic size larger than $\mathrm{Mg}$ segregate to the extension sites in a twin boundary, while solutes having smaller atomic size go to the contraction sites. The solute segregation leads to a reduction of twin boundary energy. The tendency for solute segregation in binary alloys containing different types of solutes is illustrated in Figure 8. Most commonly used alloying elements in wrought $\mathrm{Mg}$ alloys have a strong tendency for segregation in twin boundaries. It is to be noted that all of these data are for binary alloys, the segregation behavior in ternary or quaternary alloys has not been extensively studied. For ternary alloys based on $\mathrm{Mg}-\mathrm{Gd}-\mathrm{Zn}$ and
Mg-Nd-Ag systems, in which both larger and smaller solutes are present, different segregation behaviors were found in recent studies made by both atomic-resolution STEM and first-principles DFT calculation. ${ }^{[6,71]}$ In the $\mathrm{Mg}-\mathrm{Gd}-\mathrm{Zn}$ alloys, both $\mathrm{Gd}$ and $\mathrm{Zn}$ atoms segregate into the extension sites, but in the $\mathrm{Mg}-\mathrm{Nd}-\mathrm{Ag}$ alloys $\mathrm{Nd}$ and $\mathrm{Ag}$ atoms segregate separately into the extension and the contraction sites. The solute segregation generates a strong pinning effect on twin boundary migration and an annealing strengthening phenomenon. Such effects influence strongly twinning behavior during plastic deformation and thermomechanical processing.

Apart from intra-granular deformation modes of slip and twinning, there also exist inter-granular deformation modes such as grain boundary sliding. Grain boundary sliding ${ }^{[76,77]}$ becomes important when the grain size approaches $1 \mu \mathrm{m}$ or less in polycrystalline $\mathrm{Mg}$ and its alloys. ${ }^{[78-80]}$ In contrast to studies made on slip and twinning, few studies have been made so far on grain boundary sliding in $\mathrm{Mg}$ alloys. This is mainly because the grain size in wrought $\mathrm{Mg}$ alloys produced by conventional processes is typically above $5 \mu \mathrm{m}$ at which grain boundary sliding is usually thought unlikely to occur.

\section{Recrystallization}

Recrystallization occurs by the formation of new strain-free grains within the deformed microstructure, Figure 2(d). It can take place during plastic deformation, known as dynamic recrystallization (DRX), or annealing after the deformation process, known as static recrystallization $(\mathrm{SRX}){ }^{[81]}$ Dynamic recrystallized grains generally form in grain boundaries, ${ }^{[82-85]}$ deformation twins, ${ }^{[86,87]}$ shear bands ${ }^{[88,89]}$, and/or regions surrounding relatively large second-phase particles ${ }^{[90,91]}$ where stress concentrations are predominantly located. Similarly, static recrystallized grains also form in grain boundaries and twin boundaries. ${ }^{[92]}$ The mechanism of either dynamic or static recrystallization in $\mathrm{Mg}$ and its alloys is less clearly established, as both continuous recrystallization and discontinuous recrystallization have been reported. ${ }^{[93-98]}$ The continuous dynamic recrystallization involves a continuous, and slow, evolution of the size and misorientation of sub-grains formed in the deformed microstructure. It is expected to operate in plastically deformed metals and alloys having a uniform distribution of the stored energy, and to occur homogeneously in the microstructure. In contrast, the discontinuous dynamic recrystallization involves nucleation of new grains in a discontinuous and fast manner. It is usually favored in deformed metals and alloys that have a non-uniform distribution of the stored energy, and it occurs heterogeneously in the microstructure. The resultant microstructure contains a mixture of recrystallized regions and unrecrystallized regions.

While the above mechanisms are different and their operation conditions in $\mathrm{Mg}$ and its alloys remain to be fully established, it is convenient to use the discontinuous recrystallization to describe the recrystallization process, especially the grain size and its evolution. The critical factors influencing the size and orientation of 


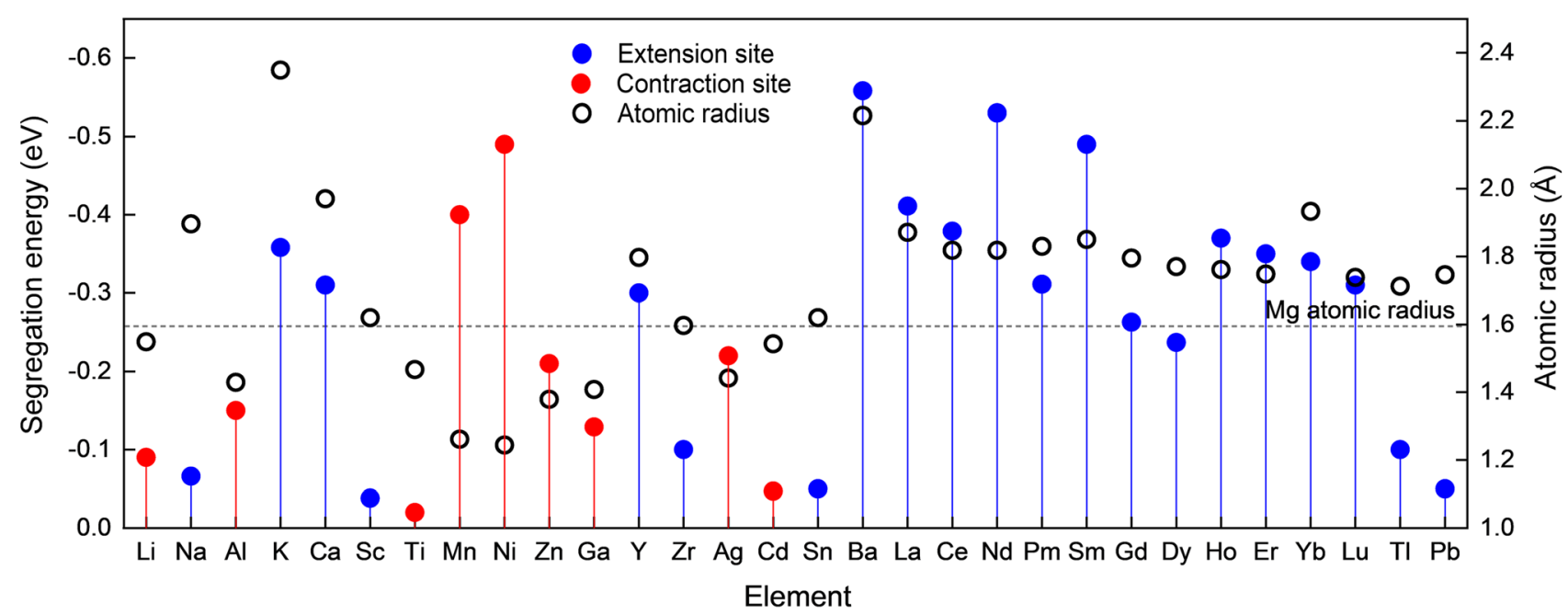

(a)



(b)

Fig. 8-Computed segregation energies of solutes in fully coherent $(a)\{10 \overline{1} 2\}$, and $(b)\{10 \overline{1} 1\}$ twin boundaries (Data from Refs. [71-75]). Atomic sizes ${ }^{[19]}$ of $\mathrm{Mg}$ and solute atoms are also included to show the relationship between atomic size and segregation sites.

fully recrystallized grains are the temperature, strain, strain rate, solutes, and in some cases second-phase particles. For example, for a given strain and a strain rate, the use of a lower temperature and/or some specific solutes will tend to suppress dynamic recrystallization, allowing a higher stored energy and a wider spread of orientations to be obtained. Consequently, the larger driving force for recrystallization will lead to a higher nucleation rate and eventually a smaller size of the recrystallized grains; and the wider spread orientations will give rise to a weaker texture after recrystallization. The presence of the solutes in the solid solution will also lead to a decreased grain boundary mobility via a solute push/drag effect. It is well known that recrystallization behavior and texture can be changed by some specific alloying elements (Sections III-V), even at remarkably low concentrations, but the precise roles of such alloying elements in texture changing remain speculative. It is to be noted that the basal texture weakening or texture changing often occurs in $\mathrm{Mg}$ alloys that have strong solute segregation in grain boundaries and twin boundaries (Sections III-V). The possible relationship between the solute segregation in grain boundaries and the basal texture weakening in two binary $\mathrm{Mg}-\mathrm{RE}$ alloys has been discussed by Robson and co-workers in a recent report. ${ }^{[99]}$

\section{DEFORMATION AND MICROSTRUCTURES OF PURE MAGNESIUM}

\section{A. Single Crystals}

\section{Deformation behavior at room temperature}

a. Compression under different loading conditions The room temperature response of single crystals of pure $\mathrm{Mg}$ under plane-strain compression at a strain rate of $10^{-3}$ $\mathrm{s}^{-1}$ is shown in Figure 9, for different orientations of the 




(a)



(b)



(c)

Fig. 9-Stress-strain curves of single crystals of pure $\mathrm{Mg}$ deformed at room temperature by plane-strain compression along different crystallographic directions A-G. (a) Compression along [0001] axis with constraint along $\langle 10 \overline{1} 0\rangle$ (A) and $\langle 1 \overline{2} 10\rangle$ (B). (b) Compression along $\langle 10 \overline{1} 0\rangle$ (C) and $\langle 1 \overline{2} 10\rangle$ (D), with constraint along [0001]. (c) Compression along $\langle 10 \overline{10}\rangle$ with constraint in $\langle 1 \overline{2} 10\rangle$ (E), along $\langle 1 \overline{2} 10\rangle$ with constraint in $\langle 1010\rangle(\mathrm{F})$, and orientation $\mathrm{G}$ for basal slip. Adapted from Ref. [100].

crystals with respect to the loading direction. ${ }^{[100,101]}$ For crystals with their $c$-axes parallel to the loading direction, orientations A and B in Figure 9(a), they exhibit quite limited plastic strain $(\sim 0.04)$ before fracture. This low formability is attributable to the lack of multiple deformation modes. The operating deformation mode under this forming condition has been unclear, even though it was reported to be $\{10 \overline{1} 1\}\langle\overline{1} 012\rangle$ contraction twinning, and subsequent occurrence of secondary twinning on $\{10 \overline{1} 2\}$ and basal slip inside the double-twinned region, in the early studies made by Wonsiewicz and Backofen ${ }^{[102]}$ and by Kelley and Hosford. ${ }^{[100]}$ The initiation of twinning on the $\{10 \overline{1} 1\}$ was observed only at strain levels close to fracture. While only basal slip traces were observed up to a strain level of 0.04 , these traces were attributed ${ }^{[101]}$ to the operation of basal slip that resulted from misalignment of the $c$-axis of the tested pure $\mathrm{Mg}$ crystal with the loading axis.

Under plane-strain compression at the same strain rate, a pure $\mathrm{Mg}$ single crystal exhibits a larger plastic strain when its $c$-axis is perpendicular to the loading axis, Figures 9(b) and (c). The larger strain is associated with the formation of profuse twins. Under the condition of plane-strain compression perpendicular to the constrained $c$-axis, orientations C and D in Figure 9(b), single crystals of pure $\mathrm{Mg}$ may exhibit a larger plastic strain before failure. While such orientations are favorable for prismatic slip and pyramidal I slip, slip traces of such deformation systems were not found in optical micrographs. ${ }^{[100]}$ Instead, plastic deformation occurs by simultaneous operation of $\{10 \overline{1} 1\}\langle\overline{1} 012\rangle$ twinning, $\{10 \overline{1} 2\}\langle\overline{1} 011\rangle$ twinning, and dynamic recrystallization within bands of the $\{10 \overline{1} 1\}$ twins. It was suggested ${ }^{[103]}$ that the dynamic recrystallization occurs after the formation and widening of the $\{10 \overline{1} 1\}$ twins to accommodate further plastic strain.

When the loading axis is parallel to the $\langle 10 \overline{1} 0\rangle$ direction and the deformation along the $c$-axis is constrained, i.e., orientation $\mathrm{E}$ in Figure 9(c), deformation proceeds until the single crystal becomes fully $\{10 \overline{1} 2\}$ twinned at approximately 0.064 strain, followed by the operation of $\{10 \overline{1} 1\}\langle\overline{1} 012\rangle$ twinning, inside the re-oriented regions of the deformed crystal, until fracture. Pure $\mathrm{Mg}$ can be deformed to a much larger plastic strain if the loading axis is parallel to the $\langle 1 \overline{2} 10\rangle$ direction and the deformation along the $c$-axis is constrained, orientation F in Figure 9(c). This enlarged strain level was attributed ${ }^{[100]}$ to the subsequent operation of basal slip and $\{10 \overline{1} 1\}\langle\overline{1} 012\rangle$ twinning inside the re-oriented regions of the crystal once the original crystal is fully consumed by the $\{10 \overline{1} 2\}$ twins.

Single crystals of pure $\mathrm{Mg}$ can be deformed readily at a significantly lower stress, and to a much larger plastic strain, when their orientations are such as to favor basal slip. One example is the orientation $G$ in Figure 9(c), in which the $c$-axis of the crystal is initially inclined at $45 \mathrm{deg}$ to the compression direction and the deformation along the $\langle 10 \overline{1} 0\rangle$ direction is constrained. As illustrated in Figures 9(c) and 10, the single crystal with the orientation $G$ exhibits substantial plasticity: it can be deformed to 0.6 strain, ${ }^{[104]}$ and even up to 1.0 strain, ${ }^{[103]}$ without fracturing. The plastic deformation is accompanied by a significantly larger strain hardening rate for the strain range 0.6 to 1.0 . The plastic deformation is not uniform across the crystal with an increase in plastic strain. The crystal deforms initially by basal slip, leading to a gradual rotation of the $c$-axis towards the compression direction. The continued deformation leads to the formation of macroscopic bands comprising $\{10 \overline{1} 2\}$ 



Fig. 10 - (a) Stress-strain curves of single crystals of pure $\mathrm{Mg}$ deformed by plane-strain compression, at room temperature and a strain rate of $10^{-3} \mathrm{~s}^{-1}$, for orientations D-G that are shown in Fig. 9. ( $b$ through $d$ ) EBSD orientation maps and corresponding (0002) pole figures showing $(b, c)$ deformed microstructures of specimens at 0.03 strain of orientations $\mathrm{E}$ and $\mathrm{F}$, respectively, and (d) sub-grains and dynamic recrystallized grains in orientation $\mathrm{F}$ at 1.0 strain. Adapted from Refs. [103,104].

twins, with two $\{10 \overline{1} 2\}$ twin variants arranged in a tweed structure that is parallel to the constraint direction $\langle 10 \overline{1} 0\rangle$. The volume fraction of such bands increases with an increase in plastic strain. The formation of the $\{10 \overline{1} 2\}$ twins is anomalous, because it has a negative Schmid factor and generates a strain opposite to the imposed deformation. However, the chevron arrangement of the two twin variants leads to no macroscopic twin shear along the constraint direction $\langle 10 \overline{1} 0\rangle$. The formation of the $\{10 \overline{1} 2\}$ twins makes the $c$-axis of the initial matrix further away from the compression direction, which compensates for the lattice rotation caused by the basal slip. It was argued ${ }^{[104]}$ that it is the formation of the chevron $\{10 \overline{1} 2\}$ twins that leads to a softened orientation and thus a larger plasticity.

The deformation behaviors of single crystals of pure $\mathrm{Mg}$ under these loading and constraint conditions have been confirmed in later studies. ${ }^{[103-106]}$ Figure 10(a) shows the stress-strain curves of orientations D, E, F, and $G$, which are similar to those shown in Figure 9 but contain more data especially for the orientations exhibiting substantially larger plasticity. While the orientations $\mathrm{E}$ and $\mathrm{F}$ both allow for $c$-axis extension, they exhibit drastic difference in plasticity. The crystal of the orientation $\mathrm{E}$ starts to yield at a very low stress, followed by rapid strain hardening, and eventually fractures at a stress of $\sim 400 \mathrm{MPa}$ and a plastic strain of 0.15 . The crystal of the orientation $F$ exhibits an initial strain hardening and the onset of plastic deformation at a lower stress, followed by a rapid increase in hardening rate and yielding drop at approximately 220 $\mathrm{MPa}$. Further loading leads to continuous plastic deformation at a lower but constant strain hardening rate, but there is no fracture or failure for strain up to 0.6 and even 1.0. ${ }^{[103,104]}$

Figures 10(b) and (c) show electron backscatter diffraction (EBSD) orientation maps of crystals with orientations $\mathrm{E}$ and $\mathrm{F}$ and subjected to 0.03 compressive strain, respectively. An extensive amount of $\{10 \overline{1} 2\}$ twins is visible in both specimens. While the area fractions of twins $(\sim 53 \mathrm{pct})$ in these two specimens are approximately the same, the numbers of crystallographic variants of the twins are clearly different. Only one twin variant (marked by red color) has formed in the orientation E, but two twin variants (marked by orange color) are activated in the orientation F. Furthermore, an appreciable fraction of secondary $\{10 \overline{1} 2\}$ twins is also activated inside the primary $\{10 \overline{1} 2\}$ twins in the orientation F, indicated by STW in the map in Figure 10(b), in contrast to the absence of secondary twins in the specimen in the orientation E. It is important to emphasize that the orientations of the twin variants, with respect to the loading and constrain directions, are drastically different in these two cases. For the orientation $\mathrm{E}$, the orientation of the formed $\{10 \overline{1} 2\}$ twins is such that it makes secondary twinning hard to occur (i.e., a hard orientation for twinning). However, for the orientation $\mathrm{F}$, it is possible for $\{10 \overline{1} 2\}$ twins to form and grow continuously inside the parent crystal until the bulk of the parent crystal is consumed at a strain of approximately $0.08 .{ }^{[103]}$ While secondary and tertiary $\{10 \overline{1} 2\}$ twins also form inside the primary $\{10 \overline{1} 2\}$ twins due to impingement of the primary twin variants, their number density and volume fraction are both quite low in samples deformed by up to 0.08 strain. Snapshot-based examination of the deformed microstructures indicated the formation of "fragmented twin bands" at 0.11 strain, at which the yield drop occurs, Figure 10(a). These fragmented twin bands were 
reported $^{[103]}$ to result from $\{10 \overline{1} 1\}$ twins that have formed inside primary twins, even though the formation of the $\{10 \overline{1} 1\}$ twins was not directly shown in that work. In fact, such fragmented twin bands resemble the feature of dynamic recrystallization within deformation bands. With continued plastic deformation, the volume fraction of the dynamic recrystallized grains increases in the bulk sample and these dynamic recrystallized grains have a strikingly weak basal texture, Figure 10(d). The substantial plasticity of pure $\mathrm{Mg}$ in this orientation is likely attributable to repeated dynamic recrystallization during the continued plastic deformation. While it has been proposed $^{[103]}$ that the dynamic recrystallized grains evolve from sub-grain boundaries and their progressive rotation to high-angle boundaries, a more thorough multiscale characterization is needed in order to establish the dynamic recrystallization mechanisms operating under this particular deformation condition.

When a single crystal of pure $\mathrm{Mg}$ is deformed under a uniaxial compression condition along its $c$-axis, the dominant deformation mode is generally accepted to be pyramidal slip with $\langle c+a\rangle$ dislocations, even though it is not fully established whether it is $\{10 \overline{1} 1\}\langle 11 \overline{2} 3\rangle$ pyramidal I slip, $\{11 \overline{2} 2\}\langle 11 \overline{2} 3\rangle$ pyramidal II slip, or both. Other slip systems such as basal slip and prismatic slip, and $\{10 \overline{1} 2\}\langle\overline{1} 011\rangle$ extension twinning and $\{10 \overline{1} 1\}\langle\overline{1} 012\rangle$ contraction twinning modes, are absent or scarce. The early studies ${ }^{[87,107]}$ made by slip trace observations and transmission electron microscopy of crystals deformed at a strain rate of $1.7 \times 10^{-4} \mathrm{~s}^{-1}$ reported $\{11 \overline{2} 2\}\langle 11 \overline{2} 3\rangle$ pyramidal II slip as the major deformation mode, and such a result was confirmed in a recent study made by detailed characterization of dislocations in deformed single crystals. ${ }^{[108]}$ However, a more recent observation made by slip trace analysis of crystals deformed by 3 pct under similar conditions ${ }^{[109]}$ revealed that the dominant deformation mode is $\{10 \overline{1} 1\}\langle 11 \overline{2} 3\rangle$ pyramidal I slip, instead of pyramidal II slip. The critical resolved shear stress was measured to be $54 \mathrm{MPa} \cdot{ }^{[109]}$

For uniaxial compression along a direction that is close to but not parallel to the $a$-axis, in which the basal plane is slightly off the compression axis, the plastic deformation occurs at a very low stress via basal slip, followed by non-basal slip and $\{10 \overline{1} 2\}\langle\overline{1} 011\rangle$ twinning. Basal $\langle a\rangle$ dislocations, prismatic $\langle a\rangle$ dislocations, pyramidal I and II $\langle c+a\rangle$ dislocations were all observed in samples deformed at a low stress in the range 8 to 10 MPa. ${ }^{[110]}$ It was suggested ${ }^{[110]}$ that the operation of all of these slip systems is necessary to accomplish the shape change of the crystal during compression. While the external stress applied to the single crystal of pure $\mathrm{Mg}$ is far below the CRSS value required to activate non-basal slip, the non-basal slip has occurred to reduce or eliminate the stress caused by the pile-up of basal dislocations.

The stress-strain curves for single crystals of pure $\mathrm{Mg}$ under uniaxial compression at a strain rate of $10^{-4} \mathrm{~s}^{-1}$ at room temperature are shown in Figure 11, for different orientations of the crystals with respect to the loading direction. ${ }^{[111]}$ The orientations of these

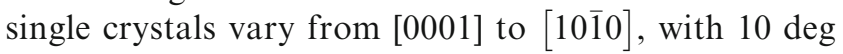
rotation about the $[1 \overline{2} 10]$ direction. Significant difference in stress-strain curves was observed, ${ }^{[111]}$ indicating the variation of deformation modes when the $c$-axis of $\mathrm{Mg}$ crystal is tilted from the [0001] to the [1010] with respect to the loading axis. Mg crystals deform at a much lower stress, and the strain hardening rate at the initial stage of plastic deformation drops drastically, when the compression axis is $10 \mathrm{deg}$ away from the $c$-axis. The flow stress and strain hardening rate both decrease further when the compression axis is further away from the $c$-axis by $20 \mathrm{deg}$. There is little change in flow stress and strain hardening rate when the crystal orientation is in the range 20 to $70 \mathrm{deg}$. Under the condition of uniaxial compression along the $[10 \overline{1} 0]$ direction, the flow stress and strain hardening rate are both small at low strains, but they increase significantly until fracture occurs at about 0.1 strain. The combination of optical microscopy and EBSD indicates that the dominant deformation mode changes from pyramidal slip, for the [0001]-oriented crystal, to $\{10 \overline{1} 2\}\langle\overline{1} 011\rangle$ twinning, for the $[10 \overline{1} 0]$-oriented crystal.

b. Tension The stress-strain curves of single crystals of pure $\mathrm{Mg}$ under uniaxial tension at room temperature at a strain rate of $10^{-4} \mathrm{~s}^{-1}$ along crystallographic directions [0001], $[10 \overline{10} 0]$ and $[90 \overline{123} 330]$ are shown in Figure $12 .^{[112]}$ In the case of pure $\mathrm{Mg}$ single crystal pulled along the [0001] direction, massive $\{10 \overline{1} 2\}$ twins were observed during the initial stage of plastic deformation. ${ }^{[12]}$ The yield stress is only $\sim 6.6 \mathrm{MPa}$, and the fracture strain is over $30 \mathrm{pct}$ in this orientation. The $\{10 \overline{1} 2\}$ twins are readily formed from the initial stage of the plastic deformation, at a low stress with a small strain hardening rate. The flow stress subsequently increases after $\sim 10$ pet strain. While the basal slip is suppressed for the initial orientation, it can be activated inside the $\{10 \overline{1} 2\}$ twins. Therefore, the strength of the single crystal along this orientation is effectively increased by the activation of basal slip. When the


is expected to be deformed under multiple slip conditions, activating prismatic slip and pyramidal $\langle c+a\rangle$ slip. The yield stress for this orientation is $\sim 109 \mathrm{MPa}$, whereas the fracture strain is limited to $\sim 1.4$ pct. The relatively higher strain hardening rate can be explained by the interaction between the different deformation


can activate prismatic slip. In this orientation, the Schmid factor for the prismatic slip is 0.5. The tensile yield stress for this orientation is $\sim 96 \mathrm{MPa}$, and the fracture strain is $\sim 10$ pct. The strain hardening rate for this orientation is smaller than that for the $[10 \overline{1} 0]$ loading direction. The single crystal with this tensile orientation is deformed only by the prismatic slip, which was confirmed by dislocation observations by transmission electron microscopy. ${ }^{[12]}$ The calculated CRSS 

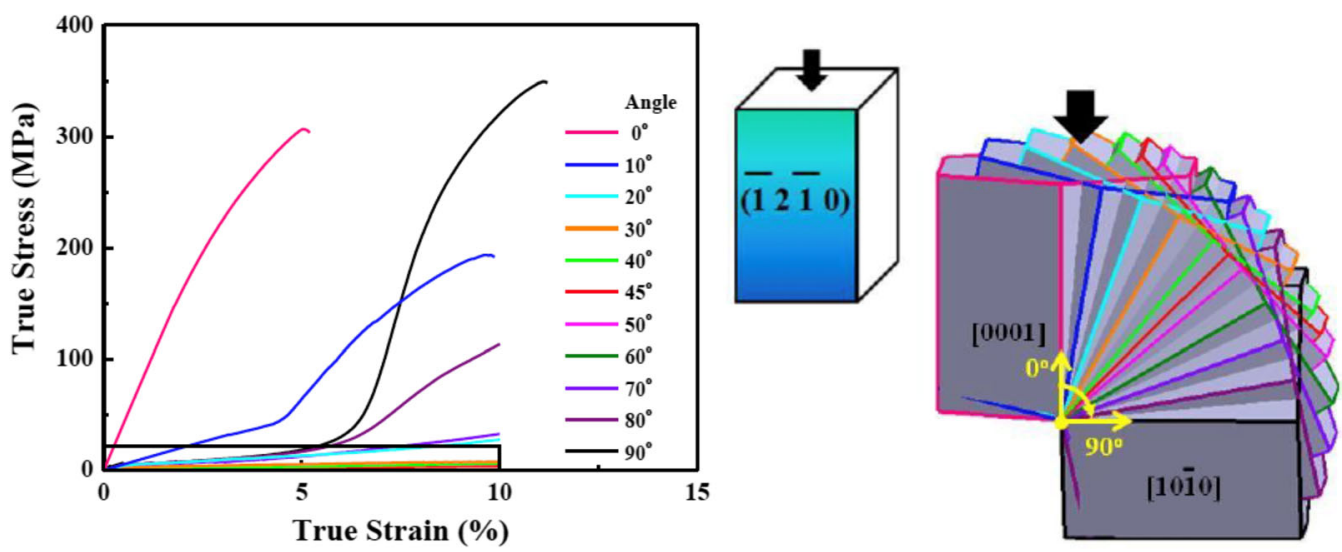

Fig. 11-Stress-strain curves of single crystals of pure $\mathrm{Mg}$ uniaxially compressed at room temperature along different directions ranging from [0001] to [1010]. Adapted from Ref. [111].

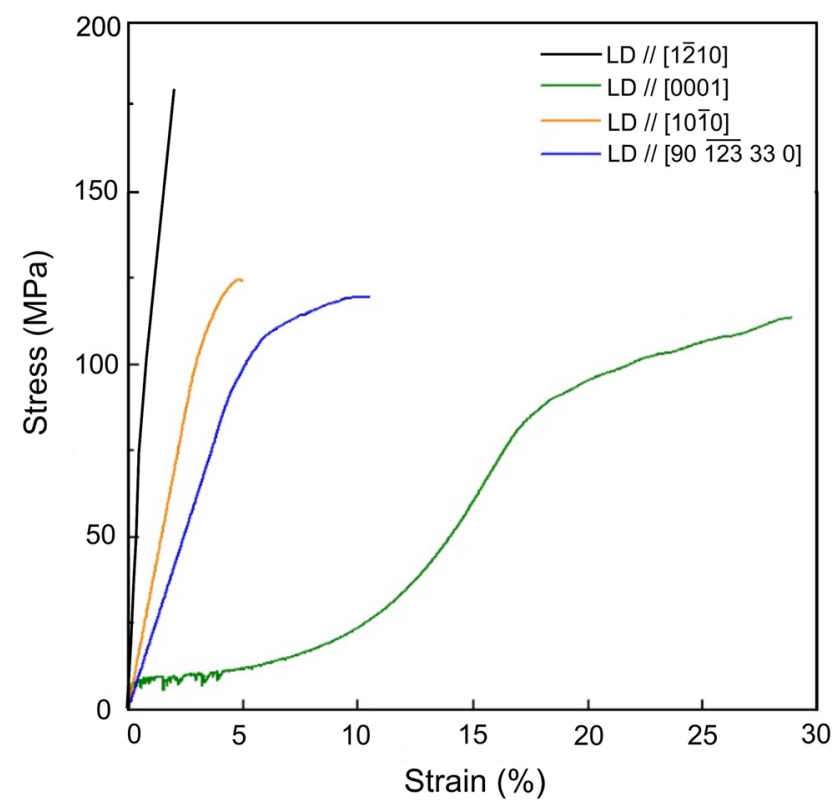

Fig. 12- Stress-strain curves of single crystals of pure Mg deformed at room temperature by uniaxial tension along [0001], [1010], [90 $\overline{123}$ $330]$ and [1210] directions Adapted from Refs. [112 and 117].

value $^{[112]}$ for the prismatic slip is in good agreement with those reported earlier. ${ }^{[113,114]}$

For single crystals deformed with the loading axis parallel to the basal plane and along the [10 $\overline{1} 0]$ direction, optical microscopy observations indicated that plastic deformation occurs primarily by prismatic slip. ${ }^{[15]}$ Two more recent studies ${ }^{[112,116]}$ revealed that the prismatic slip is activated in the early stage of plastic deformation and followed by basal slip. The stressstrain curve for a single crystal of pure $\mathrm{Mg}$ under uniaxial tension loading parallel to the basal plane and a $\langle 1 \overline{2} 10\rangle$ direction at a strain rate of $4 \times 10^{-5} \mathrm{~s}^{-1}$ is also shown in Figure 12. ${ }^{[17]}$ Optical microscopy observations indicated that, in this case, plastic deformation occurs primarily by pyramidal II slip. ${ }^{[17]}$ c. Spherical indentation Anisotropic deformation of single crystals of pure $\mathrm{Mg}$ made by a spherical indenter has been studied by Kitahara and co-workers. ${ }^{[18]}$ In their work, the indentation was made on (0001), (1100), and $(11 \overline{2} 0)$ planes. The indentation on the (0001) surface leads to isotropic deformation within the basal plane, giving rise to a circular morphology on the basal plane, Figure 13. The operative slip activities during the (0001) indentation are also illustrated in Figure 13. The basal slip and pyramidal slip occur simultaneously to allow the plastic deformation to continue symmetrically along the directions lying within and outside the basal plane in the region beneath the indentation. The indentations on the (1100) and (1120) surfaces produce indent shapes that are quite different from that associated with the (0001) indentation. In these two cases, the indent shapes are elliptical, resulting from anisotropic activation of basal slip and twinning. A large fraction of $\{10 \overline{1} 2\}$ twins is generated in regions around and beneath the indent. Such twins are mostly elongated along the [1120] direction for the (1100) indentation, and are inclined $25 \mathrm{deg}$ from (0001) for the (1120) indentation. The slip bands extend along the [0001] direction over a distance that is much larger than the size of the major axis of the elliptical indent. The complex interaction between basal slip and $\{10 \overline{1} 2\}\langle\overline{1} 011\rangle$ twinning leads to the elliptical shape of the indent.

d. Stretch formability Stretch formability of single crystal sheets of pure $\mathrm{Mg}$ along different directions has been evaluated by Erichsen cupping test at room temperature. ${ }^{[119]}$ Sheets of $1 \mathrm{~mm}$ thickness and of selected orientations were cut from bulk single crystals, and the Erichsen test was performed with a punch speed of $0.0833 \mathrm{~mm} \mathrm{~s}^{-1}$ and a punch diameter of $20 \mathrm{~mm} .^{[119]}$ The depth of the punching at which fracture occurs, generally known as the Erichsen Index, was used to evaluate sheet formability. Table I shows the Erichsen test results at room temperature for five representative crystallographic orientations. The sheet surfaces are parallel to $(7770 \overline{777} 829), \quad(10 \overline{1} 0), \quad(1 \overline{2} 10)$, $(897 \overline{449} \overline{449} 829)$, and (0001) plane, respectively. The 



Fig. 13- Single crystals of pure Mg deformed at room temperature by spherical indentation along three different crystallographic directions. Optical micrographs showing indents on $(a)(0001),(b)(1 \overline{1} 00)$, and $(c)(1120)$ surfaces. Schematic diagrams showing $(d)$ basal slip and pyramidal slip activities during (0001) indentation, and (e) basal slip activity during (1100) and (1120) indentation. Adapted from Ref. [118].

angle between the loading direction and the $c$-axis is 45 deg for the orientations $\mathrm{A}$ and $\mathrm{D}$, and $90 \mathrm{deg}$ for the orientations $\mathrm{B}$ and $\mathrm{C}$. The loading direction is parallel to the $c$-axis for the orientation E. Plastic anisotropy in a $\mathrm{Mg}$ single crystal induces an anisotropically deformed dome shape along a certain direction during the Erichsen test. The study of single crystal sheets reveals the change of IE values with sheet orientation, which can be attributed to a non-uniform distribution of strain components due to anisotropic nature and heterogeneous twinning evolution throughout the deformed single crystal sheet.

The stress states differ from the center to the edge and through the sheet thickness, i.e., they differ across the entire dome of the deformed sheet. In such a situation, the deformation behavior of the single crystal sheet is quite different from the plane-strain compression and uniaxial compression or indentation that were mentioned before. Therefore, it is difficult to describe the dominant deformation modes, or to use the Schmid factor to explain deformation behavior and stretch formability. Figure 14 shows the values for basal slip activation for five subdivided regions in two cross sections: the $\mathrm{Y}-\mathrm{Z}$ and $\mathrm{X}-\mathrm{Z}$ sections of the orientation $\mathrm{B}$ and the orientation $\mathrm{C}$ specimens. The results show that the values for basal slip activation of the orientation $\mathrm{B}$ are higher than those for the orientation $\mathrm{C}$ throughout the deformed specimen. Interestingly, the orientation $\mathrm{C}$ exhibits an IE of $2.0 \mathrm{~mm}$, even though a considerable number of tensile twins are observed. Figure 15 shows the results of twin analysis for the five subdivided regions in the $\mathrm{X}-\mathrm{Z}$ section of three orientations. A large amount of extension twins is visible in the $\mathrm{B}$ and $\mathrm{C}$ orientations due to the geometry of their initial crystallographic orientations, whereas less extension twins are visible in the A orientation. The relative activities of the extension twins in the orientations $\mathrm{B}$ and $\mathrm{C}$ along the $\mathrm{X}$ direction are higher than that in the orientation $\mathrm{A}$. However, the results show that the extension twins in the orientation B, especially those nucleated from the bottom surface of the deformed specimen inducing the activation of additional basal slip towards the newly oriented direction, are favorable for improving room temperature stretch formability, while those in the orientation $\mathrm{C}$ are not. Therefore, the orientation $\mathrm{B}$ can be defined as the twinning-induced soft orientation, while the orientation $\mathrm{C}$ can be defined as twinning-induced hard orientation.

\section{Deformation behavior at elevated temperatures}

a. Compression under different loading conditions The major deformation modes occurring at elevated temperatures differ from those at room temperature because the CRSS values for prismatic and pyramidal slip and $\{10 \overline{1} 1\}\langle\overline{1} 012\rangle$ and $\{10 \overline{1} 3\}\langle\overline{3} 032\rangle$ twinning decrease with an increase in temperature, Figure 6. Among the deformation modes, only basal slip and $\{10 \overline{1} 2\}\langle\overline{1} 011\rangle$ twinning are much less temperature dependent. At temperatures above $300{ }^{\circ} \mathrm{C}$, the CRSS values for various slip and twinning modes are similar, implying that such deformation modes can be activated simultaneously which in turn implies that larger plasticity can be obtained.

The stress-strain curves of single crystals of pure $\mathrm{Mg}$ under plane-strain compression are shown in Figure 16, for some different orientations of the crystals with respect to the loading direction. ${ }^{[102]}$ In general, as temperature increases, plastic deformation occurs at a lower stress and plasticity is increased. The lower strain 


\begin{tabular}{|c|c|c|c|c|c|}
\hline Orientation & A & B & C & $\mathrm{D}$ & $\mathrm{E}$ \\
\hline PD section & & & & & \\
\hline PD & {$[7770 \overline{777} 829]$} & {$[10 \overline{1} 0]$} & {$[1 \overline{2} 10]$} & {$[897 \overline{449} \overline{449} 829]$} & {$\left[\begin{array}{llll}0 & 0 & 0 & 1\end{array}\right]$} \\
\hline Angle between PD \& $c$-axis (deg) & 45 & 90 & 90 & 45 & 0 \\
\hline $\mathrm{IE}(\mathrm{mm})$ & 2.5 & 6.8 & 2.0 & 1.9 & 1.5 \\
\hline
\end{tabular}

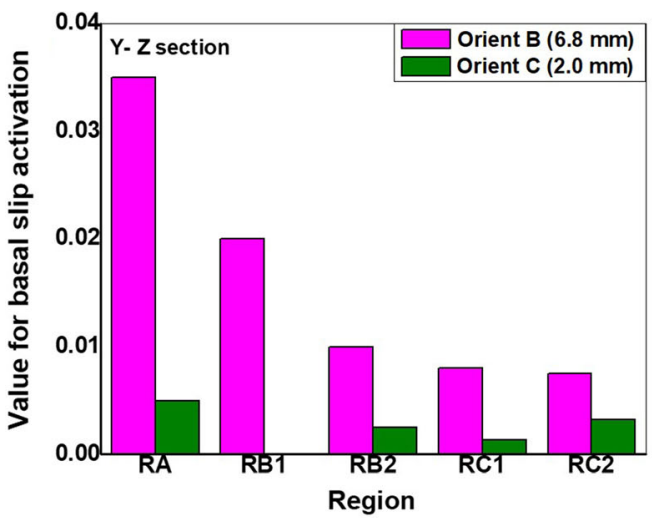

(a)



(b)

Fig. 14-Values for basal slip activation for five subdivided regions in $(a) \mathrm{Y}-\mathrm{Z}$ cross section and $(b) \mathrm{X}-\mathrm{Z}$ cross section of the orientation $\mathrm{B}$ (IE = $6.8 \mathrm{~mm})$ and the orientation $\mathrm{C}(\mathrm{IE}=2.0 \mathrm{~mm}) . \mathrm{X}$ and $\mathrm{Y}$ directions are orthogonal and they define the sheet surface. $\mathrm{Z}$ represents punching direction.

in each curve at elevated temperature is due to the artificial termination of the test for metallography observations. Figure 17(a) shows the stress-strain curve of a single crystal of pure $\mathrm{Mg}$ deformed along a direction lying at $45 \mathrm{deg}$ with respect to the $c$-axis of the crystal and with constraint deformation along $\langle 10 \overline{1} 0\rangle .^{[105]}$ The deformation behavior at 200 and $370{ }^{\circ} \mathrm{C}$ is similar to that at room temperature when the plasticity strain is less than 0.4. While strain hardening rate at the elevated temperatures gradually increases with plastic strain, the stress levels required to produce 1.0 compression strain are significantly lower than that at room temperature. Examination of microstructures of specimens deformed to 1.0 strain at 200 and $370{ }^{\circ} \mathrm{C}^{[105]}$ indicated that the amount of deformation twin in these specimens was remarkably lower than that in the counterpart at room temperature and that these specimens remained predominantly single crystalline, i.e., recrystallization was not observed.

Figure 17(b) shows stress-strain curves of single crystals of pure $\mathrm{Mg}$ deformed at 200 and $370{ }^{\circ} \mathrm{C}$ along crystal's $c$-axis and with $\langle 10 \overline{1} 0\rangle$ constraint. ${ }^{[86]}$ Data at strains larger than 0.5 are not included. These two curves are similar, except that the one obtained at $370{ }^{\circ} \mathrm{C}$ has a lower yield stress. In each case, the stress increases rapidly to a maximum, then drops sharply to about half of the maximum stress, with plastic deformation continuing at a steady strain rate. The onset of the steady-state flow at $370{ }^{\circ} \mathrm{C}$ occurs at a strain lower than that at $200{ }^{\circ} \mathrm{C}$. Examination of the microstructure of the specimen deformed to 1.0 strain at $200{ }^{\circ} \mathrm{C}$ indicated the presence of some $\{10 \overline{1} 1\}$ and $\{10 \overline{1} 3\}$ 


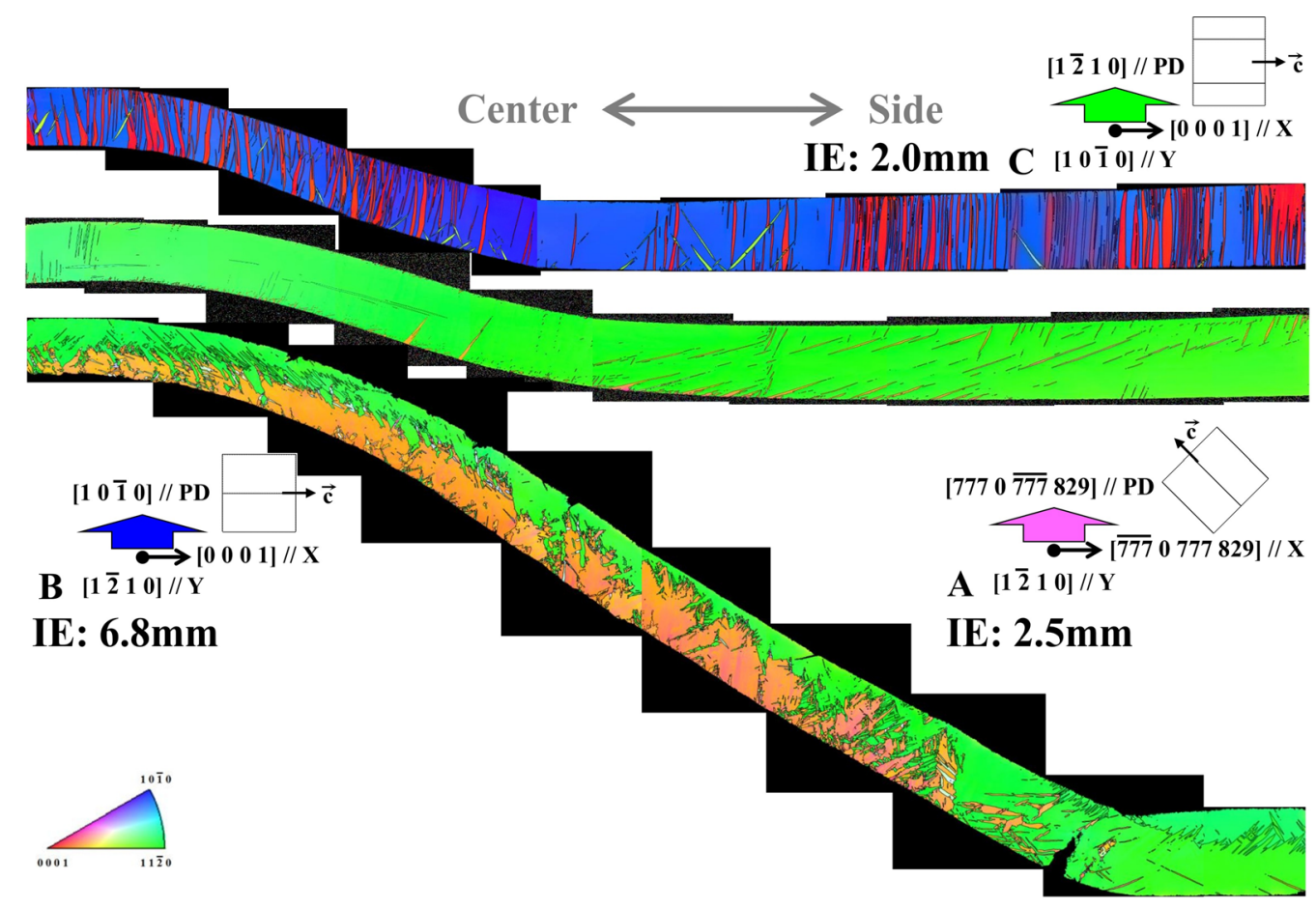

Fig. 15-EBSD orientation maps showing deformation twins formed in five subdivided regions in the $\mathrm{X}-\mathrm{Z}$ cross section of single crystal sheets of pure Mg: orientation A $(\mathrm{IE}=2.5 \mathrm{~mm})$, orientation B $(\mathrm{IE}=6.8 \mathrm{~mm})$, and orientation $\mathrm{C}(\mathrm{IE}=2.0 \mathrm{~mm})$. X and $\mathrm{Y}$ directions are orthogonal and they define the sheet surface. $\mathrm{Z}$ represents punching direction.

contraction twins and secondary $\{10 \overline{1} 2\}$ twins inside the primary twins of $\{10 \overline{1} 1\}$ and $\{10 \overline{1} 3\} .^{[86]}$ The $\{10 \overline{1} 1\}$ twin was more prevalent than the $\{10 \overline{1} 3\}$ twin. The formation of these contraction twins changed the basal plane to orientations that promote basal slip. In addition to the basal slip, the formation of the secondary $\{10 \overline{1} 2\}$ twins also provided an accommodation to the plastic strain. Additionally, some of the $\{10 \overline{1} 1\}$ twins had transformed into elongated bands comprising dynamic recrystallized grains. The microstructure of the specimen deformed by 1.0 strain at $370{ }^{\circ} \mathrm{C}$ contained much less $\{10 \overline{1} 1\}$ twins. The $\{10 \overline{1} 1\}$ twins formed at the early stage of deformation had fully transformed to bands of recrystallized grains. Analysis of the orientations of the recrystallized grains within a twin band indicated the existence of a unique texture - the $c$-axes of all newly formed recrystallized grains were almost parallel to each other and parallel to the $c$-axis of their parent $\{10 \overline{1} 1\}$ twin. This observation implies that the boundaries between recrystallized grains are effectively tilt boundaries. The dynamic recrystallization mechanism was referred to continuous, even though the sharp yield drop was also taken as the onset of discontinuous dynamic recrystallization. ${ }^{[86]}$

While the phenomenon of rapid hardening followed by rapid softening, i.e., the occurrence of a sharp yield drop shown in Figure 17(b), at the early stage of plastic deformation was attributed to the lack of easily activated slip and $\{10 \overline{1} 2\}\langle\overline{1} 011\rangle$ twinning modes (responsible for rapid hardening) and onset of dynamic recrystallization (responsible for rapid softening), ${ }^{[86]}$ it remains to be answered whether the onset of recrystallization within some twins can give rise to the phenomenon of strong and rapid softening. It also remains unclear why the stress-strain curve becomes a plateau at the later stage of the plastic deformation.

Deformation behavior of single crystals of pure $\mathrm{Mg}$ under uniaxial compression at an initial strain rate of $10^{-3} \mathrm{~s}^{-1}$ at temperatures ranging from 20 to $400{ }^{\circ} \mathrm{C}$ has been studied by Yoshinaga and Horiuchi. ${ }^{[120,121]}$ The flow stress decreases with increasing temperature. The strain hardening rate is high in the initial stage of plastic deformation, but decreases rapidly when the temperature is above $200{ }^{\circ} \mathrm{C}$, Figure 18. Such deformation behavior was confirmed in subsequent tests under similar conditions. ${ }^{[35]}$ Based on optical microscopy of deformed specimens, Yoshinaga and Horiuchi ${ }^{[120]}$ suggested that twinning led to rapid hardening and fracture at much a lower strain when the temperature was below $200{ }^{\circ} \mathrm{C}$. They also proposed that the flow stress decreased with continued twinning, and an unlimited plasticity was obtainable when the temperature was above $200{ }^{\circ} \mathrm{C}$. A subsequent TEM study ${ }^{[35]}$ suggested that, in addition to twinning, pyramidal II slip operated at all temperatures, ranging from 20 to $600{ }^{\circ} \mathrm{C}$. Obara and co-workers proposed ${ }^{[35]}$ that the strain hardening rate of the pyramidal II slip system was very high at temperatures below $200{ }^{\circ} \mathrm{C}$. The gliding dislocations in this slip system were found to be $\langle c+a\rangle$ and to have a strong preference to lie on the basal plane. Small dislocation loops lying on the basal plane were also found. The edge dislocation was much less mobile than the screw dislocation. The number densities of long 


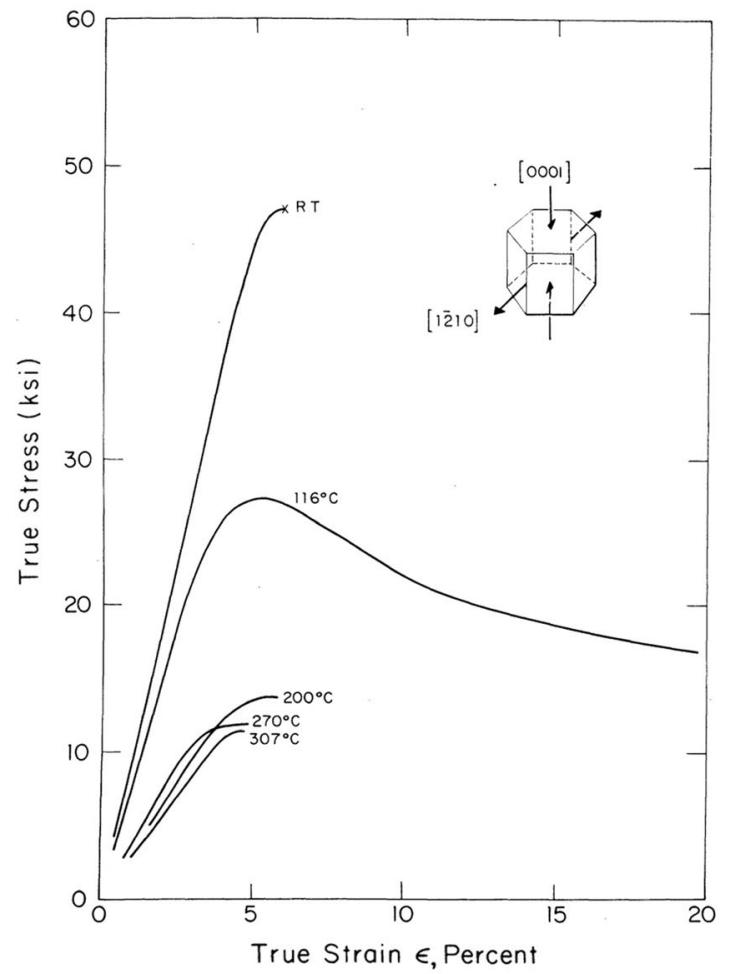

(a)

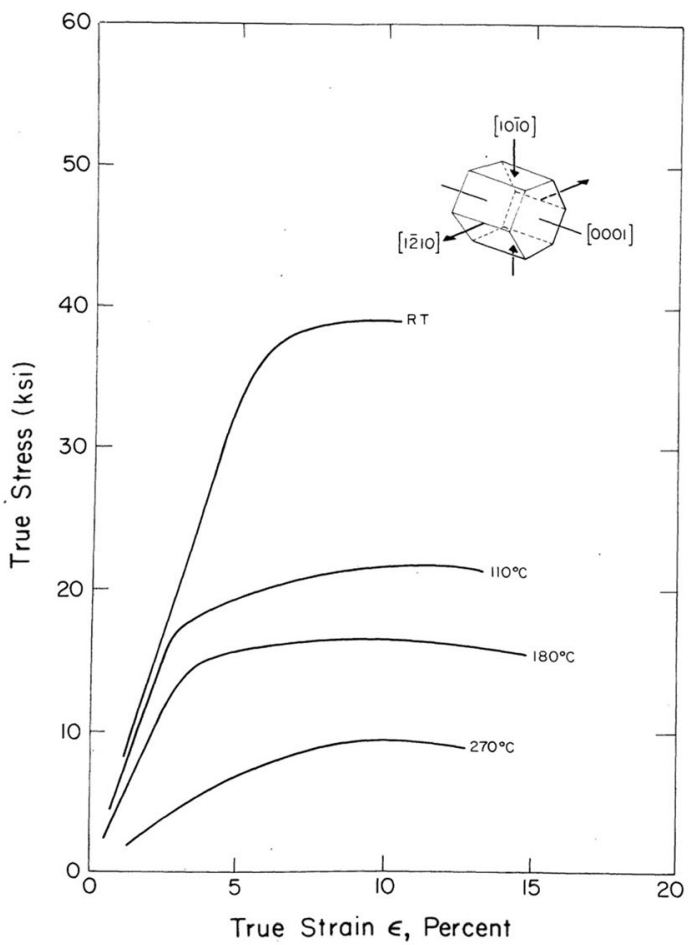

(c)

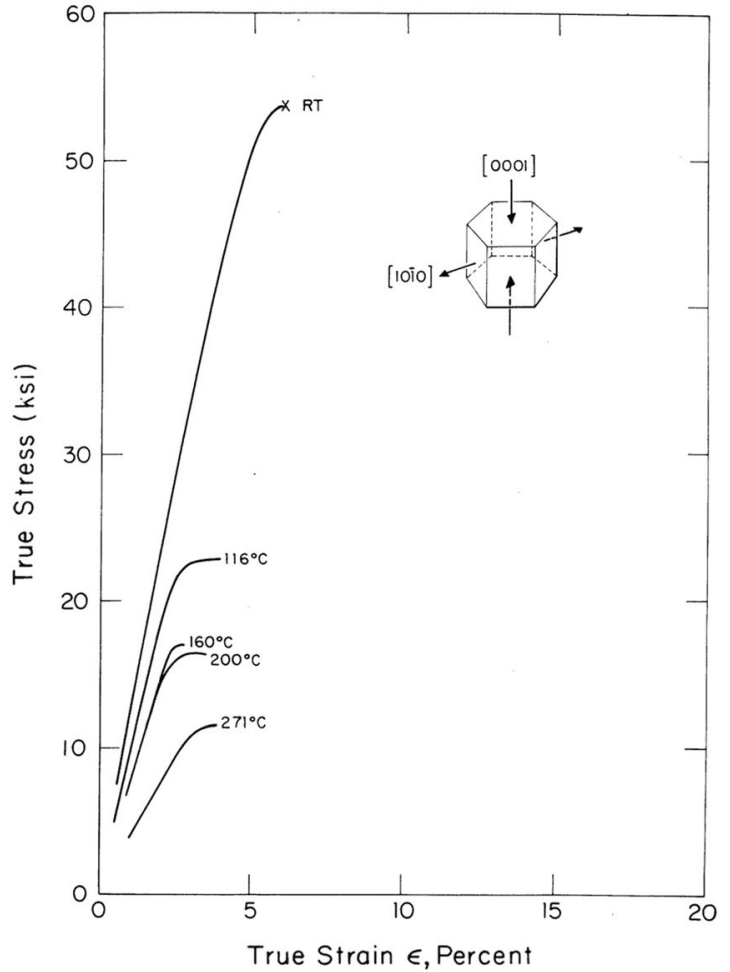

(b)



(d)

Fig. 16 - Stress-strain curves of single crystals of pure Mg deformed at elevated temperatures by plane-strain compression along [0001] direction with expansion limited to $(a)[1 \overline{2} 10]$ and $(b)[10 \overline{1} 0],(c)$ along $\langle 10 \overline{1} 0\rangle$ direction with [0001] constraint, and $(d)$ along $\langle 1 \overline{2} 10\rangle$ direction with [0001] constraint. Adapted from Ref. [102]. 


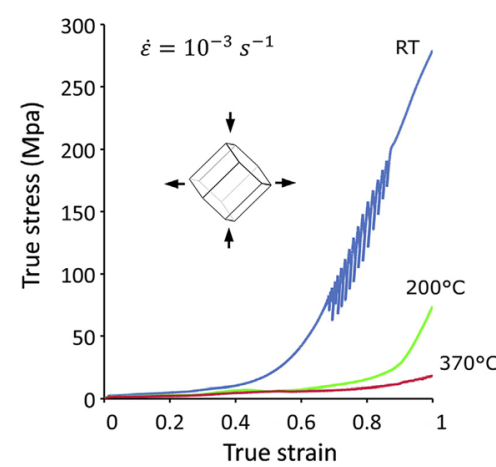

(a)

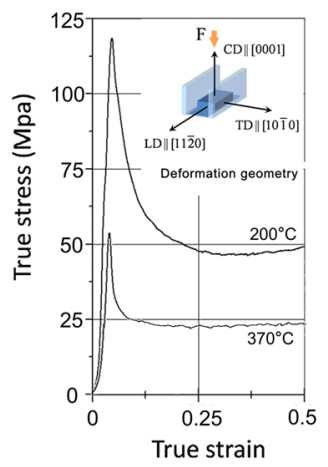

(b)
Fig. 17- Stress-strain curves of single crystals of pure $\mathrm{Mg}$ deformed at elevated temperatures by plane-strain compression at a strain rate of $10^{-3} \mathrm{~s}^{-1}$. (a) Crystal $c$-axis is inclined at $45 \mathrm{deg}$ to the compression direction with constrained deformation along $\langle 10 \overline{1} 0\rangle$. (b) Compression along the $c$-axis with $\langle 10 \overline{1} 0\rangle$ constraint. Adapted from Refs. [86 and 105].

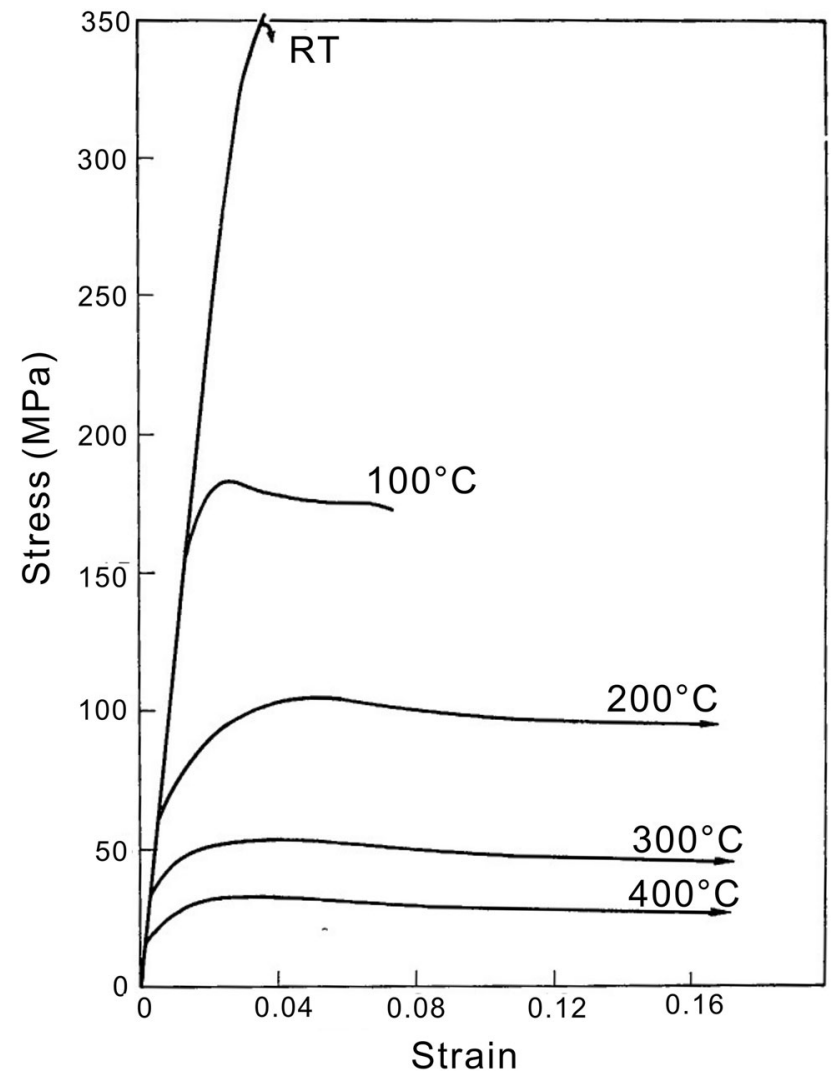

Fig. 18-Stress-strain curves of single crystals of pure $\mathrm{Mg}$ deformed at elevated temperatures by uniaxial compression along the $c$-axis at a strain rate of $10^{-3} \mathrm{~s}^{-1}$. Adapted from Ref. [120].

dislocations and small dislocation loops were high in specimens deformed at room temperature, but decreased with increasing temperature. The small dislocation loops were rarely observed in specimens deformed at $200{ }^{\circ} \mathrm{C}$ and above. It became difficult to detect the presence of long dislocations in specimens deformed at a temperature above $250{ }^{\circ} \mathrm{C}$, even if the specimen was quenched immediately after the plastic deformation, implying that the dislocations could be annealed out rapidly at such temperature. While not explained in detail, the possibility of dissociation of the $\langle c+a\rangle$ dislocation on the basal plane to two sessile partial dislocations, or $\langle c\rangle$ and $\langle a\rangle$ full dislocations, was speculated. ${ }^{[35]}$

b. Tension The stress-strain curves of single crystals of pure $\mathrm{Mg}$ deformed at elevated temperatures, in the range between room temperature and $460{ }^{\circ} \mathrm{C}$, by uniaxial tension at a strain rate of $10^{-4} \mathrm{~s}^{-1}$ along crystallographic directions [ [ $\overline{40} 2020$ 37], [90 $\overline{123} 33$ 0], and [1 0 $\overline{1} 0]$ are shown in Figure 19. The flow stresses of all three orientations decrease with increasing temperature. The flow stress is almost insensitive to temperature along the

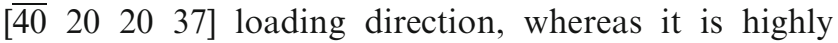
temperature dependent along the $\left[\begin{array}{llll}90 & \overline{123} & 33 & 0\end{array}\right]$ and $\left[\begin{array}{lll}1 & 0 & \overline{1}\end{array}\right.$ $0]$ loading directions. The CRSS for the basal slip is insensitive, while the CRSS for the prismatic slip or the pyramidal slip is sensitive, to the testing temperature.

\section{B. Textured Polycrystals}

Polycrystalline pure $\mathrm{Mg}$ develops a strong basal texture after thermomechanical processing such as cold/hot rolling or hot extrusion. For a rolled sheet having a strong basal texture, the $c$-axes of individual grains are almost parallel to each other and the sheet surface normal direction (ND). Furthermore, the $\langle 10 \overline{10}\rangle$ directions of most grains are aligned along the rolling direction (RD) in the deformed (especially cold-rolled) condition. This texture, abbreviated as $(0002)\langle 10 \overline{1} 0\rangle$, is called deformation basal texture. But in a fully recrystallized sheet, the $\langle 11 \overline{2} 0\rangle$ directions of most grains are aligned along the rolling direction, and this texture, $(0002)\langle 11 \overline{2} 0\rangle$, is termed recrystallization basal texture. For an extrudate having a strong basal texture, the basal planes of individual grains are almost parallel to the extrusion direction (ED), i.e., the $c$-axes of individual grains are almost perpendicular to the extrusion direction. The $\langle 10 \overline{1} 0\rangle$ directions of deformed grains are usually near the extrusion direction, and $\langle 11 \overline{2} 0\rangle$ directions of recrystallized grains are often aligned along the extrusion direction.

\section{Microstructures of sheets}

a. Plates and sheets from uni-directional rolling The microstructure of a cold-rolled $\mathrm{Mg}$ sheet is shown in Figure $20(a){ }^{[122]}$ The sheet was fully recrystallized with a strong basal texture and an averaged grain size of about $42 \mu \mathrm{m}$ before it was cold-rolled by $30 \mathrm{pct}$ thickness reduction which is the limit for cold rolling without cracking. The microstructure contains shear bands and $\{10 \overline{1} 2\}$ twins, together with a few $\{10 \overline{1} 1\}-$ $\{10 \overline{1} 2\}$ double twins. The contrast variation within each band resembles the feature of recrystallized grains. The presence of such microstructural features indicates localized distribution of plastic strain in the deformed specimen. The proportions of the shear bands and the 


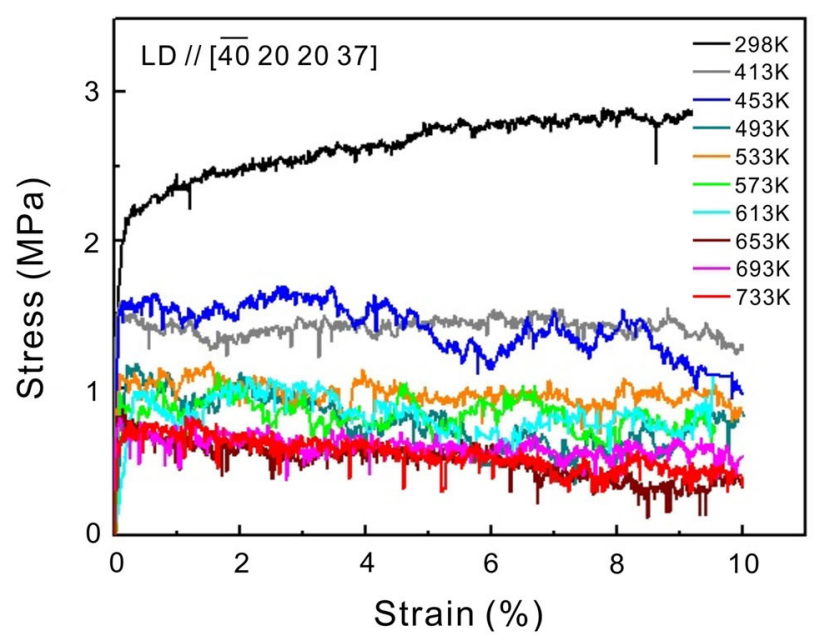

(a)

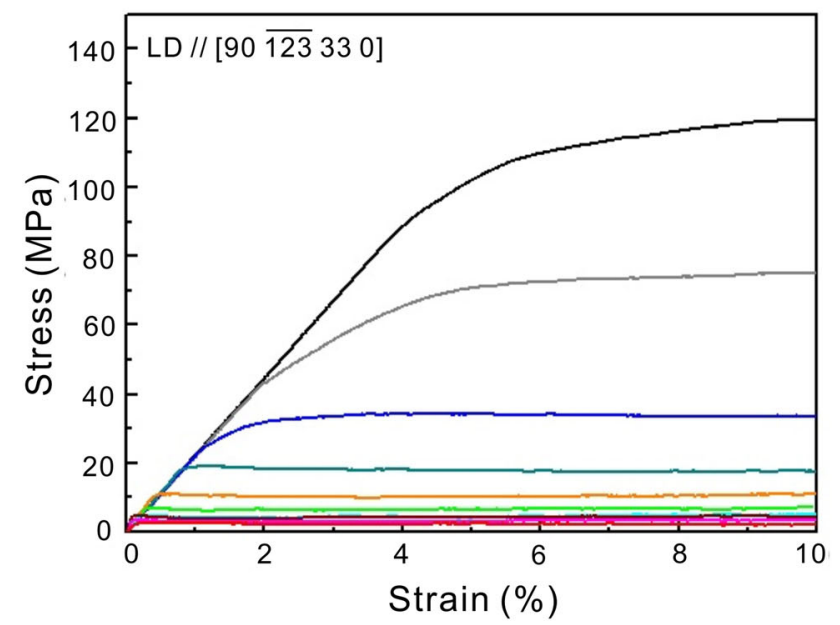

(b)

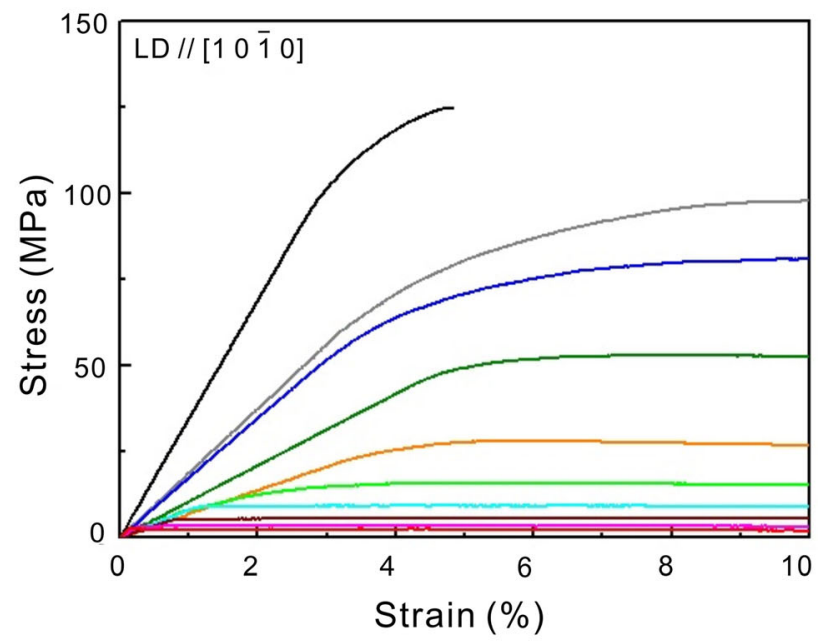

(c)

Fig. 19-Stress-strain curves of single crystals of pure Mg deformed at elevated temperatures by tension along different crystallographic

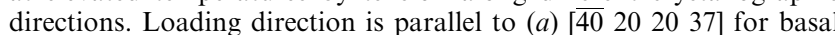
slip activation, (b) [ $\left[\begin{array}{llll}90 & \overline{123} & 33 & 0\end{array}\right]$ for prismatic slip activation, and $(c)$ $\left[\begin{array}{llll}1 & 0 & \overline{1} & 0\end{array}\right]$ for multiple slip activation. Adapted from Refs. [111, 112, and 116].
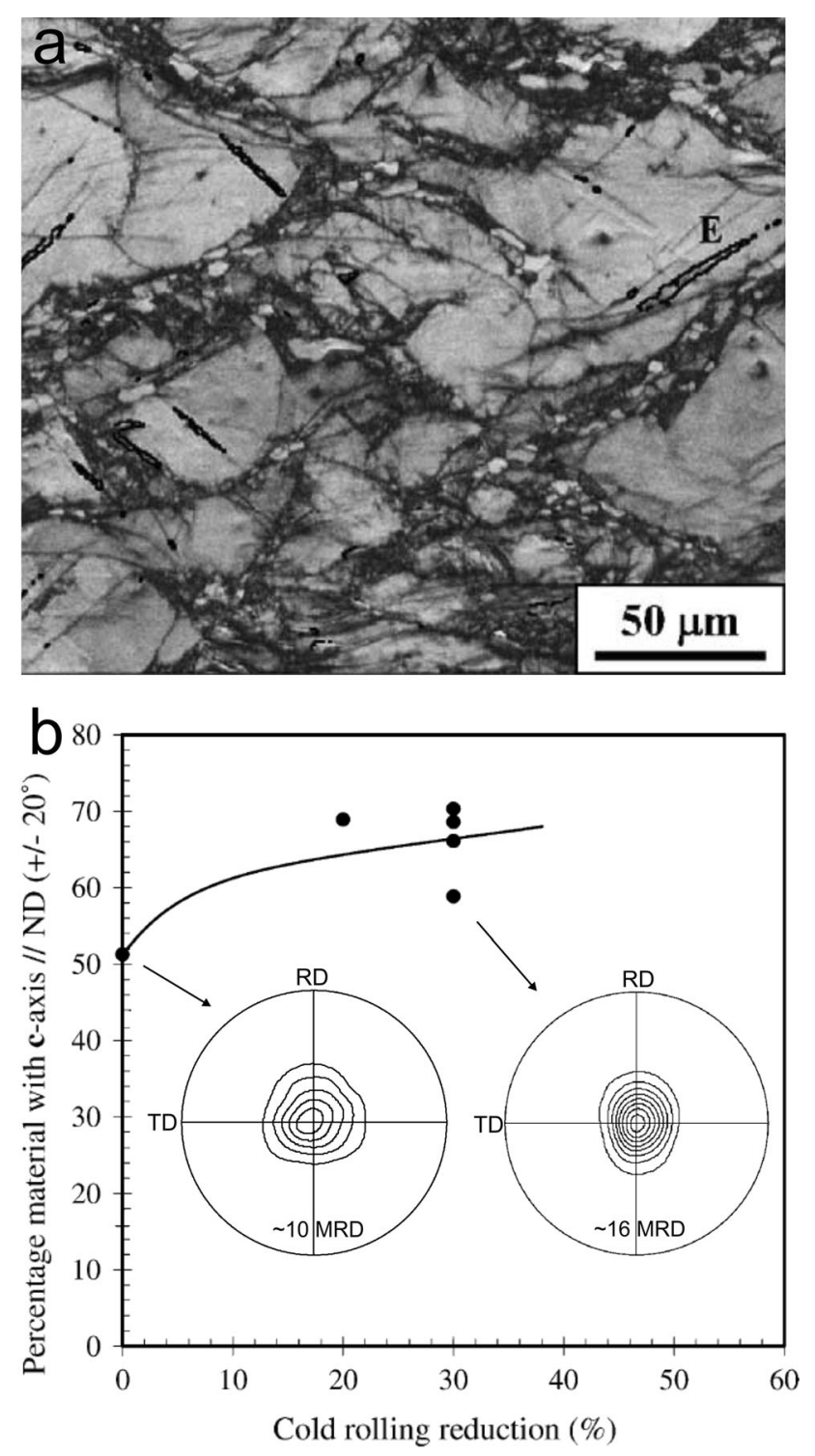

Fig. 20 - (a) EBSD Kikuchi band contrast map obtained from a pure $\mathrm{Mg}$ sheet cold-rolled by 30 pct reduction. (b) Influence of rolling reduction on the strength of deformation texture. Basal pole figures constructed from the EBSD data of the pure $\mathrm{Mg}$ sheet in the as-received (hot-rolled) state and further cold-rolled by $30 \mathrm{pct}$ thickness reduction. MRD stands for multiples of a random distribution. Adapted from Ref. [122].

$\{10 \overline{1} 2\}$ twins change with cold strain: the fraction of the shear bands increases, while that of the $\{10 \overline{1} 2\}$ twins decreases, with increasing strain. While the $\{10 \overline{1} 2\}$ twins were suggested ${ }^{[122]}$ to have formed during unloading, instead of during the rolling deformation, it remains to be confirmed whether these twins are indeed $\{10 \overline{1} 2\}$ twins and if so whether the formation of such twins is truly not related to the cold rolling process. As will be discussed in Section IV, $\{10 \overline{1} 2\}$ twins are not observed in cold-rolled thin plates of AZ31. Given the spread of the $c$-axes of grains in the sheet with respect to the sheet normal direction, it is worth carrying out quasi-in-situ EBSD experiments in the future to examine whether 
$\{10 \overline{1} 2\}$ twins would form, upon compressive loading, in those grains whose $c$-axes are deviated from the sheet normal direction before cold rolling. Cold rolling led a narrower spread of the $c$-axes of grains and thus a stronger basal texture, as shown in Figure 20(b). ${ }^{[122]}$ However, the $c$-axes tended to split along the rolling direction. While not indicated directly in the figure, most of the original grains had already rotated their $\langle 10 \overline{1} 0\rangle$ directions towards the rolling direction.

When the initial grain size was reduced to the proximity of $1 \mu \mathrm{m}$, cold rolling of a basal-textured sheet of pure $\mathrm{Mg}$ did not cause any apparent shear bands and twins to form inside individual grains. ${ }^{[123]}$ Figure 21(a) shows EBSD orientation maps of a sheet that was rolled by 50 pet in thickness reduction at room temperature

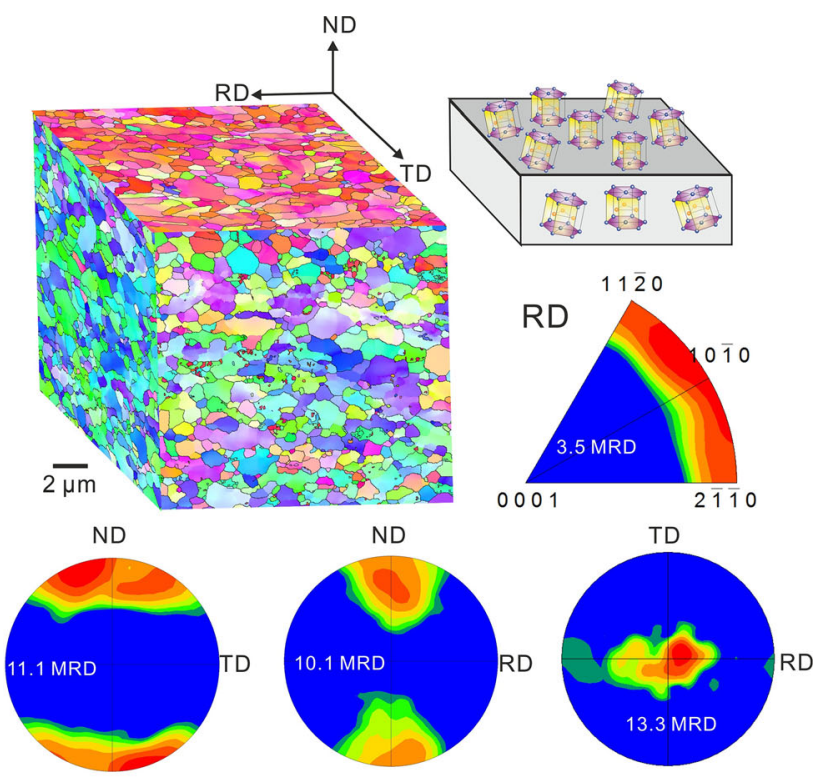

(a)

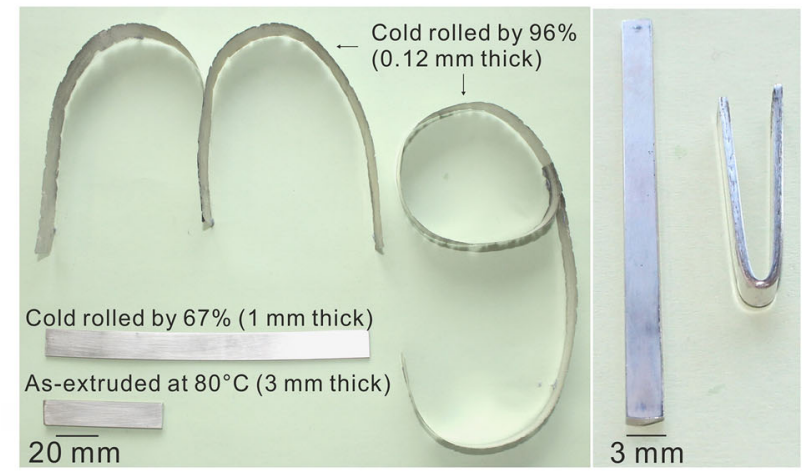

(b)

Fig. 21- (a) Cube of EBSD orientation maps of TD-ND, RD-ND, and RD-TD surfaces of a cold-rolled pure $\mathrm{Mg}$ sheet. TD is the abbreviation of transverse direction. Schematic illustration showing a basal texture, i.e., [0001]//ND. EBSD (0002) pole figures of TD-ND, RD-ND, and RD-TD surfaces of the corresponding cold-rolled sheet. The sheet is cold-rolled from an extruded plate by $50 \mathrm{pct}$ in thickness reduction. The most intensive pole is nearly aligned along the sheet normal direction. The $c$-axes spread more along the RD than the TD. (b) Photos showing one 3-mm-thick plate extruded at $80{ }^{\circ} \mathrm{C}$, and after 67 pet and 96 pet cold rolling, and a cold-rolled 1 $\mathrm{mm}$ strip that is bent by $\sim 180 \mathrm{deg}$ at room temperature. Adapted from Ref. [123]. from an extruded plate. Despite possessing a relatively strong basal texture, this sheet could be further cold-rolled to down to many times thinner, and the final sheet produced by the heavy cold rolling could be further formed substantially without cracking, Figure 21(b) ${ }^{[123]}$ The dominant deformation modes were speculated ${ }^{[123]}$ to change from those intra-granular (slip and twinning) to inter-granular modes such as grain boundary sliding when the grain size reduces to the vicinity a micron. Under such circumstance, the factors that affect intra-granular deformation may become less significant. Consequently, the strain inside individual grains is unlikely to build to a level that will cause fracture.

For a hot-rolled $\mathrm{Mg}$ sheet, its grain size is influenced strongly by the hot rolling temperature, even though its texture changes less significantly. In general, the average size of recrystallized grains increases with increasing temperature, and the microstructure changes from a mixture of deformed coarse grains and recrystallized small grains at lower rolling temperatures to fully recrystallized grains of larger size at higher temperatures. Associated with the microstructural change from the partial to full recrystallization, the texture evolves gradually from $(0002)\langle 10 \overline{1} 0\rangle$ to $(0002)\langle 11 \overline{2} 0\rangle$. A hot-rolled and annealed sheet of pure $\mathrm{Mg}$ again also had a strong basal texture with the $c$-axes lying close to the ND and $\langle 11 \overline{2} 0\rangle$ close to the RD,$^{[124]}$ Figure 22. After annealing for 5 minutes at $450{ }^{\circ} \mathrm{C}$, the hot-rolled sheet was fully recrystallized, with an average grain size of $\sim 77 \mu \mathrm{m}$, Figure 22(a). Some of the recrystallized grains were abnormally large, more than $200 \mu \mathrm{m}$ in diameter. With this microstructure, the hot-rolled and annealed sheet had a very low ductility, about 3 pct when tested at a strain rate of $10^{-3} \mathrm{~s}^{-1}$ at room temperature along the RD, TD, and the direction lying 45 deg to the RD, Figure 22(b).

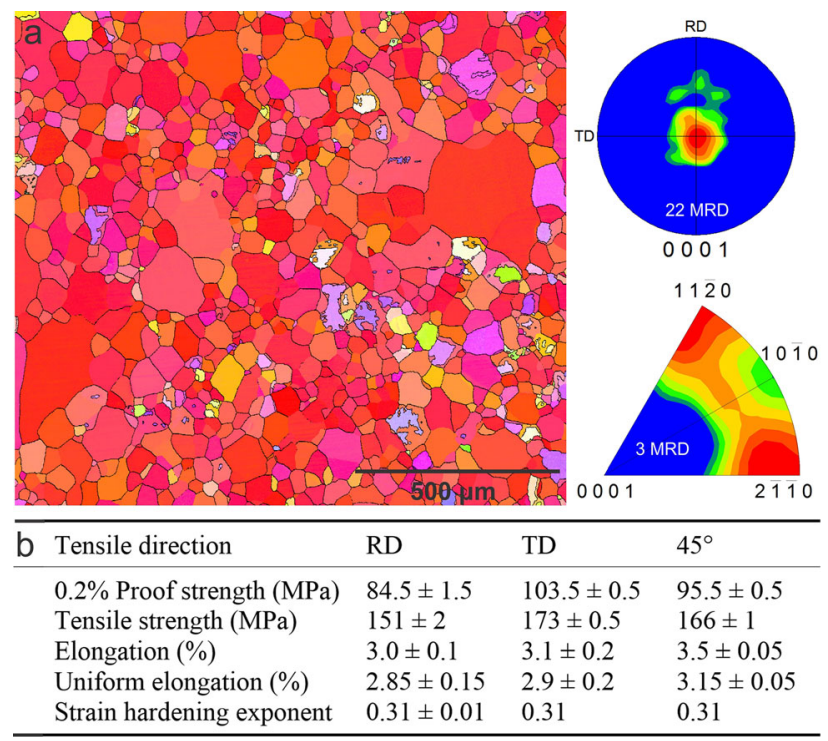

Fig. 22-(a) EBSD orientation map and corresponding (0002) pole figure and inverse pole figure along the $\mathrm{RD}$ of a pure $\mathrm{Mg}$ sheet hot-rolled at $450{ }^{\circ} \mathrm{C}$ from 5 to $1 \mathrm{~mm}$ by 8 passes, and annealed at $400{ }^{\circ} \mathrm{C}$ for 15 minutes. (b) Tensile properties along three different directions. Adapted from Ref. [124]. 
b. Plates and sheets from cross rolling Since the texture of magnesium is strongly influenced by rolling conditions such as temperature, rolling speed, and thickness reduction per single pass, the effects of unidirectional rolling, reverse rolling, and cross rolling on texture have all been studied. ${ }^{[125]}$ There was little difference between the textures resulting from multi-pass reverse rolling and multi-pass unidirectional rolling. The basal pole was shifted by about 8 to $18 \mathrm{deg}$ from the ND towards the $\mathrm{RD}$, depending on the rolling temperature, as indicated by the (0002) pole figure shown in Figure $23 .^{[125]}$ The multi-pass cross rolling also led to a basal texture, but having a weaker intensity. In this case, the basal poles were more symmetrical about the ND, they shifted towards the TD (RD1) after the final cross rolling along the RD2.

c. Plates and sheets from asymmetric rolling Asymmetric rolling of pure magnesium in the temperature range 25 to $350{ }^{\circ} \mathrm{C}$ does not seem to change the basal texture that is usually associated with plate or sheet produced by symmetric rolling. Figure 24(a) compares microstructures and textures produced by asymmetric rolling (ASR) and symmetrical rolling (SR) ${ }^{[126]}$ Plates of $10 \mathrm{~mm}$ thickness were cut from a hot forged plate of $40 \mathrm{~mm}$ thickness and were used for rolling. This plate had a fairly weak basal texture and an average grain size of $14 \mu \mathrm{m}$. The plate thickness was reduced to $2.5 \mathrm{~mm}$ by two passes, with 50 pct thickness reduction in each pass. In the case of the asymmetric rolling, the upper larger roller and the lower smaller roller had a circumferential speed of 0.92 and $0.61 \mathrm{~m} \mathrm{~s}^{-1}$, respectively. The average

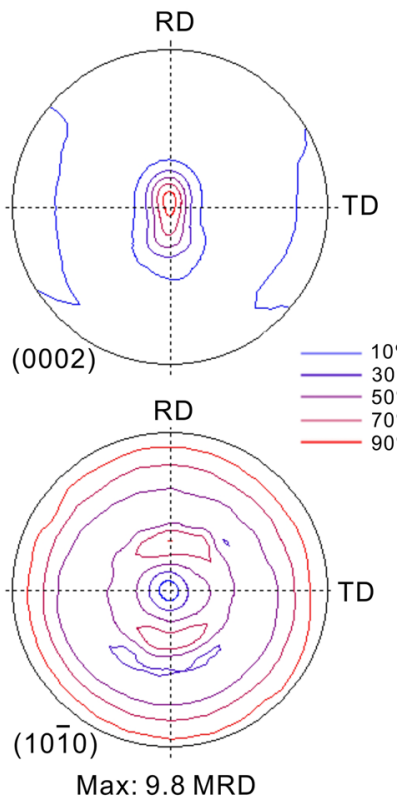

(a)

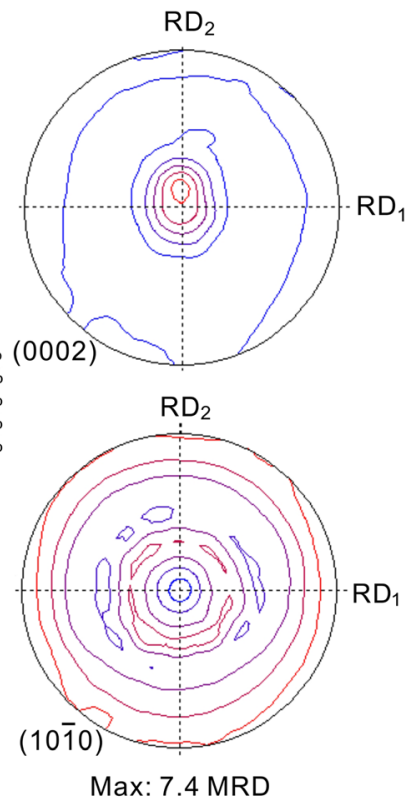

(b)
Fig. 23-XRD (0002) and (1010) pole figures showing textures of pure $\mathrm{Mg}$ sheets $(a)$ uni-directionally rolled and $(b)$ cross-rolled at $350{ }^{\circ} \mathrm{C}$ by 85 pet total thickness reduction. Each pass is for 5 pct reduction, and change the rolling direction by $90 \mathrm{deg}$ rotation of the cross-rolled sample. The texture intensity is 9.8 MRD in (a) and 7.4 MRD in (b). Courtesy R. Schwarzer. Adapted from Ref. [125]. of these two different speeds was used for the symmetric rolling. The difference in the surface speeds of the upper and lower rollers caused an additional shear deformation throughout the thickness of the sheet during the asymmetric rolling, as indicated by the inclination of an initially vertical insert shown in Figure 24(b). Under similar deformation temperatures and thickness reductions, the microstructures of the ARS and SR specimens were quite similar. There was little difference between the average grain size, even though the grain size distribution in the ASR specimen was slightly wider than that in the SR sample.

It is perhaps worth mentioning that the $\mathrm{Mg}$ plates were rolled by 75 pct thickness reduction at room temperature in both ASR and SR processes, ${ }^{[126]}$ which is substantially larger than what is usually possible (20 to $30 \mathrm{pct}$ ) for pure $\mathrm{Mg}$ plates having a strong basal texture. It is unclear whether this remarkably higher rollability is due to the initial good quality of the plate (resulting from a forging process) and/or the much higher rolling speed used in the rolling process. The average circumferential speed was about $0.75 \mathrm{~m} \mathrm{~s}^{-1}$, or $45 \mathrm{~m} \mathrm{~min}^{-1}$, which is 5 to 10 times higher than those commonly used in most laboratories and industry. As will be discussed in Section IV, the rollability of plates/sheets of $\mathrm{Mg}$ alloys can be remarkably enhanced when higher rolling speeds are used.

Inspection of the microstructures of specimens cold-rolled by 75 pct revealed the mixed presence of smaller equiaxed recrystallized grains and larger elongated deformed grains. ${ }^{[126]}$ The average grain size was about $2 \mu \mathrm{m}$ for both ASR and SR sheets. The textures of the cold-rolled specimens were similar to those of sheets rolled at higher temperatures: the $c$-axes of most grains were nearly parallel to the plate normal direction. While the basal fiber texture was rotated by 5 to $10 \mathrm{deg}$ anticlockwise from the plate normal direction in the case of the ASR, such variation in texture is unlikely to cause any change in plate formability.

Apart from the puzzle on the substantial rollability of the plate at room temperature, the presence of a considerably larger volume fraction of recrystallized grains is equally puzzling, as it is rare to see dynamic recrystallization occurring massively during rolling at room temperature of coarse-grained plates or sheets of pure $\mathrm{Mg}$. It remains to be established whether the massive formation of the recrystallized grains is due to the much larger strain imposed in each pass $(50 \mathrm{pct}$ reduction in a single pass).

\section{Microstructures of extrudates}

a. Influence of extrusion temperature and speed The microstructure of an extrudate of pure $\mathrm{Mg}$ is influenced by parameters such as extrusion temperature, extrusion speed, and extrusion ratio. The latter two factors generate dislocations and twins, while the first factor removes them, during the extrusion process. In general, the grain size in the extrudate is strongly influenced by the extrusion temperature. For a given extrusion speed and extrusion ratio, the grain size increases with 
a

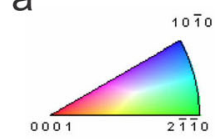
COLOR CODE
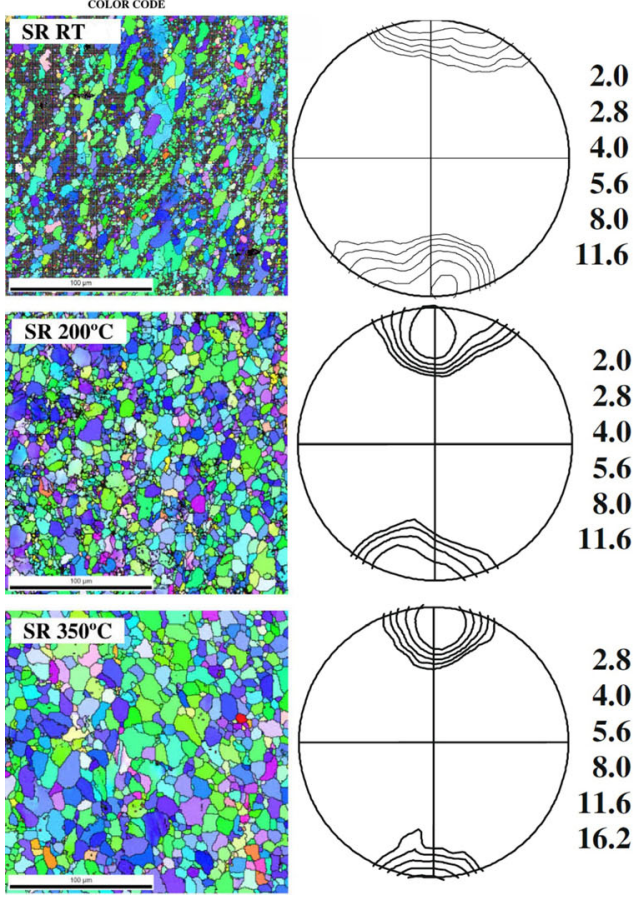
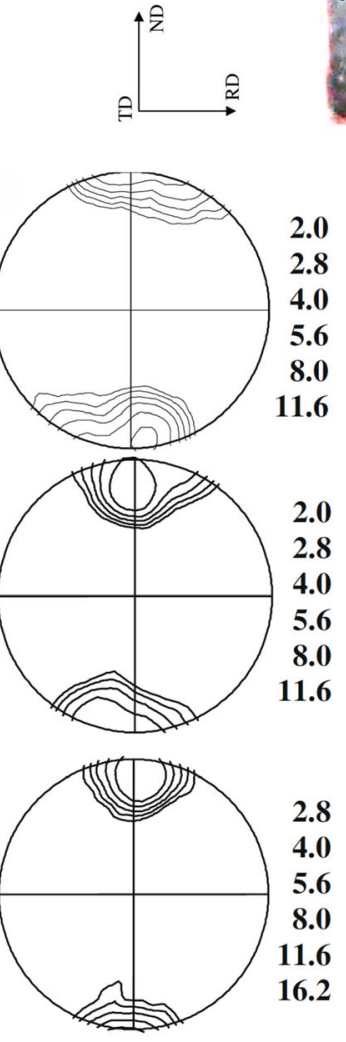
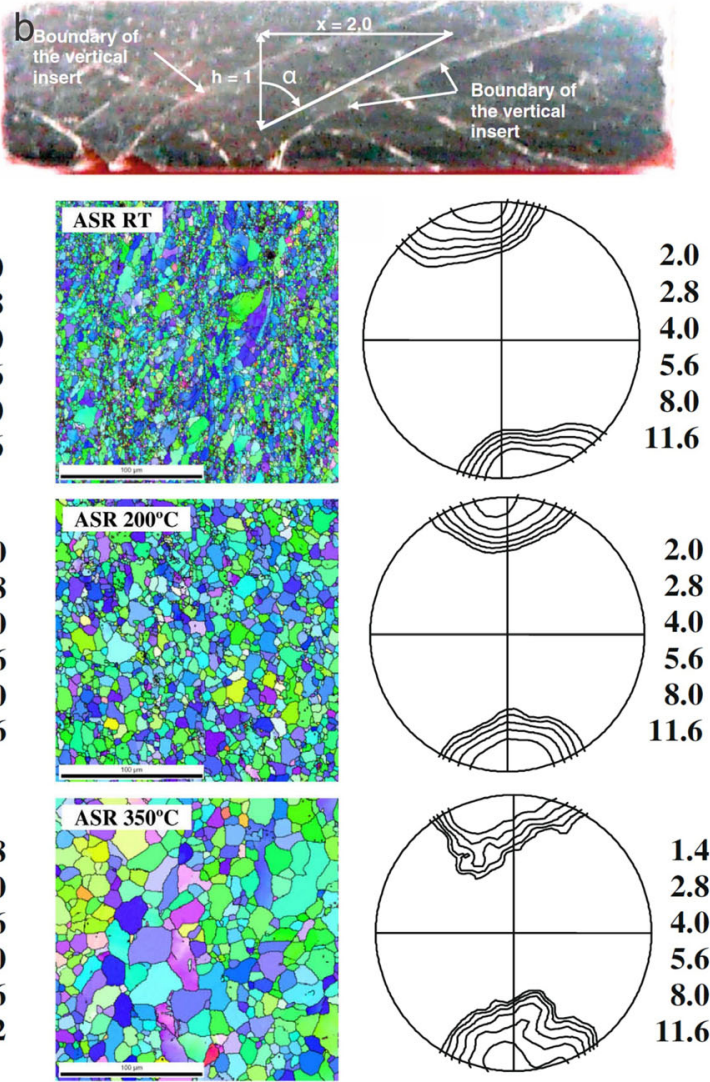

Fig. 24-(a) EBSD orientation maps of RD-ND surfaces and corresponding XRD (0002) pole figures showing microstructures and textures in pure $\mathrm{Mg}$ sheets after symmetric rolling or asymmetric rolling at room temperature, 200 and $350{ }^{\circ} \mathrm{C}$. $(b)$ Photo showing the orientation of the originally vertical insert after the first pass of asymmetric rolling. Adapted from Ref. [126].

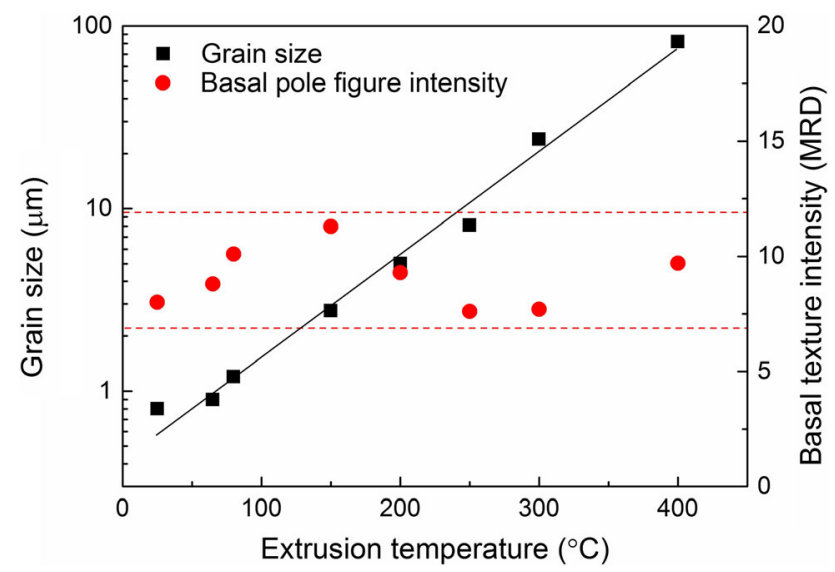

Fig. 25-Variation of grain size and basal texture intensity as a function of extrusion temperature for pure $\mathrm{Mg}$ extruded at a ram speed of $0.1 \mathrm{~mm} \mathrm{~s}^{-1}$ and an extrusion ratio of 19:1.

increasing temperature, even though the texture changes little with the extrusion temperature, Figure 25. The microstructures of pure $\mathrm{Mg}$ extruded at 65, 250, and $400{ }^{\circ} \mathrm{C}$ are shown in Figure 26. All three microstructures have the same basal texture, with the $c$-axes of most grains nearly perpendicular to the extrusion direction. However, the distribution of the $c$-axes along the radial directions within the extrudate cross-section is generally not symmetrical. As shown in Figure 27, a smaller fraction of grains have their $c$-axes parallel to the radical direction ERD1, but there is a larger fraction of grains having their $c$-axes parallel to the radical direction ERD2. For the specimens extruded at 65 and $250{ }^{\circ} \mathrm{C}$, the $\langle 10 \overline{1} 0\rangle$ axes of most grains are nearly parallel to the extrusion direction, but for the specimen extruded at $400{ }^{\circ} \mathrm{C}$, most grains have their $\langle 11 \overline{2} 0\rangle$ axes nearly parallel to the extrusion direction, Figure 26.

The grain size in the above cases varies significantly with the extrusion temperature. The grain size is $\sim 0.8$, 8.1 and $82 \mu \mathrm{m}$, respectively, for extrusions at 65,250 , and $400{ }^{\circ} \mathrm{C} \cdot{ }^{[123]}$ Figure 28 (a) shows stress-strain curves of these three specimens, together with those from specimens extruded at other temperatures, obtained under uniaxial compression at a strain rate of $10^{-3} \mathrm{~s}^{-1}$ at room temperature. ${ }^{[123]}$ The specimen extruded at $400{ }^{\circ} \mathrm{C}$ has poor formability, fractured after $\sim 20 \mathrm{pct}$ reduction in height. A large fraction of deformation twins and slip traces was observed in the fractured sample. ${ }^{[123]}$ In general, specimens extruded in the temperature range 200 to $400{ }^{\circ} \mathrm{C}$ exhibit strain hardening after yielding has occurred. The level of strain hardening decreases with decreasing extrusion temperature. For specimens extruded in the temperature range 20 to $80{ }^{\circ} \mathrm{C}$, there is no strain hardening after yielding. The true stress decreases gradually with strain, implying 

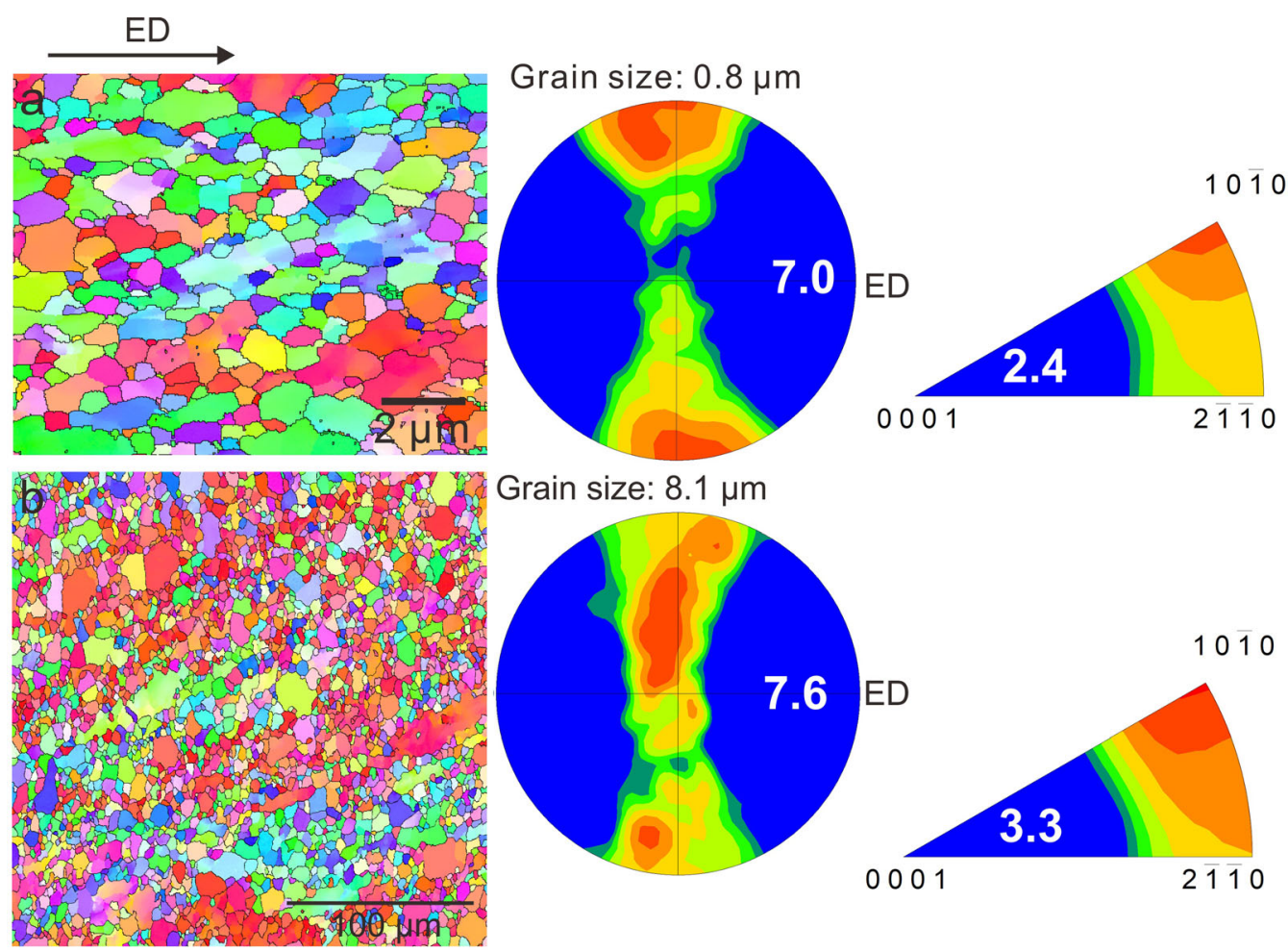

Grain size: $8.1 \mu \mathrm{m}$
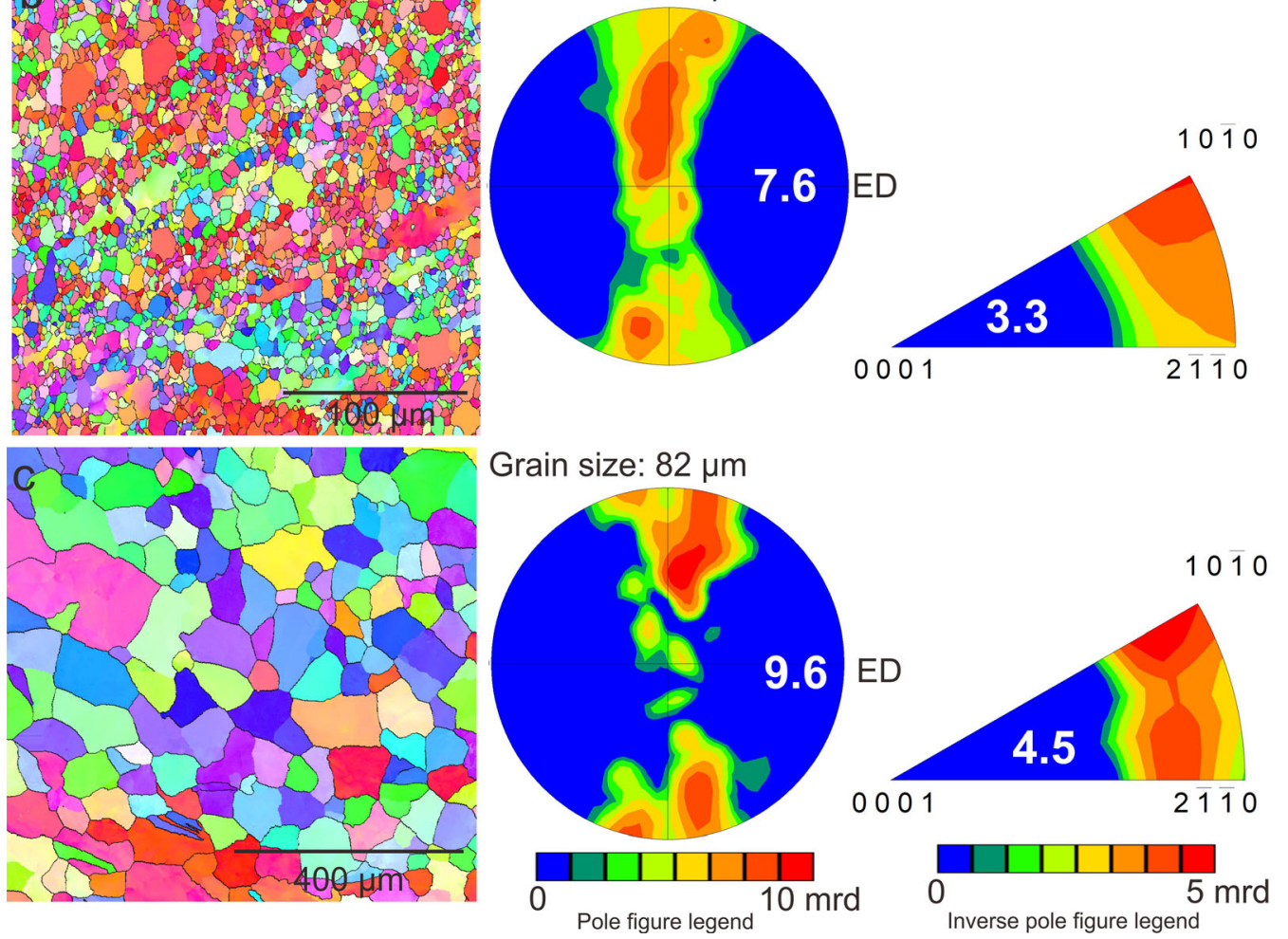

Fig. 26-EBSD orientation maps of longitudinal section and corresponding basal pole figures and inverse pole figures along the ED of pure Mg rods extruded at $(a) 65^{\circ} \mathrm{C},(b) 250{ }^{\circ} \mathrm{C}$, and $(c) 400{ }^{\circ} \mathrm{C}$ with a ram speed of $0.1 \mathrm{~mm} \mathrm{~s}^{-1}$ and an extrusion ratio of 19:1.

the insignificance of twinning and dislocation slip during the continued deformation. Indeed, primary or secondary deformation twins are rarely detectable in these specimens after considerably large deformation. It is currently unclear whether the room temperature super-formability of these specimens is attributable to mechanisms such as grain boundary sliding, and further research is needed in the future. The super-formability of the specimen extruded at $80{ }^{\circ} \mathrm{C}$ is demonstrated in Figure 28(b). This specimen could be compressed from $10 \mathrm{~mm}$ to $1.5 \mathrm{~mm}$ at which the compression was stopped due to the machine limit.

Figure 29 shows the relationship between 0.2 pct proof strength and grain size for wrought pure $\mathrm{Mg}$, including rolled sheets and bars (tested along the RD), extrudates (tested along the ED), and equal-channel angular processed (ECAP) bars (tested along the
ED). ${ }^{[123,127-130]}$ The strain rates used in the tests are also provided. In the regime where the grain size is large, the 0.2 pct proof strength increases with grain size reduction, and the $k$ value (the slope of the plot) is between 100 and $250 \mathrm{MPa} \mu \mathrm{m}^{0.5}$, depending on the loading direction with respect to the basal texture orientation, the intensity of the basal texture, and the strain rate involved in the testing. It is known that the $k$ value is influenced by texture. ${ }^{[131]}$ The maximum value of $250 \mathrm{MPa} \mu \mathrm{m}^{0.5}$ is smaller than that $\left(280 \mathrm{MPa} \mu \mathrm{m}^{0.5}\right)$ measured from cast polycrystalline $\mathrm{Mg}$ that has a random texture and much a larger grain size. ${ }^{[132]}$ In the regime of ultrafine grains, a reverse Hall-Petch relationship is observed. The 0.2 pct proof strength decreases with decreasing grain size, with a $k$ value ranging from -115 to $-65 \mathrm{MPa} \mu \mathrm{m}^{0.5}$, again depending on the loading orientation and the strain rate. The 


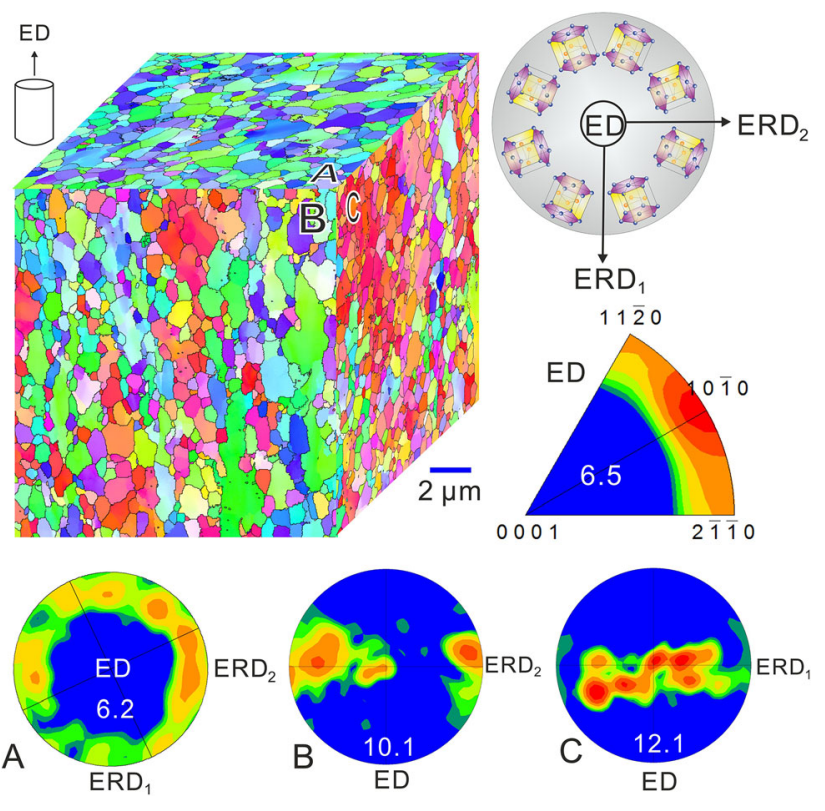

Fig. 27-Cube of EBSD orientation maps of pure $\mathrm{Mg}$ extruded at $80{ }^{\circ} \mathrm{C}$ with a ram speed of $0.1 \mathrm{~mm} \mathrm{~s}^{-1}$ and an extrusion ratio of 19:1. EBSD basal pole figures of three surfaces of the cube, and inverse pole figure along the ED. The average grain size is $\sim 1.2 \mu \mathrm{m}$.

breakdown of the Hall-Petch relationship in ultrafine-grained $\mathrm{Mg}$ occurs in both tensile and compression tests. The critical grain size for the breakdown of the Hall-Petch relationship is sensitive to the strain rate, it is $\sim 2 \mu \mathrm{m}$ at $10^{-3} \mathrm{~s}^{-1}$, but becomes $\sim 3 \mu \mathrm{m}$ at $10^{-5} \mathrm{~s}^{-1}$. While it is possible that a transition of the dominant deformation mode from intra-granular to inter-granular may occur when the grain size decreases below a critical value, it remains to be carefully examined whether the inter-granular mode is dominating the plastic deformation of ultrafine-grained $\mathrm{Mg}$ and, if so, which type it is. While dynamic recrystallization may also occur during the deformation, its role is again unclear and this aspect requires further study in the future.

\section{Deformation behavior}

a. Room temperature Plastic deformation of textured polycrystalline pure magnesium involves deformation in individual grains (or crystals) and cooperation of these grains (such as grain boundary sliding) to allow plasticity to occur without failure. For polycrystalline $\mathrm{Mg}$ with a strong texture, its deformation behavior should be, in principle, similar to that of a single crystal. Figure 30 shows deformation behavior of a polycrystalline $\mathrm{Mg}$ plate under plane-strain compression, for six different orientations of the plate with respect to the loading direction. ${ }^{[133]}$ The (0002) pole figure of this plate is also included. The plate was produced by hot rolling, with an average grain size of $91 \mu \mathrm{m}$. It had a strong basal texture, with the $c$-axes of individual grains lying predominantly in the plate thickness direction. There was considerably larger rotation of the basal poles about the transverse direction than the rolling direction, i.e., a split of the basal poles towards the rolling direction.

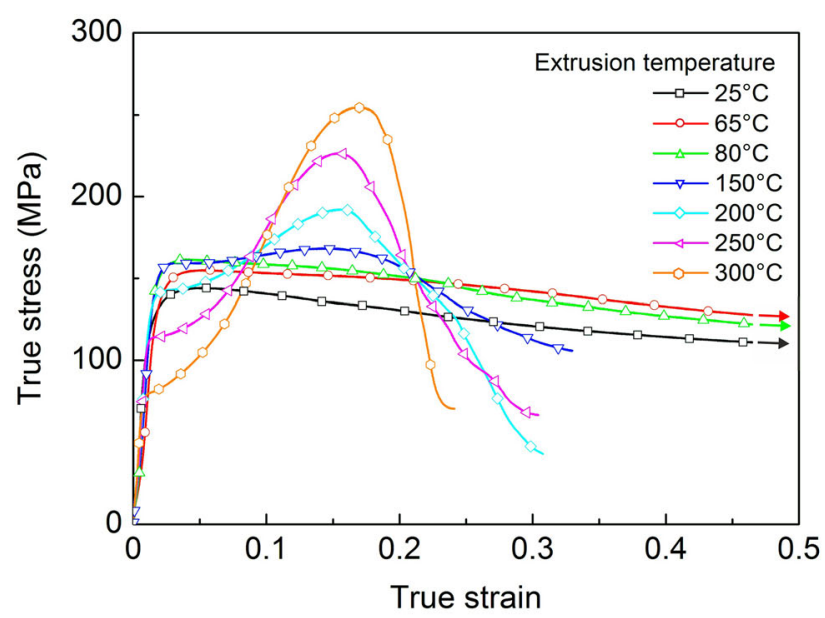

(a)

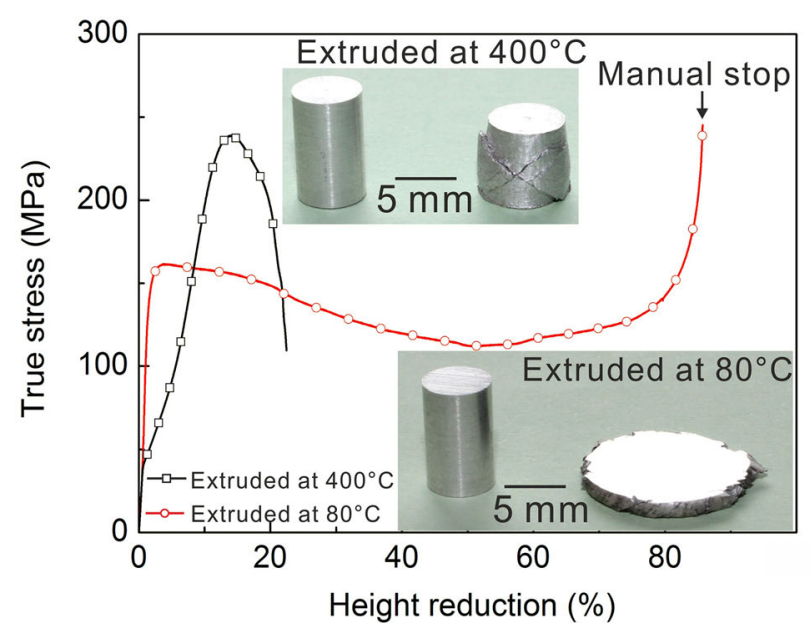

(b)

Fig. 28 - (a) Room temperature compressive true stress-strain curves of pure $\mathrm{Mg}$ extruded in the temperature range 25 to $300^{\circ} \mathrm{C}$. (b) Room temperature compression of specimens extruded at 80 and 400 ${ }^{\circ} \mathrm{C}$. Photo insets show the specimens before and after compression tests. Reprinted from Ref. [123].

The stress-strain curve of the orientation ZT is similar to those of single crystal orientations $\mathrm{A}$ and $\mathrm{B}$ in Figure 9. Since the $c$-axes of most grains in the plate were not precisely parallel to the loading direction, basal slip occurred readily, leading to significant lowering of the stress-strain curves relative to those for the single crystals. Nevertheless, the orientation ZT is the hardest along the six orientations of the plate. The stress-strain curve of the orientation ZR is remarkably lower than that of the orientation ZT. The reason for this softer orientation than the $\mathrm{ZT}$ is because of the greater spread of the basal poles about the transverse direction than the rolling direction, which makes the basal slip more favorable in a greater percent of the grains.

Orientations RT and TR resemble the single crystal orientations $\mathrm{C}$ and $\mathrm{D}$ in Figure 9. $\mathrm{Mg}$ grains in each of these two orientations were favorably oriented for basal slip, allowing easier deformation than counterpart single crystals in the early stage of loading. However, their 


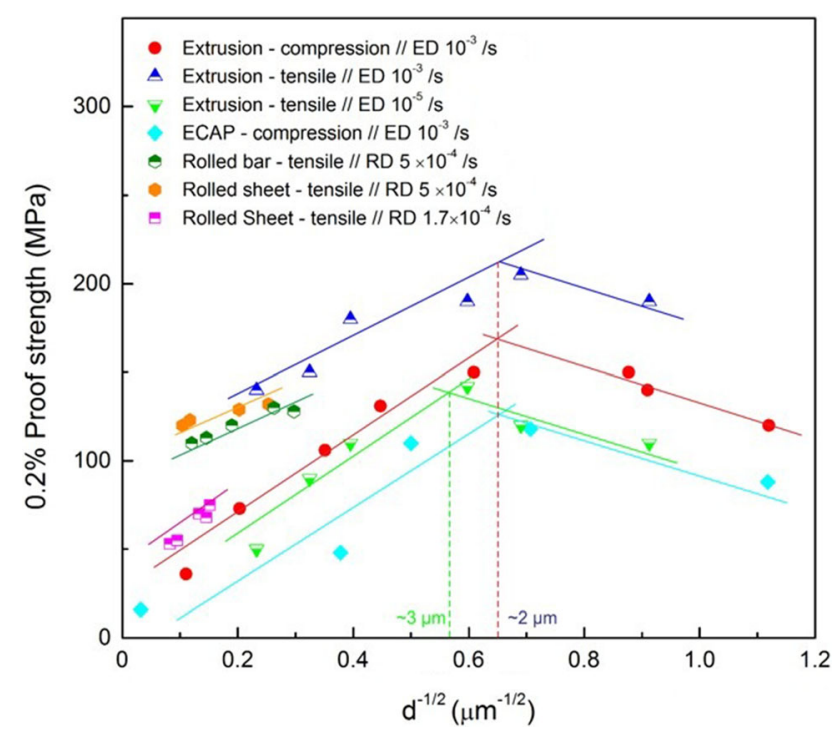

Fig. 29-Hall-Petch relationship for sheets and extrusions of pure Mg. Data from Refs. [123, 127-130].

stress-strain curves increase steadily with plastic strain and lie above those of the single crystal orientations $\mathrm{C}$ and $\mathrm{D}$ after approximately 0.06 strain.

Orientations TZ and RZ are similar to the single crystal orientations $\mathrm{E}$ and $\mathrm{F}$ in Figure 9. They deformed plastically via extensive formation of $\{10 \overline{1} 2\}$ twins in the initial stage of straining. In contrast to the curves of the single crystals $\mathrm{E}$ and $\mathrm{F}$, the strain hardening rate increased gradually with increasing strain in the strain range 0.01 to 0.05 . This phenomenon was attributed to the diversity of grain orientations and the grain size effect. ${ }^{[133]}$ In a polycrystalline specimen, the twin, and the strain it carries, can extend only within the small volume of a grain, rather than the full dimension of the specimen in the case of a single crystal. Other twins must be activated in the neighboring grain to extend the strain (twin transmission), which causes hardening. While the grain size effect is important, its quantitative role in the deformation behavior remains to be assessed and examined. As will be discussed in the following, a smaller grain size (less than 1 to $2 \mu \mathrm{m}$ ) can lead to elimination of the tension-compression yield asymmetry.

Stretch formability of hot-rolled sheets of pure $\mathrm{Mg}$ has been evaluated by Erichsen cupping test. ${ }^{[134]}$ The plate used for hot rolling was cut from an extruded bar, then hot-rolled repeatedly at $300{ }^{\circ} \mathrm{C}$ from $5 \mathrm{~mm}$ down to $1 \mathrm{~mm}$, along the direction that is at $90^{\circ}$ to the extrusion direction and with 15 pct thickness reduction each rolling pass. ${ }^{[134]}$ The roller was controlled to be $80^{\circ} \mathrm{C}$ and the final sheet was annealed at $345^{\circ} \mathrm{C}$ to remove the residual stress in the sheet. The punch diameter and punching speed of the Erichsen test were $20 \mathrm{~mm}$ diameter and $0.0833 \mathrm{~mm} \mathrm{~s}^{-1}$, respectively, similar to those used for single crystal sheets. The microstructure of the hot-rolled sheet contained equiaxed grains of $\sim 24 \mu \mathrm{m}$. There was a strong basal texture at the surface and the center of the sheet, Figure 31(a). Tensile

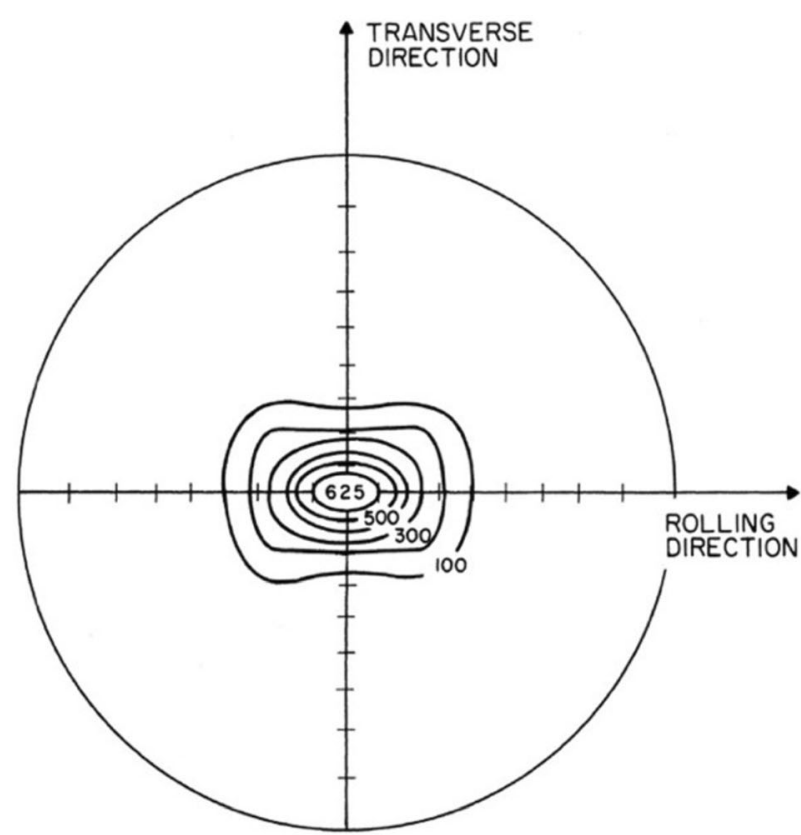

(a)

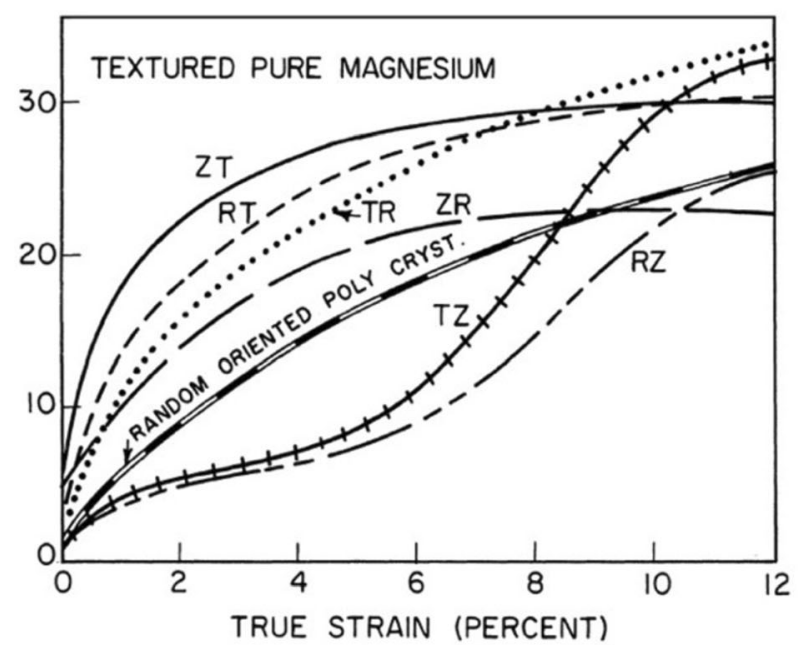

(b)

Fig. 30-(a) (0002) pole figure of a basal-textured polycrystalline plate of pure Mg. (b) Stress-strain curves of the pure Mg plates deformed at room temperature by plane-strain compression along six different crystallographic directions. Letter $\mathrm{Z}$ represents thickness direction, $\mathrm{R}$ rolling direction, and $\mathrm{T}$ transverse direction. The first letter indicates the loading direction and the second letter the extension direction. For example, the orientation ZT means compression in the thickness direction and extension in the transverse direction, i.e., constraint in the rolling direction. Adapted from Ref. [133].

properties and Lankford $r$ values, obtained at a strain rate of $1.7 \times 10^{-3} \mathrm{~s}^{-1}$ at room temperature along three different directions, are also provided in Figure 31. Based on these data, the average $r$ value and the anisotropy of the $r$ values, $\Delta r$, which is defined by the difference between the maximum and minimum, were calculated and also included in the figure. The Erichsen index value was $3.1 \mathrm{~mm}$ at the room temperature, Figure 31(b), which is almost two times larger than that 

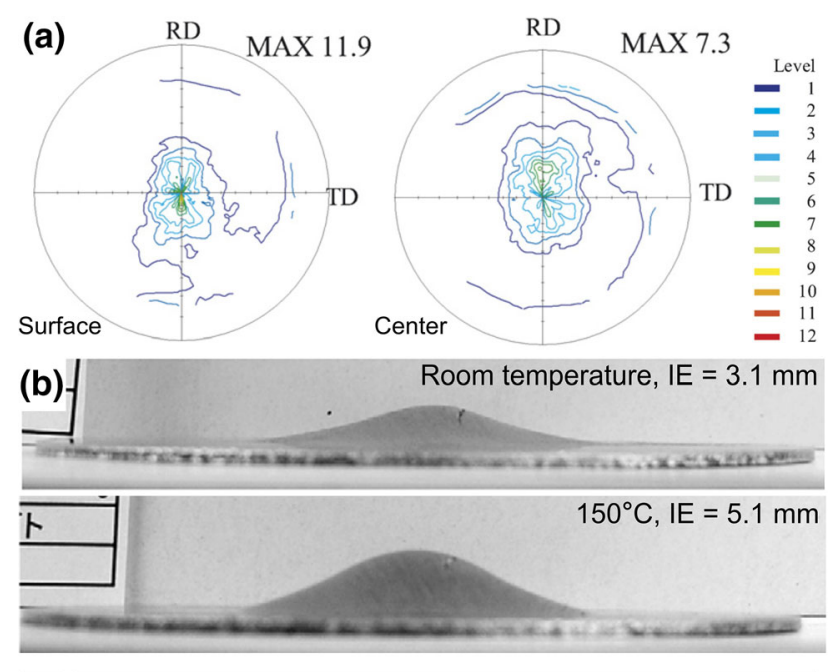

\begin{tabular}{llll}
\hline (c) Tensile direction & $\mathrm{RD}$ & $\mathrm{TD}$ & $45^{\circ}$ \\
\hline $0.2 \%$ Proof strength (MPa) & 100 & 135 & 117 \\
Tensile strength (MPa) & 183 & 210 & 196 \\
Elongation $(\%)$ & 13.5 & 9 & 13 \\
Lankford $r$-value & 1.0 & 1.55 & 1.3 \\
\hline Average $r$-value & & 1.3 & \\
Anisotropy of $r$-value $(\Delta r)$ & & 0.55 & \\
\hline
\end{tabular}

Fig. 31-(a) (0002) pole figures measured from the surface and the center of a hot-rolled sheet of pure $\mathrm{Mg}$. (b) Sheet specimens after Erichsen tests at room temperature and $150{ }^{\circ} \mathrm{C}$. (c) Tensile properties and Lankford $r$ values along $\mathrm{RD}$, TD, and 45 deg to the RD. Adapted from Ref. [134].

of the single crystal (0001) sheet shown in Table I. The better formability is associated with smaller $r$ value and lower anisotropy shown in Figure 31(c). While the better stretch formability of the polycrystalline sheet is attributable to the deviation of the $c$-axes from the sheet normal direction, which makes basal slip more favorable in a larger fraction of grains, the effects of grain size and grain size distribution on the stretch formability remain largely unexplored.

$b$. Elevated temperatures Deformation behavior of textured polycrystalline pure $\mathrm{Mg}$ at high temperatures has received much less attention. The difficulty involved in the assessment is the instability of grains at high temperatures, depending on the grain size and the strain rate. It is imaginable that products having finer grains and subjected to longer testing time are prone to grain growth and texture evolution during the hot deformation. At a higher temperature, dynamic recrystallization may also occur. Figure 32(a) shows engineering stressstrain curves of rolled sheets of pure $\mathrm{Mg}$ tested at a strain rate of $1.7 \times 10^{-4} \mathrm{~s}^{-1}$ in the temperature range -196 to $250{ }^{\circ} \mathrm{C}(77$ to $523 \mathrm{~K}) \cdot{ }^{[130]}$ The texture of the sheet was not specified in this work, but the grain size before testing was approximately $47 \mu \mathrm{m}$. As expected, the 0.2 pct proof strength of the sheet decreases with increasing temperature, while the ductility increases substantially when the temperature increases from 20 to $250{ }^{\circ} \mathrm{C}$. Data of the 0.2 pet proof strength obtained

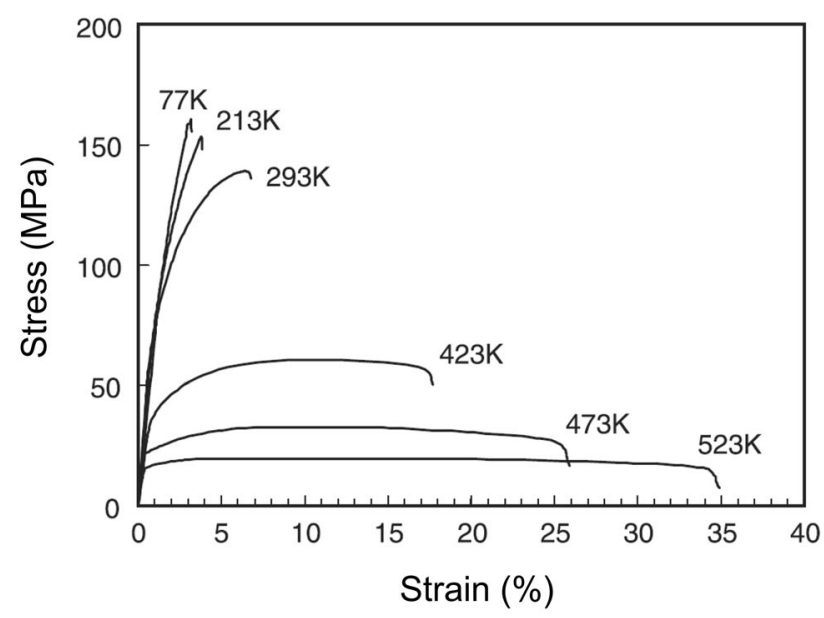

(a)

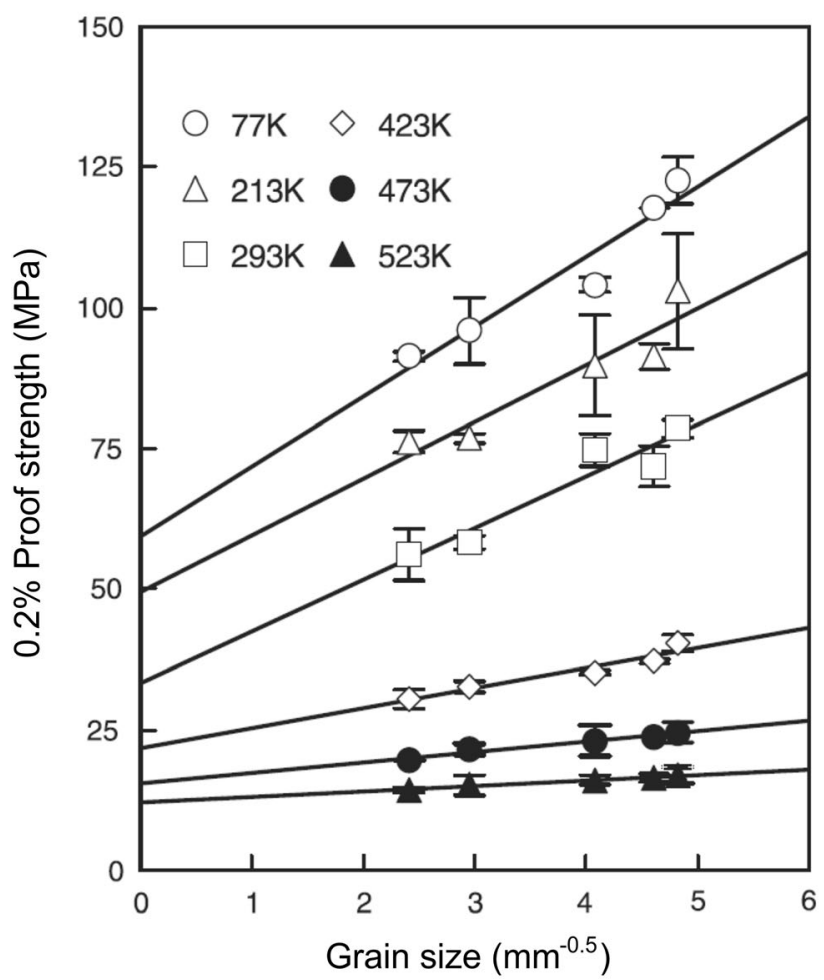

(b)

Fig. 32-(a) Engineering stress-strain curves of polycrystalline sheets of pure $\mathrm{Mg}$ in the temperature range 77 to $523 \mathrm{~K}$. $(b)$ Variation of 0.2 pct proof strength as a function of temperature and initial grain size. Adapted from Ref. [130].

from the same sheet but having different grain sizes, obtained under the same testing condition and in the temperature range -196 to $250{ }^{\circ} \mathrm{C}$ are provided in Figure 32(b). From these data, it is possible to deduce the Hall-Petch relationship between the 0.2 pet proof strength and the initial grain size (the average size of grains before testing). The slope of the data, i.e., the $k$ value, at $25^{\circ} \mathrm{C}$ is $9.2 \mathrm{MPa} \mathrm{mm}{ }^{0.5}$ or $291 \mathrm{MPa} \mu \mathrm{m}^{0.5}$, which is larger than those shown in Figure 29. It should be noted that the precise value of $k$ may vary in each case, depending on how the data points are linked or 
approximated to define the slope of the plot line. If this uncertainty is taken into account, then the difference between the $k$ values is not significant. The $k$ value is apparently temperature dependent, it decreases with increasing temperature, with a value of $\sim 62 \mathrm{MPa} \mu \mathrm{m}^{0.5}$ at $200{ }^{\circ} \mathrm{C}$ and $\sim 37 \mathrm{MPa} \mu \mathrm{m}^{0.5}$ at $250{ }^{\circ} \mathrm{C}$. Note that the grain sizes reported in this work are in the range 43 to $172 \mu \mathrm{m}$ and that such grains are expected to be relatively thermally stable during tensile tests in the temperature range -196 to $250{ }^{\circ} \mathrm{C}$.

\section{MICROSTRUCTURE AND DEFORMATION OF MAGNESIUM ALLOYS}

\section{A. Mg-Al-Based Alloys}

Among wrought $\mathrm{Mg}$ alloys, Mg-Al-based alloys represent the group that has received largest commercially application and most intensive fundamental study. Within this group, AZ31 alloy has received the most attention. As will be reviewed and discussed in this section, the Mg-Al-based alloys develop a strong basal texture after thermomechanical processing and therefore exhibit anisotropic mechanical properties such as tension-compression yield asymmetry of extrusions and inadequate sheet formability at room temperature.

\section{Single crystals}

In contrast to single crystals of pure $\mathrm{Mg}$, single crystals of $\mathrm{Mg}$ alloys have received much less research, primarily because they are more difficult to fabricate than those of pure Mg. Studies of deformation behavior of $\mathrm{Mg}-0.5 \mathrm{Al}, \mathrm{Mg}-1 \mathrm{Al}$, and $\mathrm{Mg}-2.6 \mathrm{Al}-0.3 \mathrm{Zn}$ (at. pet) single crystal alloys, ${ }^{[117,135]}$ under uniaxial tension along $\langle 11 \overline{2} 0\rangle$, indicated that the binary and ternary alloys were all much stronger than pure $\mathrm{Mg}$. At room temperature, the ternary alloy exhibited a fairly apparent elastic deformation up to $130 \mathrm{MPa}$, followed by yielding and serrated flow of the stress-strain curve before fractured at a total strain of $\sim 0.05$, which was slightly larger than that of pure $\mathrm{Mg}$. The plastic deformation of the ternary alloy was accompanied by the occurrence of $\{10 \overline{1} 1\}\langle\overline{1} 012\rangle$ twinning and pyramidal I slip.

\section{Polycrystalline plates and sheets}

a. Microstructures of rolled plates and sheets It is well known that the addition of $\mathrm{Al}$ to $\mathrm{Mg}$ does not lead to any noticeable weakening of basal texture, especially for alloys of AM and AZ series, ${ }^{[84,96,136,137]}$ irrespective of whether the Al atoms added to the alloy are in solid solution and/or exist in the form of second-phase particles. Such alloys usually contain a small amount of $\mathrm{Mn}(0.2$ to $0.6 \mathrm{wt} \mathrm{pct})$ for the purpose of corrosion resistance. The added $\mathrm{Mn}$ reacts with $\mathrm{Al}$ to form $\mathrm{Al}_{8} \mathrm{Mn}_{5}$ particles during alloy solidification. The presence of such particles, or the residual Mn atoms in the solid solution, does not seem to affect the texture after thermomechanical processing. The grain size and its distribution and microstructural homogeneity vary with the strain rate, strain, and temperature involved in the deformation processing. In the case of AZ31 alloy, the grain size is typically in the range 5 to $50 \mu \mathrm{m}$ after repeated hot rolling and annealing. ${ }^{[98,138-140]}$ When an AZ31 plate of $12 \mathrm{~mm}$ thickness was rolled at $400{ }^{\circ} \mathrm{C}$ directly from a cast billet to a total rolling strain of 0.7 , under the condition of homogenization for 8 hours at $400{ }^{\circ} \mathrm{C}$ prior to the initial hot rolling, annealing for 15 minutes at $400{ }^{\circ} \mathrm{C}$ after each rolling pass, and an average rolling strain rate of $\sim 0.1 \mathrm{~s}^{-1}$, its microstructure was always incompletely recrystallized and inhomogeneous, irrespective of the number of rolling passes. ${ }^{[140]}$ The partial recrystallization was attributed to the much coarser grains in the starting microstructure, implying the importance of grain boundary nucleation of recrystallization. This observation suggests that, to obtain a fully recrystallized microstructure, it is better to adopt repeated hot rolling with a small rolling strain per pass, instead of using less passes with a large strain per pass. The grain boundary area is expected to increase during the repeated hot rolling and annealing process, which in turn will lead to increased nucleation sites for recrystallization. Comparison ${ }^{[140]}$ of hot- and cold-rolled AZ31 plates indicated that repeated hot rolling and annealing at $400{ }^{\circ} \mathrm{C}$ was more effective in generating a fully recrystallized microstructure than heavy pass rolling and annealing.

Figure 33 shows microstructures of an AZ31 thin plate after hot rolling at $400{ }^{\circ} \mathrm{C}$ and subsequent annealing for 30 minutes at different temperatures. In this case, the as-cast AZ31 billet was rolled from 5 to $2.5 \mathrm{~mm}$ by 4 passes at $400{ }^{\circ} \mathrm{C}$, with a roller surface speed of 2 $\mathrm{mm} \min ^{-1}$ and intermediate annealing at $400{ }^{\circ} \mathrm{C}$ for 15 minutes. After the final rolling pass, the hot-rolled thin plate was quenched in cold water. The hot-rolled microstructure contains a mixture of deformed grains, large in size, and recrystallized grains that are small in size, Figure 33(a). The partially recrystallized microstructure, the whole area shown in the figure, has a strong $(0001)\langle 10 \overline{1} 0\rangle$ texture, i.e., the basal planes of most grains are nearly parallel to the thin plate surface, and the $\langle 10 \overline{1} 0\rangle$ directions of these grains are nearly parallel to the rolling direction. However, closer inspection of the textures of localized areas indicates clearly that the coarse deformed grains have strong $(0001)\langle 10 \overline{1} 0\rangle$ texture, while the fine recrystallized grains have both $(0001)\langle 2 \overline{1} \overline{1} 0\rangle$ and $(0001)\langle 10 \overline{1} 0\rangle$ textures, as shown in Figure 33(e). The partially recrystallized microstructure remains after annealing at $250{ }^{\circ} \mathrm{C}$ for 30 minutes, Figure 33(b). However, the size of the recrystallized grains becomes larger, and the volume fraction of the recrystallized grains is increased. The microstructure still has a $(0001)\langle 10 \overline{1} 0\rangle$ texture, but its texture intensity is now much lower than that in the hot-rolled condition. The thin plate becomes fully recrystallized after annealing of 30 minutes at $300{ }^{\circ} \mathrm{C}$, Figure 33(c). The microstructure contains a uniform distribution of recrystallized grains of a more uniform size. Furthermore, the texture intensity in the basal pole figure decreases further to $\sim 3 \mathrm{MRD}$, and most grains now have their directions lying between $\langle 10 \overline{1} 0\rangle$ and 

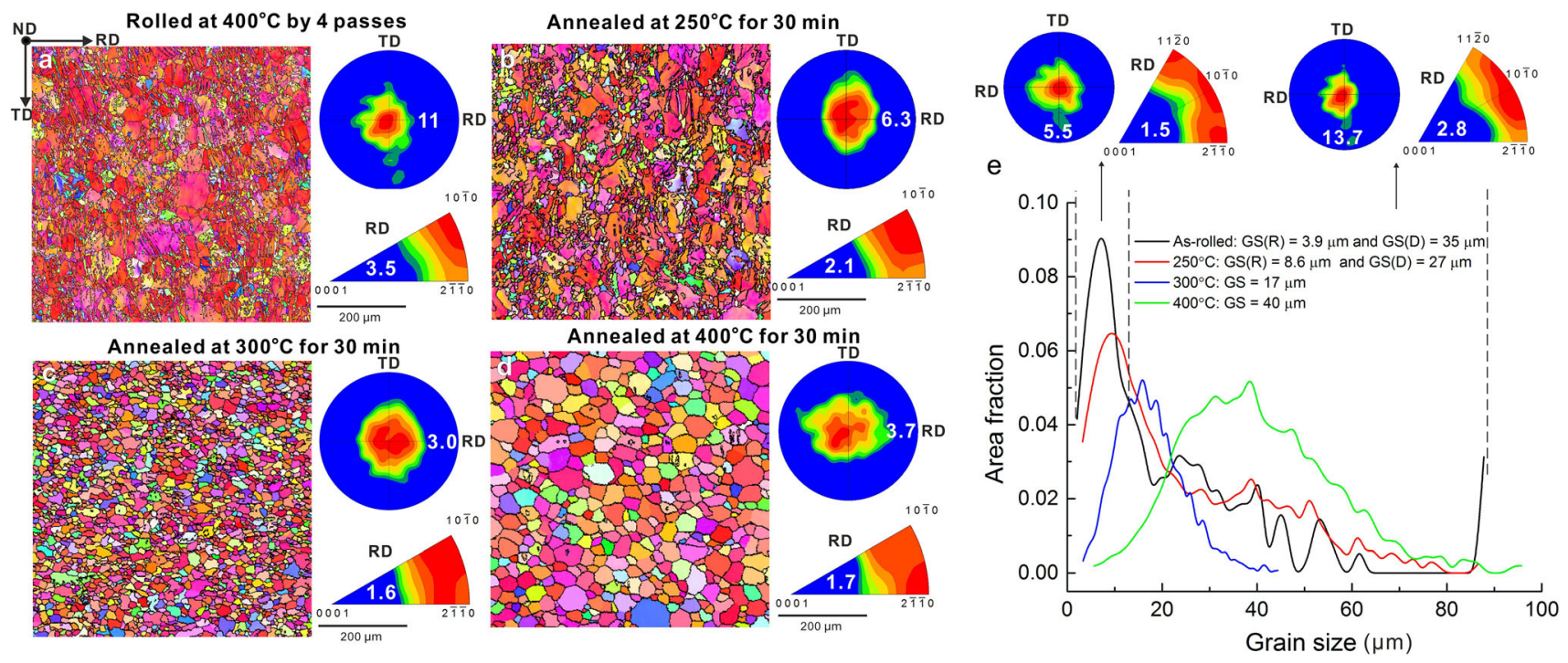

Fig. 33-EBSD orientation maps of microstructures parallel to plate surface, corresponding basal pole figures, and inverse pole figures along the RD of AZ31 thin plates in the as-hot-rolled condition $(a)$ and after 30 minutes of annealing at $(b) 250{ }^{\circ} \mathrm{C},(c) 300{ }^{\circ} \mathrm{C}$, and $(d) 400{ }^{\circ} \mathrm{C}$. (e) Distribution of grain size in each of the four conditions in $(\mathrm{a}-\mathrm{d})$. The texture intensity is included in each pole figure and inverse pole figure. GS represents grain size.

$\langle 2 \overline{1} \overline{1} 0\rangle$ parallel to the RD, i.e., $\langle 10 \overline{1} 0\rangle-\langle 2 \overline{1} \overline{1} 0\rangle / / \mathrm{RD}$. When the same annealing time is used at a higher temperature such as $400{ }^{\circ} \mathrm{C}$, Figure $33(\mathrm{~d})$, the thin plate is again fully recrystallized, as expected. However, the recrystallized grains are larger in size, and the intensity of the basal texture in the basal pole figure increases slightly. The major texture component along the RD becomes $(0001)\langle 2 \overline{1} \overline{1} 0\rangle$. The $(0001)\langle 10 \overline{1} 0\rangle$ deformation texture and the $(0001)\langle 2 \overline{1} \overline{1} 0\rangle$ recrystallization texture are related to each other by 30 deg rotation about the [0001] axis.

The texture evolution in warm-rolled AZ31 sheets during grain growth, which is caused by isothermal annealing, has been carefully characterized in some recent studies. ${ }^{[141,142]}$ The sheets had a thickness of $\sim 1.5$ $\mathrm{mm}$ and they were produced by shear rolling at $200{ }^{\circ} \mathrm{C}$. The microstructure of the warm-shear-rolled sheets contained recrystallized grains of $\sim 5.3 \mu \mathrm{m}$ in size. It had a basal texture, with an intensity of 9 MRD in the basal pole figure. The basal poles spread slightly towards the rolling direction. While XRD measurements revealed a random orientation of $(10 \overline{1} 0)$ poles with respect to the rolling direction, ${ }^{[141]}$ EBSD maps indicated the slight presence of the $(0001)\langle 10 \overline{1} 0\rangle$ texture. ${ }^{[142]}$ The sheets were annealed at 260 to $450{ }^{\circ} \mathrm{C}$ for 1 to 604,800 seconds, during which grain size might grow up to $50 \mu \mathrm{m}$. The basal texture intensity changed little during annealing at $300{ }^{\circ} \mathrm{C}$, but became much stronger after annealing at 400 or $450{ }^{\circ} \mathrm{C}$. Its intensity increased to $\sim 16 \mathrm{MRD}$ after annealing for 7 days at $400{ }^{\circ} \mathrm{C}$. The $(0001)\langle 2 \overline{1} 10\rangle$ texture component, reportedly present in the initial microstructure, ${ }^{[142]}$ became prominent after prolonged annealing at such high temperatures.

While the transition from the $(0001)\langle 10 \overline{1} 0\rangle$ texture to the $(0001)\langle 2 \overline{1} \overline{1} 0\rangle$ during annealing at high temperatures has now been well documented for AZ31 and pure $\mathrm{Mg}$, the origin and the mechanism of the transition remain controversial. There are several interpretations of the texture transition. One school of thoughts attributes it to the anisotropy of grain boundary energy and mobility (continuous recrystallization) ${ }^{[142]}$ while another school suggests it to be discontinuous nucleation and growth of recrystallized grains, i.e., not the recovery process like in-situ or continuous recrystallization. ${ }^{[143]}$ It was proposed $^{[142]}$ that this transition is due to the preferential growth of recrystallized grains when the recrystallized grains share a $30 \mathrm{deg}$ [0001] orientation relationship with the deformed matrix grain. While these interpretations can explain some features of the texture evolution, none of them offers an explanation that is fully consistent with experimental observations. It is currently unclear why the $(0001)\langle 2 \overline{1} \overline{1} 0\rangle$ texture will replace the $(0001)\langle 10 \overline{1} 0\rangle$ texture during grain growth and what mechanism is operating in the texture change. Perhaps an important clue is the presence of a continuous spectrum of grain orientations lying from $\langle 10 \overline{1} 0\rangle$ to $\langle 2 \overline{1} \overline{1} 0\rangle$, Figure 33(c), which indicates unambiguously the occurrence of other in-plane textures before $(0001)\langle 2 \overline{1} \overline{1} 0\rangle$ becomes the dominant texture component.

b. Plastic deformation of rolled plates and sheets Figure 34 shows stress-strain curves of AZ31 plates under plane-strain compression at a strain rate of $10^{-2} \mathrm{~s}^{-1}$ in the temperature range 20 to $450{ }^{\circ} \mathrm{C}$, for three different orientations with respect to the compression direction. ${ }^{[144]}$ The plate had a strong basal texture and an average grain size of $25 \mu \mathrm{m}$ before the tests, but the information on grain size distribution and texture intensity was not provided. ${ }^{[144]}$ At room temperature, Figure 34(a), compression along the ND led to a high yield stress and a high strain hardening rate. In contrast, loading along the TD caused yielding to occur at 

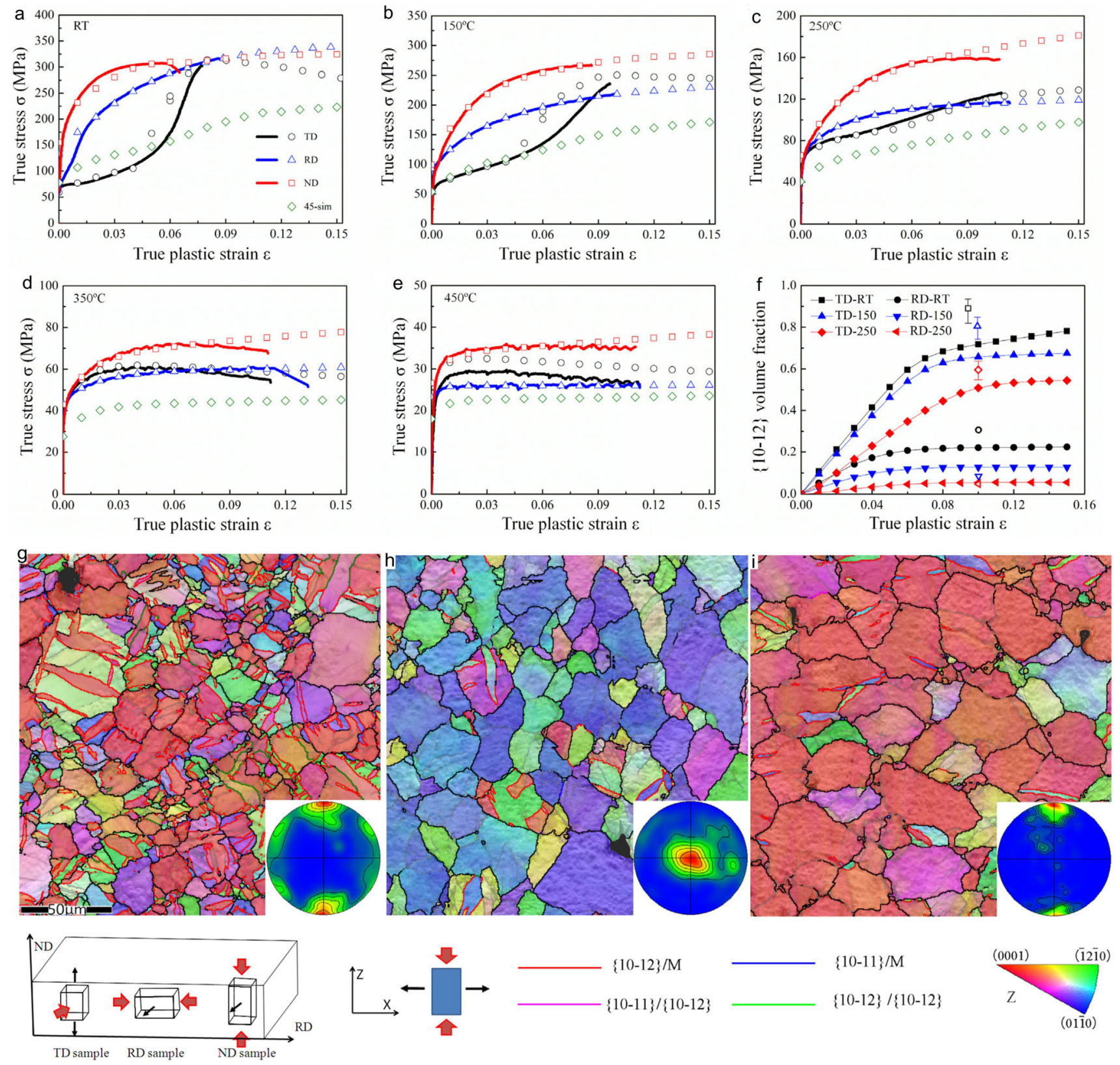

$\{10-11\} / \mathrm{M}$

$\{10-12\} /\{10-12\}$

$\{10-11\} /\{10-12\}$
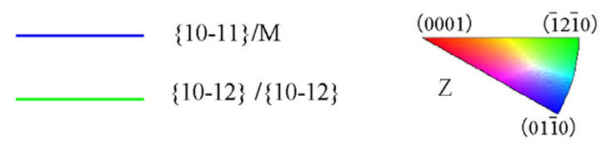

Fig. 34-Experimental (solid lines) and simulated (symbols) stress-strain curves of AZ31 plate deformed by plane-strain compression along three different directions ND, RD, and TD at $(a)$ room temperature, $(b) 150{ }^{\circ} \mathrm{C},(c) 250{ }^{\circ} \mathrm{C},(d) 350{ }^{\circ} \mathrm{C}$, and $(e) 450{ }^{\circ} \mathrm{C}$. $(f)$ Predicted variation of twin volume fraction as a function of temperatures for TD and RD orientations. ( $g$ - $i$ ) EBSD orientation maps and corresponding basal pole figures showing microstructures of $(\mathrm{g}) \mathrm{TD}$, (h) RD, and (i) ND after 0.1 compression strain at $250{ }^{\circ} \mathrm{C}$. Grains with their $c$-axes parallel to the $\mathrm{ND}$ are in red, with compression direction $\mathrm{Z}$ vertical and extension direction $\mathrm{X}$ horizontal. Adapted from Ref. [144].

$\sim 70 \mathrm{MPa}$. After yielding, the strain hardening rate was initially low, but increased significantly with plastic strain after $\sim 0.05$ strain. The plastic deformation below 0.05 strain was caused by an extensive formation of $\{10 \overline{1} 2\}$ twin. Microstructures of the TD, RD, and ND specimens after 0.1 compression strain at $250{ }^{\circ} \mathrm{C}$ are also shown in Figure 34. The fraction of twins reached about 60 pct and 5 pct, respectively, when the TD and $\mathrm{RD}$ specimens were deformed at $250^{\circ} \mathrm{C}$. The $\{10 \overline{1} 2\}$ twin was absent in the ND specimen deformed under the similar condition. While the experimental stress-strain curves at warm and high temperatures were reproduced by using the viscoplastic self-consistent (VPSC) model, the model used in this ${ }^{[144]}$ and other studies ${ }^{[145-147]}$ only considered different combinations of different deformation modes, the potential contribution of dynamic recrystallization was not taken into account. While it has been reported ${ }^{[143]}$ that AZ31 undergoes dynamic recrystallization during plane-strain compression at temperatures above $200{ }^{\circ} \mathrm{C}$, the formation temperature and the kinetics of recrystallization under different loading conditions have not been systematically explored so far. 
The influences of strain rate, strain, and temperature on dynamic recrystallization, under the condition of uniaxial compression at a strain rate in the range 0.01 to $1 \mathrm{~s}^{-1}$ at 300 to $450{ }^{\circ} \mathrm{C}$, were examined using both wrought (fine grain) and as-cast (coarse grain) specimens of AZ31. ${ }^{[96]}$ The specimen was quenched into water after a desired strain was reached. In this study, Beer and Barnett found that the level of dynamic recrystallization and the size of the dynamic recrystallized grains were both sensitive to the applied deformation conditions and the initial microstructure. Higher temperatures and lower strain rates, thus smaller values of the Zener-Hollomon parameter Z, led to larger percentages of DRX and larger sizes of dynamic recrystallized grains. The recrystallized grains from the wrought specimen were smaller than those from the as-cast specimen, and the kinetics of DRX in the wrought specimen was much higher than for that in the as-cast specimen. Furthermore, the DRX did not fully occur with decreasing $\mathrm{Z}$ in the as-cast specimen.

The room temperature stretch formability and uniaxial tensile properties of AM sheets containing different contents of Al are shown in Figure $35 .^{[148]}$ These sheets were produced by hot rolling from extruded plates. The as-cast billets were initially extruded at $400{ }^{\circ} \mathrm{C}$ into plates of $5 \mathrm{~mm}$ thickness, which were subsequently rolled at $460{ }^{\circ} \mathrm{C}$ to $1.26 \mathrm{~mm}$ thickness by six rolling passes, followed by a final rolling pass to $1 \mathrm{~mm}$ thickness at 500 to $550{ }^{\circ} \mathrm{C}$, which is unusually high for hot rolling. Such temperatures are very close to the solidus temperatures of individual alloys. The rolled sheets were subsequently annealed for 1 hour at $350{ }^{\circ} \mathrm{C}$. The Erichsen tests were carried out with a hemispherical punch of $20 \mathrm{~mm}$ diameter, but the punching speed was not provided. ${ }^{[148]}$ Uniaxial tensile tests were made at an initial strain rate of $3 \times 10^{-3} \mathrm{~s}^{-1}$. The hot-rolled sheets of the AM alloys all had a strong basal texture. The final annealing significantly weakened the basal texture, with the AM60 sheet having the weakest texture and the AM80 processing the strongest. The microstructures of these sheets contained a uniform distribution of recrystallized grains (equiaxed and 10 to $17 \mu \mathrm{m}$ in size). The Erichsen values of these sheets are provided in Figure 35. The stretch formability of the AM40-AM70 sheets is surprisingly outstanding, as the Erichsen values are compatible with those of commercial Al alloys, Table II[148-159] and Figure 52. In general, the Erichsen values of the sheets made from alloys of similar compositions, such as AZ31, are around 4 or less. The superior room temperature formability of such sheets is
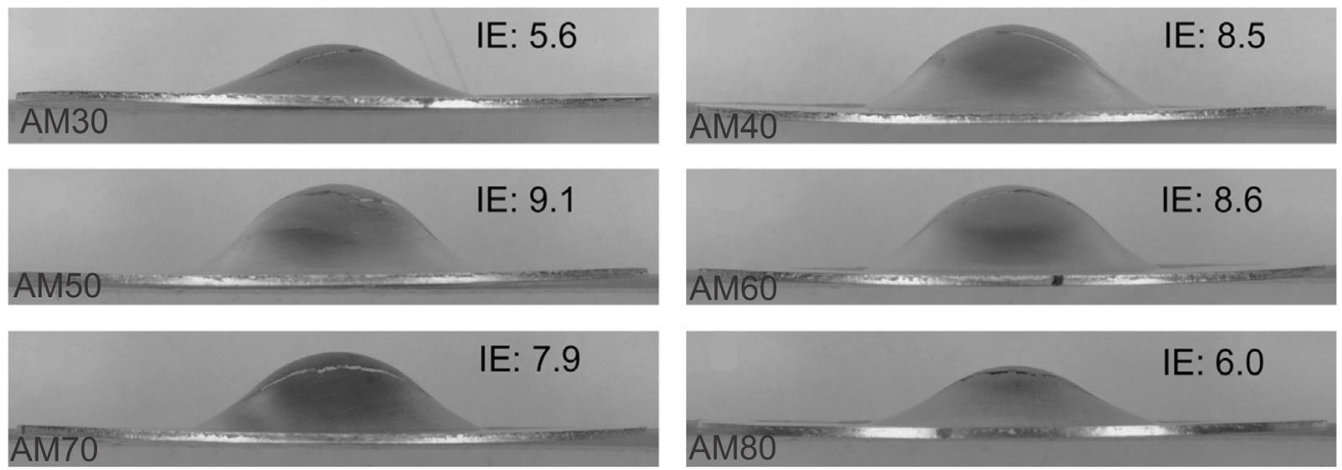

(a)

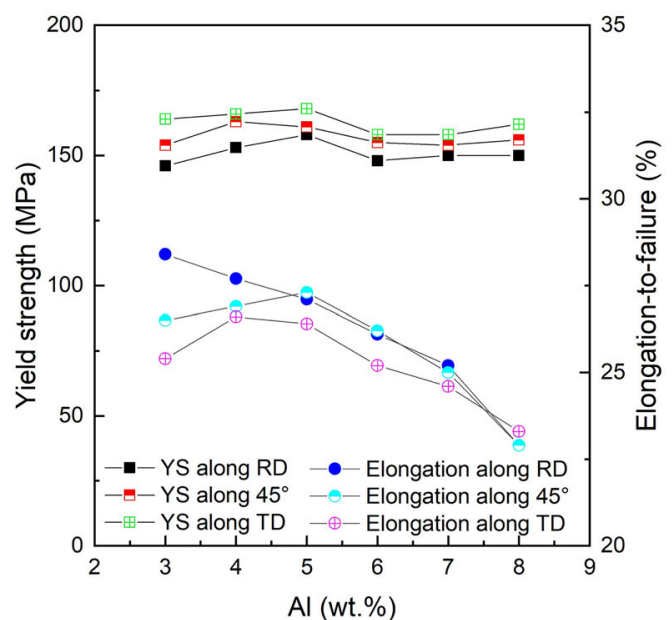

(b)

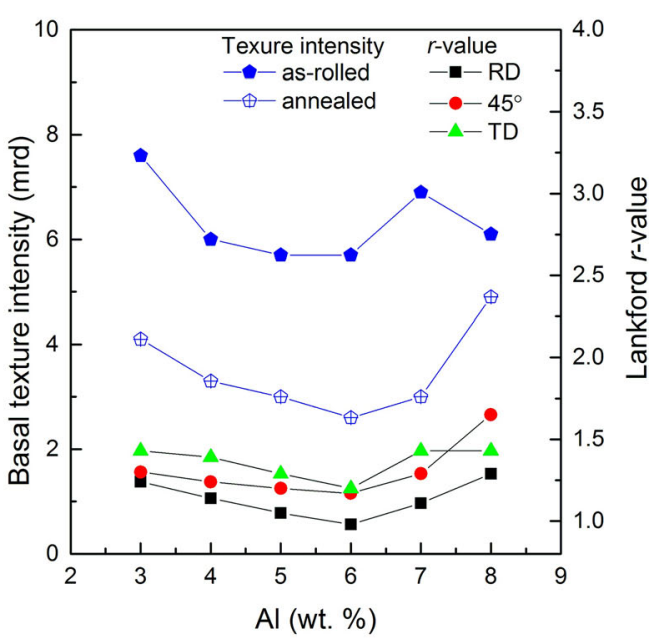

(c)

Fig. 35- (a) Deformed circular blanks after Erichsen testing of AM30, AM40, AM50, AM60, AM70, and AM80 sheets. The Erichsen values (IE) are indicated in the photos. $(b, c)$ Tensile yield strengths and elongation, Lankford $r$ values, and basal texture intensities of AM30-AM80 sheets. All tests were made at room temperature. Adapted from Ref. [148]. 
Table II. Texture, Grain Size, Tensile Properties, and Formability at Room Temperature of Mg-Al-Based Sheets of Different Alloy Compositions and Produced under Different Processing Conditions

\begin{tabular}{|c|c|c|c|c|c|c|c|}
\hline \multirow[b]{2}{*}{ Alloys (Wt Pct) } & \multirow[b]{2}{*}{ Processing Condition } & \multicolumn{2}{|c|}{ Microstructure } & \multicolumn{3}{|c|}{ Properties* } & \multirow[b]{2}{*}{ References } \\
\hline & & $\begin{array}{l}\text { Basal Tex- } \\
\text { ture } \\
(\mathrm{MRD})\end{array}$ & $\begin{array}{c}\text { GS } \\
(\mu \mathrm{m})\end{array}$ & $\begin{array}{c}\text { TYS } \\
\text { (MPa) }\end{array}$ & $\begin{array}{c}\mathrm{El} \\
(\mathrm{Pct})\end{array}$ & $\begin{array}{c}\mathrm{IE} \\
(\mathrm{mm})\end{array}$ & \\
\hline $\mathrm{Mg}-3 \mathrm{Al}$ & hot rolling, annealing & 18.4 & 60 & 100 & 17 & 5.6 & [149] \\
\hline AM30 & extrusion, hot rolling, annealing & 4.1 & 12 & 146 & 28 & 5.6 & [148] \\
\hline AM40 & & 3.3 & 10 & 153 & 28 & 8.5 & \\
\hline AM50 & & 3.0 & 10 & 158 & 27 & 9.1 & \\
\hline AM60 & & 2.6 & 12 & 148 & 26 & 8.6 & \\
\hline AM70 & & 3.0 & 12 & 150 & 25 & 7.9 & \\
\hline AM 80 & & 4.9 & 17 & 150 & 23 & 6.0 & \\
\hline AZ31 & hot rolling, annealing & 7.9 & 15 & 150 & 19 & 4.3 & {$[150]$} \\
\hline \multirow[t]{2}{*}{ AZ31 } & hot rolling at $0.1 \mathrm{~m} \mathrm{~s}^{-1}$, annealing & 4.4 & 10 & 161 & 20 & 4.9 & {$[151]$} \\
\hline & hot rolling at $0.4 \mathrm{~m} \mathrm{~s}^{-1}$, annealing & 3.1 & 12 & 122 & 24 & 6.3 & \\
\hline \multirow[t]{2}{*}{ AZ31 } & hot rolling, annealing & 10.6 & 16 & 166 & 23 & 2.6 & {$[152]$} \\
\hline & hot DSR, annealing & 8.8 & 16 & 146 & 26 & 4.0 & \\
\hline \multirow[t]{2}{*}{ AZ31 } & hot rolling (final-pass $450^{\circ} \mathrm{C}$ ), annealing & 5.4 & 11 & 165 & 26 & 4.5 & [153] \\
\hline & hot rolling (final-pass $525^{\circ} \mathrm{C}$ ), annealing & 2.8 & 12 & 144 & 27 & 8.6 & \\
\hline \multirow[t]{2}{*}{ AZ31 } & twin-roll casting, annealing & 5.3 & 16 & 124 & 17 & 4.2 & {$[154]$} \\
\hline & twin-roll casting, hot rolling, annealing & 5.7 & 6 & 158 & 13 & 3.1 & \\
\hline AZ31 & hot rolling, annealing & 13.7 & 12 & 163 & 27 & 2.7 & {$[155]$} \\
\hline AZ61 & extrusion, hot rolling, annealing & 3.1 & 19 & 152 & 24 & 7.8 & [156] \\
\hline \multirow[t]{2}{*}{ AZ80 } & extrusion, hot rolling, and annealing & 5.5 & 7 & 187 & 24 & 3.7 & {$[157]$} \\
\hline & extrusion, hot DSR, and annealing & 5.7 & 7 & 182 & 25 & 4.5 & \\
\hline $\mathrm{Mg}-3 \mathrm{Al}-0.1 \mathrm{Ca}$ & hot rolling, annealing & 10.1 & 30 & 100 & 20 & 6.5 & [149] \\
\hline $\mathrm{Mg}-1 \mathrm{Al}-1 \mathrm{Zn}-0.1 \mathrm{Ca}-0.5 \mathrm{Mn}$ & & 3.8 & 19 & 140 & 30 & 7.6 & {$[155]$} \\
\hline $\mathrm{Mg}-3 \mathrm{Al}-1 \mathrm{Zn}-0.5 \mathrm{Ca}$ & hot rolling, annealing & 6.6 & 8 & 190 & 16 & 5.0 & [158] \\
\hline $\mathrm{Mg}-3 \mathrm{Al}-1 \mathrm{Zn}-1 \mathrm{Mn}-0.5 \mathrm{Ca}$ & & 8.8 & 11 & 167 & 21 & 4.8 & \\
\hline $\mathrm{Mg}-3 \mathrm{Al}-1 \mathrm{Zn}-1 \mathrm{Mn}-0.5 \mathrm{Ca}$ & twin roll casting, hot rolling, annealing & 5.0 & 5 & 219 & 16 & 8.0 & \\
\hline $\mathrm{Mg}-1.2 \mathrm{Al}-0.5 \mathrm{Ca}-0.4 \mathrm{Mn}$ & hot rolling, annealing & 4.8 & 9 & 145 & 28 & 5.9 & [159] \\
\hline $\mathrm{Mg}-1.2 \mathrm{Al}-0.5 \mathrm{Ca}-0.4 \mathrm{Mn}-0.8 \mathrm{Zn}$ & & 3.5 & 11 & 144 & 32 & 7.7 & \\
\hline
\end{tabular}

Data from Refs. [148-159]

*Along the rolling direction. DSR: differential speed rolling, GS: grain size, El: elongation, TYS: tensile yield strength, IE: Erichsen index.

associated with significantly weakened basal texture of the sheets in the annealed state, Figure 35 . Whether the significantly weakened basal texture is caused by the adoption of the unusually high temperatures for finishing rolling is unclear and worth examination in the future. The effect of finishing rolling temperature on the basal texture intensity, Erichsen value, elongation, and $r$ value of AZ31 sheets is shown in Figure 36. When the finishing rolling temperature is at or above $525^{\circ} \mathrm{C}$, the basal texture intensity and the $r$ value both drop to a minimum, but the Erichsen value and elongation reach their maximum. While the basal texture intensities of this group of alloy sheets were significantly weakened by the use of high temperatures for the final rolling, it is still unclear how and why the basal texture become significantly weakened when the final rolling temperature is as high as that just below the solidus temperature of the alloy.

It has been reported recently ${ }^{[158]}$ that it is possible to simultaneously achieve high formability and high strength in a twin-roll cast, hot-rolled, and annealed AZMX3110 (Mg-3Al-1Zn-1Mn-0.5Ca, wt pct) alloy. The alloy sheet has an Erichsen index of $8 \mathrm{~mm}$ and a yield strength of $219 \mathrm{MPa}$ when it is tested at room temperature. Another study of similar alloy systems but with dilute alloying additions reported the possibility of developing an age-hardenable alloy with a good balance of strength and room temperature formability. ${ }^{[159]}$ After multi-stage hot and warm rolling, the rolled sheet of Mg-1.1Al-0.3Ca-0.2Mn-0.3Zn (wt pet) alloy was solution treated at $450{ }^{\circ} \mathrm{C}$ for 1 hour before tensile testing at an initial strain rate of $10^{-3} \mathrm{~s}^{-1}$ and Erichsen testing with $20 \mathrm{~mm}$ punch diameter and $6 \mathrm{~mm} \mathrm{~min}{ }^{-1}$ speed at room temperature. ${ }^{[159]}$ In the solution-treated condition (T4), the sheet had a fully recrystallized microstructure with an average grain size of $11 \mu \mathrm{m}$. It had a significantly weakened basal texture, with the distribution of basal poles exhibiting both RD-split and TD-split, which is similar to the texture of $\mathrm{Mg}-\mathrm{Zn}-\mathrm{Y}$ sheets. ${ }^{[160]}$ The intensity maxima of the basal poles was tilted by about $\pm 10^{\circ}$ from the ND towards the RD, and about $\pm 40^{\circ}$ from the ND towards the TD. The sheet had a tensile yield strength of $144 \mathrm{MPa}$ and ductility of $32 \mathrm{pct}$ and an Erichsen value of 7.7. Peak aging at $200^{\circ} \mathrm{C}$ increases the yield strength to $204 \mathrm{MPa}$ at the expense of slightly reduced ductility. ${ }^{[159]}$ The composition of the alloy was reported to be critical for achieving the good combination of strength and formability. The Erichsen 


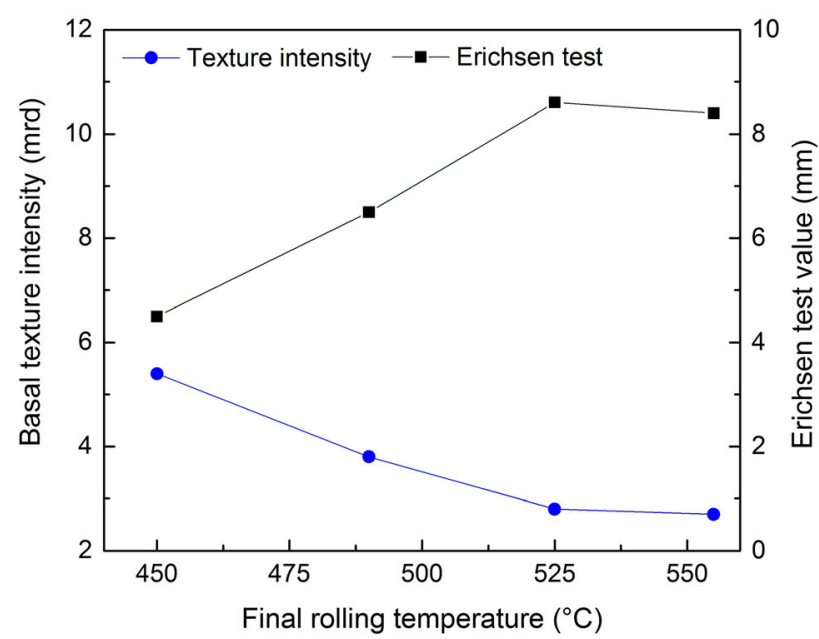

(a)

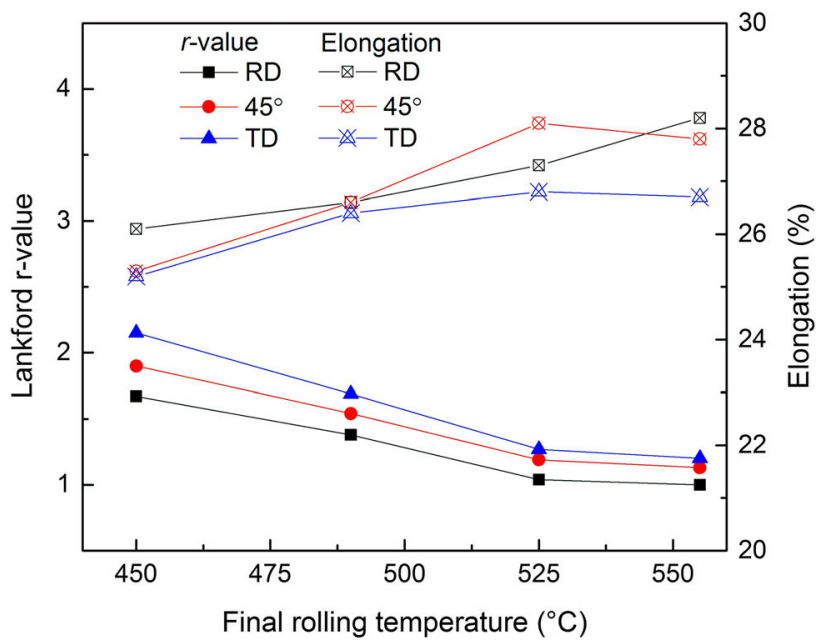

(b)

Fig. 36-(a) Erichsen values and basal texture intensities, and (b) Elongation and $r$ values of AZ31 sheets rolled with different final rolling temperatures. Data from Ref. [153]

value was decreased when $0.3 \mathrm{wt}$ pct $\mathrm{Zn}$ was removed from the alloy. The age-hardening response was speculated $^{[159]}$ to disappear if the $\mathrm{Ca}$ content was reduced from $0.3 \mathrm{wt}$ pet to $0.06 \mathrm{wt}$ pet.

Multi-pass cross rolling of an AZ31 sheet leads to a basal texture that does not have any RD-split and has a weaker intensity than those of uni-directionally rolled AZ31 sheets. The maximum basal texture intensity of the cross-rolled AZ31 sheet is about 5 to 7 MRD, ${ }^{[161-163]}$ weaker than that of the cross-rolled sheet of pure Mg. ${ }^{[125]}$ The change of rolling direction does not appear to affect grain size. Under the condition of rolling at $400{ }^{\circ} \mathrm{C}$ and 18 pet thickness reduction per pass from 6 $\mathrm{mm}$ to $1 \mathrm{~mm}$ and final annealing at $400{ }^{\circ} \mathrm{C}$ for 30 minutes, the grain size is 15 to $18 \mu \mathrm{m}$ in the cross-rolled sheets, and 15 to $16 \mu \mathrm{m}$ in the uni-directionally rolled sheets of AZ31. ${ }^{[162]}$

Asymmetric rolling of the AZ31 sheet may cause the basal poles to tilt by 5 to $8 \mathrm{deg}$ from the ND towards the $\mathrm{RD}$, with an intensity of $\sim 9 \mathrm{MRD}^{[164-166]}$ The tilting of the basal poles towards the RD is also observed in pure
$\mathrm{Mg}$ after the asymmetric rolling. The final grain size in an asymmetric rolled sheet depends on the rolling conditions. Under similar temperatures and thickness reductions, both asymmetric and symmetric rolled AZ31 sheets have approximately the same grain size. ${ }^{[166]}$

c. Polycrystalline extrudate The alloy AZ31 is also commonly used for extrusion. It usually has a strong basal texture after hot extrusion, with the basal planes and the $\langle 10 \overline{1} 0\rangle$ directions of most grains nearly parallel to the extrusion direction. ${ }^{[167]}$ The removal of $\mathrm{Zn}$ from the AZ31 alloy will not cause any changes to the texture. ${ }^{[168]}$ The formation of this texture during hot extrusion is illustrated in Figure 37. ${ }^{[167]}$ The as-cast billet was homogenized at $415^{\circ} \mathrm{C}$ for 16 hours and extruded at $300{ }^{\circ} \mathrm{C}$ using indirect extrusion at a ram speed of $10 \mathrm{~mm} \mathrm{~s}^{-1}$ and an extrusion ratio of 20:1. The partially extruded specimen was taken from an interrupted extrusion process by immediately quenching it into water to avoid annealing during cooling. The microstructure changed gradually as the material flowed towards the die exit, Figure 37(a). At the distance of $15 \mathrm{~mm}$ to the die exit, original grains were still retained, even though some of them already contained many deformation twins, Figure 37(b), and a $\langle 10 \overline{1} 0\rangle$ fiber texture component had already emerged from the originally random texture, Figure $37(\mathrm{c})$. DRX was noted to start at the position of $10 \mathrm{~mm}$ to the die exit, where the basal planes became lying closer to the ED and the $\langle 10 \overline{1} 0\rangle$ fiber texture component became stronger, Figure 37(d). The percentage of dynamic recrystallized grains increased with a further decrease in distance to the die exit. Accompanied with this event, the original grains now became elongated along the ED, leading to a bimodal microstructure. A weak $\langle 2 \overline{1} \overline{1} 0\rangle$ fiber texture component also formed, and strengthened with decreasing distance to the die exit, with both $\langle 2 \overline{1} \overline{1} 0\rangle$ and $\langle 10 \overline{1} 0\rangle$ fiber texture components formed at the position of $5 \mathrm{~mm}$ to the die exit, Figure 37(e). Complete DRX occurred at the die exit ( $0 \mathrm{~mm}$ position), and the microstructure had a $\langle 10 \overline{1} 0\rangle-\langle 2 \overline{1} \overline{1} 0\rangle / /$ ED basal texture. ${ }^{[167]}$

Effects of extrusion temperature and extrusion speed on the microstructure of AZ31 are shown in Figure 38. ${ }^{[169]}$ In this study, the as-cast billet was directly extruded at 175,300 , and $400{ }^{\circ} \mathrm{C}$ with an extrusion ram speed of $0.1 \mathrm{~mm} \mathrm{~s}^{-1}$ and at $400{ }^{\circ} \mathrm{C}$ and an extrusion ram speed of $3 \mathrm{~mm} \mathrm{~s}^{-1}$. The microstructure of the extrudate at $175^{\circ} \mathrm{C}$ had equiaxed grains with an average diameter of $0.65 \mu \mathrm{m}$, Figure 38(a). The dominant presence of sub-micron grains indicates the occurrence of dynamic recrystallization during extruding at this temperature. The microstructure had a typical extrusion texture, with the $\langle 10 \overline{1} 0\rangle$ axes of most grains nearly parallel to the extrusion direction, and a texture intensity of 4.7 MRD. With an increase in the extrusion temperature or the extrusion speed, more grains had their $\langle 10 \overline{1} 0\rangle$ axes tilted away from the ED and their $\langle 2 \overline{1} \overline{1} 0\rangle$ axes tilted towards the ED, even though the $\langle 10 \overline{1} 0\rangle \sim / /$ ED component was still the dominant texture, 

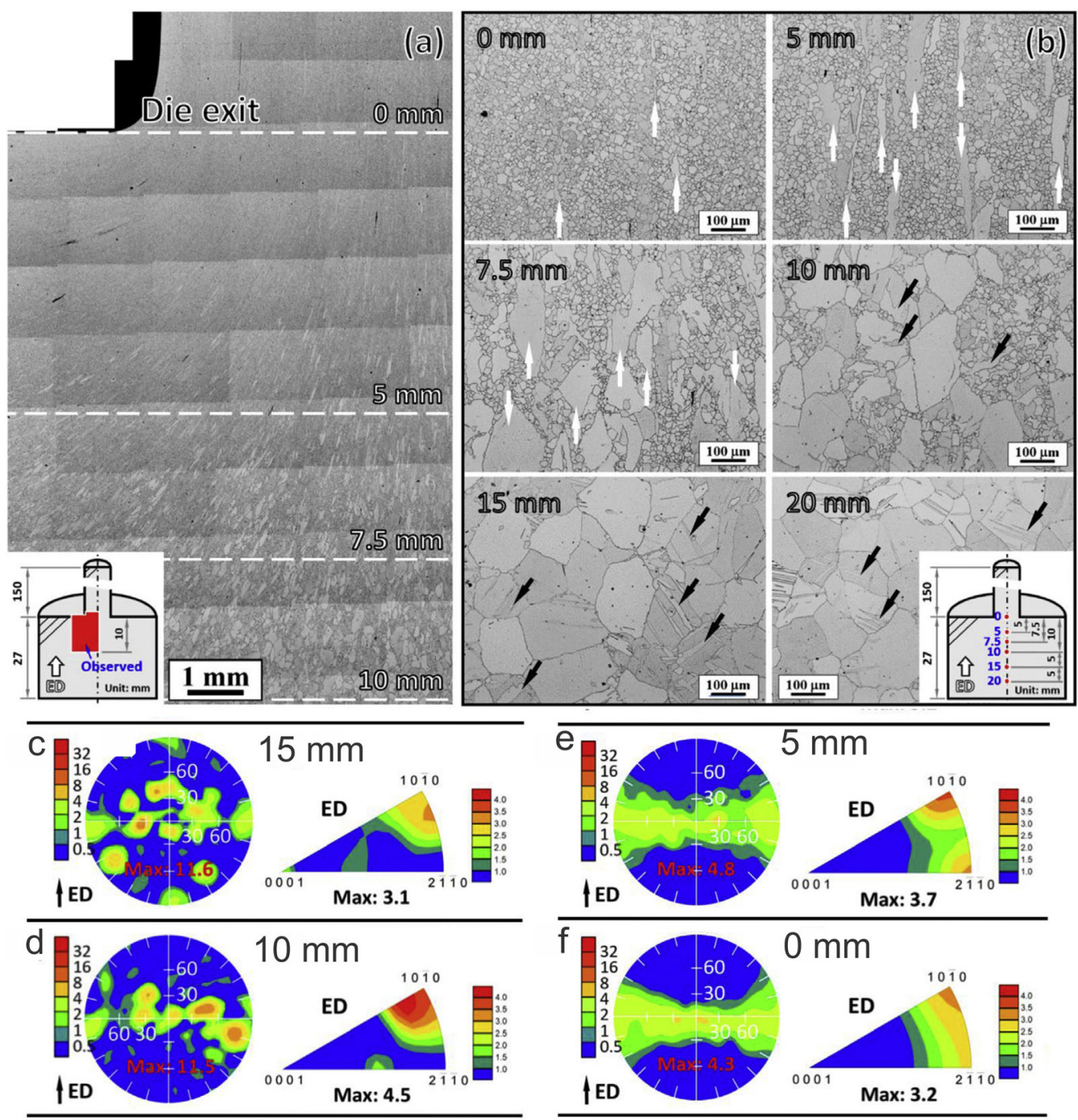

Fig. 37-Microstructures of different regions of interrupted extrusion of AZ31. (a) Microstructure near die exit, and (b) magnified microstructures. Black and white arrows indicate deformation twins and unrecrystallized grains. (c-f) Basal pole figures and corresponding inverse pole figures along the ED showing texture development. Adapted from Ref. [167].

Figures 38(b) through (c). The average grain size increased from 0.65 to $5.3 \mu \mathrm{m}$, as the extrusion temperature was increased from 175 to $400{ }^{\circ} \mathrm{C}$. For the extrusions at $400{ }^{\circ} \mathrm{C}$, an increase in the extrusion speed from 0.1 to $3 \mathrm{~mm} \mathrm{~s}^{-1}$ increased the average grain size to $\sim 14 \mu \mathrm{m}$. Irrespective of the extrusion conditions, strong segregation of $\mathrm{Zn}$ atoms in grain boundaries was found, Figures 38(e) and (f). There was no obvious segregation of $\mathrm{Al}$ and $\mathrm{Mn}$ atoms in grain boundaries, Figures $38(\mathrm{~g})$ and (h). The Al and $\mathrm{Mn}$ atoms had formed some intermetallic dispersoids along grain boundaries.

Figure 39(a) shows room temperature tensile and compressive properties of AZ31 extruded under different conditions. ${ }^{[169]}$ After the extrusion at $400{ }^{\circ} \mathrm{C}$ and a ram speed of $3 \mathrm{~mm} \mathrm{~s}^{-1}$, the yield strength was about $195 \mathrm{MPa}$ for the tensile testing and $123 \mathrm{MPa}$ for the compressive testing. The alloy exhibited apparent tension-compression yield asymmetry. A decrease in the extrusion speed to $0.1 \mathrm{~mm} \mathrm{~s}^{-1}$ at $400{ }^{\circ} \mathrm{C}$ led to a tensile and compressive yield strength of $218 \mathrm{MPa}$ and
$165 \mathrm{MPa}$, respectively. Again, there existed tension-compression yield asymmetry, even though the difference between the tensile and compressive strengths was reduced. Decreasing the extrusion temperature led to reduced tension-compression yield asymmetry. When the extrusion temperature was decreased to $175^{\circ} \mathrm{C}$, the yield strengths obtained from the tension and the compression tests were both $380 \mathrm{MPa}$, and the tension-compression yield asymmetry was now fully eliminated. The higher strength was attributed to the smaller grain size obtained at this extrusion temperature. While the grain size and texture of AZ31 in this condition are similar to those of pure $\mathrm{Mg}$ extruded at lower temperatures, the difference in yield strengths of AZ31 and pure $\mathrm{Mg}$, in either tensile or compressive tests, is remarkably large. The solid solution strengthening contribution was estimated to be approximately 50 $\mathrm{MPa}$ based on the comparison of yield strengths of AZ31 and Mg-1wt pet Zn extrusions that had similar grain size and texture. ${ }^{[169]}$ The only microstructural 


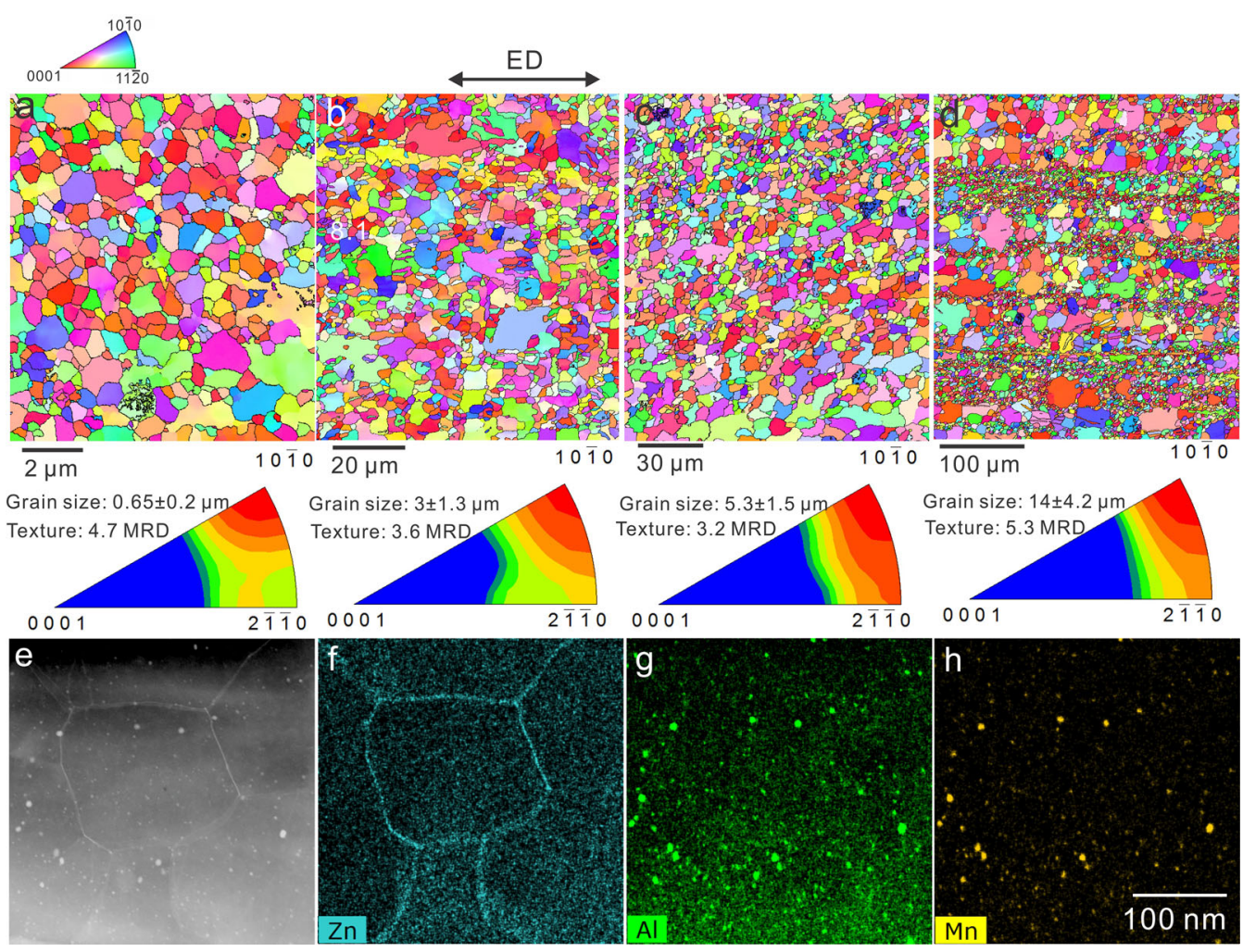

Fig. 38-EBSD orientation maps and corresponding inverse pole figures along the extrusion direction of AZ31 extruded at $(a) 175^{\circ} \mathrm{C},(b)$ $300{ }^{\circ} \mathrm{C}$, and $(c) 400{ }^{\circ} \mathrm{C}$ at $0.1 \mathrm{~mm} \mathrm{~s}^{-1}$ ram speed, and at $(d) 400{ }^{\circ} \mathrm{C}$ with ram speed of $3 \mathrm{~mm} \mathrm{~s}^{-1}$. (e-h) HAADF-STEM image and EDXS maps showing grain boundaries and the distribution of $\mathrm{Zn}, \mathrm{Al}$, and $\mathrm{Mn}$ in $\mathrm{AZ} 31$ (e-h) extruded at $175^{\circ} \mathrm{C}$ at $0.1 \mathrm{~mm} \mathrm{~s}^{-1}$ ram speed. Adapted from Ref. [169].

difference between the two materials is the apparent presence of $\mathrm{Zn}$ segregation in grain boundaries in AZ31. It was proposed ${ }^{[69]}$ that the $\mathrm{Zn}$ segregation, together with the presence of Al-Mn dispersoids, in grain boundaries suppressed the inter-granular deformation that operated in pure $\mathrm{Mg}$, switching the dominant deformation mode from grain boundary sliding to intra-granular twinning and slip. Strain-rate sensitivity tests of the sub-micron AZ31 revealed a much smaller sensitivity $(\sim 0.014)$ than that of ultrafine-grained pure $\mathrm{Mg}(\sim 0.2)$, Figure 39(b), further supporting the operation of intra-granular deformation modes in the AZ31.

Ultra-high strength has been obtained in extruded alloys based on the Mg-Al-Ca-Mn system. ${ }^{[170-172]}$ After extrusion at $350{ }^{\circ} \mathrm{C}$ and $20: 1$ ratio and a low ram speed, $0.1 \mathrm{~mm} \mathrm{~s}^{-1}$, the microstructure of $\mathrm{Mg}-3.5 \mathrm{Al}-3.3-$ $\mathrm{Ca}-0.4 \mathrm{Mn}$ (wt pet) alloy had mixed distribution of dynamic recrystallized grains of $\sim 1 \mu \mathrm{m}$, elongated strips of deformed grains, intermetallic particles of $\sim 0.5 \mu \mathrm{m}$, and nano-scale precipitates. ${ }^{[170]}$ The recrystallized grains occupied about $\sim 68$ pct of the microstructure. The microstructure had a strong basal texture, with the $c$-axes of most grains lying perpendicular to the extrusion direction and the $\langle 10 \overline{10}\rangle$ axes lying close to the extrusion direction. Under the condition of tensile testing at room temperature and at $10^{-3} \mathrm{~s}^{-1}$ strain rate, the alloy exhibited a 0.2 pct proof stress of $410 \mathrm{MPa}$ and an elongation to failure of 5.6 pct. ${ }^{[170]}$
The extrusion limit of wrought magnesium alloys is influenced strongly by the alloy composition. ${ }^{[173,174]}$ For alloys such as AZ31, the maximum extrusion (die exit) speed is typically less than $20 \mathrm{~m} \mathrm{~min}^{-1}$. A trend of the extrusion alloy development is to reduce the total content of alloying additions in the alloy ${ }^{[175]}$ to increase the extrusion speed and therefore reduce the processing cost. A recent study ${ }^{[176]}$ reported that $\mathrm{Mg}-1.3 \mathrm{Al}-0.3-$ $\mathrm{Ca}-0.4 \mathrm{Mn}$ (wt pet) alloy could be extruded at a die-exit speed of $24 \mathrm{~m} \mathrm{~min}^{-1}$, which is comparable to those of aluminum extrusions. A more recent study ${ }^{[177]}$ indicated that the extrudability of the $\mathrm{Mg}-\mathrm{Al}-\mathrm{Ca}-\mathrm{Mn}$ alloys could be further increased, from 24 to $60 \mathrm{~m} \mathrm{~min}^{-1}$ by reducing the $\mathrm{Ca}$ content from $0.33 \mathrm{wt}$ pct to $0.24 \mathrm{wt}$ pct. Four alloys, namely Mg-1.08Al-0.24Ca (AX102), Mg-1.08Al$0.24 \mathrm{Ca}-0.27 \mathrm{Mn}$ (AXM10203), Mg-1.08Al-0.24$\mathrm{Ca}-0.68 \mathrm{Mn}$ (AXM10207), and Mg-1.08Al-0.24Ca-1.03Mn (AXM1021), all in weight percentage, were indirectly extruded at $350{ }^{\circ} \mathrm{C}$ with an extrusion ratio of $20: 1$ and a die-exit speed of $60 \mathrm{~m} \mathrm{~min}^{-1} \cdot{ }^{[177]}$ The extrudate was solution treatment at $500{ }^{\circ} \mathrm{C}$ for 10 minutes, followed by water quenching and peak aging at $170{ }^{\circ} \mathrm{C}$. These alloys had an average grain size of $\sim 77$, 18,12 , and $10 \mu \mathrm{m}$, respectively. They had a relatively weak $\langle 10 \overline{1} 0\rangle-\langle 2 \overline{1} \overline{1} 0\rangle / /$ ED basal texture, Figure 40(a). The engineering stress-strain curves of these alloys, obtained under tension and compression at room temperature, are provided in Figure 40(b) through (e). 


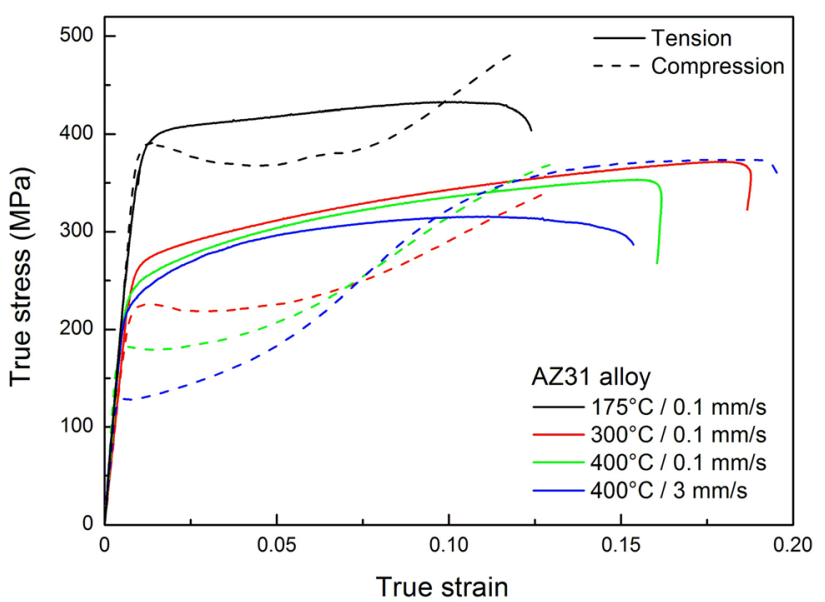

(a)

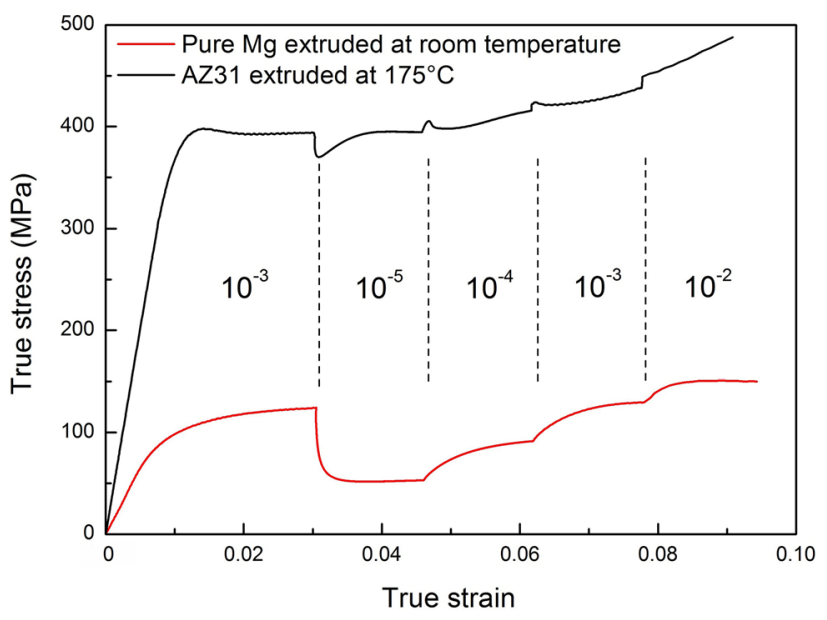

(b)

Fig. 39-(a) Room temperature tensile and compressive true stress-strain curves of AZ31 extruded under different conditions. (b) Room temperature true stress-strain curves showing strain-rate jump tests of AZ31 specimen extruded at $175^{\circ} \mathrm{C}$ and pure $\mathrm{Mg}$ specimen extruded at room temperature, compressed at different strain rates in the range $10^{-5}$ to $10^{-2} \mathrm{~s}^{-1}$. Adapted from Ref. [169].

Irrespective of alloy compositions and the post-extrusion heat treatment conditions, all of these alloys exhibited apparent tension-compression yield asymmetry. The tensile and compressive properties of these alloys, and of other Mg-Al-based extrusion alloys, are provided in Table III. ${ }^{[169,170,176-192]}$

\section{B. Mg-Zn-Based Alloys}

\section{Polycrystalline plates and sheets}

a. Microstructures of rolled plates and sheets Figure 41 shows microstructures of Mg-1.06 wt pet Zn alloy after 23 pct cold rolling and annealing of different times at $350{ }^{\circ} \mathrm{C}$. In the cold-rolled condition, the alloy had a strong basal texture, $\langle 10 \overline{1} 0\rangle \sim / / \mathrm{RD}$, with a texture intensity of about 10.5 MRD. The strong basal texture was caused predominantly by the formation and growth of $\{10 \overline{1} 2\}$ extension twins whose $c$-axes are nearly
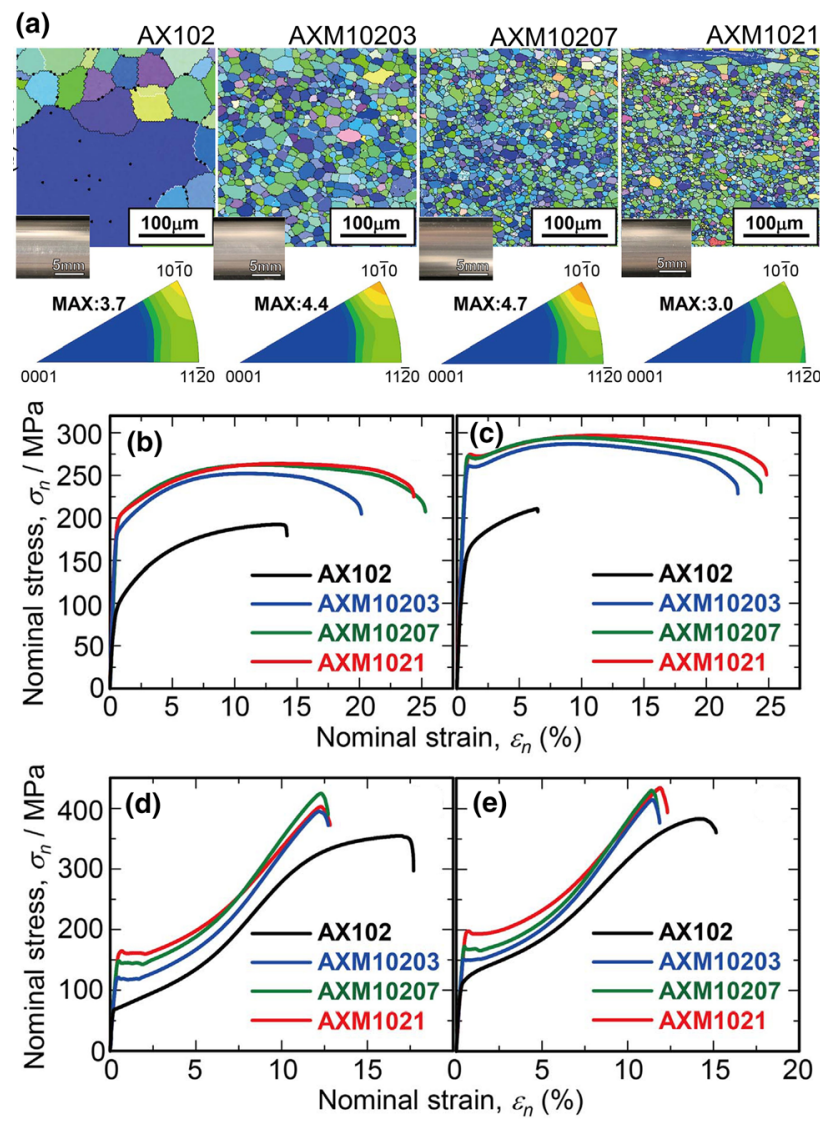

Fig. 40 - (a) EBSD orientation maps and corresponding inverse pole figures of extruded and solution-treated alloys AX102, AXM10203, AXM10207, and AXM1021, taken from the cross section perpendicular to the extrusion direction. Tensile stress-strain curves of (b) solution-treated and (c) peak-aged AX102, AXM10203, AXM10207, and AXM1021 and compressive stress-strain curves of (d) solution-treated and (e) peak-aged AX102, AXM10203, AXM10207, and AXM1021. Adapted from Ref. [177].

parallel to the sheet normal direction. Observations made on the same alloy but with 6 pct cold work indicated that about 36 pct of the sample surface had already been occupied by $\{10 \overline{1} 2\}$ twins. $\{10 \overline{1} 1\}$ twins and secondary twins were not detected, but a large fraction of shear bands was noticed in the cold-rolled microstructure. Rapid recrystallization and basal texture weakening occurred simultaneously during annealing at $350^{\circ} \mathrm{C}$. After 5 seconds, about 79 pct area fraction had recrystallized. The basal texture intensity now decreased to about 6.1 MRD, and the $\langle 11 \overline{2} 0\rangle / / \mathrm{RD}$ texture component had formed even though its intensity was weak. The recrystallized grains occupied $\sim 94$ pct of the microstructure after 100 seconds, and fully replaced the deformed grains after 900 seconds. There was little further weakening of the basal texture after 100 seconds, but the intensity of the $\langle 11 \overline{2} 0\rangle / /$ RD texture component became slightly stronger with annealing time.

Ternary additions of alkaline earth elements such as $\mathrm{Ca}$ and Sr lead to a weakened basal texture. ${ }^{[193-195]}$ The effect of a small amount of $\mathrm{Ca}$ on microstructure and its evolution is also shown in Figure 41. [193] For the purpose of comparison, the ternary alloy, 
Mg-0.8Zn-0.16Ca (wt pct), was produced under similar processing conditions. ${ }^{[193]}$ In the cold-rolled condition, there were less shear bands than the Mg-1.06wt pct $\mathrm{Zn}$ alloy. However, the alloy still had a basal texture, with its intensity of about 6.9 MRD, Figure 41(e), which is much lower than that of the counterpart binary alloy. The $\langle 10 \overline{1} 0\rangle / /$ RD texture component was also smaller than that in the counterpart binary alloy, and some grains with directions other than $\langle 10 \overline{1} 0\rangle$ were now parallel to the rolling direction. There was little change in the texture intensity after 20 seconds of annealing at $350{ }^{\circ} \mathrm{C}$, Figure $41(\mathrm{f})$. The area fraction of recrystallized grains was about 8 pct at this time, increased to about 77 pct after 100 seconds, and the recrystallization completed at 900 seconds. The basal texture was significantly weakened after 100 seconds and it changed little during prolonged annealing, Figures $41(\mathrm{~g})$ and $(\mathrm{h})$. At 900 seconds, the basal poles split away from the ND towards the TD in the pole figure, leading to a TD-split texture that is also associated with sheets of some $\mathrm{Mg}-\mathrm{Zn}-\mathrm{RE}$ alloys.

Figure 42 shows the texture evolution of the recrystallized grains that had formed inside shear bands in the $\mathrm{Mg}-0.8 \mathrm{Zn}-0.16 \mathrm{Ca}$ alloy during annealing at $350{ }^{\circ} \mathrm{C}$. After 14 seconds, some recrystallized grains had formed and their texture was similar to that of the deformed grains. With continued annealing, new recrystallized grains continued to form in this region and the recrystallized grains grew to larger size. More randomized orientations, hence a weakened basal texture, were observed after 115 seconds. These grains formed outside the shear bands and had grown into the neighboring deformed grains. The $c$-axes of these grains were tilted away from the ND. It is the formation and growth of such recrystallized grains that leads to a weakened texture after recrystallization. Solute segregation to boundaries of the recrystallized grains occurred and persisted through the annealing process. It was hypothesized $^{[193]}$ that $\mathrm{Zn}$ and $\mathrm{Ca}$ atoms co-segregated strongly to high-energy boundaries of the recrystallized grains that would otherwise grow preferentially. The co-segregation to such grain boundaries is expected to reduce, more effectively than that from sole segregation of $\mathrm{Zn}$ or $\mathrm{Ca}$, their mobility by reducing the boundary energy and exerting a solute dragging effect, which in turn lead to a more uniform growth of the recrystallized grains.

An alloy with a Mg- $0.8 \mathrm{Zn}-0.16 \mathrm{Ca}$ composition would be normally regarded as a solid solution single-phase alloy and thus it would not be expected to exhibit any hardening response during isothermal aging in the temperature range 80 to $200{ }^{\circ} \mathrm{C}$. However, annealing of the cold deformed sheet of this alloy led to a remarkable strengthening, rather than softening, effect in a wide range of deformation and annealing conditions. ${ }^{[196]}$ This observation has an implication to alloy design, as the alloy could be formed relatively easily in a cold state and become stronger after an appropriate post-forming aging treatment.

Ternary additions of $\mathrm{Mn}$ or $\mathrm{Zr}$ to $\mathrm{Mg}$ - $\mathrm{Zn}$ alloys do not change the sheet texture. ${ }^{[197]}$ However, additions of $\mathrm{RE}$ elements to $\mathrm{Mg}-\mathrm{Zn}$ alloys can lead to a remarkable change in microstructure. ${ }^{[197-205]}$ Comparison of basal textures of hot-rolled and annealed sheets of ZE10, ZEK100, ZEK410, and ZW41 alloys ${ }^{[197]}$ indicated the presence of similar features: their intensities were all weak; the $c$-axes were tilted by large angles from the ND towards the TD, forming a TD-split basal texture; and $\langle 10 \overline{1} 0\rangle$ axes tended to lie close to the sheet plane, instead of lying perpendicularly to the sheet plane as in binary $\mathrm{Mg}-\mathrm{Zn}$ and AZ31 alloys. Tensile properties and Lankford $r$ values of sheets of these alloys are provided in Table IV. ${ }^{[149,150,154,160,206-210]}$

Under similar processing conditions, sheets of $\mathrm{Mg}-1 \mathrm{Zn}-1 \mathrm{Ce}-0.6 \mathrm{Zr}$ and $\mathrm{Mg}-1 \mathrm{Zn}-1 \mathrm{Gd}-0.6 \mathrm{Zr}$ (wt pet) alloys have textures similar to those of $\mathrm{Mg}-1 \mathrm{Ce}$ and $\mathrm{Mg}-1 \mathrm{Gd}$ alloys, ${ }^{[204]}$ as will be shown in the following sub-section on Mg-RE alloys. In the as-hot-rolled condition, the RD-ND plane of the Mg- $1 \mathrm{Zn}-1 \mathrm{Ce}-0.6 \mathrm{Zr}$ and $\mathrm{Mg}-1 \mathrm{Zn}-1 \mathrm{Gd}-0.6 \mathrm{Zr}$ sheets showed a high density of shear bands, resulting from a severe plastic deformation imposed by the 80 pct thickness reduction in a single pass. ${ }^{[24]}$ Both sheets had a weakened basal texture. The basal poles split into two intensity maxima, with each intensity maxima being tilted by $\sim 20$ deg away from the sheet ND towards the RD. The basal texture of the hot-rolled $\mathrm{Mg}-1 \mathrm{Zn}-1 \mathrm{Ce}-0.6 \mathrm{Zr}$ sheet became even weaker after annealing at $350{ }^{\circ} \mathrm{C}$ and above. The original $\mathrm{RD}$-split basal texture in the hot-rolled sheets was replaced by a TD-split basal texture that had a weaker intensity. The room temperature tensile properties of these two alloys were much better than their counterpart $\mathrm{Mg}-1 \mathrm{Ce}$ and $\mathrm{Mg}-1 \mathrm{Gd}$ alloys.

The effect of cold rolling of hot-rolled ZEK100 $(\mathrm{Mg}-1.3 \mathrm{Zn}-0.2 \mathrm{Nd}-0.3 \mathrm{Zr}$, wt pct), and subsequent annealing, on texture and its evolution was examined in a recent study made by Griffiths and co-workers. ${ }^{[205]}$ The cold rolling was made following three different strain paths, as an attempt to changing dislocation and shear band activities. The initial hot-rolled microstructure was largely recrystallized, and it contained grains with an average size of $\sim 12 \mu \mathrm{m}$. The texture had the characteristic TD-split basal texture of ZEK100, forming two intensity maxima that split by $30^{\circ}$ from the ND towards the TD. It was found ${ }^{[205]}$ that cold rolling either parallel or perpendicular to the hot rolling direction led to distinct shear banding, but continuous rotating of the sheet between cold rolling passes suppressed the shear band formation. With the absence of shear bands, the TD-split texture was not produced upon annealing for full recrystallization. It was suggested ${ }^{[25]}$ that it was the strain path, rather than the dislocation activity, that determined shear band evolution and the formation of the TD-split basal texture.

b. Rollability and formability of rolled sheets Some attempts have been made to increase the plate thickness reduction per pass by changing the rolling speed. ${ }^{[211-215]}$ This is because a larger thickness reduction per pass and/or a higher rolling speed can reduce the processing cost. This approach is worth exploring especially when a lower-cost sheet is made without sacrificing useful formability and mechanical properties. A recent 
Table III. Texture, Grain Size, Tensile, and Compressive Properties at Room Temperature of Mg-Al-Based Extrusions of Different Alloy Compositions and Produced under Different Processing Conditions

\begin{tabular}{|c|c|c|c|c|c|c|c|c|c|c|}
\hline \multirow[b]{2}{*}{ Alloy (Wt Pct) } & \multicolumn{4}{|c|}{ Processing Condition } & \multicolumn{2}{|c|}{ Microstructure } & \multicolumn{3}{|c|}{ Properties* } & \multirow[b]{2}{*}{ References } \\
\hline & Ratio & $\begin{array}{c}\text { Speed } \\
\left(\mathrm{mm} \mathrm{s}^{-1}\right)\end{array}$ & $\begin{array}{l}\text { Temp. } \\
\left({ }^{\circ} \mathrm{C}\right)\end{array}$ & Remark & $\begin{array}{c}\text { Texture and } \\
\text { Intensity (MRD) }\end{array}$ & $\begin{array}{c}\mathrm{GS} \\
(\mu \mathrm{m})\end{array}$ & $\begin{array}{l}\text { El. } \\
(\mathrm{Pct})\end{array}$ & $\begin{array}{c}\text { TYS } \\
(\mathrm{MPa})\end{array}$ & $\begin{array}{l}\text { CYS } \\
(\mathrm{MPa})\end{array}$ & \\
\hline $\mathrm{Mg}-3 \mathrm{Al}$ & 16.4 & 1.8 & 350 & Tube, T4 & $\langle 10 \overline{1} 0\rangle$ & 16 & 17 & 105 & 52 & {$[178]$} \\
\hline AM11 & 23 & - & 300 & & $\langle 10 \overline{1} 0\rangle 8.5$ & 8 & 7 & 216 & 186 & [179] \\
\hline AM21 & 23 & $一$ & 300 & & $\langle 10 \overline{1} 0\rangle 6.7$ & 4 & 10 & 204 & 180 & \\
\hline AM31 & 23 & - & 300 & & $\langle 10 \overline{1} 0\rangle 5.3$ & 7 & 13 & 197 & 175 & \\
\hline AM41 & 23 & - & 300 & & $\langle 10 \overline{1} 0\rangle 3.0$ & 6 & 14 & 185 & 170 & \\
\hline \multirow[t]{2}{*}{ AM11 } & 30 & 0.5 & 300 & $\mathrm{~F}$ & $\langle 10 \overline{1} 0\rangle 11.6$ & 10 & 19 & 224 & 161 & {$[180]$} \\
\hline & 30 & 5.5 & 300 & & $\langle 11 \overline{2} 0\rangle 10.5$ & 65 & 9 & 214 & 72 & \\
\hline \multirow[t]{2}{*}{ AM81 } & 30 & 0.5 & 300 & & $\langle 10 \overline{1} 0\rangle-\langle 11 \overline{2} 0\rangle 2.9$ & 9 & 20 & 182 & 145 & \\
\hline & 30 & 5.5 & 300 & & $\langle 10 \overline{1} 0\rangle-\langle 11 \overline{2} 0\rangle 3.3$ & 11 & 13 & 164 & 137 & \\
\hline \multirow[t]{4}{*}{ AZ31 } & 19 & 0.1 & 175 & $\mathrm{~F}$ & $\langle 10 \overline{1} 0\rangle 4.7$ & 0.7 & 13 & 380 & 380 & [169] \\
\hline & 19 & 0.1 & 300 & & $\langle 10 \overline{1} 0\rangle 3.6$ & 3 & 19 & 242 & 200 & \\
\hline & 19 & 0.1 & 300 & & $\langle 10 \overline{1} 0\rangle 3.2$ & 5 & 16 & 218 & 165 & \\
\hline & 19 & 0.3 & 400 & & $\langle 10 \overline{1} 0\rangle 5.3$ & 14 & 12 & 195 & 123 & \\
\hline AZ31 & 25 & - & 380 & $\mathrm{~F}$ & $\langle 10 \overline{1} 0\rangle 13.1$ & 4 & 10 & 271 & 195 & {$[181]$} \\
\hline \multirow[t]{4}{*}{ AZ31 } & 25 & 6 & 225 & F, WQ & $\langle 10 \overline{1} 0\rangle 6.6$ & - & 18 & 270 & 255 & {$[182]$} \\
\hline & 25 & 6 & 250 & F, WQ & $\langle 10 \overline{1} 0\rangle 6.6$ & - & 23 & 280 & 250 & \\
\hline & 25 & 6 & 300 & $\mathrm{~F}, \mathrm{WQ}$ & $\langle 10 \overline{1} 0\rangle 5.6$ & - & 21 & 275 & 240 & \\
\hline & 25 & 6 & 300 & $\mathrm{~F}, \mathrm{AC}$ & $\langle 10 \overline{1} 0\rangle 4.9$ & - & 20 & 230 & 175 & \\
\hline AZ31 & 20 & 1 & 350 & $\mathrm{~F}$ & $\langle 10 \overline{1} 0\rangle-\langle 11 \overline{2} 0\rangle 3.0$ & 16 & 26 & 154 & 105 & {$[183]$} \\
\hline \multirow[t]{2}{*}{ AZ31 } & 17.7 & 1.9 & 282 & $\mathrm{~F}$ & $\langle 10 \overline{1} 0\rangle$ & - & - & 171 & 133 & {$[184]$} \\
\hline & & & & $\mathrm{T} 4$ & $\langle 11 \overline{2} 0\rangle$ & 25 & - & 150 & 107 & \\
\hline AZ31 & - & - & - & $\mathrm{F}$ & $\langle 10 \overline{1} 0\rangle 12$ & 50 & 13 & 200 & 125 & {$[185]$} \\
\hline AZ31 & 25 & - & 500 & $\mathrm{~F}$ & $\langle 10 \overline{1} 0\rangle 13$ & 71 & 11 & 250 & 90 & [186] \\
\hline AZ31 & - & - & - & $\mathrm{F}$ & $\langle 10 \overline{1} 0\rangle 4.3$ & 14.5 & 14.8 & 172 & 89 & {$[187]$} \\
\hline AZ31 & - & - & - & $\mathrm{F}$ & $\langle 10 \overline{1} 0\rangle 5$ & 22 & 13 & 210 & 90 & [188] \\
\hline AZ61 & 10.5 & - & 400 & $\mathrm{~F}$ & $\langle 10 \overline{1} 0\rangle 5$ & 30 & 19 & 207 & 120 & [189] \\
\hline AZ62 & 25 & 1 & 250 & $\mathrm{~F}$ & $\langle 10 \overline{1} 0\rangle 3.2$ & 8 & 27 & 172 & 148 & [190] \\
\hline AZ80 & 20 & 0.07 & 300 & $\mathrm{~F}$ & $\langle 10 \overline{1} 0\rangle 5.1$ & 0.4 & 11 & 403 & 390 & [191] \\
\hline \multirow[t]{2}{*}{$\mathrm{Mg}-1.1 \mathrm{Al}-0.2 \mathrm{Ca}$} & 20 & 50 & 350 & $\mathrm{~T} 4$ & $\langle 10 \overline{1} 0\rangle 3.7$ & 77 & 12 & 95 & 70 & {$[177]$} \\
\hline & & & & T6 & - & - & 6 & 157 & 109 & \\
\hline \multirow[t]{2}{*}{$\mathrm{Mg}-1.1 \mathrm{Al}-0.2 \mathrm{Ca}-1 \mathrm{Mn}$} & & & & $\mathrm{T} 4$ & $\langle 10 \overline{1} 0\rangle 3.0$ & 10 & 23 & 195 & 164 & \\
\hline & & & & $\mathrm{T} 6$ & - & - & 24 & 263 & 197 & \\
\hline \multirow[t]{2}{*}{$\mathrm{Mg}-0.3 \mathrm{Al}-0.3 \mathrm{Ca}-0.4 \mathrm{Mn}$} & 20 & 20 & 275 & $\mathrm{~T} 4$ & $\langle 10 \overline{1} 0\rangle 2.5$ & 10 & 29 & 159 & 119 & {$[176]$} \\
\hline & & & & $\mathrm{T} 6$ & - & - & 26 & 230 & 165 & \\
\hline \multirow[t]{2}{*}{$\mathrm{Mg}-1.3 \mathrm{Al}-0.3 \mathrm{Ca}-0.5 \mathrm{Mn}$} & & & & $\mathrm{T} 4$ & $\langle 10 \overline{1} 0\rangle 4.7$ & 17 & 18 & 187 & 138 & \\
\hline & & & & $\mathrm{T} 6$ & - & - & 20 & 287 & 194 & \\
\hline \multirow[t]{2}{*}{$\mathrm{Mg}-2.7 \mathrm{Al}-0.3 \mathrm{Ca}-0.4 \mathrm{Mn}$} & & & & $\mathrm{T} 4$ & $\langle 10 \overline{1} 0\rangle 4.1$ & 18 & 18 & 188 & 121 & \\
\hline & & & & T6 & - & - & 18 & 240 & 149 & \\
\hline $\mathrm{Mg}-3.6 \mathrm{Al}-3.4 \mathrm{Ca}-0.3 \mathrm{Mn}$ & 20 & 0.1 & 350 & $\mathrm{~F}$ & $\langle 10 \overline{1} 0\rangle$ & - & 5.6 & 410 & 350 & {$[170]$} \\
\hline $\mathrm{Mg}-4 \mathrm{Al}-3 \mathrm{Ca}-0.3 \mathrm{Mn}$ & 20 & 0.1 & 350 & $\mathrm{~F}$ & $\langle 10 \overline{1} 0\rangle 15.1$ & - & 8 & 331 & 285 & [192] \\
\hline Mg-3Al-0.2Ce & 16.4 & 1.8 & 350 & Tube, T4 & $\langle 10 \overline{1} 0\rangle$ & 18 & 17 & 120 & 60 & {$[178]$} \\
\hline $\mathrm{Mg}-3 \mathrm{Al}-0.5 \mathrm{Ce}$ & & & & & $\langle 10 \overline{1} 0\rangle$ & 23 & 18 & 130 & 66 & \\
\hline
\end{tabular}

\footnotetext{
Data from Refs. [169, 170, 176-192]

-Information not provided. *Along the extrusion direction. WQ: water quench, AC: air cooling, GS: grain size, El: elongation, TYS: tensile yield strength, CYS: compression yield strength.
}

study $^{[211]}$ of commercial alloys ZEK100 $(\mathrm{Mg}-1 \mathrm{Zn}-0.2 \mathrm{Nd}-0.2 \mathrm{Zr}$, wt pet) and AZ31 indicated that an increase in rolling speed from 2 to $15 \mathrm{~m} \mathrm{~min}^{-1}$ allowed the use of a significantly enlarged thickness reduction in a single pass, Figure 43. Microstructures of the sheets prior to hot rolling contained coarse grains $(\sim 138 \mu \mathrm{m})$ in ZEK100 and fine grains $(\sim 5 \mu \mathrm{m})$ in AZ31. The ZEK100 alloy had a weaker basal texture than the AZ31. The rollability of the sheets was assessed by their appearance after rolling. For the ZEK100 alloy sheets 


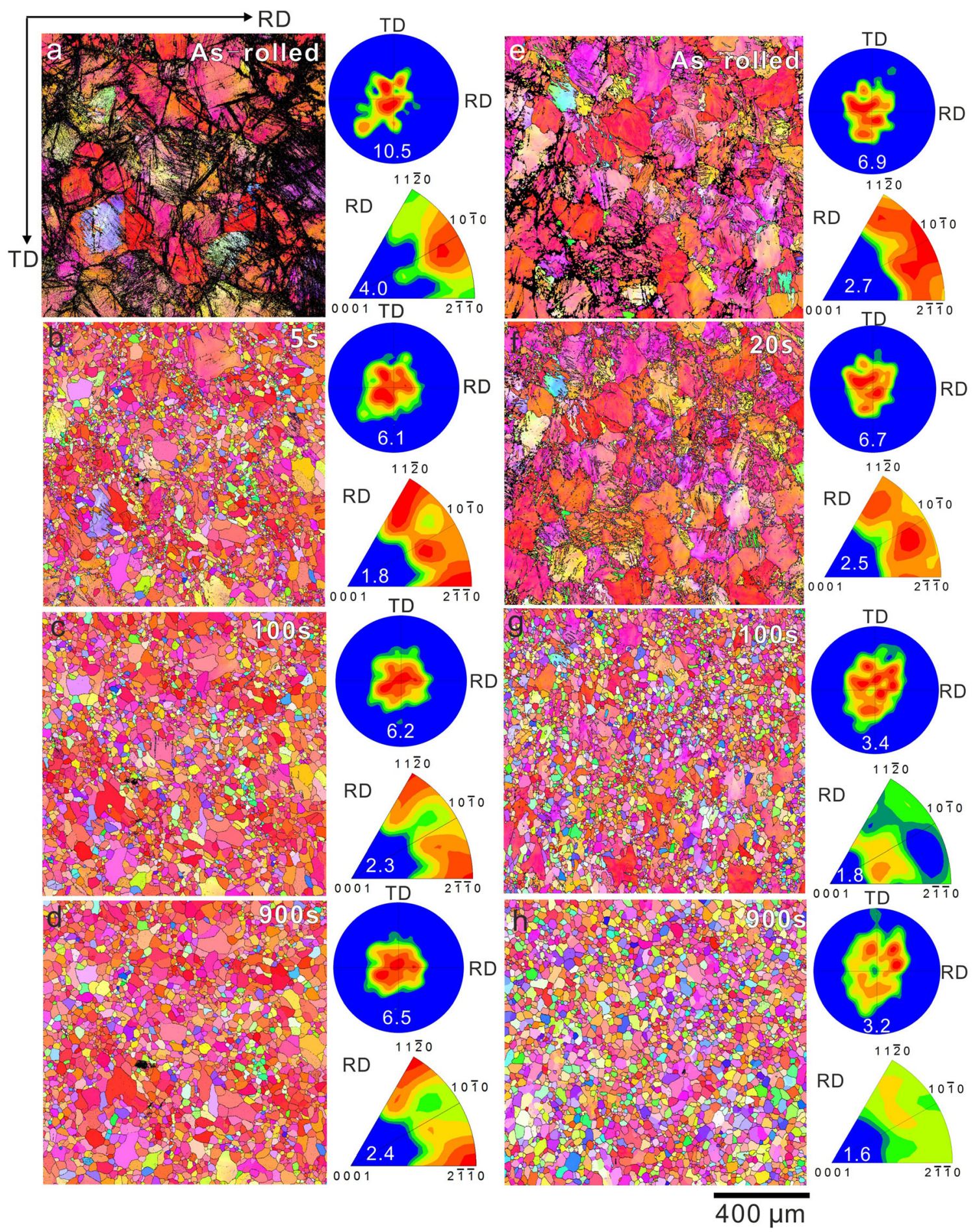

Fig. 41-Quasi-in-situ EBSD orientation maps and corresponding basal pole figures and inverse pole figures along the rolling direction showing microstructural evolution in $(a-d) \mathrm{Mg}-1.06 \mathrm{Zn}$ and $(e-h) \mathrm{Mg}-0.8 \mathrm{Zn}-0.16 \mathrm{Ca}$ (wt pct) alloy sheets cold-rolled by 23 pct thickness reduction followed by annealing at $350{ }^{\circ} \mathrm{C}$ until full recrystallization. Adapted from Ref. [193].

rolled under the same thickness reduction, severe cracking occurred at $\sim 70$ pct thickness reduction for the low-speed rolling, while the fast-rolled specimen only had some small edge cracks. The AZ31 sheets exhibited a similar trend in which the rollability increased with increasing rolling speed, edge cracking occurred at $\sim 65$ pct thickness reduction under the fast rolling, but fracture took place at a smaller thickness reduction $(\sim 40$ pct $)$ under the slow rolling.

Other studies ${ }^{[212,213]}$ reported that 80 pct thickness reduction in a single pass was possible for alloys containing much higher concentrations of $\mathrm{Zn}$, e.g., 


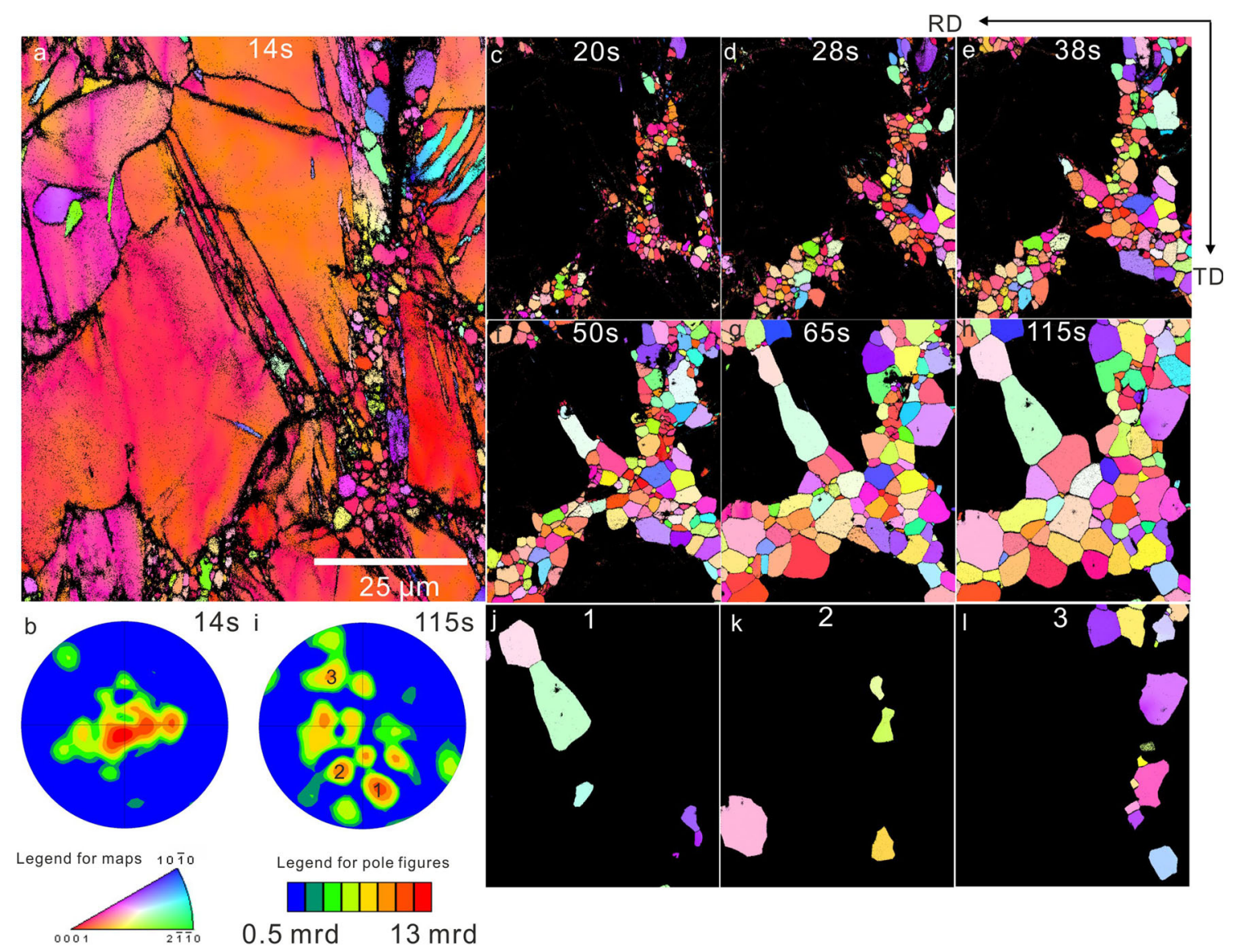

Fig. 42-Quasi-in-situ EBSD orientation maps showing microstructure and texture evolution in shear bands in cold-rolled (23 pct thickness reduction) $\mathrm{Mg}-0.8 \mathrm{Zn}-0.16 \mathrm{Ca}$ (wt pct) alloy during annealing at $350{ }^{\circ} \mathrm{C}$ for $(a, b) 14,(c) 20,(d) 28,(e) 38,(f) 50,(g) 65$, and $(h, i) 115$ seconds $(b$, i) (0002) pole figures showing textures of recrystallized grains in maps (a) and (g). Grains corresponding to the texture components, labeled 1-3 in (i), are shown in maps $(j-l)$. Reprinted from Ref. [193].

ZK60, when a rolling speed of $26 \mathrm{~m} \mathrm{~min}^{-1}$ was used for rolling at temperatures 250 to $400^{\circ} \mathrm{C}$. However, the resultant sheets had an incomplete DRX microstructure and relatively coarse recrystallized grains, and consequently their mechanical properties were not desirable. A separate study ${ }^{[214]}$ indicated that the use of an even higher rolling speed, in the range 450 to $2000 \mathrm{~m} \mathrm{~min}^{-1}$, could lead to a remarkable improvement of the rollability of AZ31. With this ultra-high-speed rolling, the maximum thickness reduction per pass could be increased up to 60 pct without any surface cracks, even when rolling was done at relatively low temperatures $\left(200-350{ }^{\circ} \mathrm{C}\right) .{ }^{[215]}$ While this technology gives rise to much better rollability, the ultra-fast speed involved makes it challenging for industrial applications.

The room temperature formability of $\mathrm{Mg}-\mathrm{Zn}-\mathrm{Ca}$ and $\mathrm{Mg}-\mathrm{Zn}-\mathrm{RE}$ alloy sheets has been evaluated by Erichsen tests. After hot extrusion at $400{ }^{\circ} \mathrm{C}$, hot rolling at $500{ }^{\circ} \mathrm{C}$, and annealing at $350{ }^{\circ} \mathrm{C}, \mathrm{Mg}-1.52 \mathrm{Zn}-0.07 \mathrm{Ca}$ and $\mathrm{Mg}-1.5 \mathrm{Zn}-0.2 \mathrm{Y}$ (wt pet) alloy sheets have an Erichsen value of $8.2^{[216]}$ and $9.2^{[217]}$ respectively, and $\mathrm{Mg}-1.5 \mathrm{Zn}-0.2 \mathrm{Ce}$ alloy has a deep drawing ratio of $1.8,{ }^{[217]}$ which is compatible with that of commercial $\mathrm{Al}$ alloys. While the excellent formability is attributable to the formation of the TD-split basal texture, it remains to be fully evaluated whether the excellent formability is also related with the hot extrusion adopted before the hot rolling. The total content of the alloying additions in these alloys is controlled to be relatively low, compared with that in AZ31 ( 4 wt pct), in order to avoid the formation of second-phase particles that can deteriorate the stretch formability.

\section{Polycrystalline extrusions}

Extrusion experiments on $\mathrm{Mg}-1.5 \mathrm{Zn}-0.2 \mathrm{Ce}$ (wt pct) alloy at different temperatures, 300 and $430{ }^{\circ} \mathrm{C}$, indicated that the texture of this alloy was strongly influenced by the extrusion temperature. ${ }^{[218]}$ Chino and co-workers found ${ }^{[218]}$ that the $\langle 10 \overline{1} 0\rangle / /$ ED texture component formed at both temperatures and dominated the microstructure. A RE-texture component, with the axes parallel to the ED lying $\sim 20$ deg away from $\langle 2 \overline{1} \overline{1} 0\rangle$ towards [0001], formed only when the alloy was extruded at $430{ }^{\circ} \mathrm{C}$. Subsequent annealing at $350{ }^{\circ} \mathrm{C}$ for 1.5 hour weakened the textures, changing the $\langle 10 \overline{1} 0\rangle$ $/ /$ ED texture component in the specimen extruded at $300{ }^{\circ} \mathrm{C}$ to $\langle 2 \overline{1} \overline{1} 0\rangle / / \mathrm{ED}$, and the basal poles in the original texture in the sample extruded at $430{ }^{\circ} \mathrm{C}$ spread more towards [0001]. While they suggested that the use 
of an extrusion temperature above $430{ }^{\circ} \mathrm{C}$ was essential for the formation of the RE-texture component, this suggestion will no doubt be affected by the extrusion ratio which was not provided in that study. ${ }^{[218]}$

The possibility for fast extrusion has been explored recently of alloys based on the $\mathrm{Mg}-\mathrm{Zn}-\mathrm{Ca}-\mathrm{Mn}$ and Mg-Zn-RE systems. ${ }^{[219,220]}$ The total content of the added alloying elements is generally low in order to reduce the flow stress of the alloy during hot extrusion and to increase the solidus temperature of the alloy to avoid hot cracking. One example is the $\mathrm{Mg}-0.53 \mathrm{Zn}-0.24 \mathrm{Ca}-0.27 \mathrm{Mn}$ (wt pct) alloy that was indirectly extruded at $300{ }^{\circ} \mathrm{C}$ with an extrusion ratio of 20:1 and die-exit speed of 6-60 $\mathrm{m} \mathrm{min}^{-1}$.219] The surface finish of this alloy looked smooth and shiny for an extrusion speed up to $24 \mathrm{~m} \mathrm{~min}^{-1}$, Figure 44(a), any speed above that led to cracking on the extrusion surface. Extrusions made with extrusion speeds in the range 6 to $60 \mathrm{~m} \mathrm{~min}^{-1}$ all had fully recrystallized microstructures, together with second-phase particles distributed linearly along the extrusion direction. The average grain size increased with increasing extrusion speed. The extrusions had weak textures. Poles lying along the extrusion direction spread in the angular region defined by $\langle 2 \overline{1} \overline{1} 4\rangle,\langle 2 \overline{1} \overline{1} 2\rangle,\langle 10 \overline{1} 2\rangle,\langle 20 \overline{2} 3\rangle$, with an intensity of 2.2-2.6, as indicated in the inverse pole figures in Figure 44(b). The intensity maxima of the poles changed within the angular region when the extrusion speed was increased. The variation of texture with the extrusion speed was also observed in extruded Mg-1.58Zn-0.52Gd (wt pct) alloy. ${ }^{[220]}$ The yield strength of the extrusion of the $\mathrm{Mg}-0.5 \mathrm{Zn}-0.24 \mathrm{Ca}-0.27 \mathrm{Mn}$ alloy decreased with increasing extrusion speed, but without any apparent loss of ductility. ${ }^{[219]}$

Textures and grain sizes, together with room temperature tensile and compressive yield strengths of representative $\mathrm{Mg}-\mathrm{Zn}$-based alloy extrusions are listed in Table V. ${ }^{[184,221-230]}$ In general, this group of extrusions exhibits apparent tension-compression yield asymmetry.

\section{Mg-RE-Based Alloys}

\section{Polycrystalline plates and sheets}

Textures of sheets produced from binary $\mathrm{Mg}-\mathrm{RE}$ alloys have been extensively studied using XRD and EBSD. ${ }^{[204,231-237]}$ These studies reported that the textures of the Mg-RE alloy sheets were similar to that of AZ31 except that their intensities were significantly weakened. The $c$-axes of most grains had broader distribution around the sheet normal direction. Figure 45 shows the (0002) pole figures of $\mathrm{Mg}-1 \mathrm{wt}$ pct $\mathrm{Ce}$ and $\mathrm{Mg}-1 \mathrm{wt}$ pct Gd alloys in the hot-rolled and the annealed conditions. ${ }^{[204,233]}$ In the as-rolled condition, there existed a weakened basal texture, the $c$-axes of most grains had a broader distribution than that seen in pure $\mathrm{Mg}$ and AZ31. The $c$-axes tended to split into two peaks, with each peak tilted by about $20 \mathrm{deg}$ away from the sheet normal direction towards the rolling direction. The Ce-containing alloy had a slightly weaker texture than the Gd-containing alloy. Since the two alloys were hot-rolled by 80 pct in a single pass, each alloy sheet contained a dense and uniform distribution of shear bands in the RD-ND plane. There was little change in texture after annealing at 250 and $300{ }^{\circ} \mathrm{C}$. Recrystallization started to occur along the shear bands at $300{ }^{\circ} \mathrm{C}$, which is about $100{ }^{\circ} \mathrm{C}$ higher than that for AZ31. The increased temperature for recrystallization was speculated $^{[233]}$ to originate from solute segregation to dislocations and in grain boundaries. Annealing at $350{ }^{\circ} \mathrm{C}$ and above led to full recrystallization and basal texture weakening. The basal texture weakening in the Gd-containing alloy was accompanied by a texture change, with the $c$-axes of grains being tilted further away from the sheet normal direction towards the rolling direction (in the range 20 to $60 \mathrm{deg}$ ). The true stress-strain curves of the sheets of these two alloys in the hot-rolled and the annealed conditions, obtained by tensile testing at room temperature and a strain rate of 5 $\times 10^{-4} \mathrm{~s}^{-1}$, are also provided in Figure 45 .

There was little change in the sheet texture when the $\mathrm{Mg}-1 \mathrm{wt}$ pet $\mathrm{Gd}$ alloy was rolled at $300{ }^{\circ} \mathrm{C}$ by multiple passes (20 pet reduction per pass) to achieve a cumulative total rolling reduction of 80 pct. ${ }^{[234]}$ The as-rolled microstructure always had a weakened basal texture with basal poles having a broader distribution and split from the normal direction towards the rolling direction. Again, the texture became much weaker after 30 minutes annealing at $400{ }^{\circ} \mathrm{C}$. The annealed microstructure had fully recrystallized grains with an average size of $18 \mu \mathrm{m}$. The majority of the recrystallized grains had their $\langle 10 \overline{1} 0\rangle$ directions scattered around the rolling direction. $^{[234]}$

Adding a larger amount of RE elements does not change the texture from that in dilute alloys, irrespective of the sheet or plate thickness. ${ }^{[238-241]} \mathrm{A}$ recent study ${ }^{[238]}$ of rolled and aged plate of WE43 (Mg-4Y-3Nd-0.5Zr; wt pct) indicated that its microstructure had fully recrystallized grains $(\sim 30 \mu \mathrm{m}$ in size $)$ that had a weakened basal texture. The $c$-axes were scattered by up to $25 \mathrm{deg}$ away from the plate normal direction towards the rolling direction. Room temperature uniaxial tension and compression tests along the rolling, normal, and transverse directions of the plate indicated an essential absence of the tension-compression yield asymmetry along these three directions of the plate.

Application of differential speed rolling (DSR) to the WE43 does not seem to change the alloy microstructure. ${ }^{[242]}$ The alloy WE43 was initially extruded into a thin plate $\left(5 \mathrm{~mm}\right.$ thick) at $450{ }^{\circ} \mathrm{C}$ and fully annealed at $500{ }^{\circ} \mathrm{C}$. The plate was rolled along the extrusion direction by four passes to $1 \mathrm{~mm}$ thick, with the billet temperature of $550{ }^{\circ} \mathrm{C}$ and the roller temperature of $300{ }^{\circ} \mathrm{C}$ and the roller speed ratio of 1.36 . The sheet microstructure had equiaxed grains of $\sim 47 \mu \mathrm{m}$ and a weakened basal texture before DSR, but elongated grains and shear bands and second-phase particles after the DSR. The basal texture was strengthened by the DSR. Subsequent annealing at $450{ }^{\circ} \mathrm{C}$ for 1 hour led to full recrystallization (grain size $\sim 18 \mu \mathrm{m}$ ) and a slightly weakened basal texture. In this condition, the WE43 sheet had a yield strength of $141 \mathrm{MPa}$ and an elongation to fracture of 22 pct and an Erichsen value of 4.4, when 


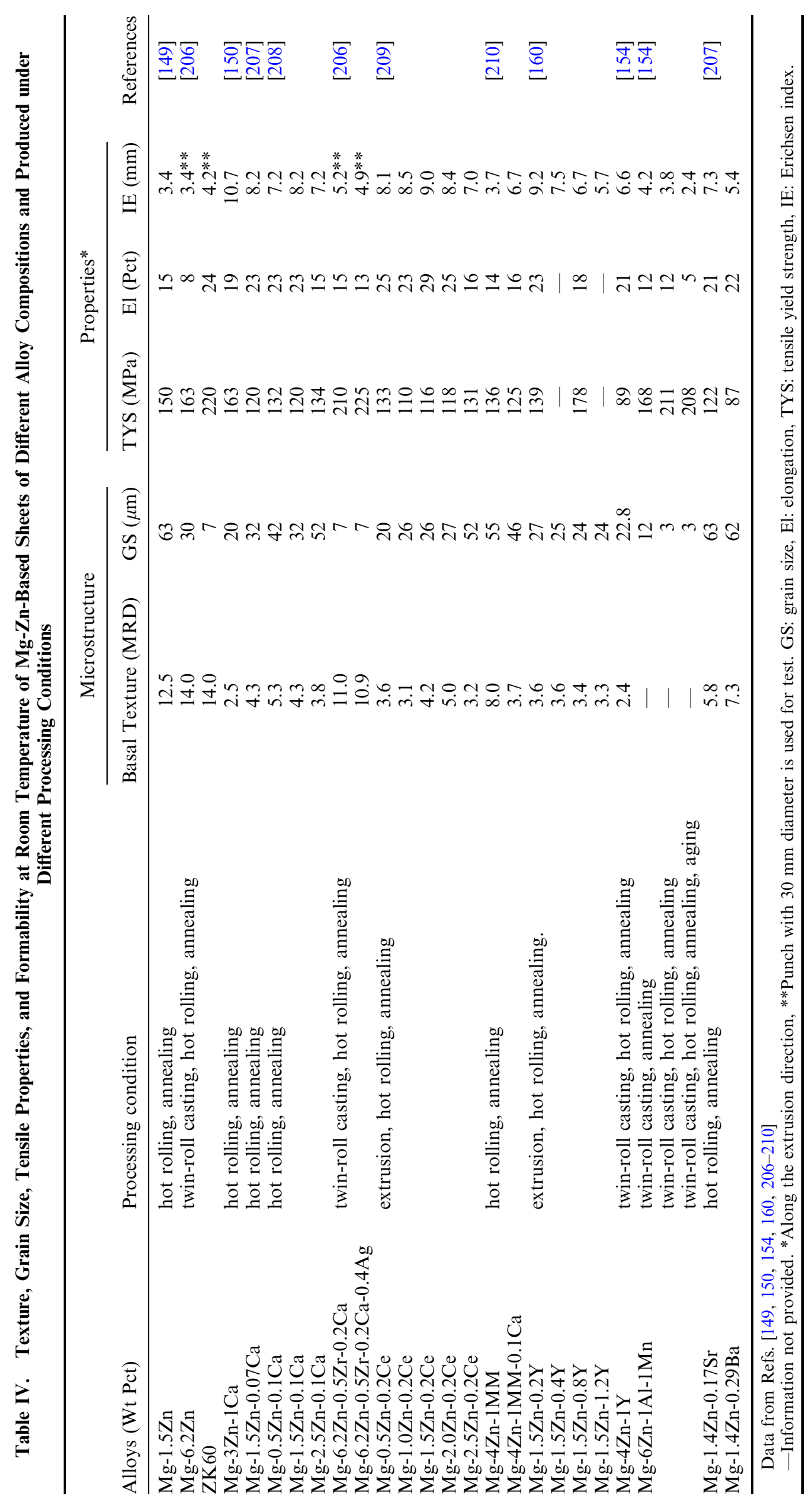


it was tested at room temperature. ${ }^{[242]}$ The difference between stress-strain curves obtained from specimens cut along the rolling direction, transverse direction, and 45 deg away from the rolling direction is subtle.

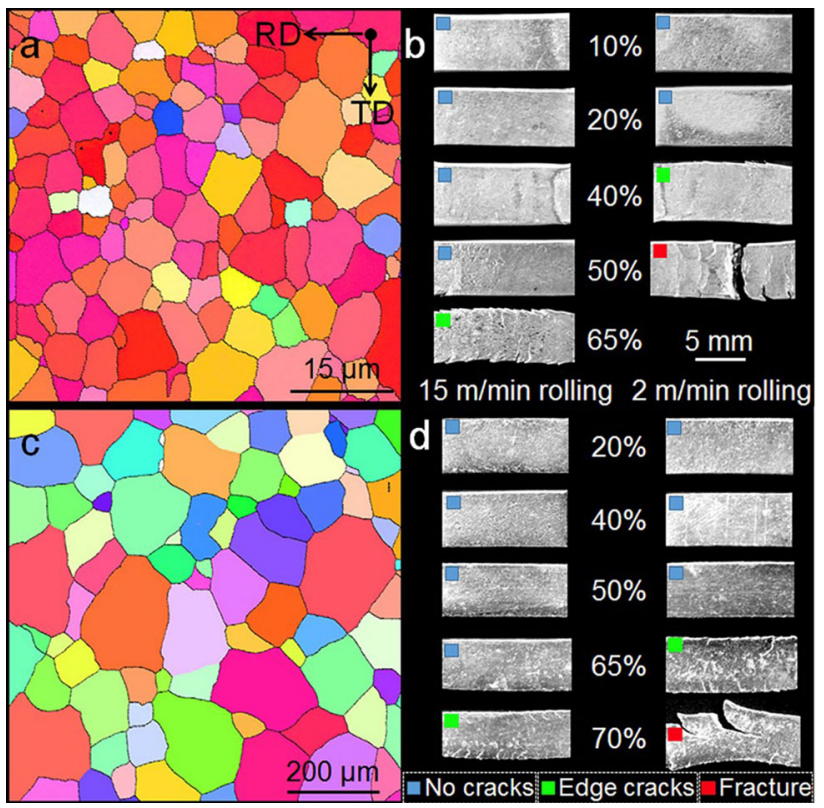

Fig. 43-EBSD orientation maps showing microstructures of $(a)$ AZ31 and (c) ZEK100 sheets prior to rolling at $380{ }^{\circ} \mathrm{C}$ for AZ31 and $400{ }^{\circ} \mathrm{C}$ for ZEK100. Photos of (b) AZ31 and (d) ZEK100 subjected to various thickness reduction in a single pass showing their rollability under rolling of 15 and $2 \mathrm{~m} \mathrm{~min}^{-1}$. Reprinted from Ref. [211].
Plastic deformation of hot-rolled and annealed thick plates of $\mathrm{Mg}-1 \mathrm{wt}$ pct $\mathrm{Ce}$ and $\mathrm{Mg}-1 \mathrm{wt}$ pct $\mathrm{Gd}$ alloys has been studied by plane-strain compression at room temperature and a strain rate of $10^{-2} \mathrm{~s}^{-1}$ along the plate normal direction and the rolling direction. ${ }^{[235]}$ These plates had a weakened basal texture, and contained fully recrystallized grains of $\sim 25 \mu \mathrm{m}$ in the Ce-containing alloy and $\sim 19 \mu \mathrm{m}$ in the Gd-containing alloy. Examination of specimens deformed to different levels of plastic strain revealed that, for each plane-strain compression mode, the texture evolved quite differently in these two alloys. Static recrystallization mechanisms inside deformation twins formed in these two alloys were reported ${ }^{[235]}$ to be different when the plastically deformed specimens were annealed in the temperature range 300 to $450{ }^{\circ} \mathrm{C}$. The recrystallization mechanism was proposed to be discontinuous in the Mg-1wt pet Gd alloy, but continuous in the $\mathrm{Mg}-1 \mathrm{wt}$ pet $\mathrm{Ce}$ alloy. It is to be noted that the mechanism proposed for the latter alloy was speculative, as the EBSD orientation maps provided in that work were not of sufficient clarity for deducing the recrystallization mechanism inside the deformation twins. If the recrystallization mechanism in the $\mathrm{Mg}-1 \mathrm{wt}$ pet $\mathrm{Ce}$ alloy were continuous, then it would remain to be reconciled whether the difference in the recrystallization mechanism between this alloy and the Mg-1wt pct Gd alloy was due to the difference in the concentration of solute atoms in the deformation twins. Ce has lower solubility than Gd in the $\mathrm{Mg}$ solid solution, and it was mentioned ${ }^{[235]}$ that some Mg-Ce-based second-phase particles had formed in the $\mathrm{Mg}-1$ wt pct Ce alloy. It is to be further noted that the
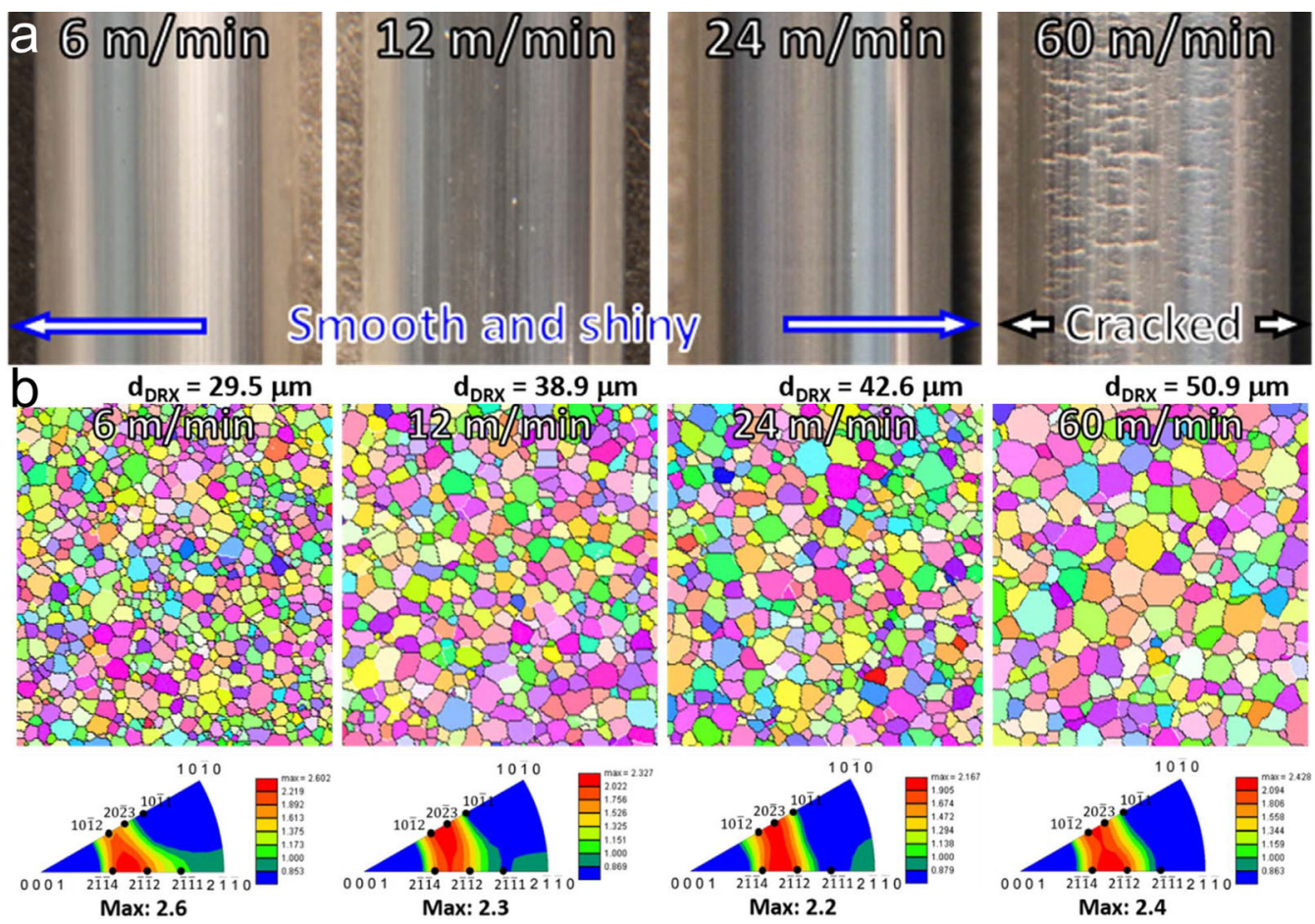

Fig. 44 - (a) Photo of extrusion surface finish, and (b) EBSD orientation maps and corresponding inverse pole figures along the ED of Mg-0.5Zn-0.24Ca-0.27Mn (wt pct) alloy extruded with different die-exit speeds. The diameter of extruded bars is $9.6 \mathrm{~mm}$. Adapted from Ref. [219]. 


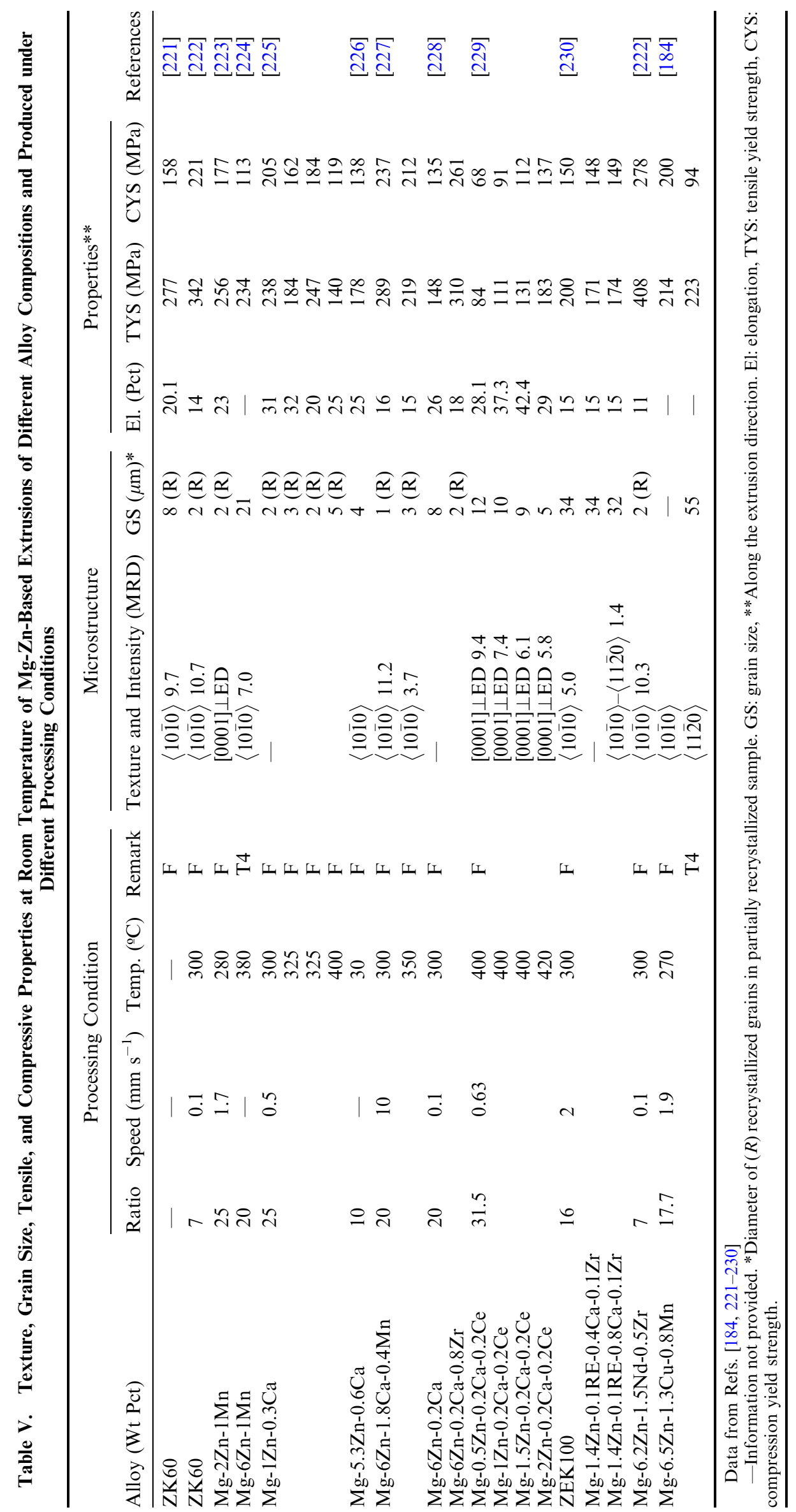




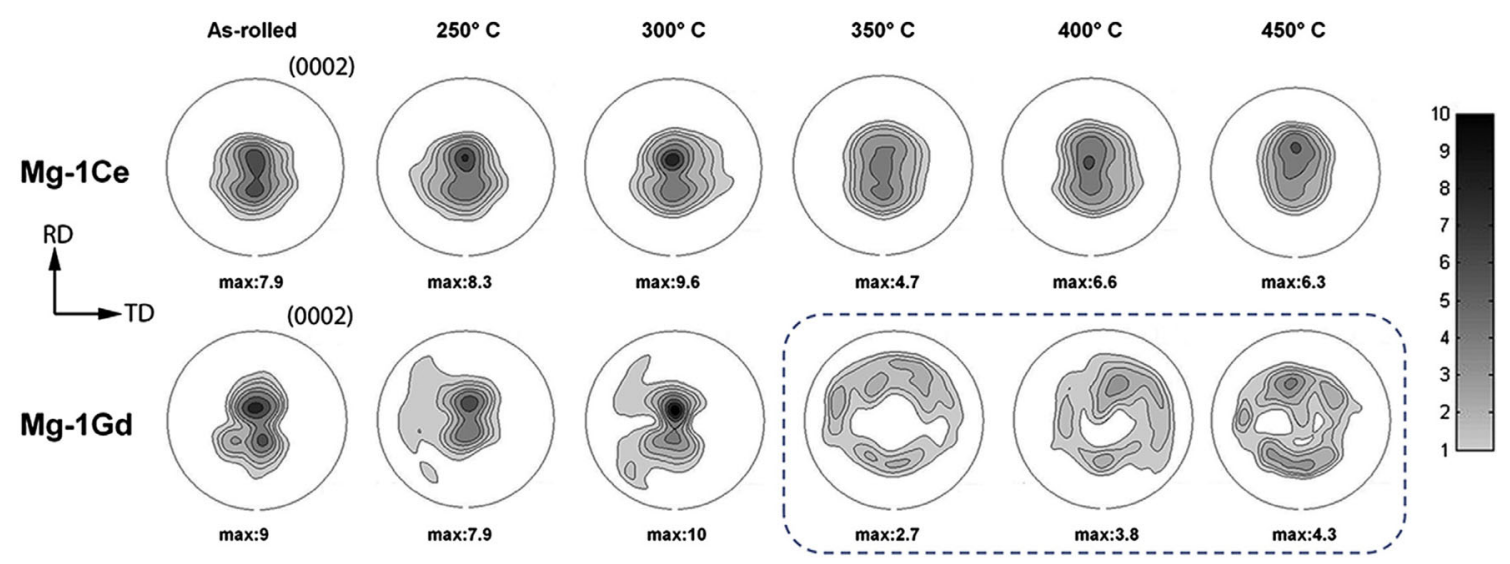

(a)

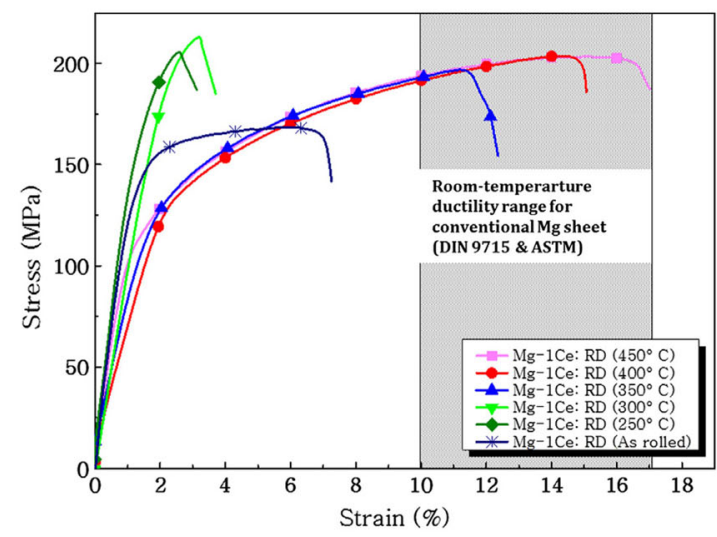

(b)

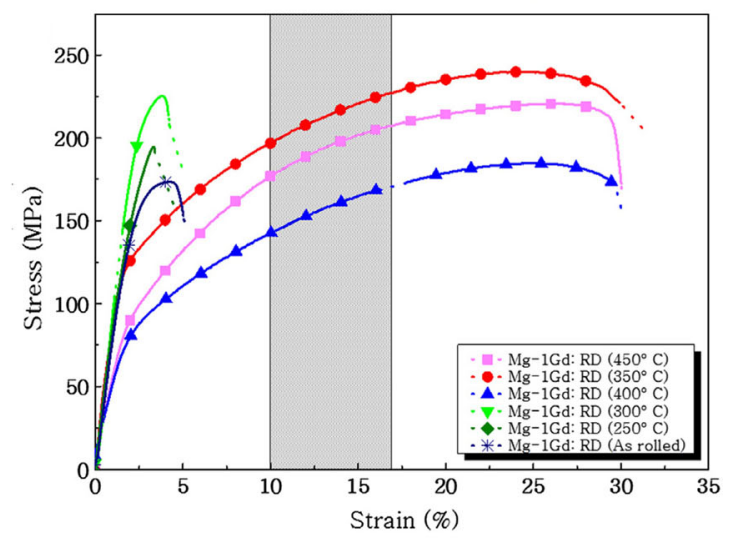

(c)

Fig. 45- (a) XRD basal pole figures of Mg-1wt pct Gd and Mg-1wt pct Ce alloy sheets in hot-rolled and annealed states. (b, $c$ ) Tensile true stress-strain curves at room temperature for different rolled-annealed states of $\mathrm{Mg}$-Ce and $\mathrm{Mg}$-Gd sheets. The alloy sheet was hot-rolled at $450{ }^{\circ} \mathrm{C}$ from a plate of $4 \mathrm{~mm}$ thick by a single pass and a thickness reduction of 80 pct. Sheet was water quenched and annealed for 1 hour at different temperatures. Adapted from Refs. [204,233].

recrystallization mechanisms were proposed to be discontinuous in the vicinity of second-phase particles.

Combined additions of RE and $\mathrm{Zn}$ appear to be more effective in improving the sheet formability. ${ }^{[204,243]} \mathrm{Wu}$ and co-workers reported ${ }^{[243]}$ that $\mathrm{Mg}-1.68 \mathrm{Gd}-1.11 \mathrm{Zn}$ (GZ21) and Mg-2.74Gd-1.06Zn (GZ31) (wt pet) alloy sheets had excellent formability at room temperature. The alloys were rolled at $430{ }^{\circ} \mathrm{C}$ and annealed for 1 hour at $400{ }^{\circ} \mathrm{C}$ before testing. The hot-rolled and annealed sheets contained recrystallized grains and second-phase dispersoids that were uniformly distributed in the microstructure. The average grain size was $\sim 16$ and $\sim 12 \mu \mathrm{m}$, respectively, in the GZ21 and GZ31 alloys. The basal texture intensity was quite low in each alloy, with the $c$-axes tilted by up to $30 \mathrm{deg}$ from the sheet normal direction towards both the rolling direction and the transverse direction. The sheets had good combination of tensile properties and ductility, together with excellent stretch formability, Table VI. ${ }^{[208,209,242-246]}$

\section{Polycrystalline extrusions}

Compared to $\mathrm{Mg}$-RE alloy-rolled sheet, extrusions of Mg-RE-based alloys exhibit more and unique RE textures. ${ }^{[184,247-251]}$ The RE texture was first reported by
Mackenzie and co-workers in their study of extruded and annealed alloy WE43. ${ }^{[184]}$ The alloy was extruded at $360{ }^{\circ} \mathrm{C}$, with an extrusion speed of $1.05 \mathrm{~m} \mathrm{~min}^{-1}$ and an extrusion ratio of $4: 1$. The as-extruded microstructure had a mixture of two texture components: one has basal planes and $\langle 10 \overline{1} 0\rangle$ parallel to the extrusion direction, and the other has basal planes oriented at $\sim 45 \mathrm{deg}$ to the extrusion direction, i.e., with $\langle 2 \overline{1} \overline{1} 1\rangle / / \mathrm{ED}$. The $\langle 10 \overline{1} 0\rangle / /$ ED component was fully replaced by the $\langle 2 \overline{1} \overline{1} 1\rangle / /$ ED after annealing for 24 hours at $525^{\circ} \mathrm{C}$. This RE texture was also found to form in dilute alloys of $\mathrm{Mg}-1.55 \mathrm{wt}$ pct $\mathrm{Gd}$ and $\mathrm{Mg}-0.22 \mathrm{wt}$ pct La, extruded at $450^{\circ} \mathrm{C}, 1 \mathrm{~mm} \mathrm{~s}^{-1}$ extrusion speed, and 30:1 extrusion ratio. ${ }^{[247]}$ When dilute $\mathrm{Mg}-\mathrm{RE}$ alloys such as Mg-1wt pet Gd were indirectly extruded at $350{ }^{\circ} \mathrm{C}$ with an extrusion ratio of $16: 1$, their microstructures had a mixture of coarse deformed grains and small recrystallized grains, Figure 46. ${ }^{[252]}$ The deformed grains were elongated along the extrusion direction and they had their basal planes and $\langle 10 \overline{1} 0\rangle$ directions parallel to the extrusion direction. While the small recrystallized grains were reported ${ }^{[252]}$ to have the same texture as that of the coarse deformed grains, their orientations were clearly different from those of the coarse deformed grains, as indicated by the difference 
Table VI. Texture, Grain Size, Tensile Properties, and Formability at Room Temperature of Mg-RE, Mg-Ca, and Mg-Ag-Based Sheets Produced under Different Processing Conditions

\begin{tabular}{|c|c|c|c|c|c|c|c|}
\hline \multirow[b]{2}{*}{ Alloys (Wt Pct) } & \multirow[b]{2}{*}{ Processing Condition } & \multicolumn{2}{|c|}{ Microstructure } & \multicolumn{3}{|c|}{ Properties* } & \multirow[b]{2}{*}{ References } \\
\hline & & $\begin{array}{l}\text { Basal Tex- } \\
\text { ture (MRD) }\end{array}$ & $\begin{array}{c}\text { GS } \\
(\mu \mathrm{m})\end{array}$ & $\begin{array}{c}\text { TYS } \\
(\mathrm{MPa})\end{array}$ & $\begin{array}{c}\mathrm{El} \\
(\mathrm{Pct})\end{array}$ & $\begin{array}{c}\mathrm{IE} \\
(\mathrm{mm})\end{array}$ & \\
\hline $\mathrm{Mg}-0.2 \mathrm{Ce}$ & extrusion, hot rolling, annealing & 5.0 & 21 & 116 & 20 & 5.5 & [209] \\
\hline \multirow[t]{2}{*}{ WE43 } & extrusion, hot DSR, and annealing at $350{ }^{\circ} \mathrm{C}$ & 4.4 & - & 247 & 13 & 1.7 & {$[242]$} \\
\hline & extrusion, hot DSR, and annealing at $450{ }^{\circ} \mathrm{C}$ & 2.4 & 18 & 141 & 22 & 4.4 & \\
\hline $\mathrm{Mg}-2 \mathrm{Gd}-1 \mathrm{Zn}$ & hot rolling, annealing & 2.2 & 16 & 130 & 40 & 7.9 & [243] \\
\hline $\mathrm{Mg}-3 \mathrm{Gd}-1 \mathrm{Zn}$ & & 2.2 & 12 & 131 & 40 & 6.8 & \\
\hline $\mathrm{Mg}-0.7 \mathrm{Y}-0.4 \mathrm{Sn}$ & hot rolling, annealing & 7.8 & 14 & 111 & 30 & 5.4 & [244] \\
\hline $\mathrm{Mg}-0.1 \mathrm{Ca}$ & hot rolling, annealing & 5.6 & 39 & - & - & 3.6 & [208] \\
\hline $\mathrm{Mg}-0.5 \mathrm{Ca}-0.1 \mathrm{Zr}$ & hot rolling, annealing & 7.3 & 20 & 133 & 14 & 4.1 & [245] \\
\hline $\mathrm{Mg}-0.5 \mathrm{Ca}-0.1 \mathrm{Zr}-0.1 \mathrm{Zn}$ & & 3.5 & 15 & 134 & 29 & 7.7 & \\
\hline $\mathrm{Mg}-3 \mathrm{Ag}-0.1 \mathrm{Ca}$ & hot rolling, annealing & 3.4 & 21.8 & 127 & 27 & 8.8 & [246] \\
\hline $\mathrm{Mg}-6 \mathrm{Ag}-0.1 \mathrm{Ca}$ & & 3.6 & 8.5 & 182 & 26 & 8.7 & \\
\hline $\mathrm{Mg}-12 \mathrm{Ag}-0.1 \mathrm{Ca}$ & & 3.1 & 8.3 & 194 & 16 & 5.1 & \\
\hline
\end{tabular}

Data from Refs. [208,209,242-246]

- Information not provided. *Along the rolling direction. DSR: differential speed rolling, GS: grain size, El: elongation, TYS: tensile yield strength, IE: Erichsen index.

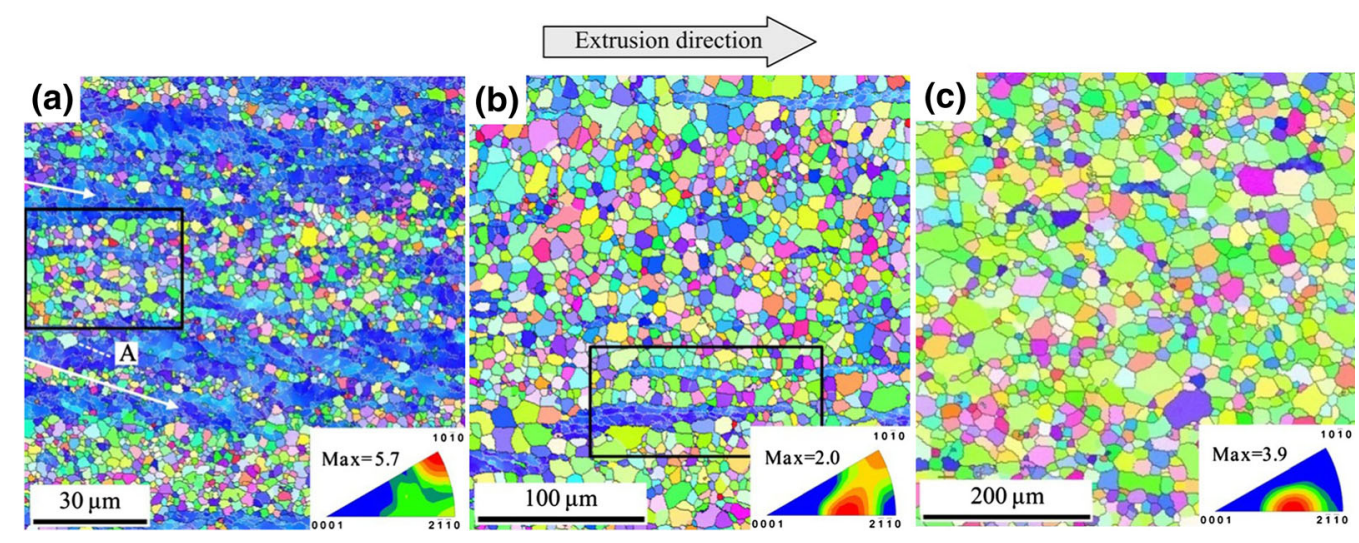

Fig. 46- (a) EBSD orientation maps of Mg-1wt pct Gd alloy extruded at $350{ }^{\circ} \mathrm{C},(b, c)$ microstructures of the alloy after annealing at (b) $400{ }^{\circ} \mathrm{C}$ for 10 minutes, and (c) $500{ }^{\circ} \mathrm{C}$ for 10 minutes. Also included are corresponding inverse pole figures of the recrystallized region in each. Adapted from Ref. [252].

between their colors, Figure 46(a). One possibility for the difference is that the recrystallized grains were embedded in the matrix of the deformed grains, and therefore their orientations were masked by those of the matrix grains, given that continuous dynamic recrystallization, which involves gradual rotation of sub-grains formed in the deformed parent grains, was proposed ${ }^{[252]}$ to have occurred. This possibility is further supported by the microstructures of the extruded and annealed specimens, Figures 46(b) and (c). The dynamic recrystallized grains clearly had a RE texture. The annealing for a short period at high temperatures increased the volume fraction of recrystallized grains that had the RE texture. A fully recrystallized microstructure having predominantly the $\langle 2 \overline{1} 1 \overline{1}\rangle / / \mathrm{ED}$ texture was obtained after 10 minutes of annealing at $500{ }^{\circ} \mathrm{C}$, Figure 46(c).

Since some RE elements have large solid solubilities in $\mathrm{Mg}$ and the others have low solid solubilities in $\mathrm{Mg}$, the effects of the identity and the concentration of RE elements on texture have also been studied. ${ }^{[248]}$ The RE elements that have received most attention are $\mathrm{Gd}$, Y, $\mathrm{Nd}, \mathrm{Ce}$, and Ce-rich misch-metal. ${ }^{[248-250]}$ Among these elements, Gd, Y, and $\mathrm{Nd}$ have relatively large solid solubilities, while Ce has a low solubility. Existing experimental results indicate that, even within the solid solubility range, the quantitative effects of the RE elements on the formation of the RE textures depend critically on the identity and the concentration of the added RE element ${ }^{[248,251]}$ and the actual processing conditions. ${ }^{[251]}$ Figures 47 (a) through (c) show the fully recrystallized microstructure of $\mathrm{Mg}-0.51 \mathrm{wt}$ pct Ce alloy and the partially recrystallized microstructure of $\mathrm{Mg}-2.51 \mathrm{wt}$ pct Gd alloy. ${ }^{[251]}$ The microstructure of the former alloy had a strong $\langle 2 \overline{1} \overline{1} 2\rangle / /$ ED texture component, while the recrystallized grains in the latter alloy had $\langle 2 \overline{1} 1 \overline{1} 1\rangle-\langle 2 \overline{1} \overline{1} 3\rangle / / \mathrm{ED}$ as the major texture component. It was found that the recrystallization texture was strongly affected by the identity and the 

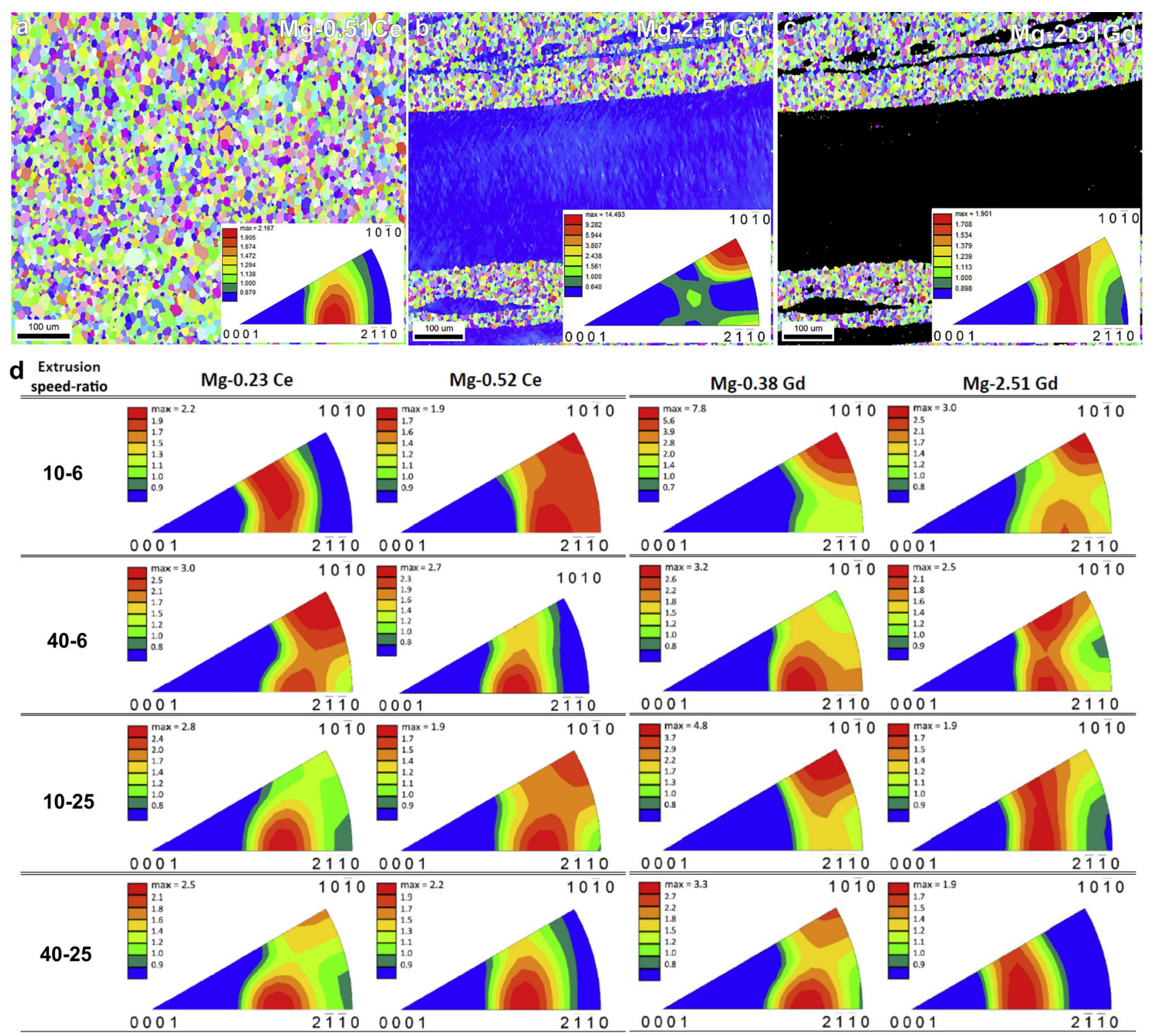

Fig. 47-EBSD orientation maps and corresponding inverse pole figures of $(a) \mathrm{Mg}-0.51 \mathrm{wt}$ pct $\mathrm{Ce}$ and $(b) \mathrm{Mg}-2.51 \mathrm{wt}$ pct $\mathrm{Gd}$ extruded at $450{ }^{\circ} \mathrm{C}$ with an extrusion ratio of $25: 1$ and a ram speed of $40 \mathrm{~mm} \mathrm{~min}^{-1}$ for (a) and $10 \mathrm{~mm} \mathrm{~min}{ }^{-1}$ for (b). (c) Same as (b) but with recrystallized grains differentiated from deformed grains by selecting grain-orientation-spread values smaller than $2 \mathrm{deg}$. $(d)$ Inverse pole figures of the recrystallized grains of binary $\mathrm{Mg}-\mathrm{Ce}$ (with 0.23 and $0.52 \mathrm{wt}$ pet $\mathrm{Ce}$ ) and $\mathrm{Mg}-\mathrm{Gd}$ (with 0.38 , and $2.51 \mathrm{wt}$ pct $\mathrm{Gd}$ ) alloys extruded at $450{ }^{\circ} \mathrm{C}$ with different ram speeds and extrusion ratios. In the first column, the first number refers to the ram speed, and the second number represents the extrusion ratio. IPFs refer to the extrusion direction. Adapted from Ref. [251].

concentration of the RE element, the extrusion speed, and the extrusion ratio, Figure 47(d), and that a broad range of RE-texture components could form at even a single temperature $\left(450^{\circ} \mathrm{C}\right)$. Such RE-texture components include $\langle 20 \overline{2} 3\rangle-\langle 2 \overline{1} \overline{1} 2\rangle / / \mathrm{ED},\langle 2 \overline{1} \overline{1} 1\rangle-\langle 2 \overline{1} \overline{1} 2\rangle$ // ED, $\langle 10 \overline{1} 0\rangle-(\langle 2 \overline{1} \overline{1} 1\rangle-\langle 2 \overline{1} \overline{1} 2\rangle) \quad / / \mathrm{ED},\langle 10 \overline{1} 1\rangle-$ $\langle 2 \overline{1} \overline{1} 2\rangle / / \mathrm{ED},\langle 10 \overline{1} 1\rangle-\langle 2 \overline{1} \overline{1} 3\rangle / / \mathrm{ED},\langle 11 \overline{2} 1\rangle-\langle 11 \overline{2} 4\rangle$ $/ / \mathrm{ED},\langle 2 \overline{1} \overline{1} 2\rangle / / \mathrm{ED}$, and $\langle 10 \overline{1} 0\rangle / / \mathrm{ED}$. The formation of sub-grains and the occurrence of grain boundary bulging were both observed, but continuous dynamic recrystallization was suggested to be the dominating mechanism in these two binary $\mathrm{Mg}$ - RE alloys. ${ }^{[251]}$
The addition of non-RE alloying elements to the Mg-RE alloys does not seem to affect the RE textures, when the major and minor alloying elements are all in low concentrations. A microstructural study made by Imandoust and co-workers ${ }^{[253]}$ of $\mathrm{Mg}$ - $\mathrm{Y}$ alloys containing various amounts of $\mathrm{Zn}, \mathrm{Al}$, and $\mathrm{Mn}$ revealed that the $\mathrm{RE}$ textures were preserved when the alloys were extruded at $450{ }^{\circ} \mathrm{C}$ and $40 \mathrm{~mm} \mathrm{~min}{ }^{-1}$ speed and $6: 1$ extrusion ratio. Depending on the specific alloy composition, the microstructure also had other texture components such as $\langle 10 \overline{1} 0\rangle / / \mathrm{ED}$ and [0001] // ED. The [0001] // ED component is rarely observed in binary Mg-RE alloys of dilute compositions and non-RE 
containing alloys. Inspection of the inverse pole figures indicates that the RE-texture components include those spreading between $\langle 11 \overline{2} 1\rangle / / \mathrm{ED}$ and $\langle 11 \overline{2} 2\rangle / / \mathrm{ED}$ with a large fraction close to $\langle 22 \overline{4} 3\rangle / /$ ED. It was proposed ${ }^{[253]}$ that the $\mathrm{Y}$ atoms promoted discontinuous dynamic recrystallization in these alloys. It was also speculated that the presence of diverse texture components was due to the segregation of $\mathrm{Y}$ atoms to grain boundaries that led to isotropic growth of recrystallized grains.

The use of mixed RE alloying elements at high concentrations leads to more complex texture evolution. Figure 48 shows the microstructure of Mg-6Y-7Gd-0.5Zr (wt pct) alloy, also known as Elektron 675, extruded under different processing conditions. ${ }^{[254]}$ Extrusions in the temperature range 425 to $475{ }^{\circ} \mathrm{C}$ led to microstructures comprising a mixture of coarse and fine grains distributed in bands along the extrusion direction. The band structure was less obvious when the extrusion was made at $500{ }^{\circ} \mathrm{C}$. Extrusions made in the temperature range 425 to $500{ }^{\circ} \mathrm{C}$ exhibited weak and yet very different textures. Extrusion microstructures shown in Figures 48(a) and (b) have a texture component rarely observed in dilute $\mathrm{Mg}-\mathrm{RE}$ alloys: the prismatic planes and the $c$-axes of some grains are nearly parallel to the extrusion direction. The microstructure shown in Figure 48(c) has a texture component that is similar to that commonly seen in the RE-free alloys, i.e., with the basal planes and the $\langle 10 \overline{1} 0\rangle$ directions aligned nearly parallel to the extrusion direction. The $\langle 01 \overline{1} 1\rangle / / \mathrm{ED}$ texture was observed in the specimen extruded at $500{ }^{\circ} \mathrm{C}$, Figure $48(\mathrm{~d})$. The prismatic texture shown in Figures 48(a) and (b) was strengthened in all extrusions after solution treatment and these extrusions were almost free of the tension-compression yield asymmetry. Even when some asymmetry was noted, the tensile yield strength was lower, rather than higher, than the compressive yield strength. The elimination of the tension-compression yield asymmetry may be related to the weak texture and factors such as changes in the CRSS values for various deformation modes in this alloy due to a high concentration $(\sim 13.5 \mathrm{wt} \mathrm{pct})$ of added alloying elements. Note that the texture variation under these different processing conditions has not been systematically studied, and that the origin of the [0001] // ED texture component is unclear.

Additions of $\mathrm{Zn}$ or $\mathrm{Ag}^{[255-258]}$ to $\mathrm{Mg}$-RE alloys containing large amounts of $\mathrm{RE}$ elements lead to elimination of the RE-texture components that are commonly observed in dilute $\mathrm{Mg}-\mathrm{RE}$ alloys. For a $\mathrm{Mg}_{89} \mathrm{Y}_{7} \mathrm{Zn}_{4}$ (at. pct) alloy that contains a relatively large amount of long-period stacking ordered (LPSO) phase, its microstructure has a basal texture, with the basal planes and the $\langle 10 \overline{1} 0\rangle$ directions parallel to the ED, after extrusion at $450{ }^{\circ} \mathrm{C}$, a ram speed of $2.5 \mathrm{~mm} \mathrm{~s}^{-1}$, and an extrusion ratio of 10:1. ${ }^{[255]}$ Figure 49(a) shows the microstructure of $\mathrm{Mg}-15 \mathrm{Gd}-1 \mathrm{Zn}$ (wt pct) alloy, pre-heated to $\sim 500^{\circ} \mathrm{C}$ then extruded with a mold temperature of $\sim 370^{\circ} \mathrm{C}$ and an extrusion ratio of $9: 1$ and a ram speed of $2 \mathrm{~mm} \mathrm{~s}^{-1} \cdot{ }^{[256]}$ It contains fully recrystallized grains that have a mixture of [0001] // ED and $\langle 10 \overline{10}\rangle / / \mathrm{ED}$ components. Under the condition of billet pre-heating for 30 minutes at $350{ }^{\circ} \mathrm{C}$ and extrusion
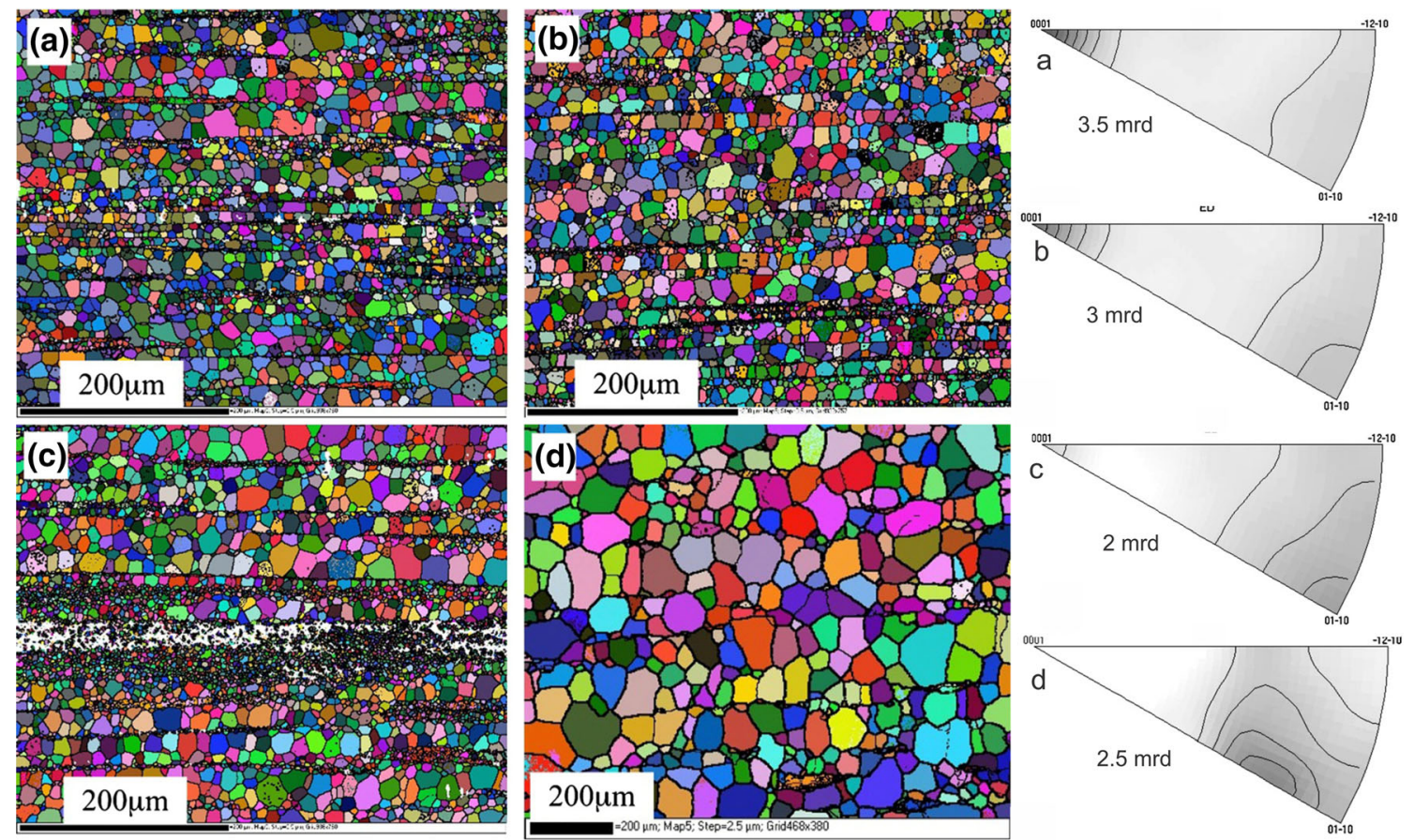

Fig. 48-EBSD maps and corresponding inverse pole figures of as-extruded microstructures of Elektron 675. (a) Extrusion at $425{ }^{\circ} \mathrm{C}$, $1.2 \mathrm{~m} \mathrm{~min}^{-1}$ speed, and $17: 1 \mathrm{ratio} ;(b)$ extrusion at $475{ }^{\circ} \mathrm{C}, 1.2 \mathrm{~m} \mathrm{~min}^{-1}$, and $17: 1 ;(c)$ extrusion at $460{ }^{\circ} \mathrm{C}, 1.1 \mathrm{~m} \mathrm{~min}^{-1}$, and $10: 1 ;(d)$ extrusion at $500{ }^{\circ} \mathrm{C}, 0.55 \mathrm{~m} \mathrm{~min}^{-1}$, and 10:1. Extrusion direction is horizontal. Adapted from Ref. [254]. 

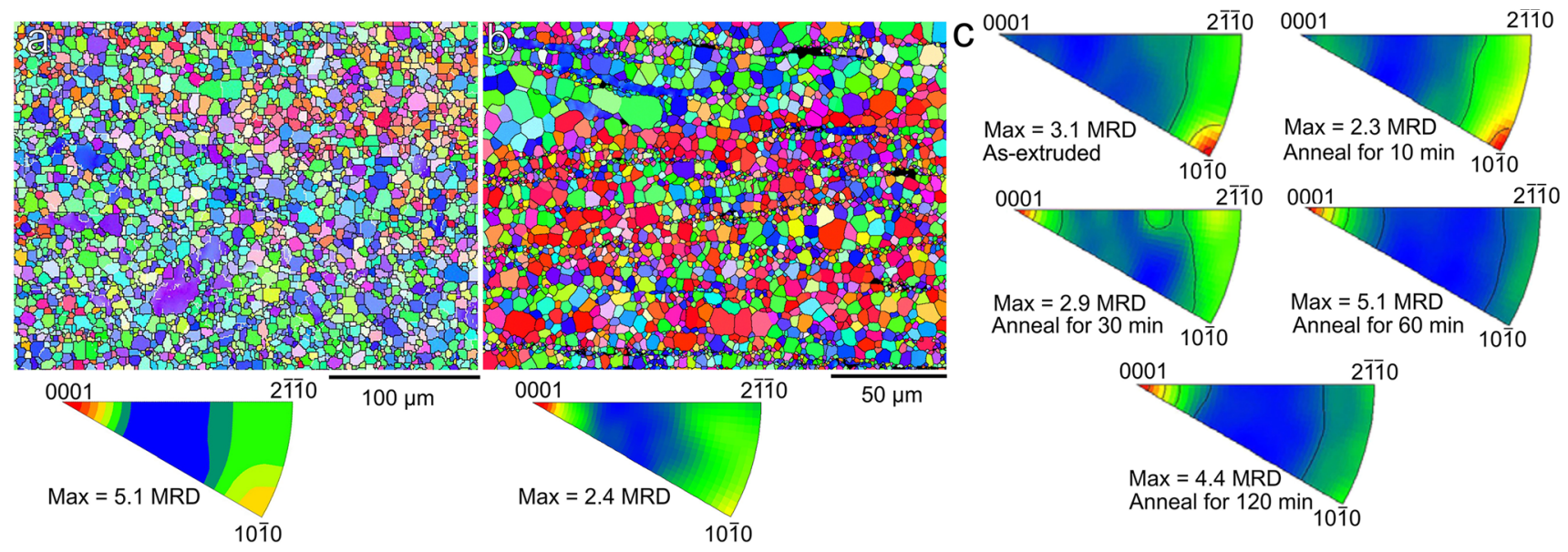

Fig. 49-EBSD orientation maps and corresponding inverse pole figures of as-extruded microstructures of $(a)$ Mg-15Gd-1 Zn, ${ }^{[257]}$ and $(b)$ $\mathrm{Mg}-5.3 \mathrm{Y}-4.7 \mathrm{Gd}-1.6 \mathrm{Ag}-0.3 \mathrm{Zr}^{[258]}$ (wt pct) alloys. (c) Inverse pole figures of the extruded and the annealed microstructures of Mg-14Gd-2Ag-0.5Zr (wt pct) alloy. ${ }^{[259]}$ Annealing temperature is $450{ }^{\circ} \mathrm{C}$. Adapted from Refs. [256-258].

with a mold temperature of $350{ }^{\circ} \mathrm{C}$ and an extrusion ratio of $9: 1$ and a ram speed of $2 \mathrm{~mm} \mathrm{~s}^{-1},{ }^{[257]}$ the microstructures of $\mathrm{Mg}-5.3 \mathrm{Y}-4.7 \mathrm{Gd}-1.6 \mathrm{Ag}-0.3 \mathrm{Zr}$ and $\mathrm{Mg}-9.2 \mathrm{Gd}-2.6 \mathrm{Y}-1.6 \mathrm{Ag}-0.3 \mathrm{Zr}$ (wt pct) alloys are quite similar, and both have a mixture of [0001] // ED and $\langle 10 \overline{1} 0\rangle / /$ ED components, Figure 49(b). Textures of the extruded and the annealed samples of $\mathrm{Mg}-14 \mathrm{Gd}-2 \mathrm{Ag}-0.5 \mathrm{Zr}$ (wt pet) alloy are shown in Figure $49(\mathrm{c}) .^{[258]}$ The alloy was extruded at $450{ }^{\circ} \mathrm{C}$, a ram speed of $0.1 \mathrm{~mm} \mathrm{~s}^{-1}$, and an extrusion ratio of $28: 1$. The as-extruded microstructure has a basal texture, with $\langle 10 \overline{1} 0\rangle / / \mathrm{ED}$. During annealing at $450{ }^{\circ} \mathrm{C}$, the $\langle 10 \overline{1} 0\rangle / /$ ED component is gradually replaced by the [0001] // ED component, Figure 49(c). It is to be noted that the above-mentioned alloys contain higher concentrations of solutes and that a large fraction of the precipitates or second-phase particles (such as LPSO) in these alloys form on the basal plane of the $\mathrm{Mg}$ matrix. The effect of alloying second-phase particles, precipitates, and the combination of $\mathrm{RE} / \mathrm{Zn}$ or $\mathrm{RE} / \mathrm{Ag}$ on the selective formation of the RE textures remains to be systematically explored.

In general, the tension-compression yield asymmetry is low in the Mg-RE-based extrusions, and it may not be apparent in alloys containing large amounts of RE elements, Table VII. ${ }^{[180,183,184,259-270]}$

\section{Other Alloys}

In addition to the alloys developed on the $\mathrm{Mg}-\mathrm{Al}$, $\mathrm{Mg}-\mathrm{Zn}$, and $\mathrm{Mg}-\mathrm{RE}$ systems, alloys based on $\mathrm{Mg}-\mathrm{Mn}$, $\mathrm{Mg}-\mathrm{Li}, \mathrm{Mg}-\mathrm{Sn}, \mathrm{Mg}-\mathrm{Ca}$, and other systems have also been developed in laboratories or industry for fabricating sheet and/or extrusion. The microstructures (texture and grain size), tensile and compressive properties, and formability of these alloys are provided in Tables VI-VIII. ${ }^{[271-277]}$ Since these alloys are less extensively studied, this section will be focused on a brief review of microstructures of the alloys based on the $\mathrm{Mg}-\mathrm{Mn}$ and $\mathrm{Mg}-\mathrm{Li}$ systems.

\section{Mg-Mn-based alloys}

There are limited studies on plates and sheets made of Mg-Mn-based alloys. ${ }^{[278-280]}$ According to the work of Pekguleryuz and co-workers, ${ }^{[279]}$ the texture of hot-rolled and annealed sheets of Mg-Mn binary alloys is similar to that of pure $\mathrm{Mg}$ and AZ31. The addition of small amounts of $\mathrm{RE}$ elements to $\mathrm{Mg}-\mathrm{Mn}$ alloys can significantly change the texture of the plate or sheet. ${ }^{[278]}$ The resultant ME alloy plates/sheets have a weakened basal texture after hot rolling. The basal poles are tilted by larger angles away from the plate/sheet normal direction towards the rolling direction, similar to that of hot-rolled sheets of dilute Mg-RE alloys.

Most studies on Mg-Mn-based alloys are focused on extrusion, because the $\mathrm{Mg}-\mathrm{Mn}$-based alloys have probably the largest processing window for extrusion among $\mathrm{Mg}$ extrusion alloys. A systematic evaluation has been made Hidalgo-Manrique and co-workers ${ }^{[280]}$ on the effects of extrusion speed and temperature on microstructure and deformation of $\mathrm{Mg}-1 \mathrm{Mn}$, $\mathrm{Mg}-1 \mathrm{Mn}-0.5 \mathrm{Nd}$, and $\mathrm{Mg}-1 \mathrm{Mn}-1 \mathrm{Nd}$ (wt pet) alloys, with the extrusion temperatures in the range 275 to $360{ }^{\circ} \mathrm{C}$ and the extrusion speed in the range 2.8 to $11 \mathrm{~mm} \mathrm{~s}^{-1}$. It was found that adding $\mathrm{Nd}$ and increasing the $\mathrm{Nd}$ content resulted in gradually weakened basal textures in which the predominant orientations changed with the extrusion condition. For the $\mathrm{Mg}-1 \mathrm{Mn}-0.5 \mathrm{Nd}$ alloy (MN10), its microstructure had a weaker basal texture than the $\mathrm{Mg}-1 \mathrm{Mn}$ alloy, with a dominant texture component of $\langle 10 \overline{1} 0\rangle / / \mathrm{ED}$. The intensity of the $\langle 10 \overline{1} 0\rangle$ $/ /$ ED component increased with increasing extrusion temperature and speed. The extrusion made at $300{ }^{\circ} \mathrm{C}$ and $2.8 \mathrm{~mm} \mathrm{~s}^{-1}$ and the extrusion made at $300{ }^{\circ} \mathrm{C}$ and $5.5 \mathrm{~mm} \mathrm{~s}^{-1}$ both exhibited a weak [0001] // ED component. For the Mg-1Mn-1Nd alloy (MN11), its microstructure had a significantly weakened basal texture. Three major texture components were observed, including A: $\langle 10 \overline{1} 0\rangle-\langle 11 \overline{2} 1\rangle / / \mathrm{ED} ; \mathrm{B}:\langle 10 \overline{1} 2\rangle-\langle 11 \overline{2} 1\rangle$ // ED; and C: [0001] // ED. The predominant texture of 
Table VII. Texture, Grain Size, Tensile, and Compressive Properties at Room Temperature of Mg-RE, Mg-Mn, Mg-Ca, and Mg-Li-Based Extrusions Produced under Different Processing Conditions

\begin{tabular}{|c|c|c|c|c|c|c|c|c|c|c|}
\hline \multirow[b]{2}{*}{ Alloy (Wt Pct) } & \multicolumn{4}{|c|}{ Processing Condition } & \multicolumn{2}{|c|}{ Microstructure } & \multicolumn{3}{|c|}{ Properties** } & \multirow[b]{2}{*}{ References } \\
\hline & Ratio & $\begin{array}{c}\text { Speed } \\
\left(\mathrm{mm} \mathrm{s}^{-1}\right)\end{array}$ & $\begin{array}{l}\text { Temp. } \\
\left({ }^{\circ} \mathrm{C}\right)\end{array}$ & Remark & $\begin{array}{c}\text { Texture and } \\
\text { Intensity (MRD) }\end{array}$ & $\begin{array}{l}\mathrm{GS}^{*} \\
(\mu \mathrm{m})\end{array}$ & $\begin{array}{l}\text { El. } \\
(\mathrm{Pct})\end{array}$ & $\begin{array}{c}\text { TYS } \\
(\mathrm{MPa})\end{array}$ & $\begin{array}{l}\text { CYS } \\
(\mathrm{MPa})\end{array}$ & \\
\hline $\mathrm{Mg}-0.2 \mathrm{Ce}$ & 25 & 10 & 400 & $\mathrm{~F}$ & - & 36 & 31 & 69 & 41 & [259] \\
\hline $\mathrm{Mg}-2.5 \mathrm{Y}$ & - & - & 350 & $\mathrm{~F}$ & $\langle 10 \overline{1} 0\rangle 2.7$ & 1 & 14 & 380 & 314 & [260] \\
\hline Mg-10Gd-5.7Y-1.6 & 10 & 0.1 & 400 & $\mathrm{~F}$ & {$[0001] \perp \mathrm{ED}$} & $0.9(\mathrm{R})$ & 4 & 419 & 400 & [261] \\
\hline $\mathrm{Zn}-0.7 \mathrm{Zr}$ & & & & T5 & - & $1.1(\mathrm{R})$ & 8 & 473 & 524 & \\
\hline $\begin{array}{l}\mathrm{Mg}-10.8 \mathrm{Gd}-3.9 \mathrm{Y}-1.1 \\
\mathrm{Zn}-0.3 \mathrm{Mn}\end{array}$ & 10 & 0.1 & 400 & $\mathrm{~F}$ & $\langle 10 \overline{1} 0\rangle 23.3$ & $1.4(\mathrm{R})$ & 5 & 381 & 430 & {$[262]$} \\
\hline $\begin{array}{l}\mathrm{Mg}-10.8 \mathrm{Gd}-3.7 \mathrm{Y}-1.1 \\
\mathrm{Zn}-0.5 \mathrm{Zr}\end{array}$ & 10 & 0.1 & 400 & $\mathrm{~F}$ & $\langle 10 \overline{1} 0\rangle 13.4$ & $1.1(\mathrm{R})$ & 10 & 361 & 410 & \\
\hline $\begin{array}{r}\mathrm{Mg}-11 \mathrm{Gd}-4.5 \mathrm{Y}-1.5 \\
\mathrm{Zn}-1 \mathrm{Nd}-0.5 \mathrm{Zr}\end{array}$ & 30 & - & 410 & $\mathrm{~F}$ & $\langle 10 \overline{1} 0\rangle 1.6$ & 3.6 & 6 & 306 & 363 & {$[263]$} \\
\hline $\begin{array}{c}\mathrm{Mg}-4.7 \mathrm{Gd}-3.4 \mathrm{Y}-1.2 \\
\mathrm{Zn}-0.5 \mathrm{Zr}\end{array}$ & 10 & 0.08 & 400 & $\mathrm{~F}$ & {$[0001] / /$ ED 7.8} & - & 13 & 255 & 201 & [264] \\
\hline WE43 & 4 & 4.4 & 360 & $\begin{array}{l}\mathrm{F} \\
\mathrm{T} 4\end{array}$ & $\begin{array}{l}\langle 10 \overline{1} 0\rangle-\langle 11 \overline{2} 2\rangle \\
\langle 11 \overline{2} 2\rangle\end{array}$ & $\overline{100}$ & - & $\begin{array}{l}185 \\
109\end{array}$ & $\begin{array}{l}184 \\
116\end{array}$ & [184] \\
\hline Mg-1Mn & 30 & $\begin{array}{l}0.56 \\
5.6\end{array}$ & 300 & $\mathrm{~F}$ & $\begin{array}{l}\langle 10 \overline{1} 0\rangle 15.7 \\
\langle 10 \overline{1} 0\rangle-\langle 11 \overline{2} 0\rangle 5.5\end{array}$ & $\begin{array}{l}8 \\
70\end{array}$ & $\begin{array}{l}6 \\
5\end{array}$ & $\begin{array}{l}183 \\
189\end{array}$ & $\begin{array}{l}126 \\
65\end{array}$ & [265] \\
\hline $\mathrm{Mg}-1 \mathrm{Mn}-0.9 \mathrm{Ce}$ & 30 & $\begin{array}{l}0.56 \\
5.6\end{array}$ & 300 & & $\begin{array}{l}\langle 10 \overline{1} 0\rangle 17.1 \\
\langle 10 \overline{1} 0\rangle-\langle 11 \overline{2} 0\rangle 3.7\end{array}$ & $\begin{array}{l}5 \\
8\end{array}$ & $\begin{array}{l}16 \\
19\end{array}$ & $\begin{array}{l}288 \\
189\end{array}$ & $\begin{array}{l}181 \\
137\end{array}$ & \\
\hline $\mathrm{Mg}-0.2 \mathrm{Mn}-1.3 \mathrm{Y}$ & 30 & $\begin{array}{l}0.56 \\
5.6\end{array}$ & 300 & & $\begin{array}{l}\langle 10 \overline{1} 0\rangle 14.2 \\
\langle 10 \overline{1} 0\rangle-\langle 11 \overline{2} 0\rangle 3.1\end{array}$ & $\begin{array}{l}5 \\
8\end{array}$ & $\begin{array}{l}16 \\
25\end{array}$ & $\begin{array}{l}232 \\
133\end{array}$ & $\begin{array}{l}159 \\
108\end{array}$ & \\
\hline $\mathrm{Mg}-1 \mathrm{Mn}-1.1 \mathrm{Y}$ & 30 & $\begin{array}{l}0.56 \\
5.6\end{array}$ & 300 & & $\begin{array}{l}\langle 10 \overline{1} 0\rangle 11.1 \\
\{11 \overline{2} 2\} 2.9\end{array}$ & $\begin{array}{l}5 \\
8\end{array}$ & $\begin{array}{l}21 \\
29\end{array}$ & $\begin{array}{l}204 \\
143\end{array}$ & $\begin{array}{l}156 \\
121\end{array}$ & \\
\hline $\mathrm{Mg}-1.7 \mathrm{Mn}-1.1 \mathrm{Y}$ & 30 & $\begin{array}{l}0.56 \\
5.6\end{array}$ & 300 & & $\begin{array}{l}\langle 10 \overline{1} 0\rangle 11.7 \\
\{11 \overline{2} 1\} 3.1\end{array}$ & $\begin{array}{l}5 \\
8\end{array}$ & $\begin{array}{l}21 \\
28\end{array}$ & $\begin{array}{l}204 \\
150\end{array}$ & $\begin{array}{l}162 \\
128\end{array}$ & \\
\hline $\mathrm{Mg}-1 \mathrm{Mn}-1 \mathrm{Nd}$ & 30 & $\begin{array}{l}0.56 \\
5.6\end{array}$ & 300 & & $\begin{array}{l}\{11 \overline{2} 1\} 1.8 \\
\{11 \overline{2} 1\} 1.8\end{array}$ & $\begin{array}{l}5 \\
10\end{array}$ & $\begin{array}{l}36 \\
42\end{array}$ & $\begin{array}{l}151 \\
102\end{array}$ & $\begin{array}{l}159 \\
109\end{array}$ & \\
\hline $\mathrm{Mg}-1 \mathrm{Mn}-1 \mathrm{Nd}$ & 30 & 5.5 & 300 & $\begin{array}{l}\mathrm{F} \\
\mathrm{T} 4\end{array}$ & $\langle 10 \overline{1} 0\rangle 2.6$ & $\begin{array}{l}14 \\
14\end{array}$ & $\begin{array}{l}26 \\
28\end{array}$ & $\begin{array}{l}105 \\
124\end{array}$ & $\begin{array}{l}105 \\
133\end{array}$ & [266] \\
\hline $\mathrm{Mg}-0.5 \mathrm{Ca}$ & 50 & $\begin{array}{l}1 \\
1 \\
1 \\
10 \\
0.3 \\
10 \\
10\end{array}$ & $\begin{array}{l}250 \\
350 \\
450 \\
350 \\
450 \\
300 \\
300\end{array}$ & $\mathrm{~F}$ & $\begin{array}{l}\langle 10 \overline{1} 0\rangle 4.0 \\
\langle 10 \overline{1} 0\rangle 3.4 \\
\langle 10 \overline{1} 0\rangle 1.9 \\
\langle 10 \overline{1} 0\rangle 1.4 \\
\langle 10 \overline{1} 0\rangle 4.8 \\
\{10 \overline{1} 2\} 1.7 \\
\langle 10 \overline{1} 0\rangle 2.3\end{array}$ & $\begin{array}{l}3(\mathrm{R}) \\
7 \\
25 \\
31 \\
8 \\
28 \\
40\end{array}$ & $\begin{array}{l}13 \\
19 \\
22 \\
21 \\
16 \\
32 \\
22\end{array}$ & $\begin{array}{l}277 \\
188 \\
133 \\
91 \\
169 \\
118 \\
68\end{array}$ & $\begin{array}{l}203 \\
133 \\
76 \\
63 \\
97 \\
90 \\
63\end{array}$ & {$[267]$} \\
\hline $\begin{array}{r}\mathrm{Mg}-0.3 \mathrm{Ca}-0.2 \\
\mathrm{Zn}-0.1 \mathrm{Mn}\end{array}$ & 20 & 1 & $\begin{array}{l}300 \\
350 \\
400\end{array}$ & $\mathrm{~F}$ & $\begin{array}{l}\langle 10 \overline{1} 0\rangle 14 \\
\langle 10 \overline{1} 0\rangle 4 \\
\langle 10 \overline{1} 0\rangle 2\end{array}$ & $\begin{array}{l}2(\mathrm{R}) \\
7(\mathrm{R}) \\
16(\mathrm{R})\end{array}$ & $\begin{array}{l}21 \\
30 \\
32\end{array}$ & $\begin{array}{l}307 \\
164 \\
120\end{array}$ & $\begin{array}{l}166 \\
126 \\
90\end{array}$ & {$[183]$} \\
\hline $\mathrm{Mg}-1 \mathrm{Mn}-0.3 \mathrm{Ca}$ & 30 & $\begin{array}{l}0.56 \\
5.6\end{array}$ & $\begin{array}{l}300 \\
300\end{array}$ & $\mathrm{~F}$ & $\begin{array}{l}\langle 10 \overline{1} 0\rangle 9.4 \\
\langle 10 \overline{1} 0\rangle 2.5\end{array}$ & $\begin{array}{l}5 \\
10\end{array}$ & $\begin{array}{l}19 \\
19\end{array}$ & $\begin{array}{l}234 \\
175\end{array}$ & $\begin{array}{l}187 \\
123\end{array}$ & [180] \\
\hline $\mathrm{Mg}-2 \mathrm{Ca}-2 \mathrm{Sn}$ & 20 & $0.3-1.3$ & $\begin{array}{l}220 \\
240 \\
280\end{array}$ & $\mathrm{~F}$ & 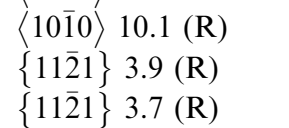 & $\begin{array}{l}0.3 \\
0.5 \\
0.7\end{array}$ & $\begin{array}{l}1 \\
3 \\
6\end{array}$ & $\begin{array}{l}443 \\
420 \\
386\end{array}$ & $\begin{array}{l}319 \\
308 \\
349\end{array}$ & [268] \\
\hline $\mathrm{Mg}-4 \mathrm{Li}$ & 25 & - & 200 & $\begin{array}{l}\mathrm{AC} \\
\mathrm{WQ}\end{array}$ & $\begin{array}{l}\langle 10 \overline{1} 0\rangle 6.6 \\
\langle 10 \overline{1} 0\rangle 13.9\end{array}$ & $\begin{array}{l}14 \\
7\end{array}$ & 15 & $\begin{array}{l}76 \\
103\end{array}$ & $\begin{array}{l}81 \\
108\end{array}$ & [269] \\
\hline & 41 & - & 200 & $\begin{array}{l}\mathrm{AC} \\
\mathrm{WQ}\end{array}$ & $\begin{array}{l}\langle 10 \overline{1} 0\rangle 5.7 \\
\langle 10 \overline{1} 0\rangle 16\end{array}$ & $\begin{array}{l}13 \\
6\end{array}$ & & $\begin{array}{l}77 \\
114\end{array}$ & $\begin{array}{l}83 \\
120\end{array}$ & \\
\hline & 71 & - & 200 & $\begin{array}{l}\mathrm{AC} \\
\mathrm{WQ}\end{array}$ & $\begin{array}{l}\langle 10 \overline{1} 0\rangle 13.4 \\
\langle 10 \overline{1} 0\rangle 14.5\end{array}$ & $\begin{array}{l}5 \\
5\end{array}$ & & $\begin{array}{l}114 \\
130\end{array}$ & $\begin{array}{l}123 \\
137\end{array}$ & \\
\hline Mg-4Li-1Al & $\begin{array}{l}25 \\
41\end{array}$ & - & 200 & $\begin{array}{l}\text { AC } \\
\text { WQ } \\
\text { AC }\end{array}$ & $\begin{array}{l}\langle 10 \overline{1} 0\rangle 4.8 \\
\langle 10 \overline{1} 0\rangle \\
\langle 10 \overline{1} 0\rangle 4.1\end{array}$ & $\begin{array}{l}12 \\
5 \\
11\end{array}$ & & $\begin{array}{l}101 \\
132 \\
105\end{array}$ & $\begin{array}{l}106 \\
136 \\
112\end{array}$ & \\
\hline
\end{tabular}


Table VII. continued

\begin{tabular}{|c|c|c|c|c|c|c|c|c|c|c|}
\hline \multirow[b]{2}{*}{ Alloy (Wt Pct) } & \multicolumn{4}{|c|}{ Processing Condition } & \multicolumn{2}{|c|}{ Microstructure } & \multicolumn{3}{|c|}{ Properties $* *$} & \multirow[b]{2}{*}{ References } \\
\hline & Ratio & $\underset{\left(\mathrm{mm} \mathrm{s}^{-1}\right)}{\text { Speed }}$ & $\begin{array}{l}\text { Temp. } \\
\left({ }^{\circ} \mathrm{C}\right)\end{array}$ & Remark & $\begin{array}{c}\text { Texture and } \\
\text { Intensity (MRD) }\end{array}$ & $\begin{array}{l}\mathrm{GS}^{*} \\
(\mu \mathrm{m})\end{array}$ & $\begin{array}{c}\text { El. } \\
\text { (Pct) }\end{array}$ & $\begin{array}{l}\text { TYS } \\
(\mathrm{MPa})\end{array}$ & $\begin{array}{l}\text { CYS } \\
(\mathrm{MPa})\end{array}$ & \\
\hline Mg-5Li-3Al-2Zn & 11 & - & 300 & $\mathrm{~F}$ & $\langle 10 \overline{1} 0\rangle 5.8$ & $5(\mathrm{R})$ & 16.9 & 151 & 104 & [270] \\
\hline $\begin{array}{l}\text { Data from Refs } \\
\text { - Information } n \\
\text { WQ: water quer }\end{array}$ & $\begin{array}{l}0,183 \\
\text { rovide } \\
\text { AC: ai }\end{array}$ & $\begin{array}{l}4,259-270] \\
(R) \text { recrys } \\
\text { ooling, GS: }\end{array}$ & zed g & elong & $\begin{array}{l}\text { ecrystallized samp } \\
\text { TYS: tensile yield }\end{array}$ & Alo & . & on dir & a. & \\
\hline
\end{tabular}

the microstructure changed from $\mathrm{A}+\mathrm{B}$ to $\mathrm{A}+\mathrm{B}+\mathrm{C}$ to $\mathrm{A}+\mathrm{C}$ to $\mathrm{A}$, with an increase in the extrusion temperature and speed. Under the condition of uniaxial tension or compression at a strain rate of $10^{-3} \mathrm{~s}^{-1}$ at room temperature, the MN10 extrusions exhibited tension-compression yield asymmetry for all extrusion speeds and temperatures, even though the phenomenon was less obvious for the extrusions made at lower temperatures, Figure 50(a). Under the same processing condition, the tension-compression yield asymmetry was significantly reduced for the MN11 extrusions, and became negligible when the extrusion speed was above $5.5 \mathrm{~mm} \mathrm{~s}^{-1}$, irrespective of the extrusion temperature, Figure 50(b). Examination of specimens extruded under different conditions indicated that the average grain size was in the range 14 to $22 \mu \mathrm{m}$ in the $\mathrm{Mg}-1 \mathrm{Mn}-0.5 \mathrm{Nd}$ alloy, and $11-22 \mu \mathrm{m}$ in the $\mathrm{Mg}-1 \mathrm{Mn}-1 \mathrm{Nd}$ alloy. For such grain sizes, the presence or absence of tension-compression yield asymmetry does not seem to be related to the grain size variation.

Extrusions of $\mathrm{Mg}-0.83 \mathrm{wt}$ pet $\mathrm{Mn}$ alloy exhibited super-formability at room temperature when they had fine grains. ${ }^{[281]}$ After extrusion at $150{ }^{\circ} \mathrm{C}$ with an extrusion ratio of $32: 1$, the alloy plate had fully recrystallized grains with an average grain size of 2.5 $\mu \mathrm{m}$ and a strong basal texture. Under an extraordinarily low forming rate, $10^{-5} \mathrm{~mm} \mathrm{~s}^{-1}$, at room temperature, the formability of the plate ${ }^{[281]}$ was as good as that of aluminum alloy 5083 .

It has been reported that $\mathrm{Mg}-0.3 \mathrm{Al}-0.21 \mathrm{Ca}-0.47 \mathrm{Mn}$ (wt pct) alloy can be extruded at ultra-fast speeds. ${ }^{[282]}$ This alloy is based essentially on the Mg-Mn system, as $\mathrm{Mn}$ is the major alloying element in terms of weight percentage in the alloy. It is therefore more appropriate to designate this alloy as MAX100 instead of AXM0301502. After indirect extrusion at $500{ }^{\circ} \mathrm{C}$, with an extrusion ratio of $20: 1$ and a die-exit speed of $60 \mathrm{~m} \mathrm{~min}^{-1}$, the extrusion was water quenched and aged for 4 hours at $200{ }^{\circ} \mathrm{C}$. The as-extruded microstructure had fully recrystallized grains that were $\sim 27 \mu \mathrm{m}$ and exhibited a weakened basal texture. Post-extrusion aging increased the yield strength from $170 \mathrm{MPa}$ in the as-extruded condition to $207 \mathrm{MPa}$, together with a small drop in ductility.

\section{Mg-Li-Based Alloys}

Plane-strain compression of single crystals of $\mathrm{Mg}-4 \mathrm{wt}$ pct Li alloy along different orientations was studied by Kelley and Hosford, ${ }^{[100,101]}$ and the results were compared with those obtained from single crystals of pure $\mathrm{Mg}$ deformed under the same condition, Figure 9. In orientations $\mathrm{C}$ and $\mathrm{D}$, the $\mathrm{Mg}-\mathrm{Li}$ alloy crystals deformed by prismatic slip, a mode not observed in the single crystals of pure $\mathrm{Mg}$. Uniaxial tension of single crystals of $\mathrm{Mg}-\mathrm{Li}$ alloys along the $\langle 2 \overline{1} \overline{1} 0\rangle$ orientation $^{[283]}$ revealed that the addition of $\mathrm{Li}$ to $\mathrm{Mg}$ decreased the yield strength that is dictated by pyramidal II slip.

Plane-strain compression of an as-cast and homogenized polycrystalline $\mathrm{Mg}-3 \mathrm{wt}$ pet $\mathrm{Li}$ alloy at room temperature and a strain rate of $5 \times 10^{-3} \mathrm{~s}^{-1}$ indicated the presence of a basal texture after a true strain of $\sim 0.3{ }^{[284]}$ The basal poles tended to align with the "normal direction" and spread towards the "rolling" direction. They were rotated away from the ND towards the RD by $\sim 20 \mathrm{deg}$, which is larger than that in the pure $\mathrm{Mg}$ deformed under the same condition. With the support from simulation results obtained from the viscoplastic self-consistent model, the formation of the deformation texture of the Mg-3wt pet Li alloy was attributed $^{[284]}$ to an increased activity of the non-basal slip of $\langle c+a\rangle$ dislocations.

Effects of texture and grain size on plastic deformation of Mg-4wt pet Li alloy were studied by Lentz and co-workers. ${ }^{[25]}$ The alloy was extruded at different temperatures $\left(200\right.$ to $\left.300{ }^{\circ} \mathrm{C}\right)$ and extrusion ratios $(25: 1$ to $71: 1)$ to obtain different grain sizes. The as-extruded microstructures had a basal texture: $\langle 10 \overline{1} 0\rangle / /$ ED or $\langle 10 \overline{1} 0\rangle-\langle 2 \overline{1} \overline{1} 0\rangle / / \mathrm{ED}$, depending on the extrusion temperature and ratio used. The basal texture intensity was found to increase with increasing extrusion ratio. The $\langle 10 \overline{1} 0\rangle / /$ ED component was relatively strong in the fine-grained extrusions, while the $\langle 2 \overline{1} \overline{1} 0\rangle / / \mathrm{ED}$ component was more obvious in the coarse-grained extrusions. For all extrusions, their compressive yield strength was slightly higher than the tensile yield strength, regardless of the texture and the grain size. This unusual tension-compression yield asymmetry was attributed $^{[285]}$ to an increased CRSS value to activate $\{10 \overline{1} 2\}\langle\overline{1011}\rangle$ extension twinning. Mg-4wt pet Li-1wt pet Al alloy produced under similar extrusion conditions had a weaker basal texture, with $\langle 10 \overline{1} 0\rangle-\langle 2 \overline{1} \overline{1} 0\rangle / /$ ED. ${ }^{[285]}$ While the addition of Al to the Mg-4wt pet $\mathrm{Li}$ alloy increased the yield strength in both tension and compression, the Mg-4wt pet Li-1wt pet Al alloy exhibited again the same phenomenon: the compressive yield strength was slightly higher than the tensile yield strength, regardless of the texture and the grain size. 
Effects of cold rolling and cold plane-strain compression on plasticity of thermomechanically processed Mg-4wt pet Li alloy were studied and reported by Al-Samman. ${ }^{[286]}$ With an average grain size of $80 \mu \mathrm{m}$ and a basal texture, this alloy exhibited remarkable room temperature formability: it could be cold-rolled by 86 pet without fracture. In contrast, AZ31 having a similar microstructure could be cold-rolled by a maximum thickness reduction of 26 pct, even with the use of a small thickness reduction per cold rolling pass. ${ }^{[286]}$ The microstructure of the Mg-4wt pet Li alloy cold-rolled by 86 pct contained a large volume fraction fine-scale shear bands that were aligned at approximately \pm 35 deg from the rolling direction. Under the condition of room temperature plane-strain deformation at a strain rate of $10^{-4} \mathrm{~s}^{-1}$, the Mg-4wt pet Li alloy could be deformed by up to 1.2 strain. Examination of the microstructures of specimens deformed by 1.0 strain revealed the absence of voids and the presence of both $\{10 \overline{1} 2\}$ and $\{10 \overline{1} 1\}$ twins. Al-Samman suggested ${ }^{[286]}$ that twinning was an important deformation mode. He further suggested that the remarkable formability at room temperature was due to enhanced non-basal slip, especially the $\langle c+a\rangle$ slip mode that was promoted by the $\mathrm{Li}$ addition.

\section{REMAINING AND EMERGING ISSUES}

Despite the significant progress that has been made on wrought Mg alloys in the past 20 years, ${ }^{[287-297]}$ there are still some unsolved and challenging scientific and technological issues on microstructure, deformation, and property of these group of alloys. For example, at the scientific level, the origin of the mysterious pyramidal plane fiber textures and their evolution with strain, strain rate, and temperature in alloys containing different types and concentrations of alloying elements remain unclear; and at the technological level, room temperature formability of $\mathrm{Mg}$ alloy sheet still needs to be further improved and to be combined with higher strength. Such issues will now be discussed further in the following five sections.

\section{A. Deformation and Recrystallization Textures}

A relatively wide range of textures have been observed in wrought $\mathrm{Mg}$ alloys. In order to reveal and highlight remaining and emerging issues associated with deformation and recrystallization textures, and more importantly, the influence of alloy composition, strain path, and annealing, all the textures reported so far are analyzed under the category of sheets and extrusions.

\section{Textures in sheets}

For sheets made of different alloys, they all have basal textures, even though the dominant texture component may change with alloy composition and processing condition. In general, the basal texture can be classified into two groups: strong basal (SB) and weak basal (WB), and within each group there are two special components, Figure 51(a). The two special components in the SB group:
[0001] // ND, and $\langle 10 \overline{1} 0\rangle / /$ RD, SB-1

[0001]// ND, and $\langle 2 \overline{1} 10\rangle / /$ RD. SB-2

SB-1 and SB-2 components are related with each other by $30 \mathrm{deg}$ rotation about the [0001] axis. Basal textures having a mixture of these two components, or spreading between these two components, are not listed for simplicity, even though they also form in $\mathrm{Mg}$ sheet. Such textures include, for example, [0001] // ND and $\langle 10 \overline{1} 0\rangle-\langle 2 \overline{1} 10\rangle / / \mathrm{RD}$, where the expression of $\langle 10 \overline{1} 0\rangle-\langle 2 \overline{1} \overline{1} 0\rangle$ represents the directions lying in the basal plane and spreading between the $\langle 10 \overline{1} 0\rangle$ and $\langle 2 \overline{1} \overline{1} 0\rangle$ directions. It is to be noted that SB-1 component is the dominant texture of severely deformed sheet of pure $\mathrm{Mg}$ and all $\mathrm{Mg}$ alloys, and therefore it can be designated as deformation texture. The SB-2 component is the dominant texture of fully recrystallized microstructure of pure $\mathrm{Mg}$ and $\mathrm{Mg}$ alloys free of $\mathrm{Ca}$ and RE, and it is termed recrystallization texture.

Similar to the SB group, the WB group also has two special components:

[0001] $\sim \pm$ from ND towards RD (RD-split) WB-1

[0001] $\sim A$ from ND towards TD, and $\langle 10 \overline{10}\rangle / / \mathrm{RD}$ (TD-split) WB-2

It is currently difficult to assess what poles are parallel, or close to, to the TD or RD in the WB-1 component, as this information is not provided in most previous studies. Inspection of the inverse pole figure along the RD of Mg-1wt pet Gd sheet ${ }^{[234]}$ indicates that $\langle 10 \overline{1} 0\rangle$ scatters around the RD, implying that $\langle 10 \overline{1} 0\rangle$ might have rotated by $\pm \alpha$ away from $R D$ towards ND. This needs to be examined in future research. The angles of $\alpha$ and $\beta$ change with the deformation, annealing, and alloying additions. The angle of $\alpha$ can be as high as $35 \mathrm{deg}$, and that of $\beta$ can be up to $40 \mathrm{deg}$. The WB-1 texture forms in Mg-RE alloys, and WB-2 is often associated with $\mathrm{Mg}-\mathrm{Zn}-\mathrm{Ca}$ and $\mathrm{Mg}-\mathrm{Zn}-\mathrm{RE}$-based alloys.

\section{Textures in extrusions}

Mg alloy extrusions have a wider range of textures than $\mathrm{Mg}$ alloy sheets. Extrusions of even a single alloy may have quite different textures, depending on its composition, extrusion profile, and extrusion conditions. For simplicity, only the cylindrical profile is considered in the classification of fiber textures of $\mathrm{Mg}$ extrusions. Similar to the texture classification made for sheets, textures associated with cylindrical Mg alloy extrusions can be classified into three groups: basal fiber $(\mathrm{BF})$, pyramidal fiber $(\mathrm{PyF})$, and prismatic fiber $(\mathrm{PrF})$, Figure 51(b). The BF group has two special components:

(0002) $/ / \mathrm{ED}$, and $\langle 10 \overline{1} 0\rangle / / \mathrm{ED}, \mathrm{BF}-1$

(0002) $/ / \mathrm{ED}$, and $\langle 21 \overline{1} 0\rangle / / \mathrm{ED}$. BF-2

Again, the basal texture spreading between these two components, namely, (0002) // ED and $\langle 10 \overline{1} 0\rangle-\langle 2 \overline{1} \overline{1} 0\rangle$ $/ / \mathrm{ED}$, is not listed for simplicity. BF-1 is the dominant texture of cold or warm extruded pure $\mathrm{Mg}, \mathrm{AM}, \mathrm{AZ}$, $\mathrm{Mg}-\mathrm{Mn}, \mathrm{Mg}-\mathrm{Li}$, and $\mathrm{Mg}-\mathrm{RE}$ alloys, and is thus termed deformation texture. BF-2 is the dominant texture of fully recrystallized microstructure of pure $\mathrm{Mg}$ and $\mathrm{AM}$, 
$\mathrm{AZ}, \mathrm{Mg}-\mathrm{Mn}$, and $\mathrm{Mg}-\mathrm{Li}$ alloys, and is hence designated recrystallization texture.

The PyF group has two special components:

Pyramidal plane //ED, and $\langle 10 \overline{1} \mathrm{~m}\rangle / / \mathrm{ED}, \mathrm{PyF}-1$

Pyramidal plane // ED, and $\langle 2 \overline{1} \overline{1} \mathrm{n}\rangle / / \mathrm{ED}, \mathrm{PyF}-2$

where $\mathrm{m}$ represents $2 / 3,1$, or 1.5 , and $\mathrm{n}$ represents 1 ,

2 , or 3. Pyramidal fiber textures having a mixture of these two components, or spreading between these two components, are not listed for simplicity, even though they are frequently found in $\mathrm{Mg}$ extrusions. Such textures include, for example, pyramidal plane // ED and $\langle 2 \overline{1} \overline{1} \mathrm{n}\rangle-\langle 10 \overline{1} \mathrm{~m}\rangle / / \mathrm{ED}$, where the expression of $\langle 2 \overline{1} \overline{1} \mathrm{n}\rangle-\langle 10 \overline{1} \mathrm{~m}\rangle$ represents the directions lying in the pyramidal plane and spreading between the $\langle 2 \overline{1} \overline{1} \mathrm{n}\rangle$ and $\langle 10 \overline{1} \mathrm{~m}\rangle$ directions. Since the crystallographic position of the intensity maxima of the poles along the ED was not clearly marked in the inverse pole figure in most studies made in the past, ${ }^{[184,247,248,251,254]}$ and the area selected for an EBSD map might not be sufficiently large in some previous studies, it is difficult to know precisely which one of the $\langle 2 \overline{1} \overline{1} \mathrm{n}\rangle$ family forms most frequently, and which one of the $\langle 10 \overline{1} \mathrm{~m}\rangle$ family often occurs. The use of a larger area for EBSD mapping, and more careful and accurate analyses of the resultant EBSD data are needed in future studies. The PyF-1 and PyF-2 textures form frequently in $\mathrm{Mg}$ - RE alloys and $\mathrm{Mg}-\mathrm{Zn}-\mathrm{Ca}-\mathrm{Mn}$ alloys.

The PrF group has only one component:

Prismatic plane // ED, and [0001] // ED.

This texture is found in a few alloys that are extruded under some particular conditions, and such alloys include $\mathrm{Mg}$-Mn-RE alloys, Elektron 675 and $\mathrm{Mg}-\mathrm{RE}-\mathrm{Zn}$ and Mg-RE-Ag alloys that contain a larger amount of RE elements.

In the case of extrusion textures, they appear to change significantly with extrusion parameters and alloy compositions, especially for the pyramidal fiber textures. For example, $\mathrm{Mg}-\mathrm{RE}$ dilute alloys may exhibit any of the extrusion textures of the three groups mentioned above, depending on the extrusion speed, ratio, and temperature used; but $\mathrm{Mg}-\mathrm{RE}$ alloys containing higher concentrations of $\mathrm{RE}$ elements and $\mathrm{Zn}$ (or $\mathrm{Ag}$ ) do not seem to have any pyramidal fiber components. The presence of second-phase particles, precipitates, or larger concentrations of $\mathrm{RE}$ and $\mathrm{Zn} / \mathrm{Ag}$ atoms seems to affect the formation of the individual RE-texture components. The condition under which each texture component forms still remains largely unclear.

\section{Alloying effects on texture and dynamic} recrystallization

Considerable efforts have been made in the past 20 years on texture characterization by EBSD, and a trend of using inverse pole figures to analyze EBSD data has emerged. The use of inverse pole figures provides important clues to the type of texture in alloys produced under different strain paths or thermomechanical processing conditions. While the texture types in wrought $\mathrm{Mg}$ alloys are relatively well established, the origin of texture weakening or texture change caused by some specific alloying additions, such as $\mathrm{RE}, \mathrm{Ca}$, or combined additions of $\mathrm{RE} / \mathrm{Ca}$ and $\mathrm{Zn}$, is still largely unclear. In most studies, EBSD is used to reveal the nucleation and the early stage of growth of recrystallized grains. The spatial resolution of EBSD is about several-hundred nanometres, and therefore the size of the region that this technique can analyze is well above that corresponding to the nucleation stage or even the early stage of growth. An associated deficiency is that EBSD alone cannot provide any information on the chemistry in that region. While it is generally accepted that recrystallized grains form in highly strained regions, there is currently little information on the identity, distribution, and concentration of solute atoms in deformed regions, especially the regions where the recrystallized grains start to form. To reveal the origin of the texture change, the EBSD technique needs to be combined with other techniques that are capable of providing texture and chemical information at a much finer scale. The emerging techniques of transmission Kikuchi diffraction $(\mathrm{TKD})^{[298]}$ and transmission scanning electron microscopy $(\text { TSEM })^{[299]}$ have a spatial resolution of tens of nanometres, which are an order of magnitude better than EBSD. The combined use of these diffraction and imaging techniques, together with energy-dispersive $\mathrm{X}$-ray spectroscopy (EDXS) mapping technique, offers an opportunity for collecting texture and chemistry information from a nano-sized recrystallized grain and its neighboring deformed grain(s). An additional advantage of TSEM is its capability for in-situ straining and direct observation of the evolution of dislocations, twins, and stacking faults during the straining process. With these modern techniques, it is now timely to explore the origin of the mysterious pyramidal plane fiber textures and their evolution with strain, strain rate, and temperature in alloys containing different types and concentrations of alloying elements.

Dynamic recrystallization is an effective way to accommodate plastic deformation. If it could be tailored to occur readily at room temperature, then room temperature formability of $\mathrm{Mg}$ sheet would be substantially improved. Currently, there are limited studies on dynamic recrystallization, even in pure $\mathrm{Mg}$. Effects of alloying elements, which exist in the form of solute atoms, solute clusters, or/and precipitates inside grains or segregation along grain boundaries, on the recrystallization temperature are largely unknown. The interactions between solute/solute-cluster/precipitate and strain carriers (dislocation and twin), and that between segregated solutes and inter-granular deformation/migration mechanisms, have not been characterized in detail. The limited studies made so far indicate that solute atoms of some alloying elements may form ordered clusters ${ }^{[300]}$ and may segregate strongly to, and interact strongly with, twin boundaries and tilt boundaries. ${ }^{[6,71,301]}$ While it has also been recognized that the atoms of some added alloying elements may segregate strongly to grain boundaries, as will be discussed in the sub-section B, the precise influence of these alloying elements on texture formation and evolution seems to have been largely overlooked in the past. The solute atoms segregated in grain boundaries may change the boundary structure and may also exert a strong pinning force 
during boundary deformation and/or migration. Their presence also leads to reduced grain boundary energy which in turn leads to reduced tendency for the migration of that section of the grain boundary.

\section{B. Solute Segregation in Grain Boundary}

With the application of imaging and spectroscopy techniques of STEM and atom probe tomography, it is now known that atoms of some added alloying elements often segregate to grain boundaries in $\mathrm{Mg}$ alloys. Such alloying elements include at least Gd and $Y^{[302-305]}$ There are controversial reports on the other alloying elements such as $\mathrm{Al}, \mathrm{Zn}$, and $\mathrm{Mn}$. In the work made by EDXS attached to a conventional transmission electron microscope, Hadorn and co-workers ${ }^{[302]}$ reported that $\mathrm{Y}$ atoms segregated strongly to grain boundaries in hot-rolled and annealed $\mathrm{Mg}-\mathrm{Y}$ binary alloys, but that $\mathrm{Zn}$ atoms did not segregate in a $\mathrm{Mg}$ - $\mathrm{Zn}$ alloy that was produced under similar thermomechanical processing conditions. However, a study made recently by Zeng et al. ${ }^{[169]}$ on extruded Mg-1wt pet Zn alloy using EDXS mapping of aberration-corrected STEM indicated clearly that $\mathrm{Zn}$ atoms segregated to grain boundaries. The segregation of $\mathrm{Zn}$ atoms to grain boundaries was also observed in AZ31 without and with $\mathrm{Ca}$ additions ${ }^{[172]}$ that were extruded under similar conditions, Figure 38, and in hot-rolled AZMX3110 (Mg-3Al-1Zn-1Mn-0.5Ca, wt pet) alloy ${ }^{[158]}$ where the $\mathrm{Zn}$ segregation was revealed by atom probe tomography (APT). Another study made by EDXSSTEM of hot-rolled and annealed $\mathrm{Mg}-1.1 \mathrm{Zn}$ and $\mathrm{Mg}-0.16 \mathrm{Ca}$ binary alloys and $\mathrm{Mg}-0.8 \mathrm{Zn}-0.16 \mathrm{Ca}$ ternary alloy (all in wt pct) also found the segregation of $\mathrm{Zn}$, and $\mathrm{Ca}$, in grain boundaries. ${ }^{[193]}$ These latest characterization results indicate that the segregation of $\mathrm{Zn}$ atoms in grain boundaries is common.

There also exist controversial reports on the segregation of $\mathrm{Al}$, which is the most commonly used alloying element in $\mathrm{Mg}$ alloys. A study made recently by EDXS-STEM did not detect any apparent segregation of $\mathrm{Al}$ atoms in grain boundaries of AZ31 that was extruded at both low and high temperatures. ${ }^{[169]}$ Two recent studies made by APT and EDXS-STEM indicated that $\mathrm{Al}$ atoms segregated to grain boundaries in hot-rolled AZMX3110 $0^{[158]}$ and extruded AZ31 with Ca additions. ${ }^{[172]}$ It is to be noted that grain boundary segregation of $\mathrm{Ca}$ atoms was also found in the AZMX3110 alloy and the AZ31 with $\mathrm{Ca}$ additions, and that $\mathrm{Al}$ and $\mathrm{Ca}$ have strong affinity. It remains to be reconciled whether the apparent segregation of the $\mathrm{Al}$ atoms depends on specific alloy compositions.

For the reason that is not fully understood, there are again controversial reports on yet another commonly used alloying element, Mn. An early study of an extruded Mg-Mn binary alloy by APT reported that $\mathrm{Mn}$ atoms segregated to grain boundaries. But two recent studies, made by EDXS-STEM ${ }^{[169]}$ and APT, ${ }^{[158]}$ reported that $\mathrm{Mn}$ did not segregate to grain boundaries in AZ31 and AZMX3110.

Concerted efforts are needed in the forthcoming years in order to resolve the above-mentioned controversial reports and to establish the relationship between solute segregation and the type of grain boundaries. Computation studies of solute segregation and its effects on grain boundary structure and migration ${ }^{[306,307]}$ also need to be done at the same time. It is to be noted that there are high-angle grain boundaries and low-angle grain boundaries in all wrought products, regardless of the texture type that results from a particular processing condition. If solute atoms of a given alloying element would prefer to segregate to grain boundaries, then the atoms of this element would be expected to segregate to a high-energy, rather than low-energy, boundary. Under this hypothesis, some grain boundaries would contain segregated atoms of this element, while the others would not. It is also natural to expect different concentrations of the segregated solute atoms in different types of grain boundaries. It is rather unfortunate that all characterization results reported so far do not provide such information - whether the observed solute segregation is associated with a grain boundary that is of high-angle and thus high energy. Future characterization needs to combine quantitative EDXS-STEM with electron diffraction techniques, or combine ATP with EBSD and focused ion beam (FIB), to collect information on both grain boundary type and solute concentration in such boundaries. This information is critically needed for the understanding of the roles of solute segregation in grain boundary deformation, grain boundary migration, and recrystallization mechanisms.

\section{Room Temperature Formability of Sheet}

The data from pure $\mathrm{Mg}$ and the alloys shown in Tables II, IV, and VI are plotted in Figure 52 to illustrate the relationship between room temperature formability, texture, grain size, and yield strength. The formability is represented by the Erichsen value, and the texture is indicated by the basal texture intensity. Since the basal texture intensity is influenced by the technique (XRD or EBSD) used in the measurements and the parameters such as the scan area, step size, and index rate in the use of EBSD, an effort is made in this review to make sure that the data selected for the plots were all obtained from the XRD or EBSD scans from sufficiently large areas (containing about 600 to 3500 grains) that are representative. Note that there are some uncertainties on the accuracy of grain sizes, as most studies made so far did not vigorously use the ASTM E112 standard for their grain size measurements and they rarely took surface-truncation correction into consideration when they converted the measured planar grain size into the spatial grain size. Further note that, while the use of grain size is simpler, it may mask or overlook the potential influence of another factor that is intimately related with grain size: the grain size distribution. Inspection of the trend of the data in Figure 52(a) seems to indicate that the sheet formability is influenced by the texture and the grain size, except the $\mathrm{Mg}-\mathrm{Zn}-\mathrm{Ca}$ alloys whose formability is good even at larger grain sizes $(30-50 \mu \mathrm{m})$. For the banana-shaped relationship between Erichsen value and basal texture intensity, Figure 52(b), the trend of the data indicates clearly that better formability is associated with weaker 
Table VIII. Texture, Grain Size, Tensile, and Compressive Properties at Room Temperature of Mg-Sn-Based Extrusions of Different Alloy Compositions and Produced under Different Processing Conditions

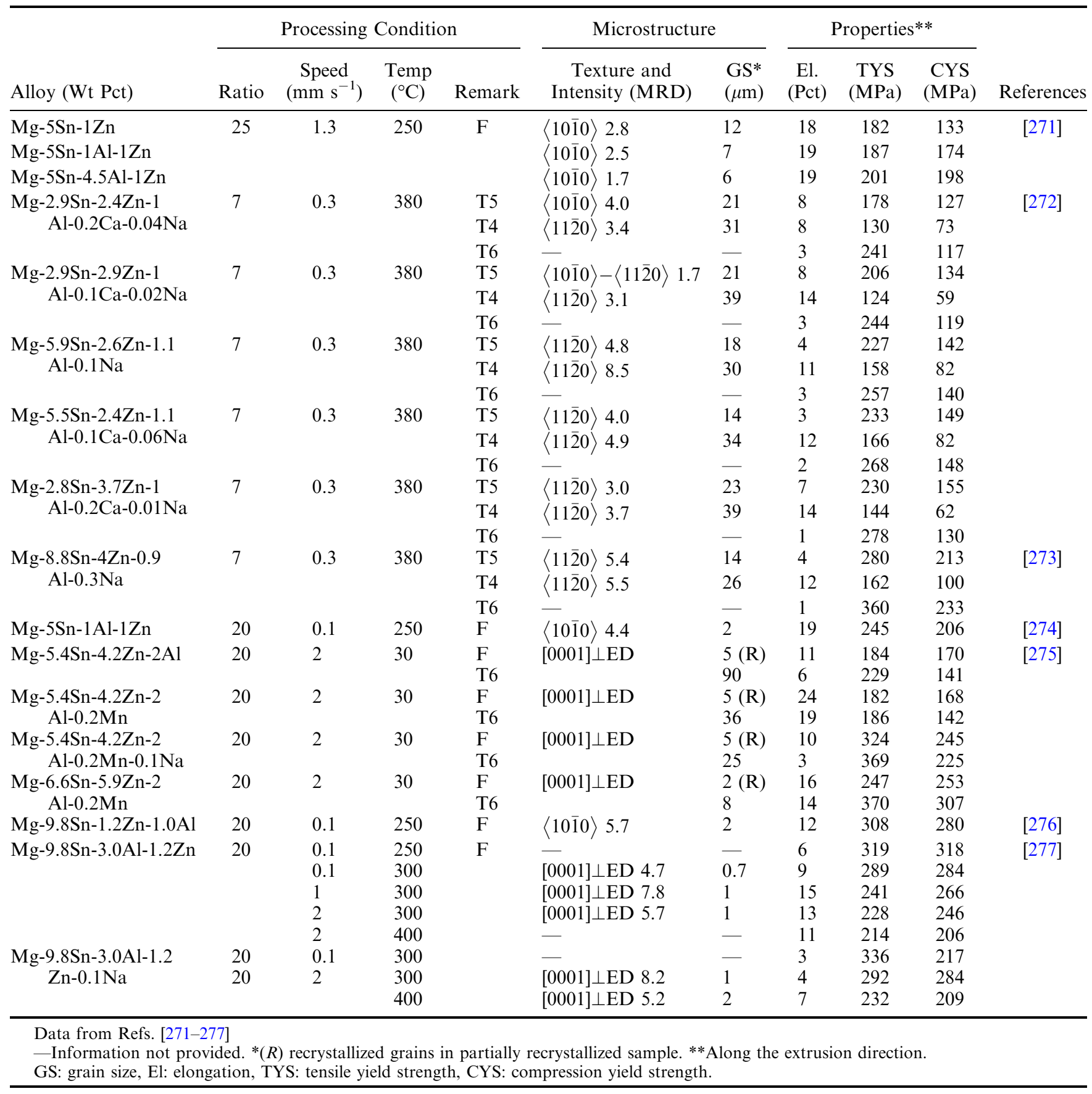

basal texture intensity. Sheets with an Erichsen value above 7 all have a basal texture intensity less than 5 MRD. In general, sheets with lower basal texture intensity have higher ductility and lower yield strength, Figure 53(a) and (b).

The influence of grain size on sheet formability is less clear, as shown in Figure 52(c). If good formability is defined as having an Erichsen value of 7 or larger, then the grain size in sheets having good formability can be as large as $50 \mu \mathrm{m}$, as indicated by the data inside the red dashed frame in Figure 52(c). Even if the data from the
$\mathrm{Mg}-\mathrm{Zn}-\mathrm{Ca}$ alloys are not considered, the grain sizes in sheets having good formability are still in the range 5 to $25 \mu \mathrm{m}$. For sheets having small grain sizes, even around $10 \mu \mathrm{m}$, their Erichsen values vary dramatically between 3 and 9. It is to be noted that a small grain size usually leads to higher strength, Figures 53(c) and (d), which usually makes sheet less formable. The grain size effect on sheet strength is more obvious in sheet having a stronger basal texture, Figure 53(c). As indicated by the banana-shaped curve in Figure 52(d), sheets with high yield strengths are usually of poor formability. At the 
present, there is only one alloy, based on the $\mathrm{Mg}-\mathrm{Al}-\mathrm{Ca}$ system, having a combination of good formability $(>7$ EI) and high strength ( $>200 \mathrm{MPa})$. Further
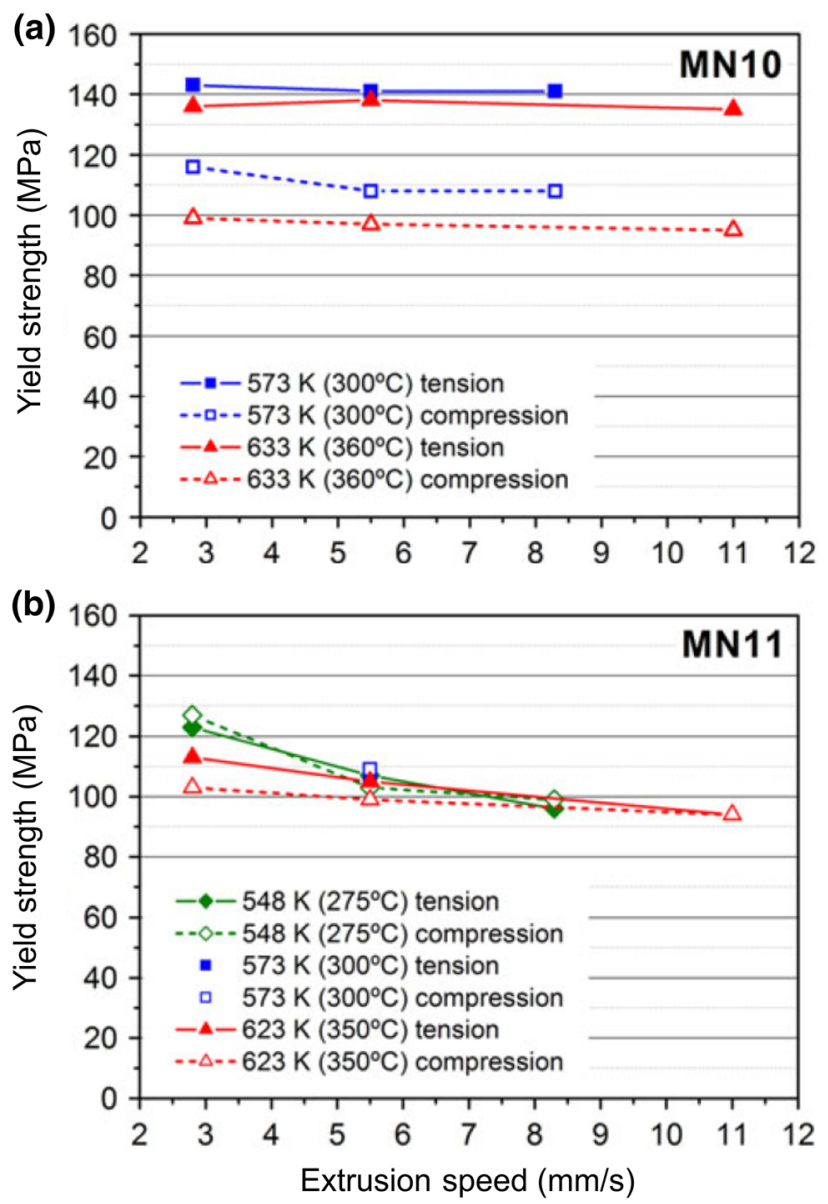

Fig. 50-Variation of room temperature tensile and compressive yield stresses with extrusion temperature and speed for (a) MN10 and (b) MN11 alloys. Reprinted from Ref. [280]. development in alloy sheet needs to either enhance the strength of those having good formability (outlined by the red dashed frame), or increase the formability of those having high strength (blue dashed frame).

\section{Tension-Compression Yield Asymmetry}

The problem of tension-compression yield asymmetry is intrinsic of single crystals of pure $\mathrm{Mg}$ deformed along some specific directions, Figures 11 and 12. This problem also exists in polycrystalline products such as pure $\mathrm{Mg}$ and AZ31 that are produced by conventional thermomechanical processing in the temperature range 300 to $450{ }^{\circ} \mathrm{C}$. Such wrought products generally have a strong basal texture and grain sizes in the range 5 to $50 \mu \mathrm{m}$. Due to the presence of the strong basal texture, plastic deformation occurs at much lower stress in compression than that in tension along the extrusion direction, due to the occurrence of $\{10 \overline{1} 2\}\langle\overline{1} 011\rangle$ twinning that cannot be activated upon tensile loading. The $\{10 \overline{1} 2\}\langle\overline{1011}\rangle$ twinning was suggested to be grain size dependent and to occur in AZ31 extrusions having an average grain size above $2 \mu \mathrm{m} .{ }^{[188]}$ It seems that it is for this observation, and the reasoning based on it, that the tension-compression yield asymmetry has been traditionally attributed to the occurrence of $\{10 \overline{1} 2\}\langle\overline{1} 011\rangle$ twinning that is associated with the strong basal texture, and that attempts made in the past 20 years have been focused mainly on basal texture weakening.

However, it has been demonstrated in recent years that the tension-compression yield asymmetry problem can be fully eliminated even with the presence of a strong basal texture. Notable examples include $\mathrm{Mg}-\mathrm{Mn}-\mathrm{RE}$ and $\mathrm{Mg}-\mathrm{Li}(-\mathrm{Al})$ alloys that are produced by conventional extrusion conditions, in which the grain size is in the range 5 to $25 \mu \mathrm{m}$, and pure $\mathrm{Mg}$ and AZ31 that are extruded at temperatures lower than those used

(a) Strong basal Weak basal

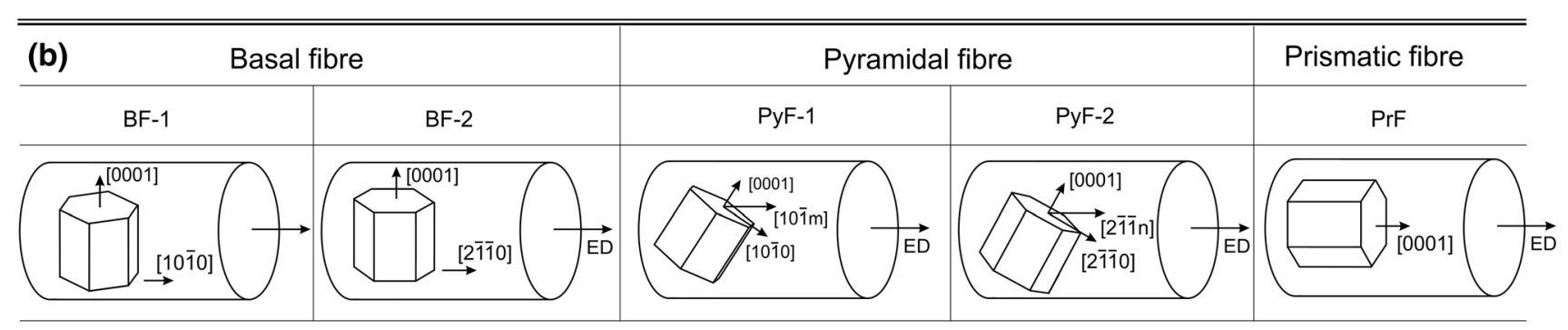

Fig. 51-(a) Sheet textures, and (b) extrusion textures of pure $\mathrm{Mg}$ and its alloys. 


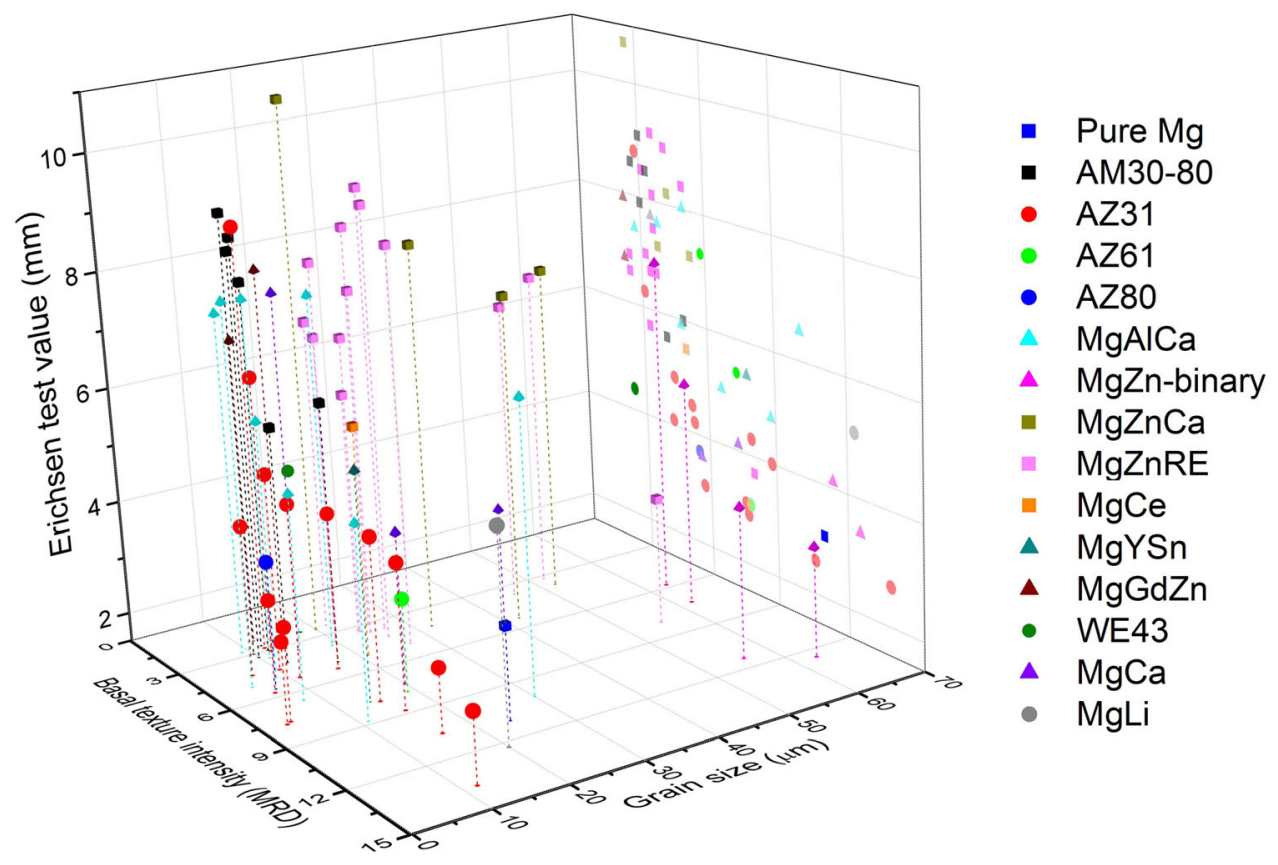

(a)

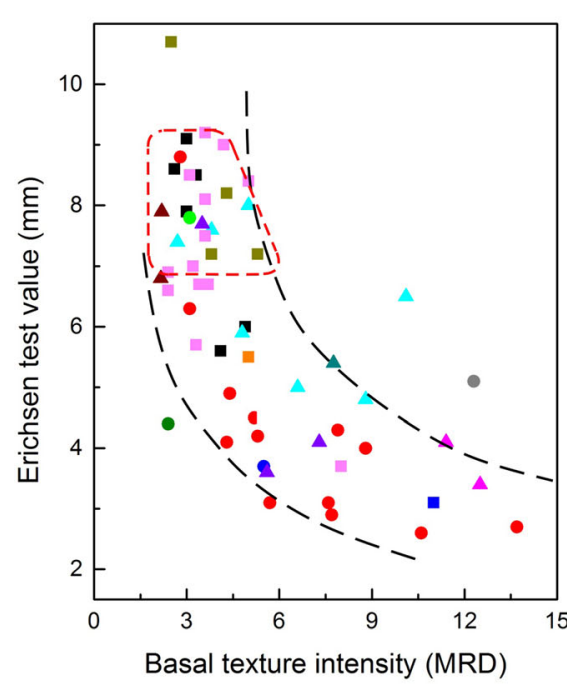

(b)

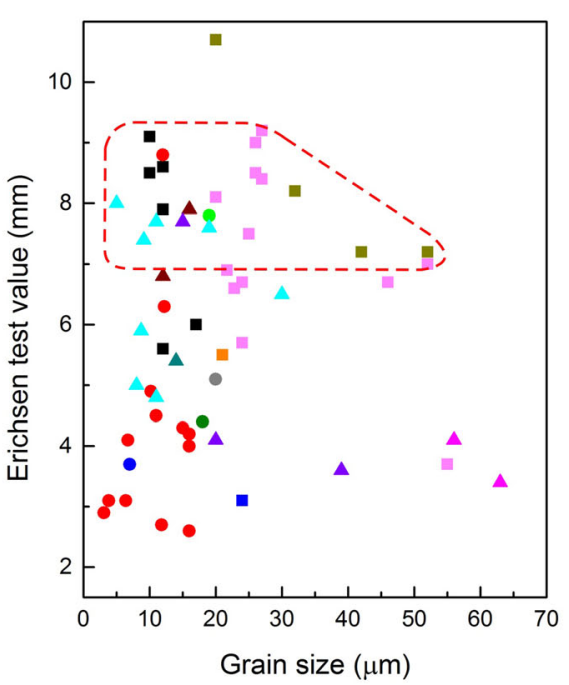

(c)

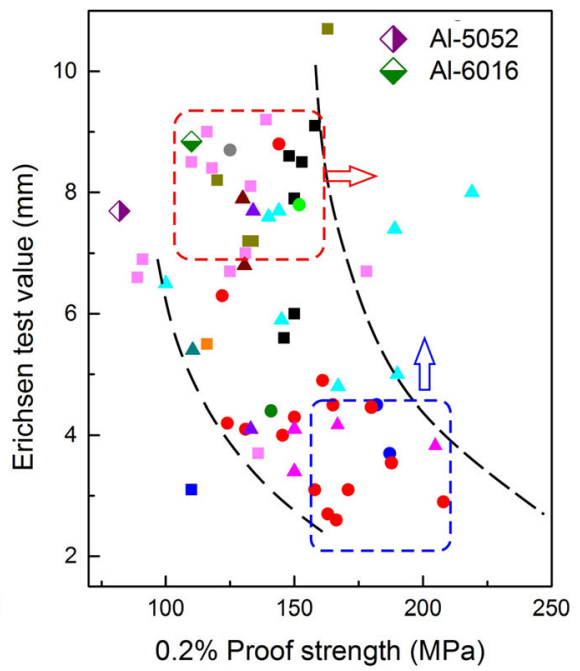

(d)

Fig. 52-Relationship between room temperature formability and $(a)$ basal texture intensity and grain size, $(b)$ basal texture intensity, $(c)$ grain size, and $(d)$ tensile yield strength along the rolling direction for pure $\mathrm{Mg}$ and $\mathrm{Mg}$ alloy sheets. Sheets with good formability are highlighted by red dashed frames in (b-d).

conventionally, in which the grain size is in the order of $1 \mu \mathrm{m}$. It is rather unfortunate that deformation microstructures of the Mg-Mn-RE and Mg-Li(-Al) extrusions have not been characterized in greater depth. It is therefore difficult to conclude whether the diminished or eliminated tension-compression yield asymmetry is associated with any difficulty involved in activating $\{10 \overline{1} 2\}\langle\overline{1} 011\rangle$ twinning. This aspect needs more research in the future. Pure $\mathrm{Mg}$ and AZ31 can have a fully recrystallized microstructure when they are extruded at temperatures much lower than those used in the conventional processing. While they both can have a grain size of $\sim 1 \mu \mathrm{m}$ and a dominant basal texture, they respond differently to compressive loading, Figures 28 and 39. The dominant deformation mode in each is still speculative and worth further exploration in the future. It is to be noted that there is a strong segregation of $\mathrm{Zn}$ atoms, in addition to the presence of Al-Mn dispersoids, in grain boundaries of the AZ31. Given that $\mathrm{Zn}$ segregation in grain boundaries also occurs in the coarse grain microstructure, it is currently unclear whether the concentration of segregated $\mathrm{Zn}$ atoms in a fine-grained microstructure is similar to that in a coarse-grained microstructure. While it is natural to think of a lower concentration of $\mathrm{Zn}$ atoms in a 


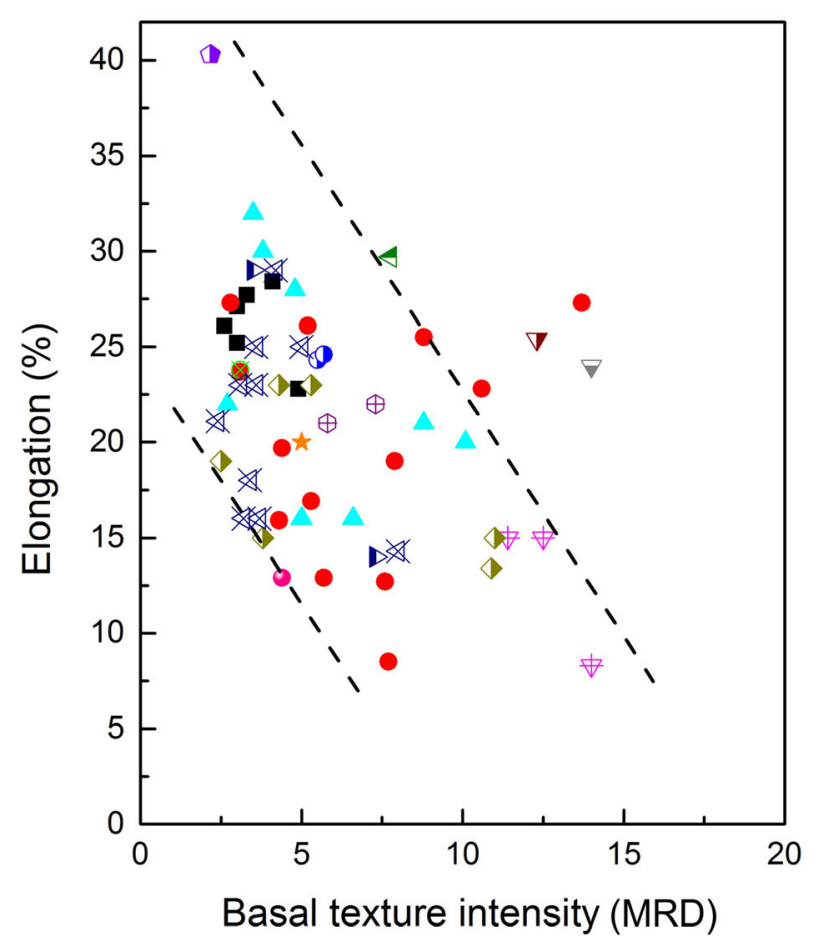

(a)

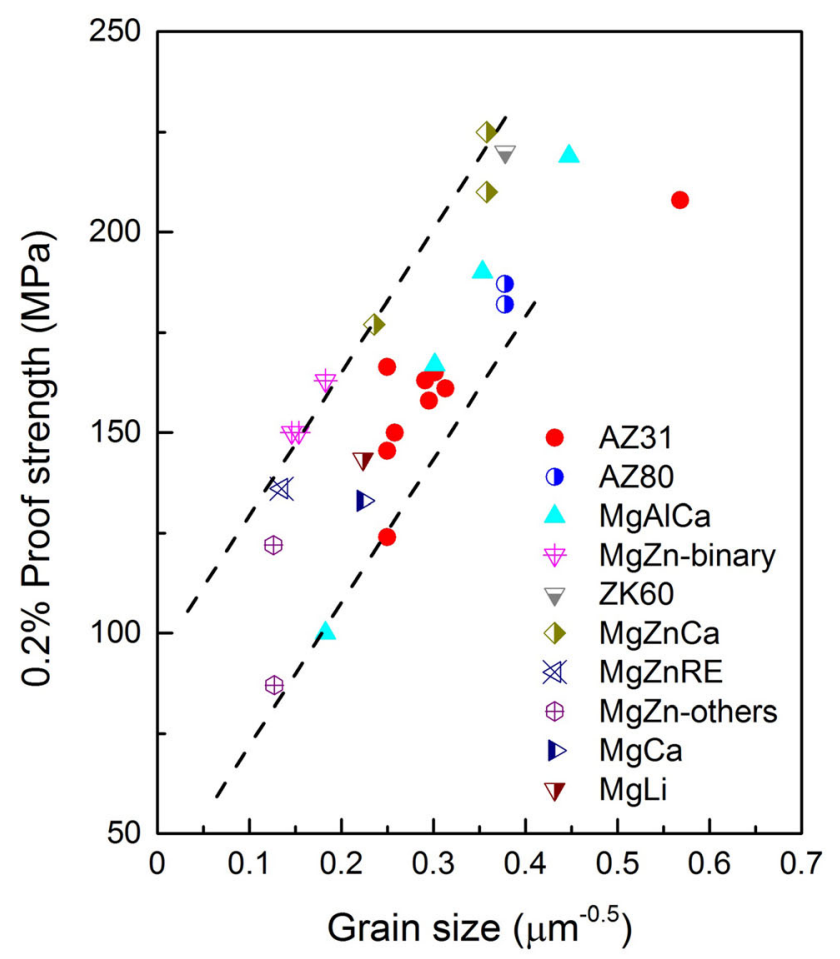

(c)

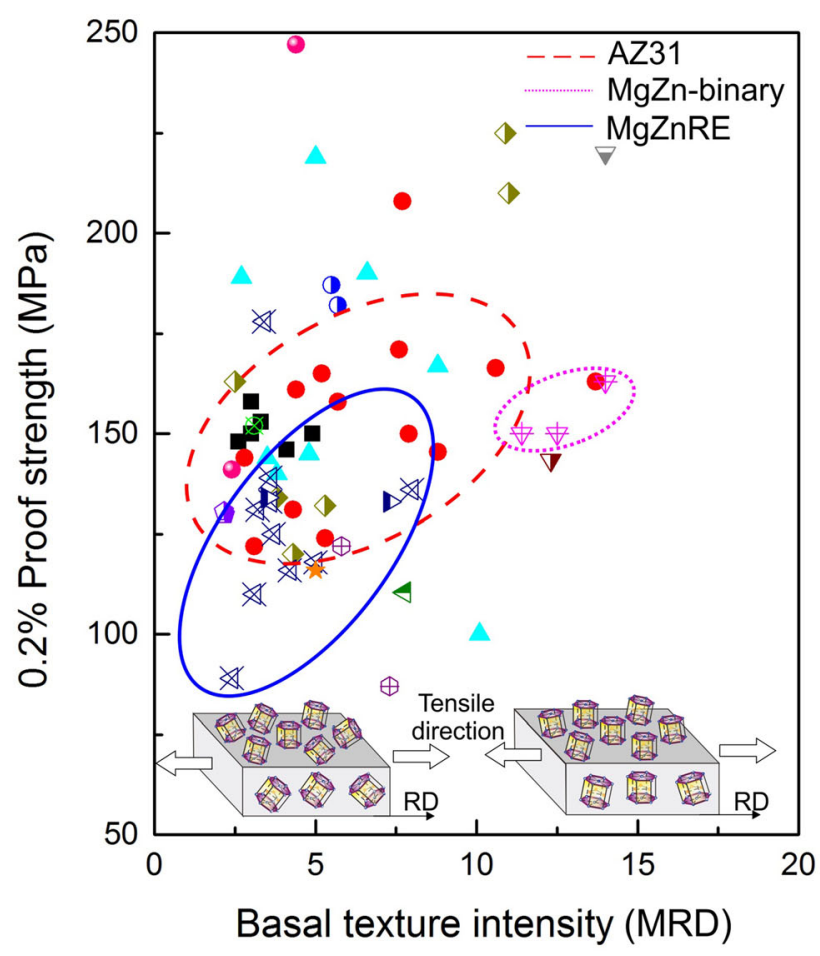

(b)

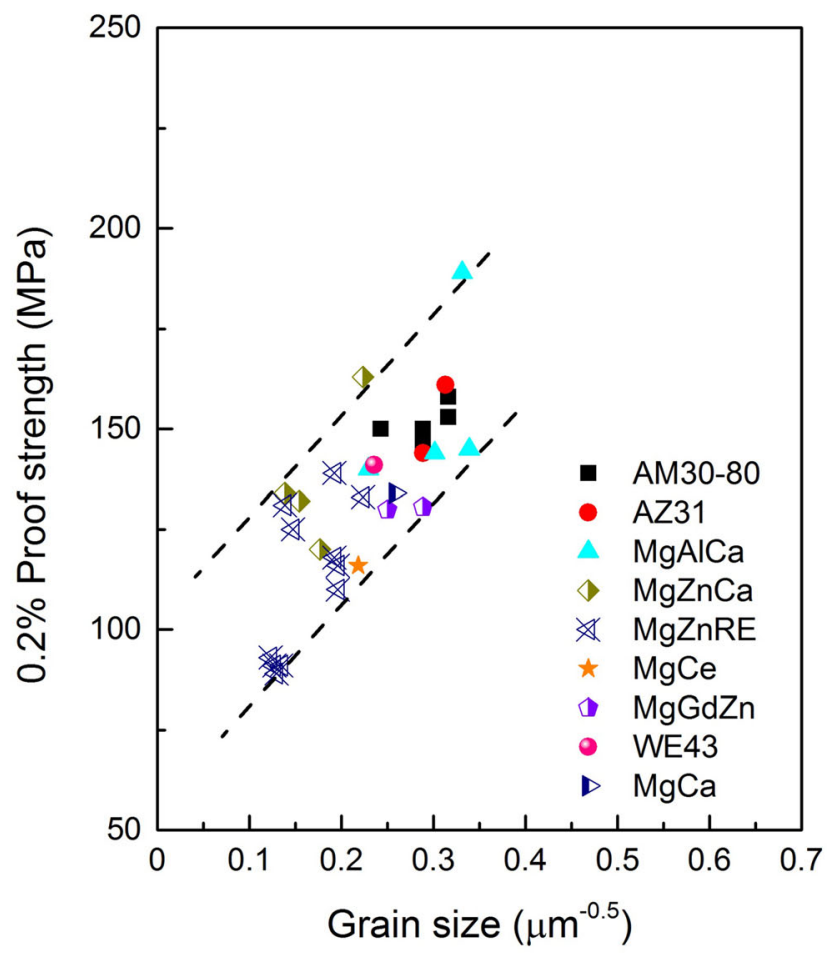

(d)

Fig. 53-Relationship between $(a)$ elongation and basal texture intensity, $(b)$ tensile yield strength along the rolling direction and basal texture intensity, and $(c, d)$ tensile yield strength along the rolling direction and grain size for $\mathrm{Mg}$ alloy sheets. The basal texture intensity value is larger than 5 in $(c)$ and smaller than 5 in $(d)$. The Hall-Petch coefficient $k$ value is $\sim 375 \mathrm{MPa} \mu \mathrm{m}^{0.5}$ for sheets having a strong basal texture (c), and $\sim 250 \mathrm{MPa} \mu \mathrm{m}^{0.5}$ for sheets having a weak basal texture $(d)$. 
fine-grained microstructure due to the larger fraction of grain boundaries, the fine-grained microstructure is usually produced at a lower extrusion temperature and thus more $\mathrm{Zn}$ atoms may be available to segregate to grain boundaries from the solid solution matrix. This aspect requires detailed characterization using APT or quantitative spectroscopy techniques of STEM. The role of segregated atoms of added alloying elements in plastic deformation is a subject that requires more research in the future.

Based on the existing data of pure $\mathrm{Mg}$ extrusions and the data of $\mathrm{Mg}$ alloy extrusions in Tables III, V, VII, and VIII, the relationships between tension-compression yield asymmetry, texture, grain size, and tensile yield strength are plotted and shown in Figure 54. The trend of the data seems to indicate that the texture and the grain size are probably equally important in the control of the tension-compression yield asymmetry. With a decrease in the basal texture intensity, the grain size, or both, the tension-compression yield asymmetry reduces, Figure 54(a). It is to be noted that extrusions having higher basal texture intensities can have similar yield strengths in tension and in compression, Figure 54(b), and coarse-grained extrusions always have

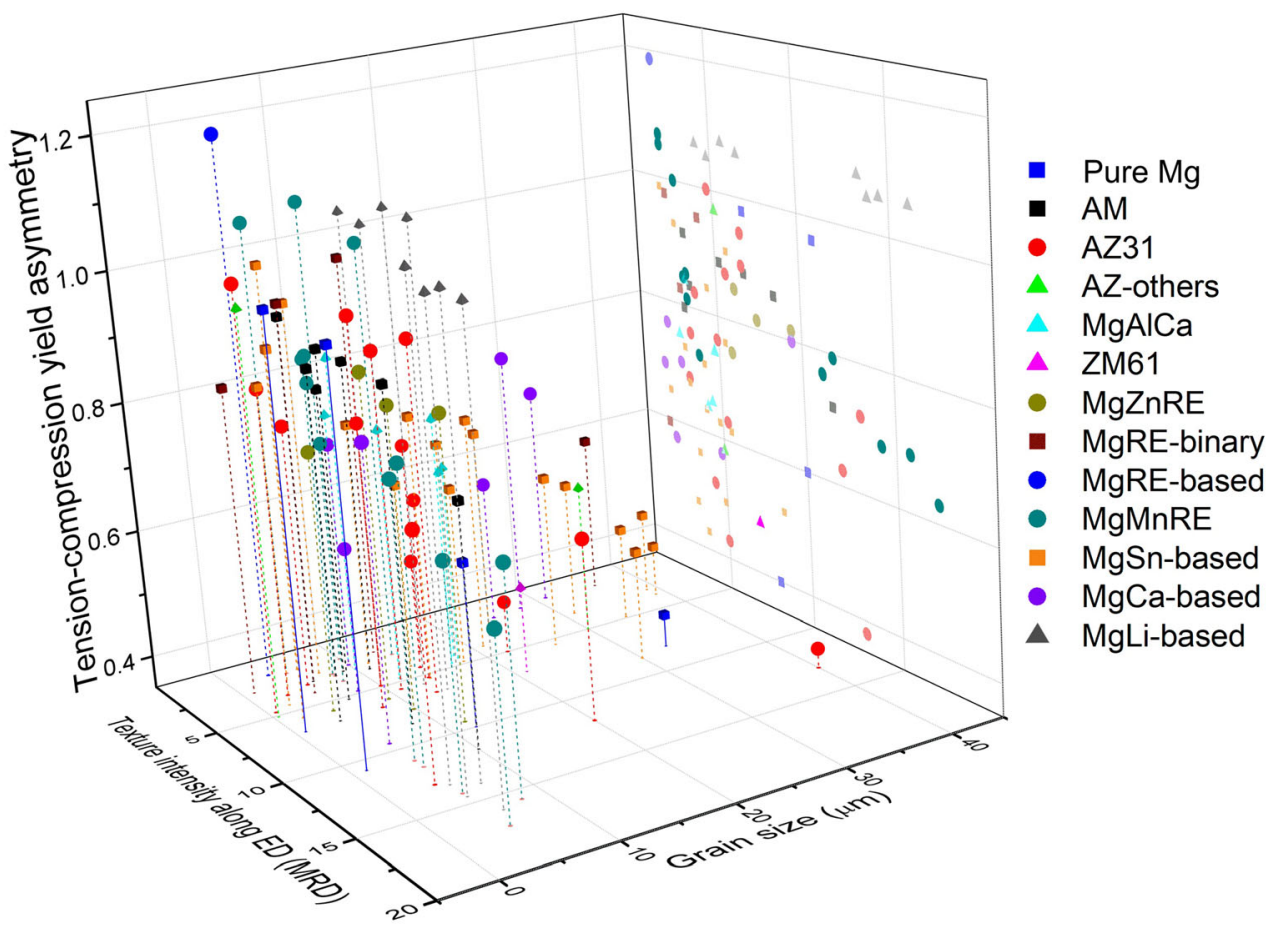

(a)

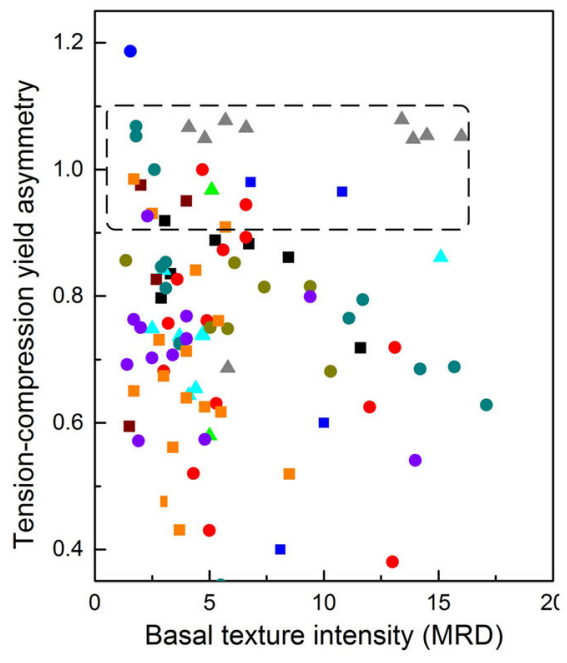

(b)

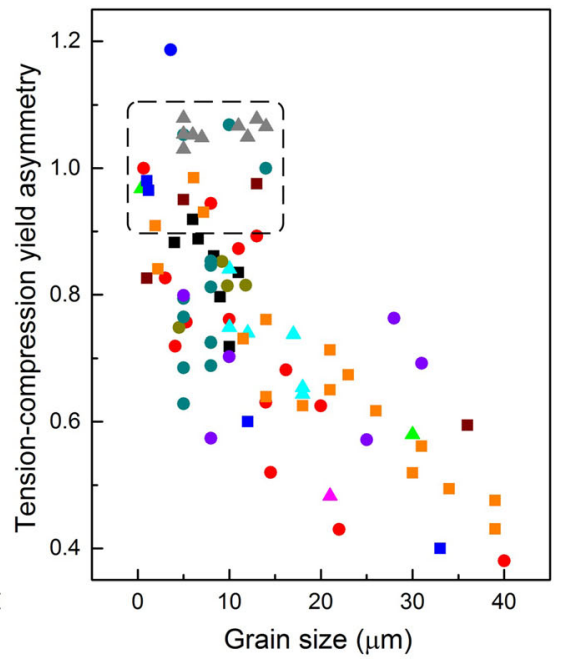

(c)

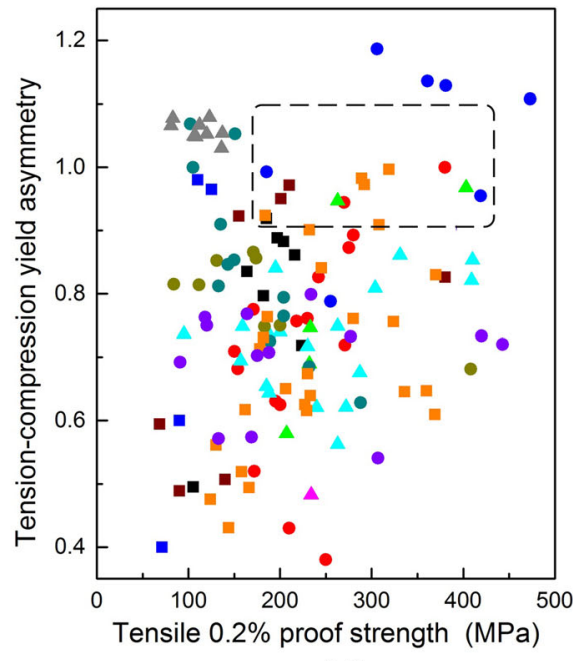

(d)

Fig. 54 -Relationship between tension-compression yield asymmetry and $(a)$ basal texture intensity along the extrusion direction and grain size, (b) basal texture intensity along the extrusion direction, (c) grain size, and $(d)$ tensile yield strength for extrusions of Mg and its alloys. Extrusions with minimum or no tension-compression yield asymmetry are highlighted by dashed frames in $(b-d)$. 
the tension-compression yield asymmetry, Figure 54(c). The plot of the relationship between the tension-compression yield asymmetry and the tensile yield strength, Figure 54(d), indicates that most extrusions made so far have their yield strengths in the range 150 to $250 \mathrm{MPa}$ and the ratio of compressive and tensile yield strengths in the range 0.6 to 0.9 . Currently, only a few extrusions can simultaneously meet the isotropic and the higher strength requirements.

\section{E. Trend in Alloy Development}

There is a trend in recent years to develop alloys with leaner compositions and lower-cost processes. The use of a dilute concentration in the alloy allows a wrought $\mathrm{Mg}$ product to be more readily processed, either by rolling or by extrusion. It has been demonstrated that sheets made of dilute alloys can exhibit excellent formability at room temperature, together with good combination of strength and ductility. ${ }^{[160,209,216]}$ The sheet strength obtained so far is generally adequate, but a higher strength would be needed for wider applications. One approach to this issue is to further reduce the grain size by optimizing thermomechanical processing parameters. Ultrafine grains $(\sim 1 \mu \mathrm{m}$ or less) have been achieved in $\mathrm{Mg}$ extrusion alloys, and even in pure $\mathrm{Mg}$, and these ultrafine-grained extrusions exhibit higher strength and better ductility. However, it remains difficult to produce sheets containing a uniform distribution of recrystallized grains of $\sim 1 \mu \mathrm{m}$ or less in dilute alloys. An alternative approach is to design dilute alloys that are age-hardenable after the forming process. One example is a dilute $\mathrm{Mg}-\mathrm{Al}-\mathrm{Ca}-\mathrm{Mn}-\mathrm{Zn}$ sheet alloy that has good room temperature formability and good age hardenability during post-forming processing. [159]

At the processing level, there are some approaches to higher speed extrusion or higher speed rolling, with the aim to reducing the processing cost by increasing the production rate. ${ }^{[176,177,282]}$ In general, the higher speed extrusion leads to coarser grains than those obtained from lower speeds. The balance between the production rate and alloy properties is still far from being optimized, and a considerable effort is still needed in this area. Higher speed rolling allows a larger thickness reduction per pass than lower-speed rolling, at a given temperature. In such cases, the increased level of strain and strain rate may offer an opportunity to explore the potential of achieving a higher nucleation rate of recrystallization and thus finer grains. Again, this is an area that needs some attention in future research.

\section{SUMMARY}

Significant progress has been made in the past 20 years on the understanding of lattice defects, deformation, texture and properties of wrought $\mathrm{Mg}$ alloys. The key highlights include the following:

(1) Intrinsic stacking faults $I_{1}$ and $I_{2}$ are frequently observed in plastically deformed $\mathrm{Mg}$ alloys. The $I_{1}$ fault can be generated by three different mechanisms: dissociation of $\langle c+a\rangle$ dislocation, condensation of vacancies, and formation of steps having a single- (or three-)layer height on twin boundaries. The $I_{2}$ fault can also be generated by three different mechanisms: dissociation of $\langle a\rangle$ dislocation, formation of a precipitate having an ABCA stacking on the basal plane of the $\mathrm{Mg}$ matrix phase, and formation of steps on twin boundaries. Segregation of solute atoms of some specific alloying elements to stacking faults can occur, and the segregation may reduce the stacking fault energy. However, there are limited experimental observations of the segregation patterns in $\mathrm{Mg}$ alloys. Precaution is needed in the analysis of electron microscopy images for the identification of the $I_{1}$ and $I_{2}$ faults using the conventional $\boldsymbol{g}_{(0002)} \cdot \boldsymbol{b}$ analysis. Stacking faults on pyramidal I and II planes are always observed in computations, but they have not been experimentally confirmed. It remains to be fully assessed, at both computational and experimentally levels, whether the energy difference between these two types of pyramidal stacking faults is the main cause for the improved ductility in some $\mathrm{Mg}$ alloys.

(2) Deformation twins $\{10 \overline{1} 2\}$ and $\{10 \overline{1} 1\}$ both form frequently in deformed $\mathrm{Mg}$ and its alloys. Annealing of plastically deformed alloys leads to solute segregation in fully coherent twin boundaries. In binary alloys, solutes with larger atomic size than $\mathrm{Mg}$ usually segregate to extension sites of the twin boundaries, while solutes having smaller atomic size generally segregate to contraction sites of the boundaries. In ternary alloys containing both larger and smaller solutes, the solutes can segregate simultaneously to occupy extension sites or alternating sites of extension and contraction. The solute segregation leads to a strong pinning effect of twin boundaries.

(3) Deformation behavior of alloy single crystals under different loading conditions at room temperature and elevated temperatures remains largely unclear. This aspect deserves considerable efforts if the precise effects of alloying elements on slip and twinning modes and thus deformation behavior are to be unambiguously established. It also requires the study of interactions between solute atoms and different types of gliding dislocations and propagating twins using advanced characterization facilities and computation tools.

(4) Under specific conditions, pure Mg single- or polycrystals can exhibit excellent ductility and super-formability at room temperature. In the case of polycrystalline pure $\mathrm{Mg}$, an ultrafine grain size (in the order of $1 \mu \mathrm{m}$ ) can lead to excellent room temperature formability, even with the presence of a relatively strong basal texture.

(5) Sheets of pure $\mathrm{Mg}$ and its alloys all have basal textures. In general, the basal texture can be classified into two groups: strong basal (SB) and weak basal (WB), with two special components in each group. The two special components in the 
SB group:

[0001] // ND, and $\langle 10 \overline{1} 0\rangle / / \mathrm{RD}, \mathrm{SB}-1$

[0001] // ND, and $\langle 2 \overline{1} \overline{1} 0\rangle / /$ RD. SB-2

SB-1 is the deformation texture, and SB-2 is the recrystallization texture. These two components are related with each other by $30 \mathrm{deg}$ rotation about the [0001] axis. Texture spreading between these two components is commonly observed. The two special components in the WB group are as follows:

[0001] tilted from ND towards RD (RD-split) WB-1

[0001] tilted from ND towards TD, and $\langle 10 \overline{1} 0\rangle / /$ RD (TD-split) WB-2

The addition of most alloying elements does not change the strong basal texture of $\mathrm{Mg}$, regardless of processing conditions. The WB-1 or WB-2 component is often associated with alloying additions of RE elements or combined addition of $\mathrm{Zn}$ and $\mathrm{Ca}$ elements, but the actual weakening effect depends critically on the processing condition. Room temperature sheet formability of most conventional alloys is influenced mainly by texture; weakened basal texture leads to better formability. However, Mg-Li-based binary and ternary alloys with a strong basal texture can exhibit remarkably good formability at room temperature.

(6) Textures associated with cylindrical extrusions of pure $\mathrm{Mg}$ and its alloys can be classified into three groups: basal fiber (BF), pyramidal fiber $(\mathrm{PyF})$, and prismatic fiber (PrF). The BF group has two special components:

(0002) // ED, and $\langle 10 \overline{1} 0\rangle / / \mathrm{ED}, \mathrm{BF}-1$

(0002) // ED, and $\langle 2 \overline{1} \overline{1} 0\rangle / / \mathrm{ED}$. BF-2

Texture spreading between these two components is common. BF-1 is the deformation texture, and BF-2 is the recrystallized microstructure of pure $\mathrm{Mg}$ and $\mathrm{AM}, \mathrm{AZ}, \mathrm{Mg}-\mathrm{Mn}$, and $\mathrm{Mg}$-Li alloys. The PyF group also has two special components:

Pyramidal plane // ED, and $\langle 10 \overline{1} \mathrm{~m}\rangle / / \mathrm{ED}, \mathrm{PyF}-1$ Pyramidal plane // ED, and $\langle 2 \overline{1} \overline{1} n\rangle / /$ ED. PyF-2 Pyramidal fiber textures having a mixture of these two components, or spreading between these two components, are common. These group of textures form frequently in $\mathrm{Mg}-\mathrm{RE}$ alloys and $\mathrm{Mg}-\mathrm{Zn}-\mathrm{Ca}-\mathrm{Mn}$ alloys. The PrF group has only one component:

Prismatic plane // ED, and [0001] // ED.

This texture forms in Elektron 675 and $\mathrm{Mg}-\mathrm{Mn}-\mathrm{RE}$ alloys that are extruded under some particular conditions. It also forms in $\mathrm{Mg}-\mathrm{RE}-\mathrm{Zn}$ and $\mathrm{Mg}-\mathrm{RE}-\mathrm{Ag}$ alloys that contain high concentrations of RE elements. Tension-compression yield asymmetry of extrusions is influenced by both texture and grain size, it diminishes with weakened texture, or reduced grain size, or both. Tension-compression yield asymmetry may fully disappear in pure $\mathrm{Mg}$ and $\mathrm{Mg}$ alloys when the grain size is in the order of one micron, even in the presence of the basal texture.
(7) The origin of texture weakening or change is still not fully understood. The final texture of an alloy is determined by the following factors: (i) the initial texture and quality of the as-processed alloy, for example, casting condition and cooling rate; (ii) the deformation texture of the alloy resulting from various processing conditions, including thermomechanical processing methods (rolling, extrusion, and forging), processing temperature, strain rate, and strain; and (iii) the recrystallization texture obtained during processing and/or after subsequent heat treatment. The addition of alloying elements affects the texture of the alloy in every step described above. In $\mathrm{Mg}$ and its alloys, the evolution of deformation texture is much more complicated than those in face-centered cubic and body-centered cubic metals, because of various possible slip and twinning modes. The specific alloying elements and their added quantities change CRSS and flow stresses of various deformation modes in different ways and their relative ratios, which will certainly change the activities of various slip/twinning modes during plastic deformation and, as a result, affect the final deformation texture. Therefore, it is crucial to understand the effect of alloying addition on the ratio of CRSS and relative activities of different deformation modes. Unfortunately, our understanding in this area is very limited at the moment. Further study is crucial to understand the origin of texture weakening or change. Solute segregation to grain boundaries can also occur, but it has not been well characterized. The experimental reports on solute segregation are still controversial. When solute atoms of a given alloying element segregate to a grain boundary, it remains to be established whether these atoms would segregate only to the high energy, rather than low energy, part of the boundary, and whether such segregation would change the grain boundary structure to activate specific deformation modes. Dynamic recrystallization mechanisms remain to be established for the strain paths, processing temperatures, and alloy compositions of scientific and technological significance.

(8) There is an emerging trend of developing dilute alloys for higher speed extrusion or higher speed rolling. Strengthening of such dilute alloys can be achieved by obtaining ultrafine grains or generating nano-scale precipitates via post-extrusion/ rolling aging.

\section{ACKNOWLEDGMENT}

This work is supported by the Australian Research Council. 


\section{REFERENCES}

1. T.B. Abbott: Corrosion, 2015, vol. 71, pp. 120-27.

2. N. Chetty and M. Weinert: Phys. Rev. B, 1997, vol. 56, pp. 10844-51

3. A.E. Smith: Surface Sci., 2007, vol. 601, pp. 5762-65.

4. P.M. Anderson, J.P. Hirth, and J. Lothe: Theory of Dislocations, 3rd ed., Cambridge University Press, New York, 2017.

5. Y.M. Zhu, S.W. Xu, and J.F. Nie: Acta Mater., 2018, vol. 143, pp. $1-12$.

6. X.J. Zhao, H.W. Chen, N. Wilson, Q. Liu, and J.F. Nie: Nat. Commun., 2019, vol. 10, p. 3243.

7. F.L. Wang, C.D. Barret, R.J. McCabe, H. El Kadiri, L. Capolungo, and S.R. Agnew: Acta Mater., 2019, vol. 165, pp. 471-85.

8. C. He, Y. Zhang, C.Q. Liu, Y. Yue, H.W. Chen, and J.F. Nie: Acta Mater., 2020, vol. 188, pp. 328-43.

9. W.Y. Wang, S.L. Shang, Y. Wang, Z.G. Mei, K.A. Darling, L.J. Kecskes, S.N. Mathaudhu, X.D. Hui, and Z.K. Liu: Mater. Res. Lett., 2014, vol. 2, pp. 29-36.

10. B. Yin, Z. Wu, and W.A. Curtin: Acta Mater., 2017, vol. 136, pp. 249-61.

11. Q. Dong, Z. Luo, H. Zhu, L. Wang, T. Ying, Z. Jin, D. Li, W. Ding, and X. Zeng: J. Mater. Sci. Technol., 2018, vol. 34, pp. $1773-80$.

12. S.L. Shang, W.Y. Wang, B.C. Zhou, Y. Wang, K.A. Darling, L.J. Kecskes, S.N. Mathaudhu, and Z.K. Liu: Acta Mater., 2014 , vol. 67, pp. 168-80.

13. S.H. Zhang, I.J. Beyerlein, D. Legut, Z.H. Fu, Z. Zhang, S.L. Shang, Z.K. Liu, T.C. Germann, and R.F. Zhang: Phys. Rev. B, 2017, vol. 96, p. 224106.

14. Y.F. Wu, S. Li, Z.G. Ding, W. Liu, Y.H. Zhao, and Y.T. Zhu: Scripta Mater., 2016, vol. 112, pp. 101-05.

15. J. Han, X.M. Su, Z.H. Jin, and Y.T. Zhu: Scripta Mater., 2011, vol. 64, pp. 693-96.

16. M. Muzyk, Z. Pakiela, and K.J. Kurzydlowski: Scripta Mater., 2012, vol. 66, pp. 219-22.

17. A. Datta, U.V. Waghmare, and U. Ramamurty: Acta Mater., 2008, vol. 56, pp. 2531-39.

18. J. Zhang, G. Liu, and X. Wei: Mater. Lett., 2015, vol. 150, pp. 111-13.

19. L. Pauling: J. Am. Chem. Soc., 1947, vol. 69, pp. 542-53.

20. S. Sandlobes, M. Friak, S. Zaefferer, A. Dick, S. Yi, D. Letzig, Z. Pei, L.F. Zhu, J. Neugebauer, and D. Rabbe: Acta Mater., 2012, vol. 60, pp. 3011-21.

21. J.F. Nie, K. Oh-ishi, X. Gao, and K. Hono: Acta Mater., 2008, vol. 56, pp. 6061-76.

22. J.F. Nie: Metall. Mater. Trans. A, 2012, vol. 43A, pp. 3891-3939.

23. Y.M. Zhu, M. Weyland, A.J. Morton, K. Oh-ishi, K. Hono, and J.F. Nie: Scripta Mater., 2009, vol. 60, pp. 980-83.

24. Y.M. Zhu, A.J. Morton, M. Weyland, and J.F. Nie: Acta Mater., 2010, vol. 58, pp. 464-75.

25. C.Q. Liu, H.W. Chen, H. Liu, X.J. Zhao, and J.F. Nie: Acta Mater., 2018, vol. 144, pp. 590-600.

26. B. Yin, Z. Wu, and W.A. Curtin: Acta Mater., 2017, vol. 123, pp. 223-234.

27. C.Q. Liu, H.W. Chen, N. Wilson, and J.F. Nie: Scripta Mater., 2018, vol. 155, pp. 89-93.

28. D. Zhang, B. Zheng, Y. Zhou, S. Mahajan, and E.J. Lavernia: Scripta Mater., 2014, vol. 76, pp. 61-64.

29. M. Itakura, H. Kaburaki, M. Yamaguchi, and T. Tsuru: Phys. Rev. Lett., 2016, vol. 116, p. 225501.

30. R. Ahmad, B. Yin, Z. Wu, and W.A. Curtin: Acta Mater., 2019, vol. 172, pp. 161-84.

31. R. Ahmad, Z. Wu, and W.A. Curtin: Acta Mater., 2020, vol. 183, pp. 228-41.

32. Z.X. Wu, R. Ahmad, B.L. Yin, S. Sandlobes, and W.A. Curtin: Science, 2018, vol. 359, pp. 447-452.

33. Z.X. Wu and W.A. Curtin: Nature, 2015, vol. 526, pp. 62-67.

34. J.F. Stohr and J.P. Poirier: Philos. Mag., 1972, vol. 25, pp. 1313-29.

35. T. Obara, H. Yoshinga, and S. Morozumi: Acta Metall., 1973, vol. 21, pp. $845-53$

36. J. Geng, M.F. Chisholm, R.K. Mishra, and K.S. Kumar: Philos. Mag. Lett., 2014, vol. 94, pp. 377-86.

37. S.R. Agnew, L. Capolungo, and C.A. Calhoun: Acta Mater., 2015, vol. 82, pp. 255-65.
38. B.Y. Liu, F. Liu, N. Yang, X.B. Zhai, L. Zhang, Y. Yang, B. Li, J. Li, E. Ma, J.F. Nie, and Z.W. Shan: Science, 2019, vol. 365, pp. 73-75.

39. L.N. Ma, K. Xie, J. Cai, and K. Hemker: Mater. Res. Lett., 2020, vol. 8, pp. $145-50$.

40. C.Q. Liu, C. He, H.W. Chen, and J.F. Nie: J. Mater. Sci. Tech., 2020, vol. 45, pp. 230-40.

41. D. Buey, L.G. Hector, Jr, and M. Ghazisaeidi: Acta Mater., 2018, vol. 147, pp. 1-9.

42. K.H. Kim, J.B. Jeon, N.J. Kim, and B.J. Lee: Scripta Mater., 2015, vol. 108, pp. 104-08.

43. T. Tsuru and D.C. Chrzan: Scientific Reports, 2015, vol. 5, p. 8793 .

44. A. Moitra, S.G. Kim, and M.F. Horstemeyer: Acta Mater., 2014, vol. 75, pp. 106-112.

45. A. Tehranchi, B. Yin, and W.A. Curtin: Acta Mater., 2018, vol. 151, pp. 56-66.

46. P.G. Partridge: Metall. Rev., 1967, vol. 12, pp. 169-94.

47. S. Mahajan and D.F. Williams: Int. Metall. Rev., 1973, vol. 18, pp. 43-61.

48. J.W. Christian and S. Mahajan: Prog. Mater. Sci., 1995, vol. 39, pp. 1-157.

49. M.H. Yoo: Metall. Trans. A, 1981, vol. 12A, pp. 409-18.

50. J. Wang, I.J. Beyerlein, and C.N. Tome: Scripta Mater., 2010, vol. 63 , pp. $741-46$.

51. I.J. Beyerlein, R.J. McCabe, and C.N. Tome: J. Mech. Phys. Solids, 2011, vol. 59, pp. 988-1003.

52. R.L. Xin, C.F. Guo, Z.R. Xu, G.D. Liu, X.X. Huang, and Q. Liu: Scripta Mater., 2014, vol. 74, pp. 96-99.

53. M. Arul Kumar, I.J. Beyerlein, R.J. McCabe, C.N. Tome: Nat. Commun., 2016, vol. 7, 13826.

54. X. Hong, A. Godfrey, and W. Liu: Scripta Mater., 2016, vol. 123, pp. 77-80.

55. H. Liu, F.X. Lin, P. Zhao, N. Moelans, Y. Wang, and J.F. Nie: Acta Mater., 2018, vol. 153, pp. 86-107.

56. I.J. Beyerlein, J. Wang, M.R. Barnett, and C.N. Tome: Proc. R. Soc. $A, 2012$, vol. 468, pp. 1496-1520.

57. J. Jain, J. Zou, C.W. Sinclair, and W.J. Poole: J. Microsc., 2011, vol. 242 , pp. $26-36$

58. R.L. Xin, C.F. Guo, J.J. Jonas, G. Chen, and Q. Liu: Mater. Sci. Eng. $A, 2017$, vol. 700 , pp. 226-33.

59. J. Wang, J.P. Hirth, and C.N. Tome: Acta Mater., 2009, vol. 57, pp. 5521-30.

60. I.J. Beyerlein, L. Capolungo, P.E. Marshall, R.J. McCabe, and C.N. Tome: Philos. Mag., 2010, vol. 90, pp. 2161-90.

61. M.R. Barnett: Mater. Sci. Eng. A, 2007, vol. 464, pp. 1-7.

62. X. Liao, J. Wang, J.F. Nie, Y. Jiang, and P. Wu: MRS Bull., 2016, vol. 41, pp. 314-19.

63. H. El Dadiri, J. Kapil, A.L. Oppedal, L.G. Hector, Jr, S.R. Agnew, M. Cherkaoui, and S.C. Vogel: Acta Mater., 2013, vol. 61, pp. 3549-63.

64. A. Luque, G. Ghazisaeidi, and W.A. Curtin: Acta Mater., 2014, vol. 81 , pp. $442-56$

65. M.S. Hooshmand and M. Ghazisaeidi: Acta Mater., 2020, vol. 188, pp. 711-19.

66. J.D. Robson, N. Stanford, and M.R. Barnett: Acta Mater., 2011, vol. 59, pp. 1945-56.

67. J. Wang and N. Stanford: Acta Mater., 2015, vol. 100, pp. 53-63.

68. N. Stanford, J. Geng, Y.B. Chun, C.H.J. Davies, J.F. Nie, and M.R. Barnett: Acta Mater., 2012, vol. 60, pp. 218-28.

69. J.D. Robson: Acta Mater., 2016, vol. 121, pp. 277-287.

70. P. Hidalgo-Manrique and J.D. Robson: Metall. Mater. Trans. A, 2019, vol. 50A, pp. 3855-67.

71. J.F. Nie, Y.M. Zhu, J.Z. Liu, and X.Y. Fang: Science, 2013, vol. 340, pp. 957-60.

72. J. Zhang, Y.C. Dou, and Y. Zheng: Scripta Mater., 2014, vol. 80, pp. 17-20.

73. A. Kumar, J. Wang, and C.N. Tome: Acta Mater., 2015, vol. 85, pp. 144-54.

74. G. Xi, J. Zhang, and C. Fang: Mater. Lett., 2016, vol. 182, pp. 198-200.

75. T. Tsuru, H. Somekawa, and D.C. Chrzan: Acta Mater., 2018, vol. 151, pp. 78-86.

76. J. Koike, R. Ohyama, T. Kobayashi, M. Suzuki, and K. Maruyama: Mater. Trans., 2003, vol. 44, pp. 445-51. 
77. M.R. Barnett, A. Ghaderi, I. Sabirov, and B. Hutchinson: Scripta Mater., 2009, vol. 61, pp. 277-80.

78. H. Somekawa, D.A. Basha, and A. Singh: Mater. Sci. Eng. A, 2019, vol. 766, p. 138384.

79. R.B. Figueiredo, S. Sabbaghianrad, A. Giwa, J.R. Greer, and T.G. Langdon: Acta Mater., 2017, vol. 122, pp. 322-31.

80. H.J. Choi, Y. Kim, J.H. Shin, and D.H. Bae: Mater. Sci. Eng. A, 2010, vol. 527, pp. 1565-70.

81. F.J. Humphreys and M. Hatherly: Recrystallisation and Related Annealing Phenomena, 2nd ed., Elsevier, Oxford, 2004.

82. S.E. Ion, F.J. Humphreys, and S.H. White: Acta Metall., 1982, vol. 30, pp. 1909-1919.

83. M.R. Barnett: Mater. Trans., 2003, vol. 44, pp. 571-77.

84. M.R. Barnett, A. Sullivan, N. Stanford, N. Ross, and A. Beer: Scripta Mater, 2010, vol. 63, pp. 721-24.

85. D.K. Sun, C.P. Chang, and P.W. Kao: Metall. Mater. Trans. A, 2010, vol. 41A, pp. 1864-70.

86. T. Al-Samman, K.D. Molodov, D.A. Molodov, G. Gottstein, and S. Suwas: Acta Mater., 2012, vol. 60, pp. 537-45.

87. K.D. Molodov, T. Al-Samman, D.A. Molodov, and G. Gottstein: Acta Mater., 2014, vol. 76, pp. 314-30.

88. M. Lentz, S. Gall, F. Schmack, H.M. Mayer, and W. Reimers: $J$. Mater. Sci., 2014, vol. 49, pp. 1121-29.

89. A. Kula, T. Tokarski, and M. Niewczas: Metall. Mater. Trans. A, 2020, vol. 51A, pp. 3742-48.

90. J.D. Robson, D.T. Henry, and B. Davis: Acta Mater., 2009 , vol. 57 , pp. 2739-47.

91. T. Al-Samman: Mater. Sci. Eng. A, 2013, vol. 560, pp. 561-66.

92. A.D. Murphy and J.E. Allison: Metall. Mater. Trans. A, 2018, vol. 49A, pp. 1492-1508.

93. T. Al-Samman and G. Gottstein: Mater. Sci. Eng. A, 2008, vol. 490, pp. 411-20.

94. S.B. Yi, S. Zaefferer, and H.G. Brokmeier: Mater. Sci. Eng. A, 2006, vol. 424 , pp. $275-81$.

95. J.C. Tan and M.J. Tan: Mater. Sci. Eng. A, 2003, vol. 339, pp. $124-32$.

96. A.G. Beer and M.R. Barnett: Metall. Mater. Trans. A, 2007, vol. 38A, pp. 1856-67.

97. A. Galiyev, R. Kaibyshev, and G. Gottstein: Acta Mater., 2001, vol. 49, pp. 1199-07.

98. X. Huang, K. Suzuki, M. Yuasa, and Y. Chino: Mater. Sci. Eng. A, 2013, vol. 587, pp. 150-60.

99. J.D. Robson, S.J. Haigh, B. Davis, and D. Griffiths: Metall. Mater. Trans. A, 2016, vol. 47A, pp. 522-30.

100. E. W. Kelley, W. F. Hosford: Tech. Report, Dept. Chem. Metall. Eng., Uni. Michigan, 1967.

101. E.W. Kelley and W.F. Hosford: Trans. Metall. Soc. AIME, 1968, vol. 242 , pp. $5-13$.

102. B.C. Wonsiewicz and W.A. Backofen: Trans. Metall. Soc. AIME, 1967, vol. 239, pp. 1422-31.

103. K.D. Molodov, T. Al-Samman, D.A. Molodov, and G. Gottstein: Metall. Mater. Trans. A, 2014, vol. 45A, pp. $3275-81$.

104. K.D. Molodov, T. Al-Samman, and D.A. Molodov: Mater. Sci. Eng. A., 2016, vol. 651, pp. 63-68.

105. K.D. Molodov, T. Al-Samman, D.A. Molodov, and G. Gottstein: Acta Mater., 2016, vol. 103, pp. 711-23.

106. A. Chapuis: Mater. Sci. Eng. A, 2014, vol. 590, pp. 401-5.

107. T. Kitahara, S. Ando, M. Tsushida, H. Kitahara, and H. Tonda: Key Eng. Mater., 2007, vols. 345-346, pp. 129-32.

108. B. Syed, J. Geng, R.K. Mishra, and K.S. Kumar: Scripta Mater, 2012, vol. 67, pp. 700-3.

109. K.Y. Xie, Z. Alam, A. Caffee, and K.J. Hemker: Scripta Mater, 2016, vol. 112, pp. 75-8.

110. M. Niewczas, A. Kula, H. Kitahara, and S. Ando: Acta Mater., 2019, vol. 164, pp. 714-27.

111. M.Z. Bian and K.S. Shin: unpublished research.

112. H. Kwon and K.S. Shin: unpublished research.

113. A. Akhtar and E. Teghtsoonian: Acta Metall, 1969, vol. 17, pp. $1351-56$

114. P.W.W. Flynn, J. Mote, and J.E. Dorn: Trans. Metall. Soc. AIME, 1961, vol. 221, pp. 1148-54.

115. R.E. Reed-Hill and W.D. Robertson: JOM, 1957, vol. 9, pp. 496-502.
116. H. Kwon: Master's Degree Thesis, Seoul National University, 2018.

117. S. Ando, A. Kodera, K. Fukushima, M. Tsushida, and H. Kitahara: Mater. Sci. Forum, 2014, vols. 783-786, pp. 341-45.

118. H. Kitahara, T. Mayama, K. Okumura, Y. Tadano, M. Tsushida, and S. Ando: Acta Mater., 2014, vol. 78, pp. $290-300$.

119. C.S. Hyun, M.S. Kim, S.H. Choi, and K.S. Shin: Acta Mater., 2018, vol. 156, pp. 342-55.

120. H. Yoshinaga and R. Horiuchi: Trans. JIM, 1963, vol. 4, pp. 1-8.

121. H. Yoshinaga and R. Horiuchi: Trans. JIM, 1964, vol. 5, pp. 14-21.

122. M.R. Barnett, M.D. Nave, and C.J. Bettles: Mater. Sci. Eng. A, 2004, vol. 386, pp. 205-11.

123. Z.R. Zeng, J.F. Nie, S.W. Xu, C.H.J. Davies, and N. Birbilis: Nat. Commun., 2017, vol. 8, p. 972.

124. Z.R. Zeng, M.Z. Bian, S.W. Xu, C.H.J. Davies, N. Birbilis, and J.F. Nie: Mater. Sci. Eng. A, 2016, vol. 674, pp. 459-71.

125. A.K. Singh and R.A. Schwarzer: Z. Metallkd., 2005, vol. 96, pp. $345-51$

126. B. Beausir, S. Biswas, D.I. Kim, L.S. Tóth, and S. Suwas: Acta Mater., 2009, vol. 57, pp. 5061-77.

127. H. Somekawa and T. Mukai: Metall. Mater. Trans. A, 2015, vol. 46A, pp. 894-902

128. J. Li, W. Xu, X. Wu, H. Ding, and K. Xia: Mater. Sci. Eng. A, 2011, vol. 528, pp. 5993-98.

129. G.S. Rao and Y.V.R.K. Prasad: Metall. Trans. A, 1982, vol. 13A, pp. 2219-26.

130. N. Ono, R. Nowak, and S. Miura: Mater. Lett., 2004, vol. 58, pp. 39-43.

131. H.H. Yu, C.Z. Li, Y.C. Xin, A. Chapuis, X.X. Huang, and Q. Liu: Acta Mater., 2017, vol. 128, pp. 313-26.

132. C.H. Caceres, G.E. Mann, and J.R. Griffiths: Metall. Mater. Trans. A, 2011, vol. 42A, pp. 1950-59.

133. E.W. Kelley and W.F. Hosford: Trans. Metall. Soc. AIME, 1968, vol. 242, pp. 654-61.

134. Y. Chino, M. Kado, and M. Mabuchi: Mater. Sci. Eng. A, 2008, vol. 494, pp. 343-49.

135. S. Ando, M. Tsushida, and H. Kitahara: Mater. Sci. Forum, 2012, vols. 706-709, pp. 1122-1127.

136. A. Styczynski, C. Hartig, J. Bohlen, and D. Letzig: Scripta Mater., 2004, vol. 50, pp. 943-47.

137. A. Levinson, R.K. Mishra, R.D. Doherty, and S.R. Kalidindi: Acta Mater., 2013, vol. 61, pp. 5966-78.

138. M. Wang, R. Xin, B. Wang, and Q. Liu: Mater. Sci. Eng. A, 2011, vol. 528, pp. 2941-51.

139. X. Huang, K. Suzuki, and Y. Chino: J. Alloys Compd., 2011, vol. 509, pp. 4854-60.

140. M.R. Barnett, Z. Keshavarz, and M.D. Nave: Metall. Mater. Trans. A, 2005, vol. 36A, pp. 1697-1704.

141. M.A. Steiner, J.J. Bhattacharyya, and S.R. Agnew: Acta Mater., 2015, vol. 95, pp. 443-55.

142. J.J. Bhattacharyya, S.R. Agnew, and G. Muralidharan: Acta Mater., 2015, vol. 86, pp. 80-94.

143. G. Gottstein and T. Al-Samman: Mater. Sci. Forum, 2005, vols. 495-497, pp. 623-32.

144. A. Chapuis and Q. Liu: Mater. Sci. Eng. A, 2018, vol. 725, pp. $108-118$.

145. S.R. Agnew, C.N. Tomé, D.W. Brown, T.M. Holden, and S.C. Vogel: Scripta Mater., 2003, vol. 48, pp. 1003-1008.

146. D.W. Brown, S.R. Agnew, M.A.M. Bourke, T.M. Holden, S.C. Vogel, and C.N. Tomé: Mater. Sci. Eng. A, 2005, vol. 399, pp. $1-12$.

147. L. Zhao, X. Guo, A. Chapuis, Y. Xin, Q. Liu, and P. Wu: Metall. Mater. Trans. A, 2019, vol. 50A, pp. 118-31.

148. X. Huang, K. Suzuki, Y. China, and M. Mabuchi: Mater. Sci. Eng. A, 2015, vol. 633, pp. 144-53.

149. Y. Chino, T. Ueda, Y. Otomatsu, K. Sassa, X. Huang, K. Suzuki, and M. Mabuchi: Mater. Trans., 2011, vol. 52, pp. $1477-82$.

150. J.Y. Lee, Y.S. Yun, B.C. Suh, N.J. Kim, W.T. Kim, and D.H. Kim: J. Alloys Compd., 2014, vol. 589, pp. 240-46.

151. T. Zhou, Z. Yang, D. Hu, T. Feng, M. Yang, and X. Zhai: $J$. Alloys Compd., 2015, vol. 650, pp. 436-43. 
152. X. Huang, K. Suzuki, A. Watazu, I. Shigematsu, and N. Saito: $J$. Alloys Compd., 2009, vol. 470, pp. 263-68.

153. X. Huang, K. Suzuki, Y. China, and M. Mabuchi: J. Alloys Compd., 2011, vol. 509, pp. 7579-84.

154. D.H. Kang, D.W. Kim, S. Kim, G.T. Bae, K.H. Kim, and N.J. Kim: Scripta Mater., 2009, vol. 61, pp. 768-71.

155. M.Z. Bian, T.T. Sasaki, T. Nakata, Y. Yoshida, N. Kawabe, S. Kamado, and K. Hono: Acta Mater., 2018, vol. 158, pp. $278-88$.

156. X. Huang, K. Suzuki, Y. Chino, and M. Mabuchi: J. Alloys Compd., 2015, vol. 632, pp. 94-102.

157. X. Huang, K. Suzuki, and N. Saito: Mater. Sci. Eng. A, 2009, vol. 508 , pp. $226-33$.

158. T.T.T. Trang, J.H. Zhang, J.H. Kim, A. Zargaran, J.H. Hwang, B.C. Suh, and N.J. Kim: Nat. Commun., 2018, vol. 9, p. 2522.

159. M.Z. Bian, T.T. Sasaki, B.C. Suh, T. Nakata, S. Kamado, and K. Hono: Scripta Mater., 2017, vol. 138, pp. 151-55.

160. Y. Chino, K. Sassa, and M. Mabuchi: Mater. Sci. Eng. A, 2009, vols. 513-514, pp. 394-400.

161. S. Liang, X. Wang, H.S. Zurob, and N. Bassim: Metall. Mater. Trans. A, 2018, vol. 49A, pp. 3674-82.

162. Y. Chino, K. Sassa, A. Kamiya, and M. Mabuchi: Mater. Trans., 2006, vol. 47, pp. 2555-60.

163. T. Al-Samman and G. Gottstein: Scripta Mater., 2008, vol. 59, pp. $760-63$.

164. W.J. Kim, J.B. Lee, W.Y. Kim, H.T. Jeong, and H.G. Jeong: Scripta Mater., 2007, vol. 56, pp. 309-12.

165. H. Watanabe, T. Mukai, and K. Ishikawa: J. Mater. Process. Tech., 2007, vol. 182, pp. 644-47.

166. X. Huang, K. Suzuki, A. Watazu, I. Shigematsu, and N. Saito: $J$. Alloys Compd., 2009, vol. 479, pp. 726-31.

167. M.G. Jiang, C. Xu, H. Yan, G.H. Fan, T. Nakata, C.S. Lao, R.S. Chen, S. Kamado, E.H. Han, and B.H. Lu: Acta Mater., 2018, vol. 157, pp. 53-71.

168. C.D. Barrett, A. Imandoust, A.L. Oppedal, K. Inal, M.A. Tschopp, and H. El Kadiri: Acta Mater., 2017, vol. 128, pp. $270-83$.

169. Z.R. Zeng, Y.M. Zhu, R.L. Liu, S.W. Xu, C.H.J. Davies, J.F. Nie, and N. Birbilis: Acta Mater., 2018, vol. 160, pp. 97-108.

170. S.W. Xu, K. Oh-ishi, S. Kamado, F. Uchida, T. Homma, and K. Hono: Scripta Mater., 2011, vol. 65, pp. 269-72.

171. H. Pan, R. Kang, J. Li, H. Xie, Z. Zeng, Q. Huang, C. Yang, Y. Ren, and G. Qin: Acta Mater., 2020, vol. 186, pp. 278-90.

172. Z.R. Zeng, Y.M. Zhu, J.F. Nie, S.W. Xu, C.H.J. Davies, and N. Birbilis: Metall. Mater. Trans. A, 2019, vol. 50A, pp. 4344-63.

173. L.D. Atwell and M.R. Barnett: Metall. Mater. Trans. A, 2007, vol. 38A, pp. 3032-41.

174. S.W. Bai, G. Fang, and J. Zhou: Metall. Mater. Trans. A, 2019, vol. 50A, pp. $3246-64$.

175. T. Nakata, T. Mezaki, C. Xu, K. Oh-ishi, K. Shimizu, S. Hanaki, and S. Kamado: J. Alloys Compd., 2015, vol. 648, pp. 428-37.

176. T. Nakata, C. Xu, R. Ajima, K. Shimizu, S. Hanaki, T.T. Sasaki, L. Ma, K. Hono, and S. Kamado: Acta Mater., 2017, vol. 130, pp. 261-70.

177. T. Nakata, C. Xu, R. Ajima, Y. Matsumoto, K. Shimizu, T.T. Sasaki, K. Hono, and S. Kamado: Mater. Sci. Eng. A, 2018, vol. 712, pp. 12-19.

178. A.A. Luo, W. Wu, R.K. Mishra, L. Jin, A.K. Sachdev, and W. Ding: Metall. Mater. Trans. A, 2010, vol. 41A, pp. 2662-74.

179. M.Z. Bian, A. Tripathi, H. Yu, N.D. Nam, and L.M. Yan: Mater. Sci. Eng. A, 2015, vol. 639, pp. 320-26.

180. K. Illkova, P. Dobroň, F. Chmelík, K.U. Kainer, J. Balík, S. Yi, D. Letzig, and J. Bohlen: J. Alloys Compd., 2014, vol. 617, pp. 253-64.

181. J. He, B. Jiang, H. Xie, Z. Jiang, B. Liu, and F. Pan: Mater. Sci. Eng. A, 2016, vol. 675, pp. 76-81.

182. J. Bohlen, S.B. Yi, J. Swiostek, D. Letzig, H.G. Brokmeier, and K.U. Kainer: Scripta Mater., 2005, vol. 53, pp. 259-64.

183. M.G. Jiang, C. Xu, T. Nakata, H. Yan, R.S. Chen, and S Kamado: J. Alloys Compd., 2016, vol. 668, pp. 13-21.

184. L.W.F. Mackenzie, B. Davis, F.J. Humphreys, and G.W. Lorimer: Mater. Sci. Technol., 2007, vol. 23, pp. 1173-80.

185. J.B. Lin, W.J. Ren, X.Y. Wang, and L.F. Ma: Mater. Sci. Tech., 2016, vol. 32, pp. 1855-60.
186. Y. Chino, K. Kimura, M. Hakamada, and M. Mabuchi: Mater. Sci. Eng. A, 2008, vol. 485, pp. 311-17.

187. B. Song, H. Pan, L. Chai, N. Guo, H. Zhao, and R. Xin: Mater. Sci. Eng. A, 2017, vol. 689, pp. 78-88.

188. M.R. Barnett, Z. Keshavarz, A.G. Beer, and D. Atwell: Acta Mater., 2004, vol. 52, pp. 5093-5103.

189. S. Kleiner and P.J. Uggowitzer: Mater. Sci. Eng. A, 2004, vol. 379, pp. 258-63.

190. S.W. Bae, S.H. Kim, J.U. Lee, W.K. Jo, W.H. Hong, W. Kim, and S.H. Park: J. Alloys Compd., 2018, vol. 766, pp. 748-58.

191. H. Yu, S.H. Park, and B.S. You: Mater. Sci. Eng. A, 2014, vol. 610 , pp. $445-49$

192. S.W. Xu, K. Oh-ishi, S. Kamado, H. Takahashi, and T. Homma: Mater. Sci. Eng. A, 2012, vol. 542, pp. 71-78.

193. Z.R. Zeng, Y.M. Zhu, S.W. Xu, M.Z. Bian, C.H.J. Davies, N. Birbilis, and J.F. Nie: Acta Mater., 2016, vol. 105, pp. 479-94.

194. D. Guan, X. Liu, J. Gao, L. Ma, B.P. Wynne, and W.M. Rainforth: Sci. Rep., 2019, vol. 9, p. 7152.

195. D.W. Kim, B.C. Suh, M.S. Shim, J.H. Bae, D.H. Kim, and N.J. Kim: Metall. Mater. Trans. A, 2013, vol. 44A, pp. 2950-61.

196. Z.R. Zeng, Y.M. Zhu, M.Z. Bian, S.W. Xu, C.H.J. Davies, N. Birbilis, and J.F. Nie: Scripta Mater., 2015, vol. 107, pp. $127-30$

197. J. Bohlen, M.R. Nurnberg, J.W. Senn, D. Letzig, and S.R. Agnew: Acta Mater., 2007, vol. 55, pp. 2101-22.

198. T. Al-Samman and X. Li: Mater. Sci. Eng. A, 2011, vol. 528, pp. 3809-22.

199. L.W.F. Mackenzie and M.O. Pekguleryuz: Scripta Mater., 2008, vol. 59 , pp. $665-68$.

200. S. Yi, J. Bohlen, F. Heinemann, and D. Letzig: Acta Mater., 2010, vol. 58, pp. 592-605.

201. H. Yan, R.S. Chen, and E.H. Han: Mater. Sci. Eng. A, 2010, vol. 527, pp. 3317-22.

202. K.H. Kim, B.C. Suh, J.H. Bae, M.S. Shim, S. Kim, and N.J. Kim: Scripta Mater., 2010, vol. 63, pp. 716-20.

203. J. Luo, H. Yan, R.S. Chen, and E.H. Han: Mater. Sci. Eng. A, 2014 , vol. 614 , pp. $88-95$.

204. I. Basu and T. Al-Samman: Acta Mater., 2014, vol. 67, pp. 116-33.

205. D. Griffiths, B. Davis, and J.D. Robson: Metall. Mater. Trans. A, 2018, vol. 49A, pp. 321-32.

206. T. Bhattacharjee, B.C. Suh, T.T. Sasaki, T. Ohkubo, N.J. Kim, and K. Hono: Mater. Sci. Eng. A, 2014, vol. 609, pp. 154-60.

207. M. Yuasa, N. Miyazawa, M. Hayashi, M. Mabuchi, and Y. Chino: Acta Mater., 2015, vol. 83, pp. 294-303.

208. Y. Chino, K. Sassa, X. Huang, K. Suzuki, and M. Mabuchi: $J$. Jpn. Inst. Metals, 2011, vol. 75, pp. 35-41.

209. Y. Chino, X. Huang, K. Suzuki, K. Sassa, and M. Mabuchi: Mater. Sci. Eng. A, 2010, vol. 528, pp. 566-72.

210. T. Nakata, C. Xu, Y. Uehara, T.T. Sasaki, and S. Kamado: $J$. Alloys Compd., 2019, vol. 782, pp. 304-14.

211. M. Bian, Z. Zeng, S. Xu, W. Tang, C.H.J. Davies, N. Birbilis, and J.F. Nie: Metall. Mater. Trans. A, 2016, vol. 47A, pp. $5709-13$.

212. S.Q. Zhu, H.G. Yan, J.H. Chen, Y.Z. Wu, B. Su, Y.G. Du, and X.Z. Liao: Scripta Mater., 2012, vol. 67, pp. 404-07.

213. S.Q. Zhu, H.G. Yan, J.H. Chen, Y.Z. Wu, J.Z. Liu, and J. Tian: Scripta Mater., 2010, vol. 63, pp. 985-88.

214. T. Sakai, H. Utsunomiya, N. Yoshida: US Patent, 2008, 0075624 A1.

215. T. Sakai, H. Utsunomiya, H. Koh, and S. Minamiguchi: Mater. Sci. Forum, 2007, vols. 539-543, pp. 3359-64.

216. Y. Chino, X. Huang, K. Suzuki, and M. Mabuchi: Mater. Trans., 2010, vol. 51, pp. 818-21.

217. Y. Chino, X. Huang, K. Suzuki, M. Yuasa, and M. Mabuchi: Mater. Trans., 2014, vol. 55, pp. 1190-1195.

218. Y. Chino, X. Huang, K. Suzuki, K. Sassa, and M. Mabushi: Mater. Trans., 2011, vol. 52, pp. 1104-07.

219. M.G. Jiang, C. Xu, T. Nakata, H. Yan, R.S. Chen, and S. Kamado: Mater. Sci. Eng. A, 2016, vol. 678, pp. 329-38.

220. M.G. Jiang, C. Xu, T. Nakata, H. Yan, R.S. Chen, and S. Kamado: Mater. Sci. Eng. A, 2016, vol. 667, pp. 233-39.

221. Y. Xiong, Q. Yu, and Y. Jiang: Mater. Sci. Eng. A, 2018, vol. 710, pp. 206-213. 
222. S. Lv, F. Meng, X. Lu, Q. Yang, X. Qiu, Q. Duan, and J. Meng: J. Alloys Compd., 2019, vol. 806, pp. 1166-79.

223. J. She, P. Peng, L. Xiao, A.T. Tang, Y. Wang, and F.S. Pan: Mater. Sci. Eng. A, 2019, vol. 765, p. 138203.

224. S.H. Safi-Naqvi, W.B. Hutchinson, and M.R. Barnett: Mater. Sci. Technol., 2008, vol. 24, pp. 1283-92.

225. J. Hofstetter, S. Rüedi, I. Baumgartner, H. Kilian, B. Mingler, E. Povoden-Karadeniz, S. Pogatscher, P.J. Uggowitzer, and J.F. Löffler: Acta Mater., 2015, vol. 98, pp. 423-32.

226. L.B. Tong, M.Y. Zheng, S. Kamado, D.P. Zhang, J. Meng, L.R. Cheng, and H.J. Zhang: J. Magnesium Alloys, 2015, vol. 3, pp. 302-08.

227. S.W. Xu, K. Oh-ishi, H. Sunohara, and S. Kamado: Mater. Sci. Eng. A, 2012, vol. 558, pp. 356-65.

228. T. Homma, C.L. Mendis, K. Hono, and S. Kamado: Mater. Sci. Eng. A, 2010, vol. 527, pp. 2356-62.

229. G. Wang, G. Huang, X. Chen, Q. Deng, A. Tang, B. Jiang, and F. Pan: Mater. Sci. Eng. A, 2017, vol. 705, pp. 46-54.

230. S. Kamrani and C. Fleck: Mater. Sci. Eng. A, 2014, vol. 618, pp. $238-43$.

231. K. Hantzsche, J. Bohlen, J. Wendt, K.U. Kainer, S.B. Yi, and D. Letzig: Scripta Mater., 2010, vol. 63, pp. 725-30.

232. N. Stanford, D. Atwell, and M.R. Barnett: Acta Mater., 2010 , vol. 58, pp. 6773-83.

233. I. Basu, T. Al-Samman, and G. Gottstein: Mater. Sci. Eng. A, 2013, vol. 579, pp. 50-56.

234. W.X. Wu, L. Jin, F.H. Wang, J. Sun, Z.Y. Zhang, W.J. Ding, and J. Dong: Mater. Sci. Eng. A, 2013, vol. 582, pp. 194-202.

235. I. Basu and T. Al-Samman: Acta Mater., 2015, vol. 96, pp. 111-32.

236. J. Hadorn, K. Hantzsche, S. Yi, J. Bohlen, D. Letzig, and S. Agnew: Metall. Mater. Trans. A, 2012, vol. 43A, pp. 1363-75.

237. J. Hadorn, R. Mulay, K. Hantzsche, S. Yi, J. Bohlen, D. Letzig, and S. Agnew: Metall. Mater. Trans. A, 2013, vol. 44A, pp. $1566-76$

238. M. Jahedi, B.A. McWilliams, P. Moy, and M. Knezevic: Acta Mater., 2017, vol. 131, pp. 221-32.

239. D. Guan, W.M. Rainforth, J. Gao, J. Sharp, B. Wynne, and L. Ma: Acta Mater., 2017, vol. 135, pp. 14-24.

240. D. Guan, W.M. Rainforth, J. Gao, L. Ma, and B. Wynne: Acta Mater., 2018, vol. 145, pp. 399-412.

241. D. Guan, W.M. Rainforth, L. Ma, B. Wynne, and J. Gao: Acta Mater., 2017, vol. 126, pp. 132-44.

242. X. Huang, K. Suzuki, and Y. Chino: Mater. Sci. Eng. A, 2012, vol. 538, pp. 281-87.

243. D. Wu, R.S. Chen, and E.H. Han: J. Alloys Compd., 2011, vol. 509, pp. 2856-63.

244. Q. Wang, Y. Shen, B. Jiang, A. Tang, Y. Chai, J. Song, T. Yang, G. Huang, and F. Pan: Mater. Sci. Eng. A, 2018, vol. 736, pp. 404-16.

245. M.Z. Bian, Z.R. Zeng, S.W. Xu, S.M. Zhu, Y.M. Zhu, C.H.J. Davies, N. Birbilis, and J.F. Nie: Adv. Eng. Mater., 2016 , vol. 18, pp. 1763-69.

246. M. Bian, X. Huang, and Y. Chino: J. Alloys Compd., 2020 , vol. 834, p. 155017

247. N. Stanford and M.R. Barnett: Mater. Sci. Eng. A, 2008, vol. 496, pp. 399-408.

248. N. Stanford: Mater. Sci. Eng. A, 2010, vol. 527, pp. 2669-77.

249. C. Xu, G.H. Fan, T. Nakata, X. Liang, Y.Q. Chi, X.G. Qiao, G.J. Cao, T.T. Zhang, M. Huang, K.S. Miao, M.Y. Zheng, S. Kamado, and H.L. Xie: Metall. Mater. Trans. A, 2018, vol. 49A, pp. 1931-47.

250. L.J. Long, G.H. Huang, D.D. Yin, B. Ji, H. Zhou, and Q.D. Wang: Metall. Mater. Trans. A, 2020, vol. 51, pp. 2738-51.

251. A. Imandoust, C.D. Barrett, A.L. Oppedal, W.R. Whittington, Y. Paudel, and H. El Kadiri: Acta Mater., 2017, vol. 138, pp. 27-41.

252. W.X. Wu, L. Jin, Z.Y. Zhang, W.J. Ding, and J. Dong: J. Alloys Compd., 2014, vol. 585, pp. 111-19.

253. A. Imandoust, C.D. Barrett, T. Al-Samman, M.A. Tschopp, E. Essadiqi, N. Hort, and H. El Kadiri: Metall. Mater. Trans. A, 2018, vol. 49A, pp. 1809-29.

254. J.D. Robson, A.M. Twier, G.W. Lorimer, and P. Rogers: Mater. Sci. Eng. A, 2011, vol. 528, pp. 7247-56.
255. K. Hagihara, Z. Li, M. Yamasaki, Y. Kawamura, and T. Nakano: Acta Mater., 2019, vol. 163, pp. 226-39.

256. R. Wei, Y. Zhang, Y. Wu, M. Sun, J. Chen, Y. Wang, J. Han, L. Peng, and H. Ding: J. Alloys Compd., 2017, vol. 692, pp. 805-16.

257. Y. Zhang, W. Rong, Y. Wu, and L. Peng: Mater. Charact., 2020, vol. 167 , p. 110473 .

258. R. Li, J. Zhang, G. Fu, L. Zong, B. Guo, Y. Yu, and S. Guo: Adv. Eng. Mater., 2018, vol. 20, p. 1701129.

259. R.K. Mishra, A.K. Gupta, P.R. Rao, A.K. Sachdev, A.M. Kumar, and A.A. Luo: Scripta Mater., 2008, vol. 59, pp. 562-65.

260. D. Zhang, H. Wen, M.A. Kumar, F. Chen, L. Zhang, I.J. Beyerlein, J.M. Schoenung, S. Mahajan, and E.J. Lavernia: Acta Mater., 2016, vol. 120, pp. 75-85.

261. T. Homma, N. Kunito, and S. Kamado: Scripta Mater, 2009, vol. 61, pp. $644-47$.

262. C. Xu, T. Nakata, G.H. Fan, X.W. Li, G.Z. Tang, L. Geng, and S. Kamado: J. Mater. Sci., 2019, vol. 54, pp. 10473-488.

263. Z. Yu, Y. Huang, W. Gan, C.L. Mendis, Z. Zhong, H.G. Brokmeier, N. Hort, and J. Meng: Mater. Sci. Eng. A, 2016, vol. 657, pp. 259-68.

264. T. Chen, Z. Chen, J. Shao, R. Wang, L. Mao, and C. Liu: Mater. Sci. Eng. A, 2019, vol. 750, pp. 31-39.

265. J. Bohlen, S. Yi, D. Letzig, and K.U. Kainer: Mater. Sci. Eng. A, 2010, vol. 527, pp. 7092-98.

266. P. Hidalgo-Manrique, J.D. Robson, and M.T. Pérez-Prado: Acta Mater., 2017, vol. 124, pp. 456-67.

267. T. Wang, L. Jiang, R.K. Mishra, and J.J. Jonas: Metall. Mater. Trans. A, 2014, vol. 45A, pp. 4698-4709.

268. H. Pan, G. Qin, Y. Huang, Y. Ren, X. Sha, X. Han, Z.Q. Liu, C. Li, X. Wu, H. Chen, C. He, L. Chai, Y. Wang, and J.F. Nie: Acta Mater., 2018, vol. 149, pp. 350-63.

269. M. Lentz, M. Klaus, I.J. Beyerlein, M. Zecevic, W. Reimers, and M. Knezevic: Acta Mater., 2015, vol. 86, pp. 254-68

270. X. Li, C. Cheng, Q. Le, X. Zhou, Q. Liao, X. Chen, Y. Jia, and P. Wang: J. Alloys Compd., 2019, vol. 805, pp. 947-56.

271. B. Kim, S.-M. Baek, H.Y. Jeong, J.G. Lee, and S.S. Park: J. Alloys Compd., 2016, vol. 660, pp. 304-09.

272. A.E. Davis, J.D. Robson, and M. Turski: Mater. Sci. Eng. A, 2019, vol. 744, pp. 525-37.

273. A.E. Davis, J.D. Robson, and M. Turski: Acta Mater., 2018, vol. 158, pp. 1-12.

274. S.S. Park, W.N. Tang, and B.S. You: Mater. Lett., 2010, vol. 64, pp. 31-34.

275. T.T. Sasaki, F.R. Elsayed, T. Nakata, T. Ohkubo, S. Kamado, and K. Hono: Acta Mater., 2015, vol. 99, pp. 176-86.

276. T.T. Sasaki, K. Yamamoto, T. Honma, S. Kamado, and K. Hono: Scripta Mater., 2008, vol. 59, pp. 1111-14.

277. F.R. Elsayed, T.T. Sasaki, T. Ohkubo, H. Takahashi, S.W. Xu, S. Kamado, and K. Hono: Mater. Sci. Eng. A, 2013, vol. 588, pp. 318-28.

278. J.C. McDonald: Trans. Metall. Soc. AIME, 1958, vol. 212, pp. $45-46$.

279. M.O. Pekguleryuz, M. Masoumi, and A. Becerra: Philos. Mag., 2012, vol. 92, pp. 3766-79.

280. P. Hidalgo-Manrique, S.B. Yi, J. Bohlen, D. Letzig, and M.T. Pérez-Prado: Metall. Mater. Trans. A, 2013, vol. 44A, pp. 4819-29.

281. H. Somekawa, A. Kinoshita, and A. Kato: Mater. Sci. Eng. A, 2017, vol. 697, pp. 217-23.

282. T. Nakata, T. Mezaki, R. Ajima, C. Xu, K. Oh-ishi, K. Shimizu, S. Hanaki, T.T. Sasaki, K. Hono, and S. Kamado: Scripta Mater., 2015, vol. 101, pp. 28-31.

283. S. Ando and H. Tonda: Mater. Trans., 2000, vol. 41, pp. 1188-91.

284. S.R. Agnew, M.H. Yoo, and C.N. Tome: Acta Mater., 2001, vol. 49, pp. 4277-89.

285. M. Lentz, M. Klaus, I.J. Beyerlein, M. Zecevic, W. Reimers, and M. Knezevic: Acta Mater., 2015, vol. 86, pp. 254-68.

286. T. Al-Samman: Acta Mater., 2009, vol. 57, pp. 2229-42.

287. J.F. Nie: Scripta Mater., 2003, vol. 48, pp. 981-84.

288. S.R. Agnew and J.F. Nie: Scripta Mater., 2010, vol. 63, pp. 671-73.

289. T.M. Pollock: Science, 2010, vol. 328, pp. 986-87.

290. J.F. Nie: Metall. Mater. Trans. A, 2005, vol. 36A, p. 1667. 
291. J. Hirsch and T. Al-Samman: Acta Mater., 2013, vol. 61, pp. $818-843$.

292. B.C. Suh, M.S. Shim, K.S. Shin, and N.J. Kim: Scripta Mater., 2014, vols. 84-85, pp. 1-6.

293. D. Griffiths: Mater. Sci. Technol., 2014, vol. 31, pp. 10-24.

294. W.J. Joost and P.E. Krajewski: Scripta Mater., 2017, vol. 128, pp. $107-12$.

295. Z. Zeng, N. Stanford, C.H.J. Davies, J.F. Nie, N. Birbilis: Int. Mater. Rev., 2018, pp. 1-36.

296. H. Yu, Y. Xin, M. Wang, and Q. Liu: J. Mater. Sci. Technol., 2018, vol. 34, pp. 248-56.

297. J. Wu, L. Jin, J. Dong, F. Wang, and S. Dong: J. Mater. Sci. Technol., 2020, vol. 42, pp. 175-89.

298. G.C. Sneddon, P.W. Trimby, and J.M. Cairney: Mater. Sci. Eng. $R, 2016$, vol. 110, pp. 1-12.

299. D.S. Gianola, T.B. Britton, and S. Zaefferer: MRS Bull., 2019, vol. 44 , pp. $450-58$

300. J.F. Nie, N. Wilson, Y.M. Zhu, and Z. Xu: Acta Mater., 2016, vol. 106 , pp. $260-72$.
301. Y.M. Zhu, M.Z. Bian, and J.F. Nie: Acta Mater., 2017, vol. 127, pp. 505-18.

302. J. Hadorn, K. Hantzsche, S. Yi, J. Bohlen, D. Letzig, J. Wollmershauser, and S. Agnew: Metall. Mater. Trans. A, 2012, vol. 43A, pp. 1347-62.

303. M. Bugnet, A. Kula, M. Niewczas, and G.A. Botton: Acta Mater., 2014, vol. 79, pp. 66-73.

304. J.P. Hadorn, T.T. Sasaki, T. Nakata, T. Ohkubo, S. Kamado, and K. Hono: Scripta Mater., 2014, vol. 93, pp. 28-31.

305. N. Stanford, G. Sha, J.H. Xia, S.P. Ringer, and M.R. Barnett: Scripta Mater., 2011, vol. 65, pp. 919-21.

306. L. Huber, J. Rottler, and M. Militzer: Acta Mater., 2014, vol. 80, pp. 194-204.

307. J.D. Robson: Metall. Mater. Trans. A, 2014, vol. 45A, pp. $3205-12$.

Publisher's Note Springer Nature remains neutral with regard to jurisdictional claims in published maps and institutional affiliations. 